\title{
Site U1327
}

\author{
Expedition 311 Scientists $^{2}$
}

\section{Chapter contents}

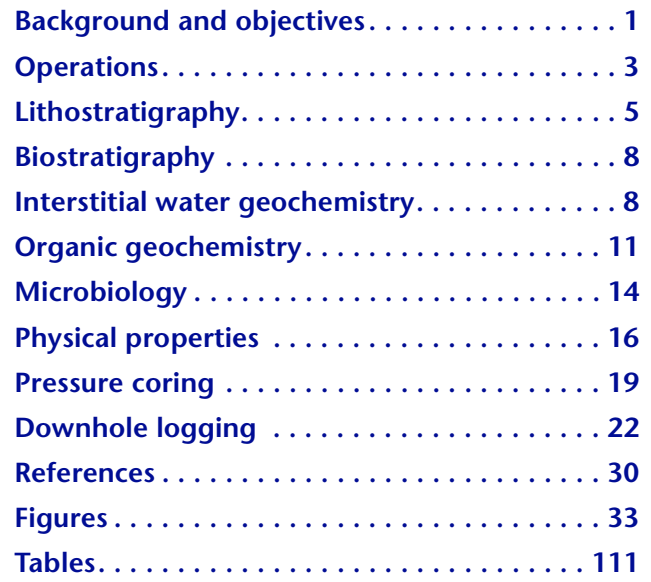

${ }^{1}$ Expedition 311 Scientists, 2006. Site U1327. In Riedel, M., Collett, T.S., Malone, M.J., and the Expedition 311 Scientists. Proc. IODP, 311: Washington, DC (Integrated Ocean Drilling Program Management International, Inc.). doi:10.2204/iodp.proc.311.105.2006 'Expedition 311 Scientists' addresses.

\section{Background and objectives}

Integrated Ocean Drilling Program (IODP) Site U1327 (proposed Site CAS-01B; Collett et al., 2005) is near Ocean Drilling Program (ODP) Leg 146 Site 889 (375 m southeast from Hole 889C). During Leg 146, three holes were drilled in the northern Cascadia margin (Westbrook, Carson, Musgrave, et al., 1994): a reference or background site for no gas hydrate or free gas in the Cascadia Basin (Site 888) and Sites 889 and 890 approximately at the midslope of the accretionary prism over a clearly defined bottom-simulating reflector (BSR).

The area of Sites 889 and 890 has been the focus of many interdisciplinary studies, including

- Two-dimensional (2-D) and three-dimensional (3-D) singlechannel seismic and multichannel seismic (MCS) surveys ranging over various frequencies (Fink and Spence, 1999; Yuan et al., 1996, 1999; Riedel et al., 2002; Zühlsdorff et al., 1999),

- High-resolution seismic surveying using a Deep-Towed Acoustic Geophysics System (Gettrust et al., 1999; Chapman et al., 2002),

- Deployment of ocean-bottom seismographs for 2-D and 3-D traveltime inversion (Hobro et al., 2005; Spence et al., 1995),

- Seafloor-towed controlled-source electromagnetic (CSEM) surveys (Edwards, 1997; Yuan and Edwards, 2000),

- Surface heat-probe measurements (Davis et al., 1990; Riedel et al., 2006),

- Piston coring with physical property measurements and geochemical analyses (Novosel, 2002; Riedel et al., 2002; Solem et al., 2002), and

- Surveys with the Remotely Operated Platform for Ocean Sciences of the Canadian Scientific Submersible Facility (Riedel et al., 2002).

The bathymetry at Site U1327 is dominated by two topographic highs, which rise $\sim 200 \mathrm{~m}$ above the surrounding seafloor (Fig. F1). The ridges, almost completely composed of seismically inferred accreted sediments that lack any coherent seismic reflectivity, are associated with underlying thrust faults that resulted in the overall uplift of the area around the two ridges (Westbrook, Carson, Musgrave et al., 1994; Riedel, 2001). 
Using 3-D seismic data, a map of the seafloor reflection coefficient was generated around Sites U1327 and 889 (Fig. F2) by calibrating the acoustic seafloor with the physical property data from piston cores, as well as employing Warner's method (Warner, 1990) of using the ratio of primary and multiple seafloor reflection strength (Riedel, 2001). The map in Figure F2 shows an area of high seafloor reflectivity northwest of Sites 889 and U1327, which was found to be the product of a widespread sand layer as determined from piston coring. Reflection coefficients for the rest of the survey area are relatively constant. Highresolution $3.5 \mathrm{kHz}$ imaging also shows that the seafloor near Site U1327 is not covered with the typical transparent Holocene layer seen in the region and as observed at Site U1325 (Fig. F3). However, farther to the northwest, this transparent layer is again observed (Shotpoints 100-400 along seismic Inline 38).

\section{Seismostratigraphy at Site 889}

The core and downhole logs from Site 889 provided the primary data needed to calibrate the seismic data for this area. Seismic Inline 38 from the 3-D MCS data in close proximity to Hole 889A is shown in Figure F4 and compared to the lithostratigraphic interpretation from Hole 889A. The distinction between incoherent accreted and bedded slope basin sediments is very clear in this data set. The core and log analyses showed three major lithostratigraphic units within the uppermost 400 meters below seafloor (mbsf). Lithostratigraphic Unit I was divided into Subunits IA and IB. Subunit IA, from the seafloor to 87 mbsf, comprises mostly clayey silts and silty clays with interbedded thin sand layers. This unit is characterized by subhorizontal to shallowly dipping beds with little deformation and is interpreted to represent slightly deformed slope basin turbidites and pelagic sediments. Subunit IB is also mainly silty clay but with less abundant sand layers. It was interpreted that the sediments in Subunit IB represent a series of sediment gravity flow deposits caused by tectonic uplift of the deformation front; therefore, Subunit IB may represent a transition between the abyssal plain sedimentation of lithostratigraphic Units II and III to the subsequent deposition of Subunit IA, which represents slope basin-type sedimentation. Units II and III consist of mainly clayey silt with a low abundance of sand layers. Lithostratigraphic Units II and III are distinguished on the basis of a significant increase in glauconite in Unit III, but no other compositional or structural differences were observed. These units were interpreted as typical abyssal plain sediments that were heavily deformed and fractured during the accretion process. Seismic profiles show that Subunit IB is seismically incoher- ent. The boundary between accreted and slope sediments was placed at $~ 90$ mbsf (two-way traveltime of $1.88 \mathrm{~s}$ ). The sediments of Subunit IB have a different history and slightly different composition compared to the accreted sediments; however, seismically there is no difference between the Subunit IB sediments and the deeper accreted sediments.

\section{Bottom-simulating reflector occurrence}

A strong BSR is observed in seismic data at this site. On MCS Line 89-08 (from the Leg 146 presite survey) the BSR is the dominant seismic reflection (Fig. F5), whereas in the higher frequency seismic data from the 3-D MCS survey, the BSR reflection strength is much weaker as seen on Inline 38 and Xline 3 (Figs. F6, F7). The BSR occurs within the accreted sediments and can be easily identified between common depth points 200 and 800 of Inline 38. In the deeper slope basin sediments, however, the BSR merges with regular, seafloor-parallel reflections and can no longer be isolated. The 3-D seismic data were used to generate a map of the BSR reflection coefficient in this area (Fig. F8) that shows values generally smaller than -0.1 , with an exception of a bright spot associated with the cold vent at Site U1328 (see the "Site U1328" chapter).

The frequency-dependent reflection coefficient of the BSR was attributed to a layer of finite thickness (several meters to a maximum of $10 \mathrm{~m}$ ) in which the seismic velocity decreases from the gas hydrate-bearing section to the gas hydrate-free and potentially free gas-rich sediments below (Chapman et al., 2002). Using the vertical seismic profile (VSP) data from Site 889 (MacKay et al., 1994), the BSR was estimated to occur at a depth of $\sim 225$ mbsf. VSP velocities were averaged to give a single interval velocity of $1636 \mathrm{~m} / \mathrm{s}$, which represents the entire section between the seafloor and the BSR. This average velocity was later used to calculate BSR depths at all other sites along the transect.

Special seismic techniques were used to describe the BSR including amplitude versus offset (AVO) and full waveform inversion (FWI) (Yuan et al., 1996, 1999). AVO can be used to define sediment properties above and below an interface of interest. In the case of the BSR, the question is how much free gas is present below and/or how much hydrate is present above the interface. Yuan et al. (1996) showed that no unique combination of free gas and gas hydrate content could be found to explain observed AVO trends in the MCS 89-08 data. FWI of the same data set yielded a fine-scale velocity model through the BSR and confirmed lower velocities from the VSP study of MacKay et al. (1994). The observed velocity drop below the BSR to values as low as $1480 \mathrm{~m} / \mathrm{s}$ was con- 
verted to free gas concentrations using the BiotGassmann theory and yielded values of $<1 \%$ of free gas (Desmons, 1996).

\section{Previous gas hydrate concentration estimates}

Leg 146 sonic and electrical resistivity logging data as well as coring data (chlorinity and electrical resistivity) have been used to estimate gas hydrate concentrations (e.g., Hyndman et al., 1999, 2001; Yuan et al., 1999). Based on measurements of core electrical resistivity and porosity, Hyndman et al. (1999) derived a set of empirical Archie coefficients ( $a=1.4$, $m=1.76$ ) that were used to calculate gas hydrate concentrations from electrical resistivity logging data. The gas hydrate concentration was found to vary between $25 \%$ and $35 \%$ of the pore volume over a $100 \mathrm{~m}$ thick interval just above the BSR. Slightly lower concentrations of $20 \%$ were found using acoustic velocity data (sonic log, MCS interval velocity, and VSP). Chlorinity data also provided an estimate of gas hydrate concentration. Combining the derived Archie coefficients from discrete core measurements with the chlorinity data, gas hydrate concentrations were calculated to approach $30 \%$ of the pore space just above the BSR.

These concentration estimates were recently reevaluated by defining different baselines for chlorinity and acoustic velocity and a different set of empirical Archie coefficients (Riedel et al., 2005; Ussler and Paull, 2001; Collett, 2000). Using these new reference log values, gas hydrate concentrations were calculated to be much lower; $<10 \%$ over the $100 \mathrm{~m}$ thick interval above the BSR. Significant uncertainty remains, however, in the interpretation of the data depending on which pore water resistivity baseline is assumed.

\section{Objectives}

The primary research objectives for this site are linked to the overriding transect concept of this expedition. Site U1327 is near Site 889, which provided critical baseline data for development of the objectives of this expedition. Site U1327 site is located near the middle of the expedition's coring transect on a broad uplifted ridge of accreted sediments, about mid-slope up the margin.

The concentration of gas hydrate in sediments is mainly determined using

- Deviations in pore water chlorinity from measured baseline conditions,

- Electrical resistivity measurements by applying Archie's relation, and

- Seismic $P$ - and $S$-wave velocities.
Results from Leg 146 left many questions unanswered (Riedel et al., 2005), such as

- What is the geochemical reference profile for chlorinity and other geochemical gas hydrate proxies?

- What is the baseline for electrical resistivity and what are the appropriate empirical Archie coefficients?

- What is the reference profile for seismic $P$ - and $S$ wave velocities?

Answers to these questions are needed to calibrate remote sensing techniques, such as seismics and CSEM, and these answers can be obtained through coring and downhole logging.

The operational plan to achieve these objectives was based on a general three-hole concept, which included

- A logging-while-drilling/measurement-while-drilling (LWD/MWD) hole;

- A continuously cored hole to characterize geochemical and microbiological baselines and proxies for gas hydrate;

- An additional "tools" hole for specialized pressure coring systems, including the IODP Pressure Core Sampler (PCS) and the HYACINTH Fugro Pressure Corer (FPC) and HYACE Rotary Corer (HRC) systems, combined with selected spot-coring using the conventional extended core barrel (XCB) system; and

- A wireline logging program in the tools hole using the triple combination (triple combo) and Formation MicroScanner-sonic tool strings, and a zerooffset VSP.

\section{Operations}

\section{Hole U1327A}

After completing LWD/MWD operations at Site U1326, the drill string was pulled back high enough to place the bit at a safe distance above the seafloor. We transited in dynamic positioning mode $8.5 \mathrm{nmi}$ to Site U1327 (proposed Site CAS-01B; Collett et al., 2005). Hole U1327A was spudded at $1830 \mathrm{~h}$ on 23 September 2005, and the seafloor was tagged at 1321.1 meters below sea level (mbsl; 1333.0 meters below rig floor [mbrf]). The hole was initiated with a controlled spud-in with 100 gallons per minute (gpm) circulation and $10-15 \mathrm{rpm}$ rotation. At 10 mbsf, top drive rotation was increased to $40 \mathrm{rpm}$ and then again to $60 \mathrm{rpm}$ at $29 \mathrm{mbsf}$ to optimize parameters for maintaining a $50 \mathrm{~m} / \mathrm{h}$ rate of penetration (ROP) while maintaining a minimum circulation of 270 gpm. The LWD/MWD safety protocol was fol- 
lowed without incident (see "Downhole logging" in the "Methods" chapter) and required no corrective action. By $0815 \mathrm{~h}$ on 24 September, the hole reached the target total depth (TD) of 300 mbsf. The hole was displaced with weighted sepiolite mud, and the drill string was pulled clear of the seafloor in preparation for transiting to Site U1328.

\section{Hole U1327B}

Following a $9.2 \mathrm{nmi}$ transit from Site U1329, we arrived at Site U1327 at 0415 h on 2 October 2005 (Fig. F9). We spudded Hole U1327B at $0855 \mathrm{~h}$ and returned a full core, which indicated we did not recover the mudline. We therefore terminated operations in Hole U1327B to obtain a mudline core from a new hole.

\section{Hole U1327C}

The bit was picked up $5 \mathrm{~m}$ and Hole U1327C was spudded without offsetting, with first core on deck at $0950 \mathrm{~h}$ on 2 October 2005. A $6.1 \mathrm{~m}$ recovery for Core $1 \mathrm{H}$, including the mudline, provided an estimated seafloor depth of $1304.5 \mathrm{mbsl}$ (1315.4 mbrf). The hole was advanced to 92.9 mbsf (104\% recovery) with the advanced piston corer (APC) system and to a TD of 300 mbsf with the XCB system (81\% recovery). Seven temperature measurements were made, four with the Advanced Piston Corer Temperature tool, two with the Davis-Villinger Temperature-Pressure Probe, and one with the Davis-Villinger Temperature Probe (Table T1). Three PCS runs were made, which returned Cores $6 \mathrm{P}$ at $44.1 \mathrm{mbsf}, 15 \mathrm{P}$ at 121.8 mbsf, and 24P at 197.3 mbsf. Core 6P was returned without pressure. After reaching TD, the hole was displaced with weighted mud, and the bit was pulled clear of the seafloor at $1545 \mathrm{~h}$ on 4 October, ending operations in Hole U1327C.

\section{Hole U1327D}

After completing operations in Hole U1327C, we offset $15 \mathrm{~m}$ to the northeast to spud a dedicated tool and logging hole with first core on deck at $1710 \mathrm{~h}$ on 4 October 2005. Two APC cores were taken to 16.4 mbsf for high-resolution sampling for pore water, gas, and microbiological analyses. The hole was washed to $83.0 \mathrm{mbsf}$ and the first PCS run returned Core 3P without pressure. By 0240 h on 5 October, we had drilled to a depth of $124.3 \mathrm{mbsf}$ in preparation for a run of the HRC pressure core system. The recorded ship heave had increased to $>4.5 \mathrm{~m}$ and it was determined that it would be impossible to keep the HRC or any of the other pressure core systems on the bottom of the hole. Competing swells from the west and east caused ship heave conditions to worsen throughout the day. The heave conditions improved by $2245 \mathrm{~h}$ and preparations began to return to coring.

The HRC (Core 4E), XCB (Core 5X), and FPC (Core $6 \mathrm{Y})$ systems were first deployed within a $16 \mathrm{~m}$ thick, high-electrical resistivity zone previously identified from the LWD/MWD logs (Table T1). The HRC was recovered under pressure, but during the transfer for $P$-wave velocity and X-ray scanning, the transfer system lost pressure. The first FPC core system fired prematurely (similar to the problem experienced in Hole U1329E) and recovered a sediment core without pressure. The hole was advanced by XCB coring to $155.1 \mathrm{mbsf}$, where the PCS was deployed and yielded a complete core under pressure (Core 10P). The hole was advanced by $\mathrm{XCB}$ coring to 170.5 mbsf, where the HRC was deployed with Core $12 \mathrm{E}$ and recovered sediments under pressure. The FPC was deployed at $203.3 \mathrm{mbsf}$ and recovered Core 13Y under pressure. The hole was advanced by drilling to 217.7 mbsf, and the HRC was deployed and recovered a complete core under pressure (Core 14E). Two additional XCB cores (Cores 15X and 16X) were taken through the depth interval of the BSR. The hole was drilled to 246 mbsf where the PCS was deployed and recovered a complete pressurized core (Core 17P).

At $1256 \mathrm{~h}$ on 7 October, a helicopter arrived with the Canadian marine mammal observer and an IODP marine laboratory specialist. After unloading passengers and supplies, the helicopter departed at $1325 \mathrm{~h}$. By $1615 \mathrm{~h}$, Hole U1327D had been drilled to a TD of 300 mbsf, but adverse ship heave conditions (>3.0 $\mathrm{m})$ were not conducive to logging. Rather than wait on weather, the time was used to condition the hole with a wiper trip and the bottom $20 \mathrm{~m}$ was reamed out and followed by a mud sweep. By $2330 \mathrm{~h}$, the heave conditions had improved. The pipe was pulled up to logging depth and the triple combo tool string was rigged and lowered to $295.4 \mathrm{mbsf}$. The hole was logged without incident until near the top of the logging run when the combination of a large ship heave event $(>3.0 \mathrm{~m})$ and the oversized borehole damaged the density tool caliper arm. The damaged triple combo tool string was returned to the ship without further incident.

The VSP logging program in Hole U1327D began at $0720 \mathrm{~h}$ on the morning of 8 October with a required $1 \mathrm{~h}$ marine mammal observation period. After this period, we ramped up the firing pressure for the generator-injector (GI) air gun. At $1000 \mathrm{~h}$, the VSP Well Seismic Tool (WST) reached TD at $276.4 \mathrm{mbsf}$ and the VSP began. The WST was moved up the hole in 5 $\mathrm{m}$ increments and had completed 16 positions when, at $\sim 136$ mbsf, it was unable to clamp although 
the caliper log from the triple combo run showed that the hole should have been suitable for clamping. Suspecting that it had been damaged, we decided to pull the WST back to the ship for inspection. Unfortunately the tool became stuck and we were unable to pull it back into the drill pipe. Two attempts to clamp the logging wireline with Kinley crimpers were unsuccessful; however, the WST was worked back into the drill pipe and pulled to the surface by $2300 \mathrm{~h}$. Operations in Hole U1327D ended at $0400 \mathrm{~h}$ on 10 October after the drill string was tripped back to the ship and the rotary table cleared.

\section{Hole U1327E}

Because of the critical nature of the downhole acoustic logging data to achieve the goals of the expedition, we decided to drill a dedicated wireline logging hole and to acquire additional PCS, HRC, and FPC pressure cores from several critical intervals not successfully cored in the previous holes at this site. The ship was offset $15 \mathrm{~m}$ to the northeast and Hole U1327E was spudded at $0850 \mathrm{~h}$ on 10 October 2005 as a special wireline logging and pressure core tools hole. The hole was started by drilling to $3.0 \mathrm{mbsf}$ and then taking a single APC core for high-resolution geochemical and microbiological sampling. An earlier attempt to sample across the sulfate/methane interface (SMI) in Hole U1327C was unsuccessful, so Hole U1327E was an opportunity to sample the SMI. The hole was then advanced by drilling to $40.0 \mathrm{mbsf}$, where PCS Core 2P yielded a full, but unpressurized, core. The hole was advanced by drilling to $80.0 \mathrm{mbsf}$ and a second PCS core (Core $3 \mathrm{P}$ ) was acquired, this time with a full and pressurized core. The hole was drilled to 128.0 mbsf, where the HRC was deployed. Core $4 \mathrm{E}$ contained sediment but was unpressurized because the flapper valve did not completely seal. A deployment of the FPC was planned at $134.0 \mathrm{mbsf}$ but was canceled because of growing ship heave conditions that exceeded 3.5 m near the end of the HRC deployment. Thus, we decided to drill Hole U1327E to the target TD of $300 \mathrm{mbsf}$, which was reached at $1630 \mathrm{~h}$ on 10 October. This completed pressure coring operations at Site U1327 with a total of thirteen pressure core deployments, of which nine were recovered under pressure (five PCS, three HRC, and one FPC).

Because of the continued high ship heave conditions throughout the day (ranging from 2.5 to $4.5 \mathrm{~m}$ ) we decided to make only one logging run with a nonstandard, caliper-free tool string. The tool string included the Hostile Environment Gamma Ray Sonde (HNGS), Phasor Dual Induction Tool (DIT), and the Dipole Sonic Imager (DSI), which provide natural gamma ray, resistivity, and acoustic transit time data.
The tool was lowered to $287 \mathrm{mbsf}$ and logged to the setback drill pipe at 72 mbsf without incident. A short repeat pass of the lower $100 \mathrm{~m}$ was completed for quality control, and the tool string was returned to the surface. After rigging down logging, the bit was pulled clear of the seafloor at $0400 \mathrm{~h}$ on 11 October, ending operations at Site U1327.

\section{Lithostratigraphy}

Site U1327 is located on the mid-continental slope off Vancouver Island ( 1309 mbsl), several hundred meters from Site 889. Four of the five holes (Holes U1327B-U1327E) at this site were cored. Hole U1327B was cored to 9.5 mbsf, Hole U1327C was advanced to a TD of 300 mbsf (297 m cored), Hole U1327D was advanced to a TD of 300 mbsf $(75.9 \mathrm{~m}$ cored), and Hole U1327E was advanced to a TD of $300 \mathrm{mbsf}$ (12.5 m cored). Recovery was good to very good $($ Hole U1327B $=103.1 \%$, Hole U1327C $=$ $88.3 \%$, Hole U1327D $=71.1 \%$, and Hole U1327E $=$ 91.4\%).

We divided the $300 \mathrm{~m}$ thick sedimentary section recovered at Site U1327 into three lithostratigraphic units (Fig. F10) based on visual inspection of the recovered cores and analysis of smear slides. Other parameters, such as mineralogy data from X-ray diffraction (XRD) analyses, helped to better define the entire stratigraphic section. The results were also compared and correlated with 2-D seismic data, downhole LWD/MWD data, and physical property measurements.

\section{Lithostratigraphic units}

\section{Lithostratigraphic Unit I}

Intervals: Sections 311-U1327B-1H-1 through 1HCC, 311-U1327C-1H-1 through $11 \mathrm{H}-4$, and Cores 311-U1327E-1H through 3P

Depths: Hole U1327B: 0.00-9.79 mbsf, Hole U1327C: 0.00-90.10 mbsf, and Hole U1327E: $3.00-12.50,40.00-41.00$, and 80.00-81.00 mbsf

Age: Quaternary

Unit I is composed of dark greenish gray (5GY 4/1) and dark gray (N4) clay and silty clay (Fig. F11) sometimes showing parallel lamination. The clay and silty clay is often interbedded with silt, clayey silt, sandy silt, sand, and gravel layers that have mostly sharp and sometimes erosional contacts (Figs. F11, F12, F13). The single layers show varying thickness from a few millimeters to several centimeters. Often, fining-upward sequences were observed (Figs. F11, F12). The major nonbiogenic components of Unit I are quartz, feldspar, volcanic glass (as much as 
$20 \%$ ), clay minerals, opaque minerals, accessory minerals (mainly amphibole), and some glauconite. A $2 \mathrm{~cm}$ thick layer rich in zeolites was identified from XRD analyses (Sample 311-U1327C-2H-5, 69$70 \mathrm{~cm}$ ), indicating highly altered volcanic ash (Fig. F14). Rare sulfide mottling, appearing as dark gray (N4) stains, occurs especially at the top and the bottom of Unit I. Sulfide concretions were observed in Cores 311-U1327C-1H, 3H, 4H, 5H, and 9H. Mostly rare to moderate bioturbation, often indicated by iron sulfide precipitates, occurs in Cores 311$\mathrm{U} 1327 \mathrm{C}-2 \mathrm{H}, 3 \mathrm{H}, 4 \mathrm{H}, 5 \mathrm{H}, 7 \mathrm{H}$, and $9 \mathrm{H}$.

The biogenic components in the major lithology have mostly very low concentrations (Fig. F10). In the minor lithology of Core $311-\mathrm{U} 1327 \mathrm{C}-1 \mathrm{H}$, an abundance of diatoms (as high as 45\%) was estimated in a smear slide. Some bivalve shell fragments are present in Cores 311-U1327C- $1 \mathrm{H}, 2 \mathrm{H}, 3 \mathrm{H}, 4 \mathrm{H}$, $9 \mathrm{H}, 10 \mathrm{H}$, and $11 \mathrm{H}$, and one gastropod is seen in Section $4 \mathrm{H}-6$.

Greenish gray (5GY 5/1) unlithified authigenic carbonate cement is found in Section 311-U1327C-10H1 (Fig. F15). XRD analyses confirm a high-Mg calcite (HMC) composition (5 mol\% $\mathrm{MgCO}_{3}$ ). No evidence of dolomite precipitation is found, although it is inferred from interstitial water (IW) chemistry results (see "Interstitial water geochemistry").

Rocks, millimeters to centimeters in size, are present in Cores 311-U1327C-1H, 4H, 7H, and 8H. Some of them are carbonates, but we also observed other lithologies (e.g., granite) (Fig. F13). The distinction between authigenic and detrital carbonates is not possible without further analyses, so they are plotted as "nodule/concretion, general" in the visual core descriptions.

Soft-sediment deformation is present in Cores 311$\mathrm{U} 1327 \mathrm{C}-4 \mathrm{H}, 7 \mathrm{H}, 8 \mathrm{H}, 9 \mathrm{H}$, and $11 \mathrm{H}$. The deformation mostly shows in distorted sand layers (Fig. F16). Sections $311-\mathrm{U} 1327 \mathrm{C}-11 \mathrm{H}-1,11 \mathrm{H}-3$, and $11 \mathrm{H}-4$ have extensive soft-sediment deformation structures, including a large, more greenish mud clast $(56 \mathrm{~cm})$. This seems to indicate a major slump event, whereas the deformational features observed in the other cores are probably only small-scale gravitational slides.

The Unit I/II boundary is marked by a sharp decrease of sand and silt layers and by an increase in the abundance of diatoms in Section 311-U1327C-11H-5 (30\% diatoms estimated at Section $11 \mathrm{H}-5,6 \mathrm{~cm}$ ), which can clearly be seen as a change in sediment color.

\section{Lithostratigraphic Unit II}

Intervals: Sections 311-U1327C-11H-5 through 20X-CC, 311-U1327D-4E-1 through 11XCC, and 311-U1327E-4E-1
Depths: Hole U1327C: 90.10-170.40 mbsf, Hole U1327D: 125.30-170.50 mbsf, and Hole U1327E: 128.00-129.00 mbsf

Age: Pleistocene $(>0.3-1.0 \mathrm{Ma})$

Unit II is composed of dark greenish gray (5GY 4/1) and dark gray (N4) clay, clay with diatoms, silty clay, silty clay with diatoms, and diatom silty clay, all locally interbedded with sandy silt and sand layers and lenses. Often the diatom-rich sections display a more brownish color (dark olive-gray, 5Y 3/2), whereas the sections barren in diatoms are more grayish. The major nonbiogenic components of Unit II are quartz, feldspar, accessory minerals (mainly amphibole), clay minerals, opaque minerals, some glauconite, and volcanic glass. Rare to moderate sulfide mottling and rare sulfide concretions are present throughout Unit II. No bioturbation is observed in this unit.

The biogenic components are distinctly different from those of Unit I. The major lithology shows a high content of diatoms (as high as 40\% in Sample 311-U1327C-20X-3, $90 \mathrm{~cm}$ ). The biogenic carbonate fraction is low, on average $1 \%$. Bivalve shell fragments are present throughout this unit, in particular in Cores 311-U1327C-18X and 19X.

A layer composed of different-colored mud clasts 1-2 $\mathrm{mm}$ in diameter is present in interval 311-U1327E4E-2, 41-48 cm (128.41-128.48 mbsf). The light-colored clasts are carbonate rich (show reaction with $\mathrm{HCl}$ ). This layer probably correlates to a similar layer observed in Hole U1327C (interval 311-U1327C16X-3, 119-141 cm; 127.89-128.11 mbsf).

Very few unlithified carbonate cements, visible as faint light spots, occur in Unit II. Lithified carbonates of different mineralogy and origin are abundant in Cores 311-U1327C-16X, 18X, and 19X and 311U1327D-5X, 6Y, and 9X through 11X (Fig. F17). The interval between 142 and 148 mbsf in Hole U1327C and between 151 and 157 mbsf in Hole U1327D (Fig. F17) is especially rich in rocks as large as $4 \mathrm{~cm}$ in diameter. Though there is a small offset, these two intervals might correlate to each other. Some pieces are rounded, and some are angular. Based on visual observation they are of very different origin. Intervals 311-U1327C-18X-2, 130-150 cm and 18X-3, 105$106 \mathrm{~cm}$ and 311-U1327D-11X-1, 7-8 cm, are of dolomitic composition (46-48 mol\% $\mathrm{MgCO}_{3}$ ), whereas interval $311-\mathrm{U} 1327 \mathrm{C}-18 \mathrm{X}-5,120-150 \mathrm{~cm}$, is a siderite. The nature of this deposit is ambiguous. Further shore-based studies on the composition of the different clasts will be carried out to better describe this deposit.

At this site, we observed soupy and mousselike sediment textures related to the presence of gas hydrate. Soupy textures are present in intervals 311-U1327C- 
16X-1, 10-20 cm; 17X-1, 0-20 cm; 18X-2, 20-72 cm; and 20X-1, 123-155 cm. Mousselike textures are present in intervals 311-U1327D-5X-1, 0-30 cm; 7X3, 0-40 cm; 7X-4, 0-75 cm; 9X-1, 0-43 cm; and 11X$1,0-25 \mathrm{~cm}$. Our observations are in agreement with the gas hydrate-bearing interval identified by infrared (IR) camera temperature anomalies (see "Physical properties"). In interval 311-U1327D-7X-4, 22$31 \mathrm{~cm}$, we observed a probably fracture-related soupy texture surrounded by mousselike sediments (Fig. F18A). Another probably fracture-related temperature anomaly was sampled in this core on the catwalk (Fig. F18B). This might indicate that gas hydrate formation in this section is fracture controlled.

\section{Lithostratigraphic Unit III}

Intervals: Sections 311-U1327C-21X-1 through 35X-CC and 311-U1327D-12X-1 through 17P-1

Depths: Hole U1327C: 170.40-300.00 mbsf and Hole U1327D: 170.50-247.00 mbsf

Age: Pleistocene (>1 Ma)

Unit III is mainly composed of dark greenish gray (5GY 4/1) silty clay and dark gray (N4) silty clay and clay in the upper part of the unit. In the lower part of the unit, below Section 311-U1327C-29X-2, dark greenish gray (5GY 4/1) silty clay with diatoms is present. Coarser grained clayey silt (with diatoms) and sandy silt occur as minor lithologies in Cores 311-U1327C-22X, 26X, 27X, and 29X.

The major nonbiogenic components of Unit III are quartz, feldspar, accessory minerals (mainly amphibole), clay minerals, and opaque minerals. Almost no sulfide mottling or sulfide concretions are present. Bioturbation is only observed in Section 311-U1327C-30X-4. Glauconite-rich layers are visually observed in Section 311-U1327C-25X-4 and 26X-3. Some rare bivalve shell fragments are present in Cores 311-U1327C-21X, 22X, 26X, 27X, and 31X through $35 \mathrm{X}$.

Unit III is distinguished from Unit II by the sudden absence of diatoms in smear slides (see also "Biostratigraphy"), as well as the degree of induration of the sediments, which shows in the occurrence of drilling biscuits (Fig. F19). Diatoms occur again at the bottom of the unit $(<25 \%)$.

Few unlithified carbonate cements, visible as faint light spots, occur in Unit III in Cores 311-U1327C23X, 29X, 30X, and 31X and 311-U1327D-16X. XRD analyses show a combination of HMC (8-11 mol\% $\mathrm{MgCO}_{3}$ ) with nonstoichiometric (Ca rich) dolomite in most of the cores, or a combination of rhodochrosite with HMC and Ca-rich dolomite in Samples
311-U1327C-29X-4, 59-60 cm (Fig. F20), and 30X-3, $80-81 \mathrm{~cm}$.

Interval 311-U1327C-24P-1, 0-69 cm, from a pressure core, contained numerous lithified carbonate rocks (Fig. F21). Three different carbonate mineralogies can be differentiated by XRD analyses: dolomite (47-49 mol\% $\left.\mathrm{MgCO}_{3}\right)$, $\mathrm{HMC}\left(14 \mathrm{~mol} \% \mathrm{MgCO}_{3}\right)$, and a mixture of $\mathrm{HMC}$ and dolomite or nonstoichiometric ( $\mathrm{Ca}$ or Fe rich) dolomite (7-10 mol\% $\mathrm{MgCO}_{3}$ and 36-48 mol\% $\mathrm{MgCO}_{3}$, respectively). Lithified carbonate rocks of different mineralogy and origin are also present in intervals 311-U1327C-32X-1, 11-12 cm; $34 \mathrm{X}-\mathrm{CC}, 2-3 \mathrm{~cm}$; and 35X-3, 70-71 cm.

\section{Environment of deposition}

Coring at Site U1327 recovered a sequence that corresponds to slope and slope basin sedimentation (see "Background and objectives").

Lithostratigraphic Unit III is characterized by finegrained (clay to silty clay) detrital sediments with few silty interlayers from turbiditic deposits and by rare to absent fossils. We suggest that the sediments were deposited in an abyssal plain environment, as the agents of transport and deposition are distal lowenergy turbidity currents. Between 197.30 and 197.99 mbsf, a conglomerate layer is present, suggesting a major event like a debris flow. The sedimentation rate $(12 \mathrm{~cm} / \mathrm{k} . \mathrm{y}$.$) , inferred from diatom$ studies (see "Biostratigraphy"), is the lowest rate at this site, consistent with a more "basin plain" setting. The presence of unlithified authigenic carbonate cements (some of them rhodochrosite rich) shows that diagenetic processes, likely driven by organic matter remineralization (see "Interstitial water geochemistry"), are active in lithostratigraphic Unit III.

Lithostratigraphic Unit II is characterized by finegrained (clay to silty clay) detrital sediments with some silty interlayers from turbiditic deposits and some siliceous fossils (mainly diatoms; see also "Biostratigraphy"). The sedimentation rate is slightly higher $(16 \mathrm{~cm} / \mathrm{k} . \mathrm{y}$.$) and intervals with a high non-$ marine/marine diatom ratio are more abundant, showing the increasing importance of intermittent terrigenous input of detrital sediments from land by turbidites (see "Biostratigraphy"). The great abundance of marine diatoms along with resting spores of Chaetoceros within lithostratigraphic Unit II suggest blooming in a shallow-water shelf environment and coastal upwelling (see "Biostratigraphy") followed by reworking by turbidity currents. The mud clast level (Cores 311-U1327E-4E and 311-U1327C-16X at $\sim 128 \mathrm{mbsf}$ ) is interpreted as reworking and redeposition of sediments following uplift of the sedimentary 
column at the deformation front. Below this level, between $\sim 142$ and 148 mbsf in Hole U1327C and 151 and 157 mbsf in Hole U1327D, numerous lithified carbonate rocks of different origin are very abundant. Some of them may be dolomite/siderite.

Lithostratigraphic Unit I is characterized by finegrained detrital sediments (clay and silty clay), with abundant coarse-grained layers as thick as $6 \mathrm{~cm}$, indicating turbiditic deposits. The greater input of turbidite sedimentation, compared to lithostratigraphic Unit II, shows in the increased sedimentation rate (from 16 to $22 \mathrm{~cm} / \mathrm{k} . \mathrm{y}$.) as well. Rocks found in Cores $311-\mathrm{U} 1327 \mathrm{C}-1 \mathrm{H}, 4 \mathrm{H}, 7 \mathrm{H}$, and $8 \mathrm{H}$ are sometimes granitic, sometimes carbonate. Scattered nonsedimentary rocks in fine-grained sedimentary facies are interpreted as dropstones (ice-rafted debris), indicating sea ice cover in the Pacific Ocean, similar to the wellknown Heinrich events in the North Atlantic Ocean.

\section{Biostratigraphy}

Hole U1327C contains the most complete stratigraphic sequence at this site: a $300 \mathrm{~m}$ thick Quaternary sedimentary sequence. The biostratigraphy determined for Site U1327 was based on an examination of all core catcher samples from Hole U1327C (Table T2).

\section{Diatoms}

Diatoms are mostly rare and poorly preserved in the interval from the seafloor to $\sim 82 \mathrm{mbsf}$ and very rare to abundant and poorly to moderately preserved in the interval from $\sim 92$ to 295 mbsf. Diatom assemblages are dominated by either marine species Neodenticula seminae, Stephanopyxis spp., Thalassionema nitzschioides, and Thalassiosira spp. or the nonmarine diatom Aulacoseira granulata s.l. The abundance of the dominant species varies greatly from sample to sample. Abundant resting spores are frequently associated with the marine diatoms in this interval. The nonmarine diatom Cyclotella spp. is abundant in Sample 311-U1327C-30X-CC. Marine- and nonmarine-dominant assemblages alternate throughout this hole, suggesting intermittent terrigenous input by turbidites.

The interval between the seafloor and Sample 311U1327C-7H-CC (0.10-55.98 mbsf) contains N. seminae but lacks Proboscia curvirostris and was assigned to North Pacific Diatom (NPD) Zone 12 (N. seminae Zone; 0-0.3 Ma). The last occurrence (LO) of P. curvirostris was recognized in Sample 311-U1327C-8H-CC (65.64 mbsf), marking the NPD Zone $12 / 11$ boundary (P. curvirostris Zone). The interval between the LO of $P$. curvirostris and Section 311-U1327C-20X-CC (66.64-167.20 mbsf) contains $P$. curvirostris but lacks
Actinocyclus oculatus and was assigned to NPD Zone 11 (P. curvirostris Zone; 0.3-1.0 Ma). The LO of A. oculatus was recognized in Sample 311-U1327C-21X-CC (178.68 mbsf), marking the NPD Zone $11 / 10$ boundary (A. oculatus Zone). The interval between the LO of A. oculatus and Section 311-U1327C-34X-CC ((178.68-295.26 mbsf) contains both P. curvirostris and $A$. oculatus and was assigned to NPD Zone 10 ( $P$. curvirostris Zone; 1.0-2.0 Ma). The three Quaternary diatom zones are recognized at both Sites U1327 and U1329, but the thickness of the three zones in Hole U1327C is almost double that of Site U1329, which might be the result of the abundant terrestrial supply by turbidites suggested by the intermittently abundant occurrences of nonmarine diatoms.

\section{Interstitial water geochemistry}

The main objectives at this site were to document the depth distribution of gas hydrate, to quantify the amount of gas hydrate in the sediment by comparing the pressure core degassing data with the IW chlorinity data, and to identify the microbially mediated and inorganic reactions associated within and below the gas hydrate stability zone (GHSZ). A total of $145 \mathrm{IW}$ samples were processed from three holes drilled at Site U1327. In Hole U1327C, 76 wholeround samples, most $10-30 \mathrm{~cm}$ in length, were squeezed and analyzed. These include 65 IW samples, 5 of which were divided into subsamples based on IR images, generating 7 additional samples for a total of 72 samples for Hole U1327C. Four samples of poor quality were not squeezed. The whole-round samples were collected with a sampling frequency of four in the second core, three in the third core, two per core in the first core and from the fourth core to a depth of $231.91 \mathrm{mbsf}$, and one per core for the remaining cores. In addition, five samples were squeezed from pressure Cores $311-\mathrm{U} 1327 \mathrm{C}-15 \mathrm{P}$ and 24P, retrieved from 121.8 and 197.3 mbsf, respectively.

In Hole U1327D, the first two APC cores were dedicated to high-resolution microbiological and geochemical sampling, from which a total of 24 whole-round samples, $15 \mathrm{~cm}$ in length, were processed. These samples cover the interval from the seafloor across the SMI to 15.9 mbsf. Whole-round samples for microbiological studies and headspace (HS) samples for gas analyses were taken adjacent to each whole-round IW sample (see "Microbiology" and "Organic geochemistry"). The sampling frequency was four whole-round samples per section to the SMI depth and one per section in the first two sections below the SMI; however, the location of the SMI appears to fall in an interval that was not recov- 
ered, between Cores 311-U1327D-1H and 2H. In addition to the high-resolution sampling in the uppermost $15.9 \mathrm{~m}$, six whole-round samples were collected by XCB coring between 129.0 and 221.0 mbsf, with the purpose of documenting the distribution of gas hydrate and calibrating the IR images. Sampling of these cores was guided by IR imaging, and only sections of the core with medium-large amplitude negative thermal anomalies were selected. Two of these samples (311-U1327D-11X-1, 62-72 $\mathrm{cm}$, and $15 \mathrm{X}-3,49-59 \mathrm{~cm}$ ) that contained clearly distinct sand and clay lithologies were divided, and the sand and clay were squeezed separately. Samples were also processed from the three types of pressure cores deployed in this hole. Two samples were taken from Core 311-U1327D-4E, one from 6Y, three from $10 \mathrm{P}$, and two from $17 \mathrm{P}$.

Hole U1327E was drilled to conduct critical logging runs that could not be completed in Hole U1327D because of operational complications (see "Operations"). From this hole, we processed 25 samples from APC Core 311-U1327E-1H, which was intended for high-resolution sampling of the SMI interval that was missed during coring in Hole U1327D. Four whole-round samples were collected per section and two samples from pressure Core 311-U1327E-3P.

Because of the more lithified nature of the formation at this site, XCB coring was used for the collection of a large portion of IW samples. Because XCB coring yields relatively more disturbed cores, these cores are more likely to be contaminated by the drilling fluid than APC cores. Four of the whole-round samples showed extreme disturbance and were deemed unsuitable for IW extraction. Data from these samples are marked by an asterisk in Table T3. Sulfate concentration below the depth of the SMI was used to identify and quantify occasional contamination by the drilling fluid. It is worth noting that samples from the pressure cores, even when pressurized, consistently show high values of IW contamination, with sulfate values between 2.0 and $5.9 \mathrm{mM}$. The chemical data were therefore corrected for contamination by the drilling fluid. The sample collected from Core 311-U1327D-6Y, which was obtained with the FPC, shows no detectable sulfate, suggesting that the FPC may be more suitable for collecting uncontaminated IW samples than the PCS. Similarly, one of the samples taken from an HRC core (311U1327D-4E-1, 95-110 cm) had no detectable sulfate; however, a second sample $(4 \mathrm{E}-1,0-20 \mathrm{~cm})$ collected from a "disturbed" interval at the top of the same core was highly contaminated (sulfate $=13.9 \mathrm{mM}$ ).

The IW data collected at Site U1327 are listed in Table T3. In addition, Table T4 lists sulfate-corrected data that represent the composition of the IW cor- rected for drill fluid contamination. The sulfate-corrected data are illustrated in Figures F22, F23, and F24.

\section{Salinity and chlorinity}

The salinity profile shows three distinct zones:

1. A continuous decrease in salinity with depth from 34.0 at the seafloor to 23.0 at 128 mbsf;

2. Discrete excursions to fresher values $(<20)$ from 128 mbsf to the depth of the BSR, suggesting that gas hydrate was present in the cores and dissociated prior to processing the samples; and

3. Values that range between 23 and 20 below the BSR to TD at $298.4 \mathrm{mbsf}$ (Fig. F22).

The zone of inferred gas hydrate occurrence based on salinity data correlates well with the zone of distinct thermal anomalies in IR scans, which are also indicative of gas hydrate dissociation (see "Physical properties"). Indeed, some of the lower salinity points shown in Figure F22 represent samples collected to specifically target the more pronounced IR temperature anomalies. The lowest salinities of 5.5 and 3.7 in Samples 311-U1327D-5X-2, 84-94 cm, and $15 \mathrm{X}-3,49-59 \mathrm{~cm}$, recovered at 128.7 and 222.0 mbsf, respectively (Table T3; Fig. F22), were identified by IR imaging and represent discrete zones of concentrated gas hydrate. Interestingly, both samples contain sand layers, and analyses revealed significantly lower salinity values in the sand than the adjacent clay matrix.

The chlorinity versus depth profile mimics the salinity trend with depth at this site, showing a striking overall continuous freshening trend with depth that corresponds to that previously observed at ODP Sites 889 and 890 (purple symbols in Fig. F22; Westbrook, Carson, Musgrave et al., 1994). The shallowest sample collected at this site (Sample 311-U1327C-1H-1, $25-40 \mathrm{~cm}$ ) has a chlorinity of $548.6 \mathrm{mM}$, which is lower than the value of seawater and most likely reflects the modern bottom-water value at this site. Chlorinity decreases from $548.6 \mathrm{mM}$ at $1.5 \mathrm{mbsf}$ to $\sim 390 \mathrm{mM}$ ( $71 \%$ of the bottom water value) at 128 mbsf, and except for the excursions to lower chlorinity values from $\sim 128$ mbsf to the depth of the BSR, it remains fairly constant at $387 \pm 3 \mathrm{mM}$ to TD. The discrete low chlorinity values are conspicuously clustered between 128 mbsf and the BSR and likely represent freshening caused by gas hydrate dissociation during core recovery, consistent with IR-inferred temperatures lower than in situ values (see "Physical properties") and high-resistivity zones in the logging data (see "Downhole logging"). The lowest chlorinity values of 67.8 and $70.4 \mathrm{mM}$ correspond to two sand subsamples collected from whole-round Samples 311-U1327D-5X-2, 84-94 cm (128.6 mbsf), 
and 15X-3, 49-59 $\mathrm{cm}$ (222.0 mbsf), respectively. These are the same samples that have the lowest salinities.

In the gas hydrate-bearing interval between 128 mbsf and the BSR, the chlorinity values of samples with decomposed gas hydrate range from 386 to 275 $\mathrm{mM}$, except for two discrete sand samples with chlorinities of 68 and $70 \mathrm{mM}$. Assuming no disseminated gas hydrate and, therefore, taking the background chlorinity as $398 \mathrm{mM}$ at this depth interval (Fig. F22; Table T4), the percent dilution by gas hydrate dissociation ranges between $3 \%$ and $30 \%$. The dilution of the two discrete sand samples having the lowest chlorinity values of 67.8 and $70.4 \mathrm{mM}$ is $\sim 82 \%$. The sand layers in these samples are $\sim 3 \mathrm{~cm}$ thick.

The observed freshening trend in the $\mathrm{Cl}$ concentration versus depth profile to $\sim 71 \%$ of the bottom water value at 128 mbsf does not reflect in situ production of water from clay dehydration (smectite to illite reaction), because temperatures of $\sim 50^{\circ}-60^{\circ} \mathrm{C}$ are required to initiate this reaction. At a geothermal gradient of $\sim 61^{\circ} \mathrm{C} / \mathrm{km}$ (see "Physical properties"), the temperatures between the seafloor and $128 \mathrm{mbsf}$ are $3^{\circ}-11^{\circ} \mathrm{C}$. If instead we assume that the observed continuous Cl-dilution profile between the seafloor and 128 mbsf is caused by dissociation of disseminated gas hydrate, the calculated pore volume occupancy by gas hydrate at $\sim 50 \%$ porosity (see "Physical properties") ranges from zero to $15 \%-18 \%$ from the seafloor to 128 mbsf, respectively. Such high concentrations of gas hydrate should have been clearly detected by the IR scans and by methane concentrations in the pressure cores. Because no chlorinity and salinity anomalies are superimposed on the overall continuous freshening trend and no IR temperature anomalies were observed between the seafloor and 128 mbsf, we conclude that the Cl-dilution profile in this depth interval is primarily dominated by diffusive communication with an advective low$\mathrm{Cl}$ fluid system at greater depth and not by gas hydrate dissociation. The absence of gas hydrate in the upper $128 \mathrm{~m}$, which is within the GHSZ, suggests that not enough methane was available for gas hydrate formation.

The nature of the $\mathrm{Cl}$ concentration versus depth profile may indicate a nonsteady-state advective system, in which advection is presently not intense. Another possible interpretation of this profile is that the rather constant concentration of $\mathrm{Cl}$ beneath the BSR to TD reflects advection of the deep-seated low-Cl fluid. Accordingly, the change in the slope of the $\mathrm{Cl}$ profile at $\sim 90$ mbsf and, in particular, the diffusive profile in the uppermost $60-70 \mathrm{~m}$ reflect a relaxation of the advective regime, potentially induced by a change in sedimentation rate. Modeling is required to distinguish between the two interpretations of the $\mathrm{Cl}$ concentration versus depth profile and to constrain the change in sedimentation rate that would be required to produce the observed change in the slope of the $\mathrm{Cl}$ profile at $90 \mathrm{mbsf}$.

\section{Biogeochemical processes}

Similar to Site U1329, the IW concentration versus depth profiles show extensive evidence of microbially mediated reactions and abiological fluid-rock reactions. The microbially mediated bacterial sulfate reduction, carbonate reduction, and methane oxidation as well as the associated authigenic carbonate formation, are particularly intense in the uppermost $20 \mathrm{~m}$ of the sediment section, as reflected in the concentration versus depth profiles of sulfate, alkalinity, ammonium, and phosphate (Fig. F23).

As seen in Figure F25, there is a slight shift in the sulfate reduction slope between Holes U1327D and U1327E. The integrated, almost linear decrease in sulfate concentration with depth from $28 \mathrm{mM}$ at 1.8 mbsf to zero concentration at 9.5 mbsf provides a reduction rate of $\sim 3.6 \mathrm{mM} / \mathrm{m}$. Note that the uppermost $1.8 \mathrm{~m}$ in Hole U1327D shows a constant sulfate concentration of $28 \mathrm{mM}$, indicating intense bioirrigation. There is an apparent depth offset of $\sim 1 \mathrm{~m}$ between Cores 311-U1327D-1H and 311-U1327E-1H. In addition, Figure F25 clearly shows that $\sim 3 \mathrm{~m}$ is missing between Cores $311-\mathrm{U} 1327 \mathrm{D}-1 \mathrm{H}$ and $2 \mathrm{H}$. High heave during the coring operations most likely caused this gap in recovery, which was rectified later by the recovery of Core $311-\mathrm{U} 1327 \mathrm{E}-1 \mathrm{H}$. The dissolved sulfate data from Core $311-\mathrm{U} 1327 \mathrm{E}-1 \mathrm{H}$ place the SMI depth between 9 and 10 mbsf. The depth of sulfate depletion at the SMI depth is concomitant with increasing methane concentration (see "Organic geochemistry"), consistent with anaerobic methane oxidation at the SMI. The greater than zero sulfate concentrations below the SMI depth of 9-10 mbsf (Fig. F23; Table T3) were used to correct for drill fluid contaminations (Table T3). In anoxic sediments, sulfate becomes the dominant electron acceptor during organic matter respiration, which can be described by the following net reaction (Claypool and Kaplan, 1974):

$$
2 \mathrm{CH}_{2} \mathrm{O}+\mathrm{SO}_{4}{ }^{2-} \leftrightarrow 2 \mathrm{HCO}_{3}{ }^{-}+\mathrm{H}_{2} \mathrm{~S},
$$

which produces $2 \mathrm{~mol}$ alkalinity for each consumed mole of sulfate. This ratio changes when methane is anaerobically oxidized by sulfate. This reaction only produces 1 mol alkalinity per mole sulfate, as shown in the following reaction:

$$
\mathrm{CH}_{4}+\mathrm{SO}_{4}{ }^{2-} \leftrightarrow \mathrm{HCO}_{3}{ }^{-}+\mathrm{HS}^{-}+\mathrm{H}_{2} \mathrm{O} \text {. }
$$

The slope of the alkalinity corrected for carbonate $(\mathrm{Ca}, \mathrm{Mg})$ versus sulfate concentration indicates that 
anaerobic methane oxidation is the dominant $(\sim 80 \%)$ sulfate reduction reaction at this site.

Within the zone of sulfate reduction and alkalinity generation, $\mathrm{Ca}, \mathrm{Mg}$, and $\mathrm{Sr}$ profiles show rapid decreases with depth, which reflect authigenic carbonate formation. In the uppermost $33 \mathrm{~m}$, this reaction preferentially consumes $\mathrm{Ca}$; therefore, calcite and/or $\mathrm{Mg}$-calcite formation leads to the observed increase in $\mathrm{Mg} / \mathrm{Ca}$ ratios to a value of 34 at $33 \mathrm{mbsf}$, more than double the maximum value observed at Site U1329 and about six times the value of seawater (Fig. F24; Table T4). At such a high $\mathrm{Mg} / \mathrm{Ca}$ ratio, high alkalinity values, and low sulfate values, dolomitization is the favored authigenic carbonate reaction. This suggestion is corroborated by the subsequent drop of the $\mathrm{Mg} / \mathrm{Ca}$ ratio and the decrease in alkalinity.

The Mg profile shows a steady decrease with depth and is strongly correlated with $\mathrm{Cl}\left(r^{2}=0.98\right.$ from 28 to $300 \mathrm{mbsf}$ ). This suggests that the observed $\mathrm{Mg}$ concentrations are mainly a function of a mixing process between seawater and a deep-seated lowchlorinity fluid that also has low $\mathrm{Mg}$ concentrations.

\section{Deep-seated fluid}

The concentration with depth data in Table T4 provide important information on the nature of the deep-seated low-Cl fluid. As indicated in Figures F22, F23, and F26, the fluid is depleted in $\mathrm{Mg}$ and $\mathrm{B}$; somewhat enriched in $\mathrm{Ca}, \mathrm{Sr}, \mathrm{K}$, and $\mathrm{Na}$; and enriched in Li concentrations. These characteristics are typical of subsurface fluids at temperatures $>150^{\circ}$ $200^{\circ} \mathrm{C}$. At a geothermal gradient of $61^{\circ} \mathrm{C} / \mathrm{km}$ (see "Physical properties"), the $150^{\circ}-200^{\circ} \mathrm{C}$ source fluid is at $>2 \mathrm{~km}$ depth. The silica concentration profile at this site is controlled by the in situ lithology and, therefore, does not provide an insight on the silica concentration of the deep fluid. The marked increase in silica concentration from an average of $\sim 550 \mathrm{mM}$ to an average of $\sim 750 \mathrm{mM}$ at $\sim 70 \mathrm{mbsf}$ does not coincide with the lithostratigraphic Unit I/II boundary (see "Lithostratigraphy"); it is $\sim 20 \mathrm{~m}$ shallower. The sharp increase in silica concentration at $\sim 70 \mathrm{mbsf}$ suggests a heterogeneous presence of diatoms from this depth to TD.

\section{Organic geochemistry}

The onboard organic geochemistry program for Site U1327 included analysis of the composition of volatile hydrocarbons $\left(\mathrm{C}_{1}-\mathrm{C}_{5}\right)$ and nonhydrocarbon gases (i.e., $\mathrm{O}_{2}$ and $\mathrm{N}_{2}$ ) from HS gas samples, void gas samples, and gas samples recovered during PCS degassing experiments. We analyzed sediment from the
IW squeeze cakes for inorganic carbon (IC) (also expressed as weight percent $\mathrm{CaCO}_{3}$ ) total carbon (TC), and total nitrogen (TN). Total organic carbon (TOC) was calculated as the difference between the TC and IC. We collected a total of 145 samples for HS and solid-state analysis at Site U1327. Most of the HS samples were collected from the ends of core sections facing the IW samples so that the gas and IW data could be integrated. The sampling plan (see "Interstitial water geochemistry") was designed to maximize vertical resolution in shallow sediments near the SMI. We collected 78 HS and sediment samples from Hole U1327C, which was sampled to 298.5 mbsf. In Hole U1327D, 37 of 43 HS samples were obtained at high vertical resolution from near the seafloor (0.4 mbsf) to 15.9 mbsf. It was later determined that the SMI interval was not recovered in this hole. We collected six additional samples from Hole U1327D to a maximum depth of 220 mbsf for safety monitoring purposes. The SMI interval missed in Hole U1327D was later recovered with a single APC core deployment in Hole U1327E. From this core, we collected 24 samples between 3.4 and 12 mbsf. In Hole U1327C, we collected a total of 46 void gas samples from depths where gas cracks in the sediment were first observed (25.6 mbsf) to $299.3 \mathrm{mbsf}$. Finally, we collected six gas samples from five PCS degassing experiments (see "Pressure coring").

The primary objectives at this site were to:

- Determine the origin (microbial versus thermogenic) of the gases recovered by HS gas, void gas, and PCS degassing techniques;

- Investigate the relationship between the gas composition and the presence of gas hydrate;

- Evaluate the fate of methane near the SMI; and

- Compare the carbon and nitrogen contents to gas related features in the sediments.

\section{Hydrocarbons}

\section{Headspace gas composition}

Hydrocarbon HS gas data from Holes U1327C, U1327D, and U1327E are listed in Table T5. Results are reported in parts per million by volume (ppmv) of methane, ethane, ethylene, and propane in the air headspace of a $25.41 \pm 0.18 \mathrm{~mL}$ serum vial containing the sediment volume listed in Table $\mathbf{T} 5$ and as the millimolar concentration of dissolved methane in the IW (see "Organic geochemistry" in the "Methods" chapter). Methane and ethane HS results from Hole U1327C are plotted in Figure F27 as the hydrocarbon gas component relative to depth. The results from high-resolution Holes U1327D and U1327E will be discussed below within the context of the sulfate data. Methane content increased rap- 
idly from just above background levels (3-7 ppmv from 1.5 to $7.6 \mathrm{mbsf}$ ) to $\sim 18,400 \mathrm{ppmv}$ from 9.5 to 28.1 mbsf. A few air samples collected from the catwalk area during Site U1327 operations had an average concentration of $1.87 \pm 0.03 \mathrm{ppmv}(n=4)$ methane, which is similar to the current atmospheric methane concentration ( 1.7 ppmv). Because the HS vials contained atmospheric air prior to sampling, this contribution should be considered in future isotopic analysis of the HS methane for low-concentration samples collected near the seafloor. The data reported in Table $\mathbf{T 5}$ are uncorrected for the atmospheric contribution. Methane values below the region of increasing gas concentrations ( $>28.1 \mathrm{mbsf}$ ) decreased slightly to $\sim 3000 \mathrm{ppmv}$ at $49.1 \mathrm{mbsf}$ and generally remained within the range of $\sim 2000-6000$ ppmv to 298.5 mbsf. Quantitative sampling of methane by the HS method is limited by the low solubility of methane in solution at atmospheric pressure $(\sim 1.2 \mathrm{mM})$. Methane exsolution from IW caused by depressurization occurs during core recovery, an effect that may be exacerbated in deeper samples with low porosity or sediments with different lithologies (i.e., sand versus clay). Low-porosity samples are compacted, which makes sampling difficult, and have a greater fraction of their sediment surface exposed to air during collection. Consequently, the apparent decrease in HS methane concentrations with depth may be a sampling artifact that does not necessarily represent in situ conditions. For example, the calculated solubility for methane at $153 \mathrm{mbsf}$ is $\sim 92 \mathrm{mM}$, whereas the calculated methane concentration was $14.6 \mathrm{mM}$. A PCS sample from $155 \mathrm{mbsf}$ contained gas hydrate (see "Pressure coring"); therefore, it is likely that the IW at 153 mbsf was saturated. Considering that the HS sample from 153 mbsf was suspected to contain some gas hydrate (concentrations above and below that depth were 2.7 and $2.0 \mathrm{mM}$, respectively), it is clear that the HS technique underestimates in situ concentrations. The reported concentrations are, therefore, minimal estimates.

Trace amounts of HS ethane $(0.8-3.0 \mathrm{ppmv})$ were present between 8.8 and $134.5 \mathrm{mbsf}$ in both Holes U1327C and U1327D. With greater depth, the concentration of ethane increased gradually from $\sim 5$ to $15 \mathrm{ppmv}$ at the projected depth of the BSR. One sample contained anomalously high concentrations of ethane (26.4 ppmv) and methane ( 21,512 ppmv) within this interval. Given that this interval also contained evidence of gas hydrate (see "Interstitial water geochemistry"), this elevated value may be the result of a small piece of gas hydrate having been captured in the sample vial. Below the projected BSR depth, the HS ethane concentrations decreased to values within the approximate range of 6-11 ppmv. Ethylene and propane were absent in HS samples from Site U1327.

\section{Void gas composition}

The composition of gas from voids in the core liner is shown in Table T6. Void gas was, on average, $>90 \%$ methane. Void gas reflects the composition of the combined gas from all phases (dissolved, free, and hydrate bound) but not the amount.

Although the concentrations of $\mathrm{C}_{2}-\mathrm{C}_{5}$ hydrocarbons were low relative to methane, their occurrence and distribution are useful for inferring the presence and type of gas hydrate. Structure I gas hydrate selectively fractionates ethane relative to the source composition, which has a greater lattice volume. Structure II gas hydrate also accommodates propane and $i$-butane (Sloan, 1998). Localized enrichment of void gases with these compounds may be used as a proxy for dissociated gas hydrate and a specific indicator for the type of hydrate (Structure I or Structure II) that was present.

Ethane was present in all void gas samples (Table T6). The concentrations of ethane increased gradually from 42 ppmv in the shallowest void gas sample (25.5 mbsf) to $157.7 \mathrm{ppmv}$ at $113.5 \mathrm{mbsf}$ (Fig. F28). With greater depth, ethane increased rapidly to $\sim 1150 \mathrm{ppmv}$ at $200.5 \mathrm{mbsf}$ and then decreased to 314 ppmv at the base of the hole. The interval of elevated ethane concentration corresponds to the interval where gas hydrate was inferred from LWD logs (see "Downhole logging"), low-temperature IR anomalies (see "Physical properties"), and lowchloride anomalies (120-223 mbsf; see "Interstitial water geochemistry"). This interval extends to the approximate depth of free gas ( 240 mbsf), as inferred from a velocity decrease in the Hole U1327D VSP (see "Downhole logging"). We can, therefore, infer that the ethane enrichment in the void gas resulted from ethane-enriched dissociated gas hydrate.

Propane, $i$-butane, $n$-butane, $i$-pentane, and $n$-pentane were also present in the void gas, primarily in the same interval where ethane was enriched (Fig. F28). Peak concentrations of propane (17.5 ppmv at $181 \mathrm{mbsf}$ ) and $i$-butane (16.9 ppmv at $214 \mathrm{mbsf}$ ) roughly correspond to the ethane peak described above. Normal butane was present from 155 mbsf to the box at the hole in the concentration range of 0.2-2.8 ppmv. Enrichment of propane and i-butane in this inferred gas hydrate-bearing interval suggests Structure II gas hydrate was present. Hydrogen sulfide was absent from all void gas samples. 


\section{Gas ratios}

$\mathrm{C}_{1} / \mathrm{C}_{2}$ ratios from the HS gas samples were consistently lower than those of the void gases from equivalent depths (Fig. F29). Although the gases recovered by the two sampling techniques clearly represent different fractions of the total gas pool, it is unclear if the offset reflects in situ differences or a sampling effect. Above the BSR, where free gas generally does not occur, the presumed origin of void and HS gas is either gas hydrate or gas that has come out of solution (exsolution). Void gas is collected directly from the core liner (see "Organic geochemistry" in the "Methods" chapter), which is "sealed" by sediment at the ends of the core barrel and frequently pressurized, whereas HS gas has been depressurized and exposed to atmosphere for a period of time (as long as $20 \mathrm{~min}$ ). Given the lower solubility and supersaturated condition of methane in recovered cores, methane will preferentially exsolve relative to ethane. The initial gas coming out of solution (captured in the core liner) should contain a greater fraction of methane than that exsolving later (captured by the HS technique). The observation of methane enrichment in the void gas and ethane enrichment in the HS gas may be explained by the difference in sampling time described above and is a factor that should be considered when comparing HS and void gas data. Further research is required to conclusively understand the relationship of the offset between the $\mathrm{C}_{1} / \mathrm{C}_{2}$ ratios of the gas components.

The $\mathrm{C}_{1} / \mathrm{C}_{2}$ ratios for the void and $\mathrm{HS}$ gas show downhole transitions related to the inferred distribution of gas hydrate at this site (see "Interstitial water geochemistry" and "Downhole logging"). $\mathrm{C}_{1} / \mathrm{C}_{2}$ of the HS gas decreased gradually from a maximum value of $\sim 14,500$ at 13.6 mbsf (the shallowest occurrence of HS ethane) to a minimum of 179 at 224.1 mbsf (the projected BSR). Void gas $C_{1} / C_{2}$ ratios decreased gradually from 25.5 (the shallowest occurrence of void gas) to $108.1 \mathrm{mbsf}$ and then rapidly to the depth of the projected BSR. The transition from a gradual to a rapid decrease in $\mathrm{C}_{1} / \mathrm{C}_{2}$ ratios of the void gas was accompanied by the occurrence of $\mathrm{C}_{3}-\mathrm{C}_{5}$ hydrocarbons (Table T6), gases with a primary thermogenic origin. The source of ethane driving the decrease in $C_{1} / C_{2}$ ratios is low-temperature diagenetic ethane production, migration of thermogenic ethane from a deep thermal source, or a combination of both. (Claypool and Kaplan, 1974). The chemical composition of the IW suggests fluids from depths where the temperature exceeds $150^{\circ}-200^{\circ} \mathrm{C}$ have migrated into the system (see "Interstitial water geochemistry"). Given that temperatures $>90^{\circ} \mathrm{C}$ are sufficient for thermal generation of hydrocarbons (Claypool and Kaplan, 1974), the fluids and thermogenic hydrocarbons may share a similar origin.

Elevated $i-\mathrm{C}_{4} / n-\mathrm{C}_{4}$ ratios in the gas hydrate-bearing interval indicated Structure II gas hydrate was present. Normal butane is too large to occupy the Structure II gas hydrate lattice, whereas $i-\mathrm{C}_{4}$ is not (Sloan, 1998). Consequently, $n-\mathrm{C}_{4}$ migrates through the region of gas hydrate stability, whereas $i-C_{4}$ is sequestered. Subsequent dissociation of the gas hydrate during core recovery results in an elevated quantity of $i-\mathrm{C}_{4}$ relative to $n-\mathrm{C}_{4}$ in the void gas. Below the depth where free gas occurs ( 240 mbsf; see "Downhole logging") to the base of the hole, the $i$ $\mathrm{C}_{4} / n-\mathrm{C}_{4}$ ratio averaged 0.94 (Fig. F30). This value represents a signature unaltered by gas hydrate sequestration and is similar to values reported from cuttings from the Mallik 5L-38 well (Lorenson et al., 2005). Above this depth the ratio increased to a maximum value of $\sim 10$ at 214 mbsf; a depth within $10 \mathrm{~m}$ of where a low-temperature IR anomaly was observed (see "Physical properties") and a discrete IW sample collected from a $3 \mathrm{~cm}$ sand layer had a salinity of 3.7 (see "Interstitial water geochemistry"). The $i-\mathrm{C}_{4} / n-\mathrm{C}_{4}$ ratios remained elevated to $128.5 \mathrm{mbsf}$, the shallowest depth where the salinity data showed excursions from background values (see "Interstitial water geochemistry"). Additional research is required to address the possibility that the observed ratios occurred as a result of low-temperature diagenetic reactions, but the agreement between the gas data and other proxies for the presence of gas hydrate described above suggests the observed ratios are related to the occurrence of gas hydrate. Gas composition expressed by the $\mathrm{C}_{1} / \mathrm{C}_{2}$ ratios of $\mathrm{HS}$ and void gas is plotted relative to sediment temperature in Figure F31. Sediment temperature is based on the calculated geothermal gradient of $59.0^{\circ} \mathrm{C} / \mathrm{km}$ (see "In situ temperature profile"). Monitoring of $\mathrm{C}_{1} / \mathrm{C}_{2}$ in void and HS samples and its relationship to temperature was developed as a safety guideline by the Joint Oceanographic Institutions for Deep Earth Sampling Pollution Prevention and Safety Panel during ODP. $C_{1} / C_{2}$ ratios are described as either "normal" or "anomalous" depending upon where they plot relative to the slightly diagonal line in Figure F31. Some values from the HS samples measured at Site U1327 were within the "anomalous" region (Pimmel and Claypool, 2001). However, all the void gas samples, which are better indicators of the in situ gas composition for reasons described above, were within the acceptable limits for safe drilling.

Results from the analysis of gas samples collected during PCS degassing experiments (see "Pressure coring") are shown in Table T7 and are plotted relative to depth with the HS and void gas data in Figure 
F29. The $\mathrm{C}_{1} / \mathrm{C}_{2}$ ratios of PCS gas samples were similar to those of void gas samples from similar depths. Because PCS gas samples are purported to reflect the in situ gas composition (including gas from dissociated gas hydrate), agreement between the two data types suggests that void gas samples also represent the in situ gas $\mathrm{C}_{1} / \mathrm{C}_{2}$. Furthermore, concentrations of methane in the void gas and PCS gas were similar ( $90 \%$ of the total gas). The $i-\mathrm{C}_{4} / n-\mathrm{C}_{4}$ ratios of PCS and void gas samples displayed similar downhole trends, but the magnitude of the values differed (Fig. F29).

\section{Biogeochemical processes}

The sulfate concentration profile established the base of the sulfate reducing zone at 9.5 mbsf (see "Interstitial water geochemistry"). IW sulfate data are plotted with dissolved methane concentrations in Figure F32 to illustrate the relationship between reduction of sulfate and anaerobic oxidation of methane. All data from Hole U1327D and select data from Hole U1327E are included in Figure F32. An interval of $\sim 1.5 \mathrm{~m}$, which happened to contain the SMI, was not recovered between Cores 311-U1327D$1 \mathrm{H}$ and $2 \mathrm{H}$. Core $311-\mathrm{U} 1327 \mathrm{E}-1 \mathrm{H}$ was collected to capture the missed SMI interval. By design, we drilled to 3.2 mbsf before shooting this core so the SMI would fall approximately in the center of the core. Consequently, no surface sediment data were obtained from Hole U1327E. In Figure F32, the surface data are from Core 311-U1327D-1H. The methane concentration profile was extended with data from Core 311-U1327E-2H to show the decreasing trend of methane concentration below $14.4 \mathrm{mbsf}$.

The SMI was centered at 9-10 mbsf where the dissolved methane and sulfate concentrations were 1.2 and $2.0 \mathrm{mM}$, respectively.

\section{Sediment carbon and nitrogen composition}

The sediment IC, carbonate $\left(\mathrm{CaCO}_{3}\right), \mathrm{TC}$, TOC, and TN concentrations and C/N ratios from Site U1327 are listed in Table T8 and plotted relative to depth (0-300 and 0-13 mbsf) in Figure F33. The IC and carbonate contents were relatively low with 82 of 83 samples containing $<1 \mathrm{wt} \%$ carbonate and an average IC of $0.34 \mathrm{wt} \%$. The variability reflects primary changes in biogenic and authigenic carbonate and does not show a clear relationship with depth from 0 to 300 mbsf. The near-surface Cores 311-U1327D-1H and $311-\mathrm{U} 1327 \mathrm{E}-1 \mathrm{H}$ were selected to obtain highresolution profiles in the uppermost $13 \mathrm{~m}$. The IC and carbonate contents were low throughout the uppermost $13 \mathrm{~m}$ (average IC $=\sim 0.35 \mathrm{wt} \%$ ) and showed no relationship to the depth of the SMI (9 mbsf). TOC ranged from 0.02 to $1.42 \mathrm{wt} \%$ (average $=0.62$ $\mathrm{wt} \%$ ), and $\mathrm{TN}$ ranged from 0.00 to $0.19 \mathrm{wt} \%$ (average $=0.08 \%)$ (Table T8; Fig. F33). Within the high-resolution cores, the TOC and TN were highest in the sample nearest the sediment/water interface $(0.89$ wt $\%$ TOC and $0.07 \mathrm{wt} \% \mathrm{TN}$ at $0.3 \mathrm{mbsf}$ ) and decreased gradually with depth to uniform values of $\sim 0.4 \mathrm{wt} \%$ TOC and $\sim 0.03 \mathrm{wt} \% \mathrm{TN}$. C/N ratios in the near-surface sediments had an average value of $\sim 10$, reflecting primary marine input with some terrestrial influence. Low values in the range of 3.7 to $\sim 6$ at $\sim 200$ mbsf are lower than what one would expect from pure marine organic matter or microbial biomass $(\mathrm{C} / \mathrm{N}=\sim 7)$. These values most likely reflect $\mathrm{ab}$ sorption of inorganic nitrogen to clay minerals because of high concentrations of ammonium in the pore water ( 6-8 $\mathrm{mM}$ at 100-200 mbsf) (see "Interstitial water geochemistry").

\section{Microbiology}

Site U1327, located near the center of the transect of sites cored across the northern Cascadia accretionary prism, was the second site sampled for microbiology. At this site, the base of the GHSZ was estimated at 223 mbsf. This site is located near Site 889. The goals of the microbiological sampling program and study were to identify the subsurface spatial distribution of optimal microbial activity and growth of methanogens and to elucidate how methanogenesis contributes to the formation of gas hydrate in the northern Cascadia margin. Within this subsurface zone of optimal microbial activity, measurements of methane production rate and organic compounds used for methane production should correlate with the biomass determined from direct cell counts and microbial community structures. It is also a goal of this effort to cultivate and characterize the anaerobic methane oxidizing and other unique communities at the SMI and in gas hydrate-associated sediment. This expedition provides the opportunity to culture novel piezophilic, aerobic (heterotrophic), and anaerobic (sulfate reducing) prokaryotes. Most of the shipboard effort was devoted to developing and implementing a sampling scheme to meet the goals of the program and to begin the cultivation of the high pressure-adapted microorganisms.

\section{Microbiological sampling}

Sampling from the mudline (interval 311-U1327C$1 \mathrm{H}-1,0-3 \mathrm{~cm}$ ) to the deepest core (interval 35X-2, 5$15 \mathrm{~cm} ; 297.05 \mathrm{mbsf})$ in Hole U1327C targeted microorganisms for aerobic and anaerobic high-pressure culturing. Sampling in the upper sediment layers of Holes U1327D and U1327E focused on the SMI, where methane consumption is expected to occur. 
Anaerobic oxidation of methane using sulfate as the electron acceptor has been the focus of several recent studies (Boetius et al., 2000; Orphan et al., 2002; Michaelis et al., 2002; Zhang et al., 2002) and is a major focus for the microbiology program of Expedition 311. Hole U1327C was completed as a continuous, deep hole, and once the sulfate and methane data had been examined, the SMI was targeted for intensive, coupled microbiological and geochemical sampling in both Holes U1327D and U1327E (see "Interstitial water geochemistry" and "Organic geochemistry"). Samples from Hole U1327D were collected from the mudline to $15 \mathrm{mbsf}$; however, the SMI region was in a coring gap and a second attempt in Hole U1327E successfully recovered the SMI between 8.2 and 9.6 mbsf (see "Interstitial water geochemistry" and "Organic geochemistry"). Samples collected from the SMI and 1-5 m above and below the SMI were divided into subsamples and stored at $-80^{\circ} \mathrm{C}$ (for deoxyribonucleic acid [DNA] analysis) or $4^{\circ} \mathrm{C}$ under nitrogen gas (for culturing and activity analyses).

Methanogenesis can exist in most anaerobic environments, but it becomes the major process when other electron donors such as nitrate, Fe(III), and sulfate are depleted. We sampled regularly downhole to below the predicted depth of the BSR to quantify methanogenesis in the sediment. Most of the methane bound within marine gas hydrate is of biogenic origin (Appenzeller, 1991), which implies that the sediment associated with gas hydrate may consist of microbial communities dominated by methanogens. The Hole U1327A LWD data (see "Downhole logging") indicated that gas hydrate might be widely distributed above the BSR. Therefore, methanogens closely associated with gas hydrate were expected to be present in this deep sediment. We started an enrichment culture experiment for methanogens with these sediment samples (see "Enrichment cultures" in the "Methods" chapter). Across this gas hydratebearing zone, Samples 311-U1327C-16X-4, 60-75 cm (128.2 mbsf); 22X-3, 115-130 cm (184.1 mbsf); and $28 \mathrm{X}-4,40-55 \mathrm{~cm}$ (232 mbsf), were used for methanogen enrichment culture studies. In postcruise experiments, we will examine the correlation between among the rates of methanogenesis and a range of other sediment properties such as direct cell counts, phylogenetic analysis, geochemical analyses of methane gas concentrations, and IW chemistry. Samples were prepared for shore-based experiments in which sediments will be heated to in situ temperatures for measuring total methane production and estimating organic compounds utilized in methanogenesis.
Gas hydrate was inferred to exist in the cores recovered from this site, and whole-round core samples spatially associated with IR thermal anomalies were collected (see "Physical properties"). The emphasis in sample processing was to work as quickly as possible without compromising microbiological integrity of the samples by minimizing warming of cores above in situ formation temperatures and minimizing exposure to oxygen. Subsamples for DNA analysis were removed immediately from the center of the whole-round core and stored at $-80^{\circ} \mathrm{C}$. All other cores were kept at $4^{\circ} \mathrm{C}$ and left undisturbed in core liners until processed. Processing of samples from Hole U1327C was conducted in the hold deck reefer on the JOIDES Resolution.

\section{Contamination tests}

\section{Perfluorocarbon tracer}

Samples for perfluorocarbon tracer (PFT) and fluorescent microsphere analyses were conducted on the whole-round cores in the reefer. Each of the analyzed cores had $\sim 5 \mathrm{~cm}^{3}$ subsamples taken from outer and inner portions for gas chromatograph analysis as described in "Microbiology" in the "Methods" chapter. We found that the contamination level of the samples at this site was less than that at Site U1329 (Table T9); however, we may still be detecting apparent PFT contamination in samples processed in the reefer from PFT-contaminated air.

\section{Fluorescent microspheres}

Comparison of paired samples collected from the edges and centers of cores for fluorescent microsphere penetration are summarized in Table T9. Microscopic analysis of the outer portion of the core showed detectable numbers of microspheres of $10^{4}$ microspheres/g of sediment, whereas numbers were generally below the detection limit of 100 microspheres/g in samples taken from core interiors.

\section{Shipboard analysis}

Samples were taken from the top (interval 311U1327C-1H-1, 0-10 cm) and bottom (interval 35X-2, 5-15 cm; $297.05 \mathrm{mbsf}$ ) of the sedimentary section for inoculation of enrichment cultures targeting high pressure-adapted heterotrophic and sulfate-reducing microorganisms. Samples were maintained at low temperature, and dilution series were inoculated to culture for microorganisms at 55.1 $\mathrm{MPa}$ and $4^{\circ} \mathrm{C}$. Cultures for sulfate reducers were prepared in the anaerobic chamber and were fed formate, acetate, or lactate as a carbon source. 


\section{Physical properties}

Site U1327 is located near Leg 146 Site 889. Seismic data suggest the presence of slope basin sediments deposited on older, accretionary complex material. Seismic indicators of gas hydrate are present, and LWD/MWD data show a resistivity increase and density decrease at a depth of $\sim 120$ to 140 mbsf, indicative of significant gas hydrate accumulation. IR and in situ temperature data indicate that the GHSZ extends to 220-230 mbsf, consistent with the BSR. Gas hydrate distribution within the GHSZ is clearly heterogeneous on the scale of the distance between holes $(\sim 25 \mathrm{~m})$.

Physical properties were measured in cores recovered from Holes U1327B through U1327E. Hole U1327B missed the mudline and contained only one core. Hole U1329C reached a depth of 300 mbsf. Selected cores from gas hydrate-bearing zones were obtained from Hole U1327D, which was dedicated to special tools. Figure F34 presents an overview of the physical property data obtained at this site. In the following sections we discuss these data and compare them to data acquired at other sites.

\section{Infrared images}

All cores were scanned on the catwalk following the track-mounted IR camera procedures described in "Physical properties" in the "Methods" chapter. Because IR anomalies indicate gas hydrate dissociation during core recovery, catwalk sampling was conducted based on these scans. Portable Document Format images of the scans of all cores are available in the "Site U1327 core descriptions." Temperature arrays in the format of comma-separated value files were exported from the IR camera software and then concatenated for each core. The arrays were then further concatenated for all cores available in a given hole. Figure F35 shows cold thermal anomalies in the concatenated false-color IR images for Holes U1327C and U1327D. This figure also shows the Hole 1327A LWD/MWD resistivity and pore water saturation derived from these data for comparison. Cold anomalies were detected in the cores from this site, consistent with the occurrence of significant amounts of gas hydrate between $\sim 120$ and 220 mbsf based on LWD resistivity measurements (see "Downhole logging") and chlorinity analyses (see "Interstitial water geochemistry").

As a precursor to quantitative studies of the temperature anomalies, downhole temperatures were averaged for each pixel row in the IR temperature array, excluding pixels $\sim 1 \mathrm{~cm}$ from the edge of the image and $2 \mathrm{~cm}$ along the midline of the image to eliminate the major thermal artifacts in the images. The resulting temperature profiles are shown in Figure F36. This processing enables us to measure the average amplitude of the cold anomalies and separate warm anomalies caused by voids from the background temperature field ("Physical properties" in the "Methods" chapter).

In Hole U1327C, cold thermal anomalies start at $\sim 109 \mathrm{mbsf}$ and continue to $225 \mathrm{mbsf}$. The highest number of anomalies and the largest negative difference from the background temperature $(\Delta T)$ are observed between 142 and 160 mbsf, offset from the high-resistivity and low-density zone observed on LWD/MWD logs in Hole U1327A. In particular, Core 311-U1327C-16X (124-132 mbsf) might be expected to exhibit anomalies similar to those in Core 19X (151-159 mbsf). Instead, the anomalies in Core 311U1327C-16X are weak. In the selected cores obtained in Hole U1327D, IR images bracket a similar range as in Hole U1327C, but the numbers of anomalies and intensities are lower, except in Core 311-U1327D$11 X$.

It should be noted that recovery was poor in this depth range, especially for Cores 311-U1327C-14X, $17 \mathrm{X}$, and 18X (see right side of Fig. F35), which is a common occurrence in gas hydrate-bearing sediments. Nonetheless, Core 311-U1327C-16X, which was located well within the depth range of the gas hydrate-bearing zone inferred from the LWD resistivity log in Hole U1327A, did not show any strong IR anomalies. Selected XCB cores obtained from Hole U1327D also show a different IR structure relative to Hole U1327C and relative to the Hole U1327A LWD resistivity results. Further discussion of the intrasite differences in resistivity and IR thermal anomalies is included in "Downhole logging" (see Fig. F66). The overall conclusion from this analysis is that there is significant lateral and vertical heterogeneity in gas hydrate distribution on a scale of $\sim 25 \mathrm{~m}$ at Site U1327.

Catwalk IR anomalies were systematically sampled for IW study (see "Interstitial water geochemistry"). The handheld IR camera was used to image the thermal structure of whole-round IW Sample 311U1327D-15X-3, 49-59 cm (221.96-222.04 mbsf), after it was removed from the core liner and before it was dissected. The resulting IR images show that the cold zone in the IR image is coincident with a sand layer, indicating that gas hydrate was present in the sand but not in the surrounding fine-grained sediment. The chlorinity data from the sand portion of this IW sample show strong freshening $(74.1 \mathrm{mM}$ $\mathrm{Cl}$ ), indicative of gas hydrate dissociation (see Table T3).

IR images of the cut ends of core sections were also acquired with the handheld IR camera. Figure F37 
shows a series of IR images of the section ends of Core 311-U1327D-2H, with a plot of associated cross-core temperature profiles. These images were collected sequentially as the core was processed for microbiology and IW studies and illustrate the temperature changes in the core over space and time. In addition to the IR images, core centerline temperatures were also taken and permit a direct estimate for emissivity ( 0.89) of wet hemipelagic sediments near the seafloor at Site U1327. The deepest section shown in Figure F37 originated at 16.44 mbsf and $3.5^{\circ} \mathrm{C}$ (see "In situ temperature profile"). By the time catwalk sampling of the core was complete $(1 \mathrm{~h}$, $18 \mathrm{~min}$ ) the core had warmed to $13^{\circ} \mathrm{C}$ in the center and $13.4^{\circ} \mathrm{C}$ at the edges.

\section{Sediment density and porosity}

Gamma ray attenuation (GRA) densities were measured on the multisensor track (MST), and bulk density, grain density, and porosity were calculated from the measured wet and dry weights and dry volume of the sediments (moisture and density [MAD] measurements) (Table T10). Both estimates of density were compared to in situ densities measured by the LWD/MWD tools (Fig. F34). In general, the agreement among these three data sets is good. Outlying low density points in the GRA data reflect the presence of cracks and voids. MAD and GRA data diverge significantly from the LWD density at specific depths. For example, we attribute differences among these data sets at $145 \mathrm{mbsf}$ to the occurrence of highdensity dropstones detected in the GRA measurements and visually in the cores. Dropstones were intentionally not sampled for MAD but would be detected and averaged out in the LWD/MWD measurements.

Generally, MAD densities increase and porosities decrease with depth, although the rate of increase is less with increasing depth (Table T11). This density profile differs from that at Site U1329, which shows no increase in density from $\sim 10$ to 60 mbsf. The increase in density with depth, however, is slower than that predicted for normal consolidation (see "Shear strength") and consistent with rapid sedimentation based on biostratigraphic analysis (see "Biostratigraphy"). In detail, however, a few anomalous zones can be noted. Figure F38 shows porosity, bulk density, resistivity, and magnetic susceptibility from 100 to $170 \mathrm{mbsf}$. LWD/MWD porosity (Hole U1327A) increases from $\sim 45 \%$ to $60 \%$ in the interval from 123 to $141 \mathrm{mbsf}$. This porosity increase, which is coincident with increased resistivity, has been interpreted to indicate the presence of gas hydrate. MAD porosity and bulk density are essentially unchanged over this depth interval. Contact resistivity also shows no change in this interval, with the exception of two data points that match the in situ resistivities. The MAD data suggest that density and porosity in this interval in Hole U1327C may differ from those in Hole U1327A. Although not definitive, this indication is consistent with the apparent lack of abundant gas hydrate in the upper part of this section based on the IR scans.

Other significant mismatches between densities measured on core samples and in situ measurements occur at 100-110 and 150-160 mbsf. In both of these intervals, the MST and MAD bulk densities are lower and porosities are higher than in the LWD/MWD data from Hole 1327A. Because the MST and MAD data generally agree and because no unusual core features that can explain this difference were noted by the sedimentologists, we interpret this discrepancy as additional evidence for lateral heterogeneity.

\section{Magnetic susceptibility}

Magnetic susceptibility data enabled us to compare the depth of Core 311-U1327B-1H, which missed the mudline, relative to Cores $311-\mathrm{U} 1327 \mathrm{C}-1 \mathrm{H}$ and $2 \mathrm{H}$ (Fig. F39A). Deeper in Hole U1327C, the magnetic susceptibility data also support inferences about interhole variability at this site. Magnetic susceptibility is low at 152-162 mbsf in Hole U1327C, whereas it is high only $30 \mathrm{~m}$ away in Hole U1327D (Fig. F39B). This change is associated with a change in lithology (Fig. F39B) and is possibly caused by a deposit containing numerous rounded and angular rocks of variable composition and size (see "Lithostratigraphy"). Large differences in magnetic susceptibility between Holes U1327C and U1327D also occur from 135 to 137 mbsf. These observations provide yet more evidence of the geologic heterogeneity on a scale of tens of meters that appears to be characteristic of Site U1327. Although the magnetic susceptibility differences may not be directly related to gas hydrate occurrence, a linkage between lithologic differences detected by the magnetic susceptibility and the occurrence of gas hydrate is possible.

\section{Compressional wave velocity from the multisensor track and Hamilton frame}

$P$-wave velocity was measured using the Hamilton frame and MST only on near-seafloor cores from Holes U1327B and U1327C (Table T12). Because of extensive cracking caused by gas exsolution during core recovery, no meaningful measurements could be made deeper than 20 mbsf. MST velocity measurements were made every $2.5 \mathrm{~cm}$ along Cores 311U1327B-1H and 311-U1327C-1H and 2H (Sections 1-3). Measurements were made on the Hamilton 
frame in all three directions, taking care to measure undisturbed sediment. $P$-wave velocities could be measured to greater depth (20.4 mbsf) in the x-direction with the Hamilton frame ( $P$-wave Sensor 3; PWS3) than with the MST because the waveforms were hand-picked.

Velocities from both methods show a linear increase in velocity with depth. Measurements made with the Hamilton frame are generally higher than those made with the MST and have greater scatter than those observed at other sites. There is a linear correlation between velocity and density MST and MAD measurements (Fig. F40).

\section{Shear strength}

Shear strength measurements were made routinely throughout Hole U1327C using the handheld Torvane (Table T13) and the automated vane shear (AVS) (Table T14). Measurements were made on the working half of the split core after resistivity and velocity measurements had been completed and after MAD samples were taken. Measurements were taken in areas of the core where the sediment was undisturbed and as close as possible to where MAD samples had been extracted. At least one shear strength measurement was taken per section and often more where there were visible changes in the sediments (i.e., color and grain size). Shear strength data are shown in Figure F41. Measurements were made with the small Torvane from 75 to 90 mbsf (Table T13). Above and below this depth, measurements were made with the medium Torvane (see "Physical properties" in the "Methods" chapter). Comparison of data obtained with both vanes from the same section at Site U1325 (see "Physical properties" in the "Site U1325" chapter) indicates that Torvane measurements have large uncertainties at high shear strengths (see "Physical properties" in the "Site U1325" chapter). Nonetheless, a comparison between results obtained with the AVS and the handheld Torvane on two sections from this site, which were retrieved from storage for this experiment, reveals a similar range of shear strength values, providing some confidence in the results.

Shear strength increases with depth. The ratio of shear strength to overburden pressure decreases from 0 to 40 mbsf and then becomes constant at a value of $\sim 0.045$ to $75 \mathrm{mbsf}$, indicative of sediment underconsolidation. A large but variable increase in shear strength is observed between 75 and 90 mbsf. Although no lithostratigraphic boundary has been defined at this depth, this depth represents a major change in physical properties as porosity decreases, thermal conductivity and contact resistivity increase, and grain density becomes less scattered (Figs. F34, F42). The cores are too deformed for reliable shear strength measurements deeper than 90 mbsf, the start of XCB coring.

\section{Electrical resistivity}

Although contact resistivity used to be routinely measured on Deep Sea Drilling Project and ODP legs, this measurement has not been made in recent years. During Expedition 311, these measurements were made using a standard four-pin Wenner-type probe array (Table T15). Contact resistivity measurements were made on all cores to 145 mbsf (Hole 1327C). At greater depths, the cores were too disturbed to yield meaningful results. Noncontact resistivity measurements were made to greater depth using the MST. Resistivity values show considerable scatter because of cracks within the sediments resulting from gas expansion during core retrieval. For the MST, measurement interval was $2.5 \mathrm{~cm}$; for the contact resistivity, the measurement interval varied depending on core quality.

Pore water resistivities were calculated from the IW salinities using equations developed by Fofonoff (1985) and corrected to $20^{\circ} \mathrm{C}$ (Fig. F42A). Values of the whole sediment resistivity ranged from 0.3 to 2.4 $\Omega \mathrm{m}$. These were used to calculate formation factor (ratio of saturated sediment resistivity to pore fluid resistivity) from the contact resistivities (Fig. F42B). Archie's parameters were then determined by fitting Archie's equation to the formation factor and MAD porosity data (Fig. F42D). The cementation coefficient $m=2.33$, and the tortuosity coefficient $a=$ 0.877 . Porosities determined from the resistivity and Archie's parameters are compared to the MAD porosities in Figure F42C. Porosities determined by the two methods agree well except in the uppermost 20 $\mathrm{m}$, where the Archie's parameters appear to overestimate porosities. Shallower sediments will be characterized by different Archie's parameters than the deeper parts of the hole during postcruise research. The cementation coefficient has a higher value than that obtained for Leg 146 Sites 889 and 890 ( $m=$ 1.76). The tortuosity coefficient is lower than the one reported for Sites 889 and $890(a=2.07)$ (Westbrook, Carson, Musgrave, et al., 1994). However, recalculation of Archie's parameters for Sites 889 and 890 using pore water resistivity values that were based on measured pore water salinity rather than seawater led to $a=1.46$ (Hyndman et al., 1999), which is closer to our results. Overestimation of the porosities in the uppermost $20 \mathrm{~m}$ also appears at Sites 889 and 890.

\section{Thermal conductivity}

Thermal conductivity ranges from 0.6 to $1.2 \mathrm{~W} /$ $(\mathrm{m} \cdot \mathrm{K})$ and shows no trend with depth (Table T16; 
Fig. F43). Values below $30 \mathrm{mbsf}$ are low because of gas expansion cracks, which resulted in poor contact between the sediment and the thermal conductivity probe. The highest values follow the regional trend defined by Davis et al. (1990). For determination of in situ temperature and heat flow, a constant thermal conductivity value of $1.1 \mathrm{~W} /(\mathrm{m} \cdot \mathrm{K})$ was assumed. Attempts to evaluate the quality of individual measurements by comparison with core photographs and barrel sheets will be undertaken postcruise.

\section{In situ temperature profile}

Although seven deployments of temperature tools were attempted in Hole U1327C, only four provided usable data. Unfortunately, two tools failed and one was subjected to excessive heave.

The data are shown in Figure F44. In situ temperatures extrapolated from the data are shown in Table T17 and compared to data from Site 889 in Figure F45. The temperatures determined for Hole U1327C are slightly higher than those determined at similar depths at Site 889 (Westbrook, Carson, Musgrave, et al., 1994) but are generally consistent with those data. The difference between the gradient determined from the Site U1327 data and the combined Sites 889 and U1327 data is not statistically significant. For the observed in situ salinity, the temperature gradient predicts the base of pure gas hydrate stability at 225-250 mbsf, consistent with other observations. Additional comparisons between the in situ temperatures recorded at this site and at other sites drilled during Expedition 311 are discussed in "In situ temperature profile" in the "Site U1326" chapter.

\section{Paleomagnetism}

Note: This section was contributed by Jennifer Henderson and Katerina Petronotis (Integrated Ocean Drilling Program, Texas A\&M University, 1000 Discovery Drive, College Station TX 77845, USA).

Alternating-field (AF) demagnetization of the sedimentary archive-half sections was used to determine the remanent magnetization components recorded in the recovered core (Fig. F46). The paleomagnetic data will be used postcruise to characterize the magnetic properties of the sediments and to construct a magnetostratigraphy of the sedimentary section recovered at Site U1327. The AF demagnetization applied at 10 and $20 \mathrm{mT}$ should have removed most of the drill string magnetic overprint, but postcruise demagnetization at higher fields will most likely be required.

Questionable data may be associated with remanence measurements over intervals disturbed or de- formed by coring. Similarly, magnetic edge effects, which can be large when measurements are within $\sim 5 \mathrm{~cm}$ of the edge of a section or edge of a void, can give biased results. To avoid interpreting results in these regions, we manually noted the disturbed intervals and voids in the cores. Data from these intervals will be removed prior to postcruise interpretation.

\section{Pressure coring}

The main objectives of pressure coring during Expedition 311 were to quantify natural gas composition and concentration in sediments and to determine the nature and distribution of gas hydrate and free gas within the sediment matrix. To achieve these objectives, we

- Measured the quantity and composition of gases released during controlled degassing experiments,

- Conducted nondestructive measurements (X-ray imaging, $P$-wave velocity, and GRA density) at in situ pressure and during degassing, and

- Preserved gas hydrate-bearing sediments at in situ pressure for more comprehensive shore-based investigations.

The nondestructive measurements not only provide a direct indication of the existence of gas hydrate, but the resulting data (acoustic impedance) can be used to help interpret regional seismic data. Site U1327 was a near-reoccupation (375-600 m) of Leg 146 Site 889 . The gas hydrate occurrence at Site 889 was estimated at $20 \%-30 \%$ of pore space in the 100 $\mathrm{m}$ thick interval above the BSR (Westbrook, Carson, Musgrave, et al., 1994). The BSR at Site 889 is a strong reflection event that occurs at 225 mbsf, with evidence of free gas beneath (Westbrook, Carson, Musgrave, et al., 1994). LWD data from Hole U1327A show a thick high-resistivity layer at $~ 125-$ 140 mbsf, which according to Archie's equation suggests that gas hydrate occupies $40 \%-70 \%$ of the pore space (see "Gas hydrate and free gas occurrence"). Specific objectives at Site U1327 were to confirm and quantify the presence of gas hydrate above the BSR, with special attention to the high-resistivity layer, and free gas below the BSR.

\section{Operation of pressure coring systems}

Pressure coring tools were deployed fourteen times at Site U1327 (Table T18): eight PCS cores (three in Hole U1327C, three in Hole U1327D, and two in Hole U1327E), four HRC cores (three in Hole U1327D and one in Hole U1327E), and two FPC cores (both in Hole U1327D). Figure F47 shows the pressure history of the cores during deployment, cor- 
ing, recovery, and chilling in the ice shuck. Based on the temperature and pressure records from the data loggers, all successful pressure cores were stabilized in the gas hydrate stability field (Fig. F48), though some of the PCS cores experienced brief (5-10 $\mathrm{min}$ ) excursions out of the gas hydrate stability field during the latter portion of core recovery.

The PCS recovered five cores under pressure (Table T18): one above all target zones (Core 311-U1327E3P; $80 \mathrm{mbsf}$ ), two near the depth of the high-resistivity layer seen in Hole U1327A data (Cores 311U1237C-15P and 311-U1237D-10P; 121.8 and 155.1 mbsf, respectively), one between the high-resistivity layer and the BSR (Core 311-U1237C-24P; 197.3 mbsf), and one below the BSR (Core 311-U1237D$17 \mathrm{P} ; 246 \mathrm{mbsf}$ ). The recovered pressures as measured by the internal data loggers were approximately half of in situ pressures.

The HRC recovered three cores under pressure (Table T18): one at the depth of the high-resistivity layer (Core 311-U1327D-4E; $125.3 \mathrm{mbsf}$ ) and two between this layer and the BSR (Cores 311-U1327D-12E and $14 \mathrm{E} ; 170.5$ and $217.7 \mathrm{mbsf}$, respectively). These cores recovered $\sim 80 \%$ of in situ pressure. A broken catcher ring in the "technical" portion of the HRC prevented the transfer of Core 311-U1237D-4E, and it had to be depressurized in the transfer chamber.

The FPC recovered one pressurized core (Core 311U1327D-13Y). This core became jammed in the transfer system, likely as a result of expansion caused by partial depressurization, and was completely depressurized in the transfer chamber. The other FPC deployment at this site, which recovered Core 311U1327D-6Y, suffered from a core liner implosion and corer over-retraction.

After all analyses were complete (see "Measurements on HYACINTH cores"), cores were archived as described in "Pressure coring" in the "Methods" chapter. The PCS cores were extruded, and HRC Cores 311-U1237D-12E and 14E were transferred to storage chambers for further shore-based analysis.

\section{Degassing experiments}

At Site U1327, the five PCS cores recovered successfully under pressure were investigated by controlled shipboard degassing experiments (Table T19). The deepest PCS core (Core 311-U1237D-17P) was taken at $246.0 \mathrm{mbsf}$, which is $\sim 25 \mathrm{~m}$ deeper than the seismically inferred BSR depth of 223 mbsf. Three of the PCS cores were taken from within the predicted depth interval of the GHSZ (Cores 311-U1237C-15P, 121.8 mbsf; 311-U1237D-10P, 155.1 mbsf; and 311U1237C-24P; $197.3 \mathrm{mbsf})$. Core 311-U1327E-3P, the shallowest PCS core at this site, was taken from 80.0 mbsf.

All degassing experiments included the following steps. First, the volume and density of sediment inside the inner core barrel of the PCS was monitored by X-ray analysis. Next, the PCS was slowly degassed in a temperature-controlled laboratory $\left(7^{\circ} \mathrm{C}\right)$, and the volume and composition of released gas and water, the pressure inside the core, and the ambient air pressure and temperature were monitored (Table T20) as described in "Pressure coring" in the "Methods" chapter. However, initial pressure readings are not available for Core 311-1327C-15P because the analog pressure gauge used was not suitable for the recovered low pressures. During the degassing procedure, the vertical density distribution of the PCS cores was repeatedly determined by GRA scans to examine the evolution of gas voids within the sediment. After degassing was completed, we X-rayed the PCS cores again, collected the water remaining in the outer core barrel for mass balance considerations, curated the sediment that was extruded from the cores, and subsampled it for IW chemistry, dissolved gases, and physical property analyses.

Degassing of the five PCS cores yielded 1.2 to $10.3 \mathrm{~L}$ of gas and showed variable methane concentrations with depth (Table T20). Mass balance calculations yield pore space methane concentrations of 83-674 $\mathrm{mM}$. They indicate $<0.3 \%$ of gas hydrate in the pore space of shallow Cores 311-U1327E-3P (80.0 mbsf) and 311-U1327C-15P (121.8 mbsf), gas hydrate pore space concentrations of $7.9 \%$ and $1.8 \%$ for deeper Cores 311-U1327D-10P (155.1 mbsf) and 311U1328C-24P (197.3 mbsf), and a free gas concentration of $1.0 \%$ in the pore space of Core $311-\mathrm{U} 1327 \mathrm{D}-$ 17P (246.0 mbsf) from below the BSR (Tables T21, T22; Fig. F49).

For all PCS cores, the composition of the released gas did not change significantly in the course of degassing (Table T20). Methane was the major component, accounting on average for $85 \% \pm 8 \%$ of gas emitted from Core 311-U1327C-15P and for 95\% \pm $3 \%$ to $98 \% \pm 2 \%$ from all other cores. Nitrogen was the second most abundant gas, contributing $12 \% \pm$ $5 \%$ to the gas released from Core 311-U1327C-15P and $<2 \%$ to the gas obtained from all other cores. Carbon dioxide, ethane, and higher hydrocarbon concentrations were below the detection limit of the Agilent gas chromatograph used for continuous gas analysis during the degassing experiments. A subset of gas samples from each core was analyzed using methods described in "Organic geochemistry" in the "Methods" chapter and yielded 113-729 ppmv ethane. 
In all degassing experiments, the pressure inside the PCS cores dropped below the predicted gas hydrate stability conditions when the port valve of the PCS was first opened and water expanded from the outer core barrel into the manifold system. Therefore, no pressure plateaus or rebounds from dissociation of gas hydrate could be expected and a steady decrease of core pressure versus removed gas volume was observed for all cores (Fig. F50).

X-ray scans of PCS cores before degassing showed no evidence of massive gas hydrate (e.g., veins or nodules). Clasts or rocks were evident in Cores 311U1327C-24P and 311-U1327D-10P (Fig. F51). Repeated density scans during degassing experiments showed overall lowering of densities caused by gas exsolution and core expansion, with some isolated sediment cracking (Fig. F51). Gas voids preferentially developed near the bottom of the PCS cores because core expansion can only occur out of the bottom of the inner core barrel. The rapid evolution of large cracks near the bottom of Core 311-U1327D-10P indicates exsolution of gas rather than presence of massive gas hydrate. This interpretation is supported by the IW chloride concentration that does not show any freshening as a result of gas hydrate decomposition (Fig. F51). None of the measured IW chloride concentrations in the PCS cores differed significantly from the background chloride trend (Table T3; Fig. F22).

\section{Measurements on HYACINTH cores}

Simultaneous and automated GRA density, $P$-wave velocity, and $\mathrm{X}$-ray measurements were made in the Geotek pressure multisensor core logger system on Cores 311-U1327D-12E and 14E. All measurements took place at $12 \mathrm{MPa}$ (near recovery pressure; $80 \%$ of in situ pressure). The velocity and density profiles are shown alongside X-ray images in Figure F52. Unlike the velocity profiles obtained for Core 311U1329E-9E, there are no distinctive velocity highs in the profiles, yet in both cores the velocities are relatively high compared with what would be expected for unconsolidated sediments. A plot of velocity versus density in Figure F53 illustrates how the Site U1327 high-velocity data cluster above the expected unconsolidated line and near the highest velocities from Core 311-U1329E-9E.

The X-ray images show horizontal layering in both cores, and the X-ray scan of Core 311-U1327D-14E shows subvertical, low-density structures with a wispy nature, which could be gas hydrate veins. However, the elevated velocities are not limited to any horizontal layer or wisp-containing zone, and our provisional interpretation of these cores is that they may contain small amounts of disseminated gas hydrate that has created a stiffer sediment matrix throughout the core, with a commensurate increase in the $P$-wave velocity. This interpretation is supported by degassing of Core 311-U1329E-9E, which contained two discrete zones of elevated velocities; both zones evolved gas during depressurization (see "Pressure coring" in the "Site U1329" chapter). However, these sediments could also be indurated with carbonate or other minerals, and these cores should be examined in detail to determine the extent of cementation.

The two HYACINTH pressure cores from Site U1327 were transported to the Pacific Geoscience Centre of the Canadian Geological Survey, Sidney, British Columbia, directly after Expedition 311. Core 311U1327D-12E was subsampled under pressure for microbiological pressure studies; the remainder of the core was curated. Core 311-U1327D-14E was rapidly depressurized, subsampled, and repressurized. The pressure was released on the storage chamber through a small valve and the ball valve was then opened. The core was removed from the chamber and quickly cut into $20 \mathrm{~cm}$ subsections, which were placed in Parr vessels and repressurized (Table T23). All vessels were filled from the same manifold, so variations in initial pressure reflect variations in gauge accuracy. Gas hydrate "flakes" were observed in the brittle clay material that was at the top and bottom of the core. These flat angular flakes, typically 3-6 $\mathrm{mm}$ wide and $0.5 \mathrm{~mm}$ thick by the time they were observed ( $15 \mathrm{~min}$ after depressurization), were oriented subvertically within the sediments. These gas hydrate flakes may correspond to the wispy subvertical $\mathrm{X}$-ray features observed in this core under pressure (Fig. F52).

\section{Gas hydrate concentration, nature, and distribution}

Based on mass balance calculations, sediments at Site U1327 contained gas hydrate at levels of at least $0.2 \%-1.8 \%$ of pore space (Table T22; Fig. F49). Core 311-U1327D-10P contained much more methane than the other PCS cores, corresponding to a gas hydrate saturation of $7.9 \%$ of pore space. The presence of free gas beneath the BSR, seen in the VSP velocities (see "Vertical seismic profile"), was confirmed by Core 311-U1327D-17P.

The high-resistivity layer seen in the Hole U1327A LWD data proved to be a moving target. Lateral heterogeneity between holes is responsible for the mismatch of IR data, wireline resistivity logs, and LWD resistivity logs at this site (see Fig. F66). The depth of the pressure cores at this site cannot be used as a simple measure of their location relative to this layer; the lateral correlation of the core position be- 
tween holes must be taken into account. Examining the pressure core depths with respect to chlorinity (Fig. F22), IR (Fig. F36), and logging data (Fig. F66), Cores 311-U1327C-15P and 311-1327E-3P were taken above the layer of increased gas hydrate concentration; Cores 311-U1327C-24P and 311U1327D-12E and 14E were taken below this layer but within the GHSZ; and Core 311-U1327D-10P was taken within the layer. Thermal anomalies indicating the presence of gas hydrate were found in the XCB cores both above and below Core 311-U1327D10P (Fig. F36).

There is evidence for both disseminated (pore filling) and vein (sediment displacing) gas hydrate at this site. The $P$-wave velocity and gamma ray density profiles of Cores 311-U1327D-12E and 14E suggest a relatively uniform distribution of gas hydrate throughout the sediment at this site (Fig. F52). The $\mathrm{X}$-ray images of the PCS cores and the gamma ray density profiles taken during degassing of the PCS cores (Fig. F51) are both consistent with this interpretation. Observations of subvertical flakes of gas hydrate and wispy, low-density structures in the corresponding X-ray images provide evidence for subvertical gas hydrate veins.

\section{Downhole logging}

\section{Logging while drilling}

\section{Operations}

Hole U1327A was spudded at 1333 mbrf water depth (drillers depth) at $1830 \mathrm{~h}$ on 23 September 2005. Hole U1327A was drilled after finishing Hole U1326A by pulling the drill string clear of the seafloor and moving the ship in dynamic positioning mode. LWD tools included the GeoVISION resistivity tool, the EcoScope tool, the SonicVISION tool, the TeleScope MWD tool, the ProVISION nuclear magnetic resonance tool, and the ADNVISION tool. For details on each tool and the measurements it makes, see "Downhole logging" in the "Methods" chapter.

Similar to the other sites, the uppermost $10 \mathrm{~m}$ of the hole was drilled with a rotation rate of 10-15 rpm, a pump flow rate of 190 gpm, and an ROP of $10-15 \mathrm{~m} /$ $\mathrm{h}$. We then increased these rates to $40 \mathrm{rpm}$ and 220 gpm until $30 \mathrm{mbsf}$, and then again to $60 \mathrm{rpm}$ and 270 gpm (to start the MWD telemetry), keeping the instantaneous ROP below $50 \mathrm{~m} / \mathrm{h}$ with depth. The target depth of $300 \mathrm{mbsf}$ (1633 mbrf) was reached at $0810 \mathrm{~h}$ on 24 September 24 . Considering the proximity between Holes U1327A and U1328A (1.9 mi apart), it was decided to raise the drill string above the seafloor and move by dynamic positioning to the location of Hole U1328A without tripping back to the surface as originally planned.

\section{Gas monitoring with real-time logging-while- drilling/measurement-while-drilling data}

LWD logs were acquired to plan coring and pressure coring operations in subsequent holes at Site U1327. As Hole U1327A was drilled without coring, the LWD data had to be monitored for safety to detect gas entering the borehole. As explained in "Downhole logging" in the "Methods" chapter, the primary measurement we used for gas monitoring was annular pressure while drilling measured by the EcoScope tool in the borehole annulus. We looked for sudden decreases of $>100$ psi in the annular pressure, which could be caused by low-density gas entering the borehole. We also monitored pressure increases of the same magnitude, which could be the result of fluid acceleration caused by a gas kick (Aldred et al., 1998).

Figure F54 shows the measured borehole fluid pressure profile in Hole U1327A after subtraction of the best-fit linear trend. The borehole fluid pressure shows only small fluctuations within \pm 5 psi over the general trend, and the fluid pressure anomalies observed were well below the 100 psi level that would have required preventive action.

We also monitored the coherence of the sonic waveforms acquired by the SonicVISION tool, focusing on the velocity of fluid in the borehole. Loss of coherence in the waveforms and a slower velocity in the drilling fluid indicate the presence of gas. The sonic waveform coherence image in Figure F54 shows a generally well defined fluid arrival with a slowness of $\sim 200 \mathrm{~ms} / \mathrm{ft}$, which corresponds to the expected fluid velocity of $\sim 1500 \mathrm{~m} / \mathrm{s}$. There are two anomalous intervals at 120-140 and 232-255 mbsf. The upper interval (120-140 mbsf) shows a fluid velocity higher than the general trend, coinciding with a high-resistivity layer interpreted to contain gas hydrate (see "Gas hydrate and free gas occurrence"). The deeper interval (232-255 mbsf) is below the GHSZ at this site, and if excess gas was present in the formation it had to be free gas. The sonic waveform coherence suggests that the fluid velocity decreased in this interval and that the slowness was higher than the upper bound of $240 \mu \mathrm{s} / \mathrm{ft}$ used in the processing. The fluid pressure measurement, however, shows no significant anomaly at this depth, and if gas was present in the drilling fluid at $\sim 232-255$ mbsf it had to be in low concentrations. These results suggest that the fluid velocity measured while drilling may indicate layers that contain gas hydrate or free gas and warrant further study. 


\section{Logging quality}

Figure F54 also shows the quality control logs for Hole U1327A. The ROP was generally $60 \mathrm{~m} / \mathrm{h}$ or less in the interval from the seafloor to TD. This is sufficient to record one measurement every $4 \mathrm{~cm}(\sim 25$ measurements $/ \mathrm{m}$ ) in the GeoVISION resistivity, and no significant resolution loss was observed with variation in ROP. The ultrasonic caliper log, which is a direct measurement of the borehole diameter recorded by the EcoScope tool, is our best indicator of borehole size. Most of the hole had a diameter slightly $>10$ inch $(25 \mathrm{~cm})$, with larger washouts slightly $>11$ inch $(28 \mathrm{~cm})$ restricted to the uppermost $70 \mathrm{~m}$ of the hole. The density correction, calculated from the difference between the short- and longspaced density measurements, generally varies from 0 to $0.2 \mathrm{~g} / \mathrm{cm}^{3}$ (Fig. F54), showing the good quality of the density measurements. Figure F55 is a summary of the LWD gamma ray, density, resistivity, and resistivity image logs with density and porosity measurements from cores from Holes U1327C and U1327D superimposed (see "Physical properties").

The depth relative to the seafloor was fixed for all LWD logs by identifying the step change in the gamma ray log associated with the seafloor. For Hole $\mathrm{U} 1327 \mathrm{~A}$, the gamma ray logging pick for the seafloor was at a depth of 1316 mbrf.

\section{Wireline logging}

\section{Operations}

Wireline logging was conducted in Holes U1327D and U1327E. Hole U1327D was drilled as a dedicated hole for pressure coring and logging, and was completed at $1625 \mathrm{~h}$ on 7 October 2005, reaching a TD of 300 mbsf. The ship's heave was consistently $>4 \mathrm{~m}$, which was unsafe for the deployment of any logging tool. We therefore had to wait until $2300 \mathrm{~h}$, when the heave decreased to $\sim 3 \mathrm{~m}$, to start rigging up. The hole was displaced with a barite and sepiolite mud mixture, and rigging of the tool string for the first run was completed by $0055 \mathrm{~h}$ on 8 October. Wireline logging operations in Hole U1327D began with deployment of the triple combo tool string (resistivity, density, and porosity measurements), which consists of the HNGS, the DIT, the Hostile Environment Litho-Density Tool (HLDT), the Accelerator Porosity Sonde, and the Temperature/Acceleration/Pressure (TAP) tool. For details on the different tools, see "Downhole logging" in the "Methods" chapter. The tool string reached the bottom of the hole at 1610 mbrf (296 mbsf) without difficulty by $0235 \mathrm{~h}$. Logging immediately showed that the hole was severely enlarged in many locations. The ship's heave was $\sim 3-3.5 \mathrm{~m}$, and during the logging run the heave compensator shut down and had to be restarted sev- eral times. Just before the caliper tool was to be closed as it entered the drill pipe, with the heave compensator turned off, the swell caused the tool string to descend suddenly, breaking the caliper's arm. This was confirmed at $0335 \mathrm{~h}$ when the tool reached the rig floor. Rig down was complete at 0530 $\mathrm{h}$ when rigging for the VSP operations started (see "Vertical seismic profile").

Hole U1327E was drilled to complete wireline operations with acoustic logs that were deemed to be critical to the scientific objectives of the cruise. To save the only HLDT left and considering that the heave was $\sim 3.5 \mathrm{~m}$ and expected to worsen, it was decided to run an arm-free tool string composed of the DSI, the Scintillation Gamma Ray Tool (SGT), and the DIT. Hole U1327E was completed to a TD of 300 mbsf at $1600 \mathrm{~h}$ on 10 October. The hole was displaced with $10.5 \mathrm{ppg}$ barite mud, and rig up of the tool string was completed at $2110 \mathrm{~h}$. Logging started when the tool string reached $1602 \mathrm{mbrf}$ ( $289 \mathrm{mbsf}$ ) at $2240 \mathrm{~h}$. The ship's heave stayed at $3 \mathrm{~m}$ or less during the entire logging run, and there was no notable difficulty. The first pass was completed to the seafloor (1313 mbrf) at $2345 \mathrm{~h}$. The tool string was then brought down for two short repeat runs from TD up to $1490 \mathrm{mbrf}$ (177 mbsf); the first was for quality control and the second to test the new heave compensation system developed by Schlumberger, which worked well. The tool string was back on the rig floor at $0155 \mathrm{~h}$ on 11 October. Rig down was completed by $0300 \mathrm{~h}$.

\section{Logging quality}

Wireline logging data from the triple combo tool string in Hole U1327D are affected by poor hole conditions (Fig. F56) typical of these unconsolidated formations. The hole shows numerous enlargements that are beyond the 16 inch $(41 \mathrm{~cm})$ maximum range of the caliper tool in intervals 110-130, 160-210, and 237-277 mbsf. The caliper tool was turned off at depths shallower than 105 mbsf. Outside these intervals, the neutron porosity and density logs give readings that are close to the core measurements. Where the hole was enlarged, however, the densities are too low and the porosities are too high. Induction log resistivities are generally not as affected by poor hole conditions as the nuclear logs. Nevertheless, the logged resistivities seem to be anomalously low and noisy at depths above $105 \mathrm{mbsf}$, where we have no caliper information and where the hole was presumably enlarged as well.

The acoustic and resistivity data measured in Hole U1327E appear to be of excellent quality. The acoustic waveforms and slowness-time coherence projection are shown in Figure F57. The quality of the re- 
corded waveforms and the high level of coherence in the monopole and upper dipole waveforms suggest that the hole was in very good condition. As a result, the velocity profiles acquired are very robust, and almost no additional processing was required to derive reliable compressional $\left(V_{\mathrm{p}}\right)$ and shear $\left(V_{S}\right)$ wave velocities. Because of operational concerns (see "Operations" in "Wireline logging"), we did not run a caliper tool in this hole. The high quality of the wireline logs suggests that Hole U1327E was more in gauge than Hole U1327D, but we have no direct measurements of hole size to confirm this conclusion.

The depth relative to seafloor for all wireline logs was fixed by identifying the step change in the gamma ray log associated with the seafloor. The gamma ray pick for the seafloor was at $1314 \mathrm{mbrf}$ in Hole U1327D and 1313 mbrf in Hole U1327E.

\section{Logging-while-drilling and wireline logging comparison}

Figure $\mathbf{F 5 8}$ shows a comparison of LWD (Hole U1327A) and wireline (Hole U1327D) data, using the gamma ray, neutron porosity, density, and resistivity logs. In general, the LWD and wireline data from each hole match relatively well, exhibiting similar curve shapes and absolute logging values. There are, however, some notable differences.

One difference is seen in gamma ray measurements, where the LWD log gives higher values (100 gAPI on average) than the wireline log (50 gAPI on average). Moreover, the LWD and wireline gamma ray curves have different shapes, and there is no obvious correlation between the two. The cause of this discrepancy has not been fully understood. The wireline data, however, were in agreement with data recorded during Leg 146.

The wireline neutron porosity and density logs contain several intervals where the neutron porosity readings are anomalously high and the density readings are anomalously low compared to the LWD logs. Most of these anomalies are in intervals where Hole U1327D was enlarged (see the caliper log in Fig. F56) and are probably caused by poor contact of the tool pad with the borehole wall.

The comparison of resistivities shows a general trend that is very similar between LWD and wireline logs. The low resistivities measured by the wireline logs in the shallow interval above 105 mbsf are probably caused by washouts in Hole U1327D. There are, however, remarkable differences between the resistivity highs in the LWD and wireline logs that seem to indicate a heterogeneous distribution of gas hydrate. LWD resistivities show a broad peak reaching $10 \Omega \mathrm{m}$ at $120-140 \mathrm{mbsf}$ and two smaller peaks (as high as $\sim 4 \Omega \mathrm{m})$ at $110-112$ and $170-173$ mbsf. The wireline resistivities do not contain any of these resistivity highs but instead have a resistivity peak that reaches $\sim 5 \Omega \mathrm{m}$ at $155-160 \mathrm{mbsf}$; this peak is not seen in the LWD resistivity logs.

There are also differences between wireline resistivity logs acquired in different holes. Figure F59 compares the gamma ray and resistivity logs acquired in Holes U1327D and U1327E. Although differences in the gamma ray logs may be the result of having used different logging tools in the two holes (the HNGS in Hole U1327D versus the SGT in Hole U1327E), the resistivity logs were acquired with the same DIT tool. Discounting differences above 105 mbsf, which are most likely caused by a washout in Hole U1327D, the resistivity peak noted earlier at 155-160 mbsf in Hole U1327D is not observed in Hole U1327E. Also, the Hole U1327E resistivity logs show two minor resistivity peaks (3-4 $\Omega \mathrm{m}$ ) at $107-115$ and $125-128$ mbsf that are not seen in the Hole U1327D logs. On the other hand, the peak at 107-115 mbsf in Hole U1327E resistivity correlates to a peak found at the same depth in the LWD resistivity log collected in Hole U1327A (cf. Figs. F59; F55).

As a quality control measure, we repeated the logging run in the bottom section of Hole U1327E; logs from this repeat run are also shown in Figure F59 for resistivity (285-175 mbsf) and for the acoustic logs (273-167 mbsf). The logs in the first and second runs are practically identical. The only significant difference is the $P$-wave velocity $\log$ between 190 and 230 mbsf, where the automated processing algorithm picked a secondary coherence high in the second pass (Fig. F57), a mistake that can be easily corrected during full postcruise processing.

The difference in resistivities logged by LWD (Hole U1327A) and wireline (Holes U1327D and U1327E) tools deserves further explanation. Here, we concentrate on carefully documenting these differences, and we discuss their origin in "Differences in resistivity logs, instrumental effects, and lateral heterogeneity."

\section{Logging units}

The logged section in Holes U1327A, U1327D, and U1327E can be divided into three logging units based on obvious changes in the LWD and wireline gamma ray, density, electrical resistivity, and acoustic measurements (Figs. F55, F56, F57). There is no obvious correlation between the logging units defined here and the lithostratigraphic units defined in "Lithostratigraphy."

Logging Unit 1 (0-120 mbsf) is characterized by a resistivity trend that steadily increases from $\sim 1 \Omega \mathrm{m}$ 
near the seafloor to $\sim 2 \Omega \mathrm{m}$ at the bottom of the unit (120 mbsf). This increase in resistivity with depth is matched by an increase in density (from $1.7 \mathrm{~g} / \mathrm{cm}^{3}$ near the seafloor to $2 \mathrm{~g} / \mathrm{cm}^{3}$ at $120 \mathrm{mbsf}$ ) and a decrease in porosity (from $70 \%$ near the seafloor to $50 \%$ at $120 \mathrm{mbsf}$ ). The $P$-wave velocities $\left(V_{\mathrm{p}}\right)$ average $\sim 1550 \mathrm{~m} / \mathrm{s}$. This unit shows only a few small resistivity peaks (e.g., at $~ 110$ mbsf in the LWD logs) (Fig. F55) that may be attributed to the presence of gas hydrate.

Logging Unit 2 (120-230 mbsf) is characterized by a constant background resistivity value of $\sim 2 \Omega \mathrm{m}$ and relatively high $V_{\mathrm{p}}$ values that average $\sim 1750 \mathrm{~m} / \mathrm{s}$ over most of the interval. Resistivity and $V_{\mathrm{p}}$ show a distinct bulge over lower values in the units above and below; this bulge is very obvious for $V_{\mathrm{p}}$ (Figs. F56, F57) but more subtle for the resistivity (Figs. F55, F56). Density and porosity are $\sim 2 \mathrm{~g} / \mathrm{cm}^{3}$ and $50 \%$, respectively. This unit shows a number of resistivity peaks that can be attributed to the presence of gas hydrate, although the peaks do not consistently correlate between holes, and the relatively high $V_{\mathrm{p}}$ also suggests gas hydrate occurrence. Although the high velocity values above 230 mbsf suggest the presence of some amount of gas hydrate, no significant waveform amplitude loss can be observed. Elsewhere, strong attenuation has been associated with large amounts of gas hydrate (e.g., Guerin and Goldberg, 2002).

Logging Unit 3 (230-300 mbsf) is characterized by a sharp decrease in $V_{\mathrm{p}}$ (Fig. F56). Below 230 mbsf, $V_{\mathrm{P}}$ drops to very low values near the fluid velocity $(\sim 1500 \mathrm{~m} / \mathrm{s})$, suggesting the presence of small amounts of free gas. This is supported by the very low dipole waveform amplitudes. $V_{\mathrm{s}}$ also decreases. Although the presence of free gas should not affect shear velocity because fluids do not transmit shear energy, the borehole might have crossed a slightly overpressured interval, where the release of free gas led to a loss of cohesiveness of the formation. The rapid contrast between high and low $V_{\mathrm{P}}$ over a short interval at 205-210 mbsf is likely the origin of the BSR, which should be confirmed by the generation of synthetic seismograms from the recorded $V_{\mathrm{p}}$ and density logs. The depth to the BSR is also discussed in more detail in the "Vertical seismic profile" results below.

Logging Unit 3 also displays a small drop in resistivity compared to Unit 2 . Whereas resistivity tends to be just above $2 \Omega \mathrm{m}$ in Unit 2 , it is just below $2 \Omega \mathrm{m}$ in Unit 3 . This resistivity decrease is subtle but clearly observable in the wireline logs (Fig. F56). Density and porosity do not show an appreciable change from Unit 2 and remain around $2 \mathrm{~g} / \mathrm{cm}^{3}$ and $50 \%$, respectively.

\section{Logging-while-drilling borehole images}

The GeoVISION, ADNVISION, and EcoScope LWD tools generate high-resolution images of borehole log data. The ADNVISION and EcoScope tools produce images of density and hole radius (computed on the basis of the density correction, which depends on the borehole standoff). The GeoVISION tool produces a gamma ray image and shallow, medium, and deep resistivity images (see "Downhole logging" in the "Methods" chapter).

Figure F60 shows some of the LWD images collected by the EcoScope and GeoVISION tools. It should be noted that the display in Figure F60 is highly compressed in the vertical direction. The unwrapped images are $\sim 90 \mathrm{~cm}$ wide (for an 11 inch diameter borehole), and the vertical scale is compressed by a factor of $\sim 37: 1$. These high-resolution images can be used for detailed sedimentological and structural interpretations and to image gas hydrate distribution in sediments (e.g., in layers, nodules, or fractures). Gas hydrate-bearing sediments exhibit high resistivities without a corresponding high bulk density. Layers with high resistivities and high densities are likely to be low-porosity, compacted, or carbonate-rich sediments. The most striking feature in the images shown in Figure F60 is the high-resistivity, low-density layer between 120 and 140 mbsf, which suggests high porosity and high gas hydrate concentration.

\section{Logging porosities}

Sediment porosities can be determined from analyses of recovered cores and from downhole measurements (see "Physical properties" and "Downhole logging," both in the "Methods" chapter). The LWD density and neutron logs from Hole U1327A were used to calculate sediment porosities. Corederived physical property data, including porosities (see "Physical properties"), were used to both calibrate and evaluate the log-derived sediment porosities.

The LWD log-derived density measurements were used to calculate sediment porosities $(\phi)$ using the standard density-porosity relation

$$
\phi=\left(\rho_{g}-\rho_{b}\right) /\left(\rho_{g}-\rho_{w}\right) .
$$

We used a constant water density $\left(\rho_{\mathrm{w}}\right)$ of $1.03 \mathrm{~g} / \mathrm{cm}^{3}$ and a grain/matrix density $\left(\rho_{\mathrm{g}}\right)$ of $2.75 \mathrm{~g} / \mathrm{cm}^{3}$, which is the average grain density measured in the core samples (see "Physical properties"). The density log-derived porosities range from $\sim 60 \%$ at $20 \mathrm{mbsf}$ to $\sim 40 \%$ at 300 mbsf (Fig. F61).

The LWD neutron porosity log (Fig. F61) yielded sediment porosities ranging from an average value of $\sim 70 \%$ at 20 mbsf to $\sim 50 \%$ at 300 mbsf. Porosities measured by the neutron $\log$ are expected to be 
higher than those computed from the density log in sediments containing clay, because the neutron log essentially measures hydrogen abundance, and hydrogen in clay minerals is counted as porosity. The EcoScope neutron porosity shown in Figure F61 is the "best thermal neutron porosity," which has been corrected for the effect of clay, so that it is only slightly higher than the density porosity.

The comparison of core- and LWD-derived porosities in Figure F61 reveals that the log-derived porosities agree with the core-derived values throughout the logged interval, with the density porosities being slightly lower and the neutron porosities slightly higher than the core porosities. The core-derived porosities, however, do not show the porosity increase displayed by LWD/MWD porosities at 120-140 mbsf in logging Unit 2.

\section{Gas hydrate and free gas occurrence}

As previously discussed (see "Downhole logging" in the "Methods" chapter), the presence of gas hydrate is generally characterized by increases in electrical resistivity and acoustic velocity that are not accompanied by a corresponding decrease in porosity. A decrease in porosity alone in a water-saturated sediment can result in an increase in resistivity and acoustic velocity. Resistivities logged in Holes U1327A, U1327D, and U1327E show a number of positive anomalies over a general increase of resistivity with depth without a corresponding decrease in porosity (Figs. F55, F56), suggesting that there are several intervals where gas hydrate may be present. The presence of gas hydrate is known to increase $P$ wave velocity and attenuation, and the relatively large $V_{\mathrm{p}}$ values measured in logging Unit 2 (Figs. F56, F57) are in agreement with the general inference of gas hydrate occurrence at this site.

\section{Water saturation from Archie's equation}

To estimate the amount of gas hydrate that might be present at Site U1327, we used the Archie relation (e.g., Collett and Ladd, 2000)

where

$$
S_{\mathrm{w}}=\left[\left(a \times R_{\mathrm{w}}\right) /\left(\phi^{\mathrm{m}} \times R_{\mathrm{t}}\right)\right]^{1 / n},
$$

$S_{w}=$ water saturation,

$a=$ tortuosity coefficient,

$R_{\mathrm{w}}=$ formation water resistivity,

$\phi=$ density porosity computed from ADNVISION enhanced resolution bulk density,

$m=$ cementation coefficient,

$R_{\mathrm{t}}=$ GeoVISION high-resolution button deep average resistivity, and

$n$ = saturation coefficient.
We use the button deep resistivity instead of the ring resistivity because the button deep resistivity matches the resistivities with the greatest depth of investigation measured by the EcoScope tool (except for having a higher resolution), whereas the ring resistivity values are generally lower than the EcoScope deep resistivities.

Gas hydrate saturation $\left(S_{\mathrm{h}}\right)$ is the percentage of pore space in sediment occupied by gas hydrate, which is the complement of the water saturation $S_{\mathrm{w}}$ :

$$
S_{h}=1-S_{w} \text {. }
$$

The procedure followed to estimate $S_{\mathrm{w}}$ with Archie's relation is illustrated in Figure F62. We first computed porosity from the density $\log$ as described above with a water density $\rho_{\mathrm{w}}$ of $1.03 \mathrm{~g} / \mathrm{cm}^{3}$ and a grain/matrix density $\rho_{\mathrm{g}}$ of $2.75 \mathrm{~g} / \mathrm{cm}^{3}$ (see "Physical properties"). Gas hydrate, however, is less dense than seawater and assuming, in principle, that water fills the pores may lead to overestimating the porosity. A simple calculation shows that this effect is small and can be neglected. If gas hydrate saturation were $100 \%$, the overestimate of porosity $\Delta \phi$ would be

$$
\Delta \phi=\left[\left(\rho_{g}-\rho_{b}\right)\left(\rho_{w}-\rho_{h}\right)\right] /\left[\left(\rho_{g}-\rho_{w}\right)\left(\rho_{g}-\rho_{h}\right)\right] .
$$

Using the values of water and grain/matrix density defined above, a gas hydrate density $\rho_{\mathrm{h}}$ of $0.91 \mathrm{~g} / \mathrm{cm}^{3}$ (Sloan, 1998), and a bulk density $\rho_{\mathrm{b}}$ of $1.7 \mathrm{~g} / \mathrm{cm}^{3}$ (which is the bulk density measured in the highresistivity interval 140-160 mbsf of Fig. F55), we find that the overestimate of porosity is only $4 \%$, even when gas hydrate saturation is $100 \%$. At first approximation, we can ignore the density effect of gas hydrate in the calculation of porosity from density. It should be noted that the small density effect of gas hydrate also implies that the bulk density decrease from $\sim 2$ to $1.7 \mathrm{~g} / \mathrm{cm}^{3}$ observed in the $140-160 \mathrm{mbsf}$ high-resistivity interval in Hole U1327A cannot simply be caused by high gas hydrate saturation. A gas hydrate saturation $S_{\mathrm{h}}$ in a sediment of porosity $\phi$ would cause a decrease in bulk density compared to a fully water-saturated sediment equal to

$$
\Delta \rho_{\mathrm{b}}=-\phi S_{\mathrm{h}}\left(\rho_{\mathrm{w}}-\rho_{\mathrm{h}}\right) .
$$

For $100 \%$ gas hydrate saturation, a porosity of $50 \%$, and densities as above, this decrease in bulk density is only $0.06 \mathrm{~g} / \mathrm{cm}^{3}$, much less than the observed density change of $0.3 \mathrm{~g} / \mathrm{cm}^{3}$. The low density in the 140 160 mbsf high-resistivity interval in Hole U1327A must be mostly caused by a porosity increase.

To continue with our Archie-based procedure, we next estimated the formation water resistivity $\left(R_{\mathrm{w}}\right)$ by first constructing a salinity versus depth function based on IW salinity measurements (see "Interstitial water geochemistry"). This salinity versus depth function is a simple exponential decay fitted to the 
data (with a salinity of 35 at the seafloor decreasing with an exponential decay constant of $55 \mathrm{~m}$ to an asymptotic value of 21 at depth). At every logging depth, we combined the salinity value with a formation temperature obtained from the geothermal gradient estimated from the downhole formation temperature measurements (see "In situ temperature profile") and used the formulas of Fofonoff (1985) to obtain the corresponding value of the water resistivity $R_{\text {w. }}$

To estimate the water saturation $S_{w}$, we also need to choose values for the Archie coefficients $a$ and $m$. One way to do this is to choose a logged interval where the sediments can be assumed to be water saturated and fit $a$ and $m$ to a plot of measured resistivity versus porosity, known as a "Pickett plot" (e.g., Doveton, 1994). In marine sediments, however, the range of porosity is relatively small and it is not possible to obtain a robust estimate of both $a$ and $m$. We prefer to set $a=1$, which is physically the most realistic value because it gives a resistivity equal to the formation water resistivity when the porosity is $100 \%$. We then compute an "estimated $m$ " coefficient by

$$
m_{\text {est }}=-\log (F) / \log (\phi),
$$

where $F=\left(R_{\mathrm{t}} / R_{\mathrm{w}}\right)$ is the formation factor. This $m_{\text {est }}$ curve should give the appropriate value to be used in Archie's law in water-saturated intervals and will give anomalously high values in intervals that contain hydrocarbons. A reasonable value of $m=2.2$ can be chosen from the baseline trend of the $m_{\text {est }}$ curve in Figure F62.

The next step is to compute the resistivity $R_{0}$ predicted by Archie's equation for a water-saturated formation of a given porosity, which is given by

$$
R_{0}=\left(a \times R_{\mathrm{w}}\right) / \phi^{m} \text {. }
$$

Using Archie coefficients of $a=1$ and $m=2.2$, we computed an $R_{0}$ curve that follows the measured resistivity $R_{\mathrm{t}}$ throughout logging Unit 1 but is significantly lower than $R_{\mathrm{t}}$ in several intervals of logging Units 2 and 3 (Fig. F62). Finally, we computed the water saturation $S_{\mathrm{w}}$ using a saturation coefficient $n=$ 2.

The most notable intervals in logging Unit 2 that show a measured resistivity $R_{\mathrm{t}}$ greater than the resistivity $R_{0}$ predicted for water-saturated conditions are at 120-140 mbsf, where the water saturation $S_{\mathrm{w}}$ predicted by Archie's law is 30\%-60\%, and 185-203 mbsf, where the predicted $S_{\mathrm{w}}$ is as low as $65 \%$. In logging Unit 3, two intervals (235-250 and 255-262 mbsf) also show a predicted water saturation $S_{\mathrm{w}}$ between $60 \%$ and $90 \%$. The Unit 2 intervals are in the GHSZ, whereas the Unit 3 intervals are below the GHSZ. This suggests the presence of free gas in the intervals $235-250$ and 255-262 mbsf, in good agreement with the sonic log, which shows $V_{\mathrm{p}}<1500 \mathrm{~m} / \mathrm{s}$ in these intervals (Fig. F56).

\section{Vertical seismic profile}

\section{Operations}

VSP operations in Hole U1327D started with rig up of the WST, which was completed by $0600 \mathrm{~h}$ on 8 October 2005. After rig up, the WST was lowered in the drill pipe just above the mudline ( 1300 mbrf), awaiting daybreak. The first GI air gun shots were fired at $0820 \mathrm{~h}, 1$ hour after the start of marine mammal observations, ramping up to the desired operational intensity over $30 \mathrm{~min}$. At $0900 \mathrm{~h}$, it was decided to send the tool to TD, with ship heave in the 3-3.5 $\mathrm{m}$ range. There were some problems getting below 1415 mbrf (101 mbsf), where the caliper log indicated a ledge. This obstruction was finally cleared at $0930 \mathrm{~h}$, and the tool reached a maximum depth of 1590 mbrf (276 mbsf) at $0945 \mathrm{~h}$. The first shots for the VSP were fired at $0950 \mathrm{~h}$, with a plan to try a station every $5 \mathrm{~m}$ and move along if there was no success in obtaining good coupling between the tool and the borehole wall. We recorded 16 successful stations between 1590 and 1495 mbrf (276-181 mbsf), shooting seven times or more at each station for subsequent stacking. Only a few $5 \mathrm{~m}$ intervals were missed, where good coupling could not be achieved because of irregularities in the borehole (see the caliper log of Hole U1327D in Fig. F56). Data acquisition was complicated by several interruptions caused by the heave compensator shutting down when the heave reached $>4 \mathrm{~m}$. At shallower depths, however, it became impossible to get any good couplings despite a number of attempts up to $1452 \mathrm{mbrf}$ (138 mbsf). We suspected damage to the arms, and at $1245 \mathrm{~h}$ we decided to bring the tool to the rig floor for inspection. The WST, however, did not pass through the bit at the end of the drill pipe. It was not clear if the reason was the flapper valve, the torn arms, or a combination of both. After several unsuccessful attempts to clamp the wire, it was decided to try again to pull the tool string. This attempt was eventually successful and the WST was back on the rig floor at $2300 \mathrm{~h}$, with its two arms damaged.

\section{Time versus depth relationship, interval velocity estimation, and depth to the bottom- simulating reflector}

The VSP provides a direct measurement of the time versus depth relationship with the first break of the direct compressional wave arrival. Figure F63 shows the stacked waveforms at the 16 stations that were successfully recorded. Stacking was accomplished by 
taking the median of the seven or more waveforms recorded at each station. The first break times can be easily seen and are marked by red crosses in Figure F63. Table T24 lists the first break times and the times corrected for the $\sim 50 \mathrm{~m}$ horizontal offset of the source, the shot depth of $2 \mathrm{mbsl}$, and the delay between the trigger time and the start of recording. Corrected first break times are traveltimes from the sea surface to each receiver along a vertical path.

The corrected first break times are plotted in Figure F64 versus the depth of the receivers. The error bars show an uncertainty in the picked first break times of $\pm 1 \mathrm{~ms}$, which combines traveltime errors caused by uncertainties in the depth of the receiver and fluctuations in the vertical source position caused by waves (the latter errors are reduced but not eliminated by stacking). In a medium in which the velocity was constant over the vertical range spanned by the receivers, the first break times follow a straight line whose slope gives the velocity. The first break times of Figure F64 clearly show two separate lines; one with a high velocity of $1843 \mathrm{~m} / \mathrm{s}$ for receivers between 181 and 234 mbsf and one with a low velocity of $1281 \mathrm{~m} / \mathrm{s}$ for receivers between 251 and $276 \mathrm{mbsf}$. The two lines fit the first break times well within the estimated errors of $\pm 1 \mathrm{~ms}$. These velocities define a relatively fast interval, possibly containing gas hydrate, above an interval whose velocities are slow enough to require the presence of at least a small amount of free gas. The velocity change between the fast and slow interval defines the location of the ubiquitous BSR. Similar VSP velocity variations near the BSR were observed at Leg 146 Site 889 on the Cascadian margin (MacKay et al., 1994) and at Sites 994, 995, and 997 on the Blake Ridge (Holbrook et al., 1996).

To compare the VSP results to other velocity measurements, it is useful to translate the first break times into interval velocities. In principle, the vertical distance between two receivers divided by the difference between the two first break traveltimes should give an immediate estimate of the interval velocity. In practice, the first break picks are not exact, and small errors in time picking can translate to large errors in the estimated velocities. A reliable estimate of interval velocity requires an inversion that combines the first break measurements and some smoothness constraint. We use here a Bayesian inversion method where the smoothness of the final solution is determined by the data, while the standard deviation of the traveltime measurement errors is fixed to $1 \mathrm{~ms}$ (see above). For method details, see Malinverno and Briggs (2004). The inversion is applied to determine the interval velocity in a layered medium with $5 \mathrm{~m}$ thick layers.
The results are shown in Figure F65, which compares interval velocities from the VSP in Hole U1327E, $P$ wave velocity measurements from the sonic log in Hole U1327D (Fig. F56), and interval velocities determined with the same inversion method from the VSP data collected in Hole $889 \mathrm{~B}$, which is $\sim 600 \mathrm{~m}$ east of Site U1327. In the VSP interval velocity inversions (Fig. F65A, F65C), the solid line shows the best estimate of compressional wave velocity and the dashed lines show its uncertainty defined by the posterior standard deviation. The posterior standard deviation measures the uncertainty in the estimated velocity caused by the uncertainty in the traveltime picks. The depth interval with the steepest velocity decrease, which should correspond to the BSR, is highlighted by gray rectangles in Figure F65. The Hole U1327D VSP shows the deepest BSR location (245-260 mbsf), whereas the Hole U1327E sonic log suggests a shallower BSR (228-243 mbsf). Apart from this depth difference, the velocities obtained by VSP inversion and measured by the sonic log are remarkably similar above and below the BSR at Site U1327. The BSR at Hole $889 \mathrm{~B}$ is shallower again, with the velocity gradient change at 215-230 mbsf.

Whereas surface seismic reflection lines show as the BSR a continuous single reflector in the area around Site U1327, high-resolution seismic surveys often resolve the BSR into a number of dipping, high-amplitude reflectors that presumably contain free gas. These bright reflectors abruptly terminate at a depth that should correspond to the bottom of the GHSZ (for examples see fig. 4 of Wood et al., 2002). If the free gas is concentrated in layers with coarser grained sediments and the local sedimentary succession is dipping with respect to the bottom of the GHSZ or is otherwise laterally heterogeneous, it is possible that two nearby boreholes may record the transition to sediment containing free gas at different depths. This lateral variability may explain the variation in the depth to the top of the free gas zone shown in Figure F65.

\section{Differences in resistivity logs, instrumental effects, and lateral heterogeneity}

Here, we propose some explanations for the differences in LWD (Hole U1327A) and wireline (Holes U1327D and U1327E) resistivities. In principle, we could assign these variations to either instrumental effects or lateral changes in gas hydrate distribution. By "instrumental effects" we mean that different logging tools may measure different resistivities in the same formation. By "lateral heterogeneity" we mean that different results in different wells are caused by the formation and/or the gas hydrate distribution 
being horizontally heterogeneous at the scale of a few tens of meters.

We focus first on instrumental effects. Two possible reasons for different logging tools measuring different resistivities in the same formation containing gas hydrate are dielectric effects and resistivity anisotropy. Gas hydrate has a dielectric constant much lower than that of formation water (e.g., Sun and Goldberg, 2005), and the dielectric properties of the formation will affect electromagnetic wave propagation in the high-frequency limit. The highest frequency electromagnetic measurements in our logging suite are carried out by the EcoScope tool, which measures resistivity from the attenuation and phase shift of $400 \mathrm{kHz}$ and $2 \mathrm{MHz}$ electromagnetic waves propagating through the formation (for more details, see "Downhole logging" in the "Methods" chapter).

If the dielectric properties of gas hydrate were responsible for the different resistivity readings, the greatest differences would be observed between the high-frequency EcoScope measurements and the lowest frequency measurements, which are the resistivities measured by the GeoVISION tool at frequencies of $1.5 \mathrm{kHz}$ (Bonner et al., 1996). Indeed, highfrequency measurements by the Array Resistivity Compensated tool (similar to the EcoScope) have been found to give resistivities higher by a factor of seven compared to resistivities measured at low frequency by the GeoVISION tool in the same gas hydrate-bearing layer of a well in the Gulf of Mexico (T. Collett, pers. comm.). On the other hand, Boissonnas et al. (2000) found no evidence of dielectric effects in gas hydrate-bearing formations using $2 \mathrm{MHz}$ LWD measurements and noted that $2 \mathrm{MHz}$ is probably too low a frequency for dielectric properties to significantly affect electromagnetic wave propagation. In Hole U1327A there is essentially no difference between the resistivity measured by the highfrequency EcoScope and the low-frequency GeoVISION tools in Hole U1327A (Fig. F55). Therefore, dielectric effects cannot explain the observed variation in measured resistivities at Site U1327.

Another instrumental effect may be the result of resistivity anisotropy. The results of detailed IW analyses (see "Interstitial water geochemistry") suggest that gas hydrate around Site U1327 may be concentrated in thin sand layers (which will have high resistivity) separated by mostly water-saturated, relatively low resistivity, clay-rich layers, which will have low resistivity. If we measured the effective resistance at scales greater than the bed thickness in such a medium, the resistance to electrical currents flowing vertically will be much higher than the resistance to currents flowing horizontally: current flow- ing vertically must go through the high-resistivity layers, whereas current flowing horizontally will focus in the low-resistivity layers. If different logging tools were affected differently by horizontal and vertical resistivities, they may measure a different resistivity in the same anisotropic layer. For example, wireline induction logs (which are only sensitive to horizontal resistivity) have been reported to measure resistivities lower than those obtained by laterolog devices (which are sensitive to both horizontal and vertical resistivity) in laminated, anisotropic formations (e.g., Chemali et al., 1987). These differences have been exploited to invert logging measurements made by different tools for horizontal and vertical resistivity of gas hydrate-bearing formations in the Mallik 5L-38 well (Collett et al., 2005).

If resistivity anisotropy is responsible for the differences in resistivities observed at Site U1327, the greatest differences should be between the measurements made by the LWD EcoScope tool and the wireline induction tool, which are only sensitive to horizontal resistivity in a vertical well (Chemali et al., 1987; Hagiwara, 1996), and the measurements made by the LWD GeoVISION tool, which focuses current vertically similarly to a laterolog measurement (Bonner et al., 1996). In fact, we observe the opposite pattern: the greatest differences are observed between the EcoScope resistivity measurements in Hole U1327A and the wireline induction measurements in Holes U1327D and U1327E, which should both be sensitive to horizontal resistivities only. The resistivities measured by the EcoScope and GeoVISION tools, which should differ the most if anisotropy is a factor, are essentially identical. Therefore, anisotropy effects cannot explain the observed variation in measured resistivities at Site U1327 either.

If lateral heterogeneity is the reason for the observed differences in measured resistivities, the predicted pattern is simply that the resistivities measured in the same borehole should be the same, whereas resistivities measured in different boreholes may differ significantly. The observations at Site U1327 agree much better with this prediction. To start, as already noted, the measurements made in Hole U1327A by the LWD EcoScope tool, which uses the highest frequencies and is only sensitive to horizontal resistivity in a vertical well, are entirely consistent with the measurements made in the same hole by the LWD GeoVISION tool, which uses the lowest frequencies and may have some sensitivity to vertical resistivity. Moreover, measurements made by the same wireline induction tool in Holes U1327D and U1327E have resistivity peaks at different depths (Fig. F59). Instrumental effects clearly cannot explain these differences. 
The IR core images taken on the catwalk, which measure the core liner temperature, give more evidence in favor of lateral heterogeneity in gas hydrate distribution (see "Physical properties"). Figure F66 shows a comparison of the LWD resistivity image in Hole U1327A with the IR images from Hole U1327C. The LWD resistivity image shows high resistivities between 120 and 140 mbsf, and the IR images show a layer of distinct low temperatures whose top is at $\sim 130$ mbsf (top of Core 311-U1327C-17X) and bottom is at $\sim 160$ mbsf (bottom of Core 19X). Given that core recovery is incomplete, these two layers have approximately the same thickness. They are, however, displaced by $\sim 10 \mathrm{~m}$ in depth. This is a significant lateral change, given that Holes U1327A and U1327C are only $\sim 15 \mathrm{~m}$ apart. Moreover, the IR images themselves show significant lateral variability on their own; the temperatures in the 133-155 mbsf intervals are different in Holes U1327C and U1327D (Fig. F66).

If there is lateral heterogeneity in gas hydrate distribution, there may be significant differences between gas hydrate occurrence in different holes. On the other hand, observations made in the same hole should agree. This is, in fact, what we observe if we compare the IR images from Hole U1327D to the wireline resistivity logs measured in the same hole. The IR images show a cold interval at 157-162 mbsf that matches a well-defined resistivity peak in the induction $\log$ at 155-160 mbsf (Fig. F66). There is also a less prominent match between a thin, cold interval at 224-225 mbsf and a broader resistivity peak at 220-228 mbsf. On the other hand, if we compare the IR images from Hole U1327D to the resistivity logs from Hole U1327E, there are no matches between cold intervals and resistivity peaks (Fig. F66).

In conclusion, we see significant differences between resistivity (and IR) measurements that ought to give the same response for horizontally continuous features in different holes and correspondence between diverse measurements taken in the same hole. Additional independent evidence for lateral variation is provided by differences in the depth to the BSR observed in VSP interval velocities and sonic logs in different holes (Hole U1327D and U1327E, respectively). Magnetic susceptibility measurements also show significant lateral variation between holes, related to a corresponding change in lithology (see "Physical properties"). This combined evidence strongly points to significant small-scale lateral heterogeneity in gas hydrate distribution at Site U1327.

\section{Temperature data}

The Lamont-Doherty Earth Observatory (LDEO) TAP tool was deployed on the wireline triple combo tool string in Hole U1327D (Fig. F67). During the process of coring and drilling, cold seawater is circulated in the hole, cooling the formation surrounding the borehole. Once drilling ceases, the temperature of the fluid in the borehole gradually rebounds to the in situ equilibrium formation temperature. Thus, the temperature data from the TAP tool cannot be immediately used to assess the in situ formation temperature. However, the plot of the temperature profile in Figure F67 reveals a few gradient changes that were caused by borehole temperature anomalies. Specifically, the sudden temperature decrease at $280 \mathrm{mbsf}$ during the uphole trip corresponds to a borehole restriction clearly visible on the caliper log (Fig. F56). The more gradual decrease in temperature during the uphole trip around 170 mbsf corresponds to a decrease in borehole radius as seen on the caliper log (Fig. F56). Finally, the large step decrease in temperature at 95 mbsf during the uphole trip is likely to be related to a large washout, although at this depth the caliper log was turned off.

\section{References}

Aldred, W., Cook, J., Bern, P., Carpenter, B., Hutchinson, M., Lovell, J., Rezmer-Cooper, I., and Leder, P.C., 1998. Using downhole annular pressure measurements to improve drilling performance. Oilfield Rev., 10(4):40-55.

Appenzeller, T., 1991. Fire and ice under the deep sea floor. Science, 252:1790-1792.

Boetius, A., Ravenschlag, K., Schubert, C.J., Rickert, D., Widdel, F., Gieseke, A., Amann, R., Jørgensen, B.B., Witte, U., and Pfannkuche, O., 2000. A marine microbial consortium apparently mediating the anaerobic oxidation of methane. Nature (London, U. K.), 407:623626. doi:10.1038/35036572

Boissonnas, R., Goldberg, D., and Saito, S., 2000. Electromagnetic modeling and in situ measurement of gas hydrate in natural marine environments. InHolder, G.D., and Bishnoi, P.R. (Eds.), Gas Hydrates: Challenges for the Future. Ann. N. Y. Acad. Sci., 912:159-66.

Bonner, S., Fredette, M., Lovell, J., Montaron, B., Rosthal, R., Tabanou, J., Wu, P., Clark, B., Mills, R., and Williams, R., 1996. Resistivity while drilling-images from the string. Oilfield Rev., 8(1):4-19.

Chapman, N.R., Gettrust, J.F., Walia, R., Hannay, D., Spence, G.D., Wood, W.T., and Hyndman, R.D., 2002. High-resolution, deep-towed, multichannel seismic survey of deep-sea gas hydrates off western Canada. Geophysics, 67(4):1038-1047. doi:10.1190/1.1500364

Chemali, R., Gianzero, S., and Su, M., 1987. The effect of shale anisotropy on focused resistivity devices. Trans. SPWLA Annu. Logging Symp., 28:H.

Claypool, G.E., and Kaplan, I.R., 1974. The origin and distribution of methane in marine sediments. In Kaplan, I.R. (Ed.), Natural Gases in Marine Sediments: New York (Plenum), 99-139. 
Collett, T.S., 2000. Quantitative well-log analysis of in-situ natural gas hydrates [Ph.D. dissert.]. Colorado School of Mines, Golden.

Collett, T.S., and Ladd, J., 2000. Detection of gas hydrate with downhole logs and assessment of gas hydrate concentrations (saturations) and gas volumes on the Blake Ridge with electrical resistivity log data. In Paull, C.K., Matsumoto, R., Wallace, P.J., and Dillon, W.P. (Eds.), Proc. ODP, Sci. Results, 164 [Online]. Available from World Wide Web: http://www-odp.tamu.edu/publications/164_SR/chap_19/chap_19.htm.

Collett, T.S., Lewis, R.E., and Dallimore, S.R., 2005. JAPEX/ JNOC/GSC et al. Mallik 5L-38 gas hydrate production research well downhole well-log and core montages. In Dallimore, S.R., and Collett, T.S. (Eds.), Scientific Results from the Mallik 2002 Gas Hydrate Production Research Well Program, Mackenzie Delta, Northwest Territories, Canada. Bull.-Geol. Surv. Can., 585.

Davis, E.E., Hyndman, R.D., and Villinger, H., 1990. Rates of fluid expulsion across the northern Cascadia accretionary prism: constraints from new heat flow and multichannel seismic reflection data. J. Geophys. Res., 95:8869-8889.

Desmons, B., 1996. Integrated study of gas hydrates in marine sediments using geophysical and geochemical data [M.Sc. dissert.]. Univ. Victoria, Canada.

Doveton, J.H., 1994. Geologic log interpretation. SEPM Short Course, 29:33-36.

Edwards, R.N., 1997. On the resource evaluation of marine gas hydrate deposits using sea-floor transient electric dipole-dipole method. Geophysics, 62:63-74. doi:10.1190/1.1444146

Fink, C.R., and Spence, G.D., 1999. Hydrate distribution off Vancouver Island from multifrequency single-channel seismic reflection data. J. Geophys. Res., 104:29092922. doi:10.1029/98JB02641

Fofonoff, N.P., 1985. Physical properties of seawater: a new salinity scale and equation of state for seawater. J. Geophys. Res., 90:3332-3342.

Gettrust, J., Chapman, R., Walia, R., Wood, W., Hannay, D., Lindwall, D., Spence, G.D., Louden, K., and Hyndman, R.D., 1999. High-resolution seismic studies of deep sea gas hydrate using the DTAGS deep towed multichannel system. Eos, Trans. Am. Geophys. Union, 80(38):439-440.

Guerin, G., and Goldberg, D., 2002. Sonic waveform attenuation in gas hydrate-bearing sediments from the Mallik 2L-38 research well, MacKenzie Delta, Canada. J. Geophys. Res., 107:2088. doi:10.1029/2001JB000556

Hagiwara, T., 1996. EM log response to anisotropic resistivity in thinly laminated formations with emphasis on 2$\mathrm{MHz}$ resistivity devices. SPE Form. Eval., 11(4):211-217.

Hobro, J.W.D., Minshull, T.A., Singh, S.C., and Chand, S., 2005. A three-dimensional seismic tomographic study of the gas hydrate stability zone, offshore Vancouver Island. J. Geophys. Res., 110. doi:10.1029/ 2004JB003477

Holbrook, W.S., Hoskins, H., Wood, W.T., Stephen, R.A., Lizzarralde, D., and the Leg 164 Science Party, 1996.
Methane gas-hydrate and free gas on the Blake Ridge from vertical seismic profiling. Science, 273:1840-1843.

Hyndman, R.D., Moran, K., and Yuan, T., 1999. The concentration of deep sea gas hydrates from downhole resistivity logs and laboratory data. Earth Planet. Sci. Lett., 172(1-2):167-177. doi:10.1016/S0012821X(99)00192-2

Hyndman, R.D., Spence, G.D., Chapman, N.R., Riedel, M., and Edwards, R.N., 2001. Geophysical studies of marine gas hydrate in northern Cascadia. In Paull, C.K., and Dillon, W.P. (Eds.), Natural Gas Hydrates, Occurrence, Distribution and Detection. Geophys. Monogr., 124:273-295.

Lorenson, T.D., Whiticar, M.J., Collett, T.S., Dalimore, S.R., and Dougherty, J.A., 2005. Complete gas composition and isotopic geochemistry from the JAPEX/JNOC/GSC et al. Mallik 5L-38 gas hydrate production well: cuttings, core, gas hydrate, and production testing results. In Dallimore, S.R., and Collett, T.S. (Eds.), Scientific Results from the Mallik 2002 Gas Hydrate Production Research Well Program, Mackenzie Delta, Northwest Territories, Canada. Bull.-Geol. Surv. Can., 585:19.

MacKay, M.E., Jarrard, R.D., Westbrook, G.K., and Hyndman, R.D., 1994. Origin of bottom-simulating reflectors: geophysical evidence from the Cascadia accretionary prism. Geology, 22(5):459-462. doi:10.1130/0091-7613(1994)022<0459:OOBSRG $>2.3 . \mathrm{CO} ; 2$

Malinverno, A., and Briggs, V.A., 2004. Expanded uncertainty quantification in inverse problems: hierarchical bayes and empirical bayes. Geophysics, 69:100-1016. doi:10.1190/1.1778243

Michaelis, W., Seifert, R., Nauhaus, K., Treude, T., Thiel, V., Blumenberg, M., Knittel, K., Gieseke, A., Peterknecht, K., Pape, T., Boetius, A., Amann, R., Jørgensen, B.B., Widdel, F., Peckmann, J., Pimenov, N.V., and Gulin, M.B., 2002. Microbial reefs in the Black Sea fueled by anaerobic oxidation of methane. Science, 297:10131015. doi:10.1126/science.1072502

Novosel, I., 2002. Physical properties of gas hydrate related sediments, offshore Vancouver Island [M.Sc. Thesis]. Univ. Victoria, Canada.

Orphan, V., House, C.H., Hinrichs, K.-U., McKeegan, K.D., and DeLong, E.F., 2002. Multiple archaeal groups mediate methane oxidation in anoxic cold seep sediments. Proc. Natl. Acad. Sci. U. S. A., 99:7663-7668.

Pimmel, A., and Claypool, G., 2001. Introduction to shipboard organic geochemistry on the JOIDES Resolution. ODP Tech. Note, 30 [Online]. Available from World Wide Web: http://www-odp.tamu.edu/publications/ tnotes/tn30/INDEX.HTM.

Riedel, M., 2001. 3-D seismic investigations of northern Cascadia marine gas hydrates [Ph.D. thesis]. Univ. Victoria, Canada.

Riedel, M., Collett, T.S., and Hyndman, R.D. 2005. Gas hydrate concentration estimates from chlorinity, electrical resistivity, and seismic velocity. Geol. Surv. Can. Open-File Rep., 4934.

Riedel, M., Novosel, I., Spence, G.D., Hyndman, R.D., Chapman, N.R., and Lewis, T., 2006. Geophysical and geochemical signatures associated with gas hydrate- 
related venting in the northern Cascadia margin. Geol. Soc. Am. Bull., 118:23-38. doi:10.1130/385720.1

Riedel, M., Spence, G.D., Chapman, N.R., and Hyndman, R.D., 2002. Seismic investigations of a vent field associated with gas hydrates, offshore Vancouver Island. J. Geophys. Res., 107(B9):2200. doi:10.1029/2001JB000269

Sloan, E.D., 1998. Clathrate Hydrates of Natural Gases (2nd ed.): New York (Marcel Dekker).

Solem, R.C., Spence, G.D., Vukajlovich, D., Hyndman, R.D., Riedel, M., Novosel, I., and Kastner, M., 2002. Methane advection and gas hydrate formation within an active vent field offshore Vancouver Island. Fourth Int. Conf. Gas Hydrates, 19023.

Spence, G.D., Minshull, T.A., and Fink, C., 1995. Seismic studies of methane gas hydrate, offshore Vancouver Island. In Carson, B., Westbrook, G.K., Musgrave, R.J., and Suess, E. (Eds.), Proc. ODP, Sci. Results, 146 (Pt 1): College Station, TX (Ocean Drilling Program), 163-174.

Sun, Y.F., and Goldberg, D., 2005. Dielectric method of high-resolution gas hydrate estimation. Geophys. Res. Lett., 32. doi:10.1029/2004GL021976

Ussler, W., III, and Paull, C.K., 2001. Ion exclusion associated with marine gas hydrate deposits. In Paull, C.K., and Dillon, W.P. (Eds.), Natural Gas Hydrates: Occurrence, Distribution, and Detection. Geophys. Monogr., 124:4151.

Warner, M., 1990. Absolute reflection coefficients from deep seismic reflections. Tectonophysics, 173:15-23. doi:10.1016/0040-1951(90)90199-I

Westbrook, G.K., Carson, B., Musgrave, R.J., et al., 1994. Proc. ODP, Init. Repts., 146 (Pt. 1): College Station, TX (Ocean Drilling Program).

Wood, W.T., Gettrust, J.F., Chapman, N.R., Spence, G.D., and Hyndman, R.D., 2002. Decreased stability of methane hydrates in marine sediments owing to phase- boundary roughness. Nature (London, U. K.), 420:656660. doi:10.1038/nature01263

$\mathrm{Xu}, \mathrm{W} ., 2002$. Phase balance and dynamic equilibrium during formation and dissociation of methane gas hydrate. Fourth Int. Conf. Gas Hydrates, 19023:199-200.

$\mathrm{Xu}, \mathrm{W} ., 2004$. Modeling dynamic marine gas hydrate systems. Am. Mineral., 89:1271-1279.

Yuan, J., and Edwards, R.N., 2000. The assessment of marine gas hydrates through electrical remove sounding: hydrate without a BSR? Geophys. Res. Lett., 27(16):2397-2400. doi:10.1029/2000GL011585

Yuan, T., Hyndman, R.D., Spence, G.D., and Desmons, B., 1996. Seismic velocity increase and deep-sea gas hydrate concentration above a bottom-simulating reflector on the northern Cascadia continental slope. J. Geophys. Res., 101(B6):13655-13671. doi:10.1029/96JB00102

Yuan, T., Spence, G.D., Hyndman, R.D., Minshull, T.A., and Singh, S.C., 1999. Seismic velocity studies of a gas hydrate bottom-simulating reflector on the northern Cascadia continental margin: amplitude modeling and full waveform inversion. J. Geophys. Res., 104(B1):11791192. doi:10.1029/1998JB900020

Zhang, C.L., Li, Y., Wall, J.D., Larsen, L., Sassen, R., Huang, Y., Wang, Y., Peacock, A., White, D.C., Horita, J., and Cole, D.R., 2002. Lipid and carbon isotopic evidence of methane-oxidizing and sulfate-reducing bacteria in association with gas hydrates from the Gulf of Mexico. Geology, 20:239-242.

Zühlsdorff, L., Spiess, V., Hübscher, C., and Breitzke, M., 1999. Seismic reflectivity anomalies in sediments at the eastern flank of the Juan de Fuca Ridge: evidence for fluid migration? J. Geophys. Res., 104:15351-15364. doi:10.1029/1999JB900061

Publication: 28 October 2006 MS 311-105 
Figure F1. Hydrosweep seafloor bathymetry around Sites U1327 and 889, showing two prominent topographic highs (from German cruise Sonne 111, provided by V. Spiess, Bremen University, Germany). MCS = multichannel seismic.

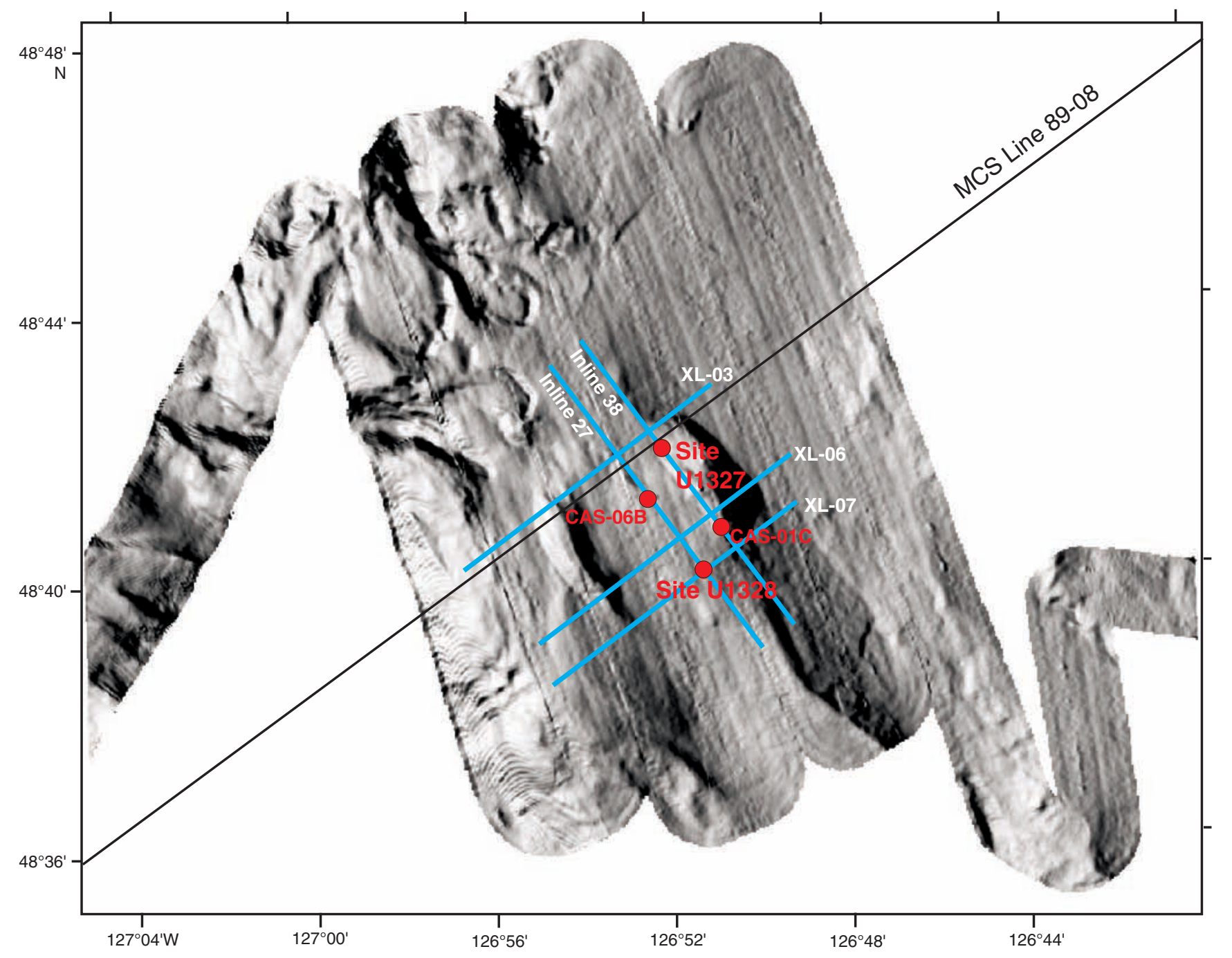


Figure F2. Seafloor reflection coefficient determined from the 1999 3-D multichannel seismic (MCS) data. An area northwest of Sites U1327 and 889 is characterized by higher seafloor reflectivity, which is attributed to the occurrence of near-surface sand accumulations as confirmed by piston coring. Axes are universal transverse Mercator (UTM) projection easting and northing coordinates using the WGS-84 reference. CDP $=$ common depth point.

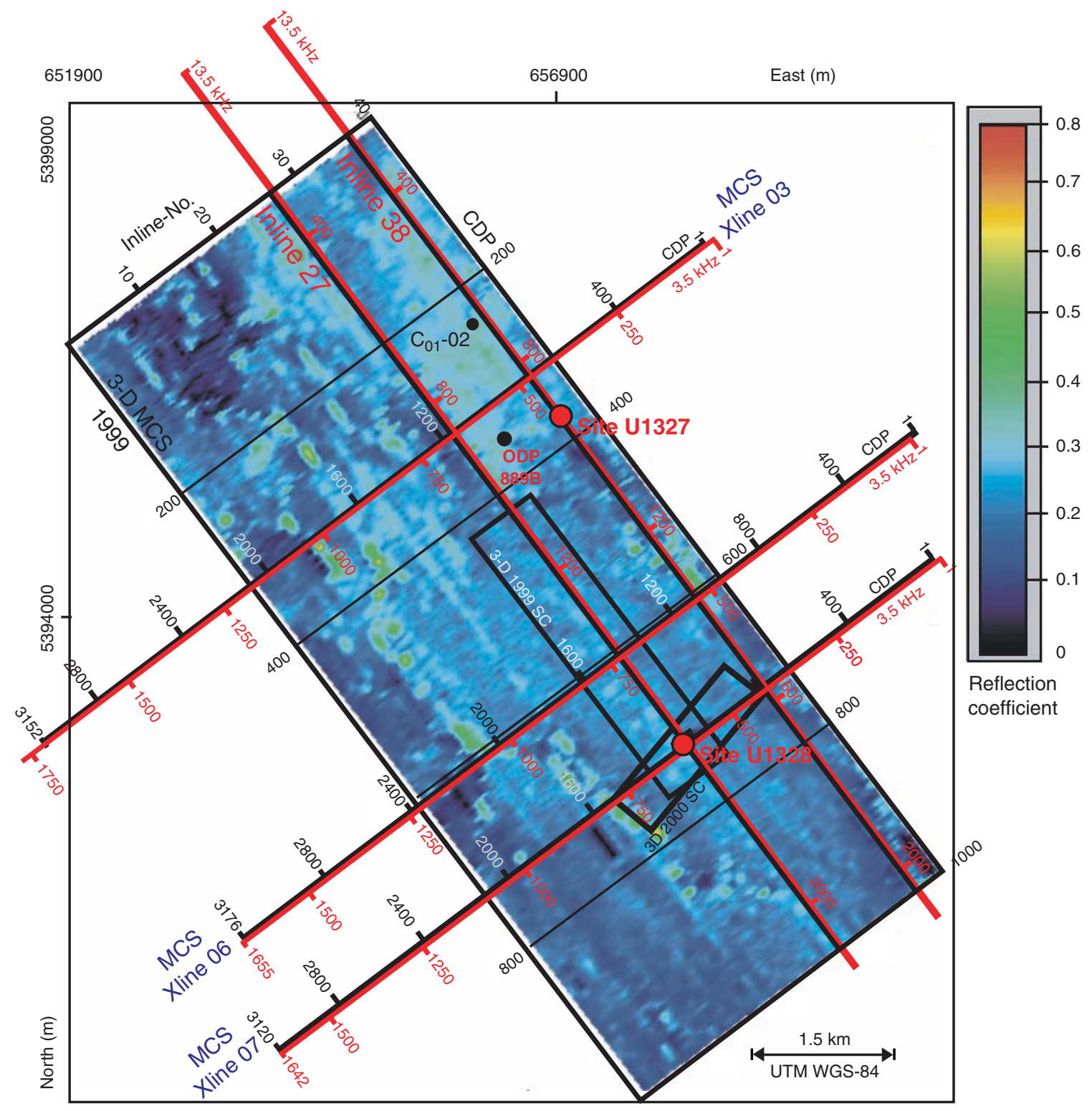


Figure F3. High-resolution $3.5 \mathrm{kHz}$ subbottom profiler data acquired along Inline 38 of the 3-D survey, showing the absence of the typical Holocene transparent layer near Site U1327. MCS $=$ multichannel seismic, V.E. = vertical exaggeration.

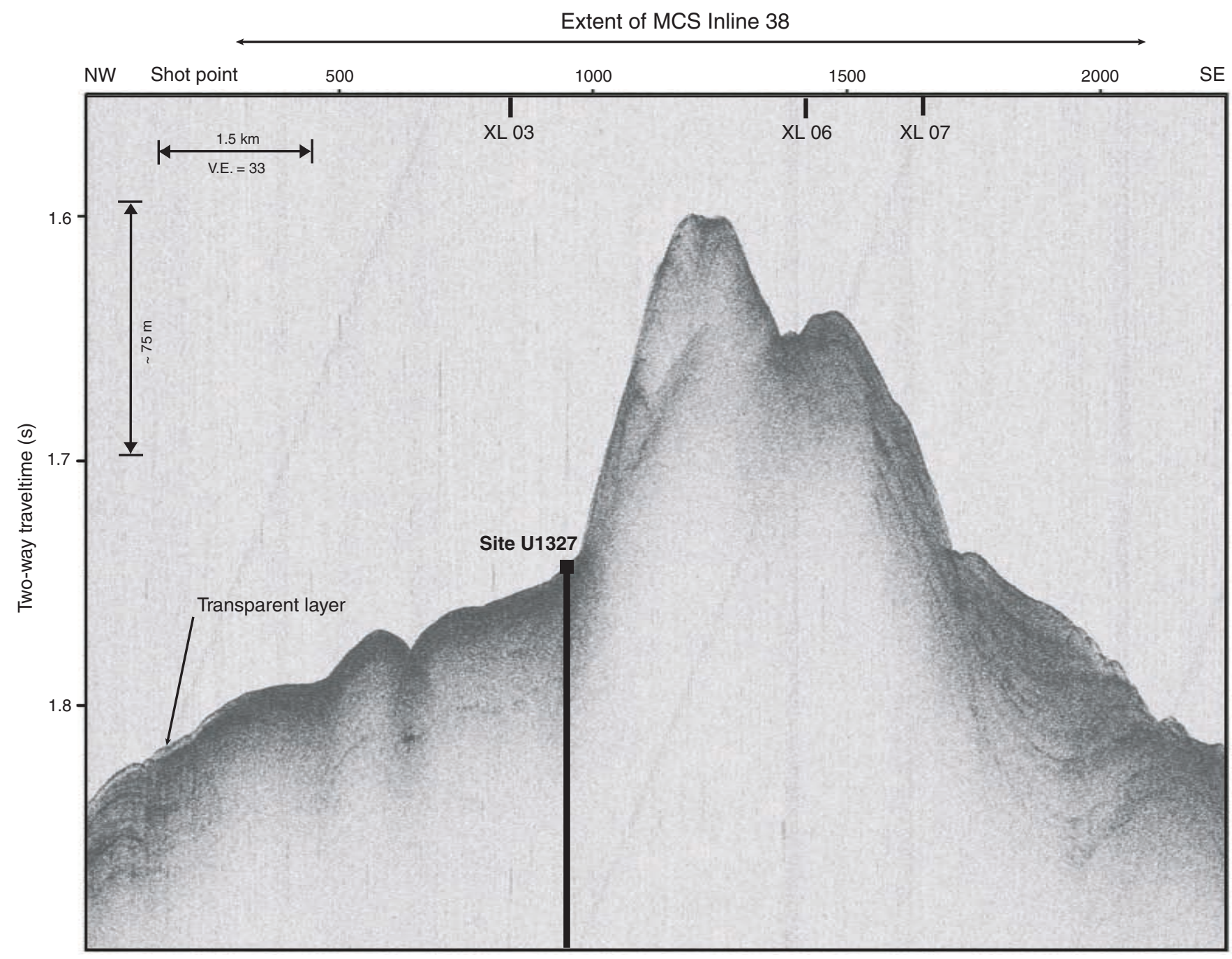


Figure F4. Comparison between lithostratigraphic units, paleostratigraphy, paleomagnetic zonation, density from MAD analysis of Site 889 (from Westbrook, Carson, Musgrave et al., 1994) and a seismic section from the 1999 3-D multichannel seismic data (from Riedel, 2001). BSR = bottom-simulating reflector.

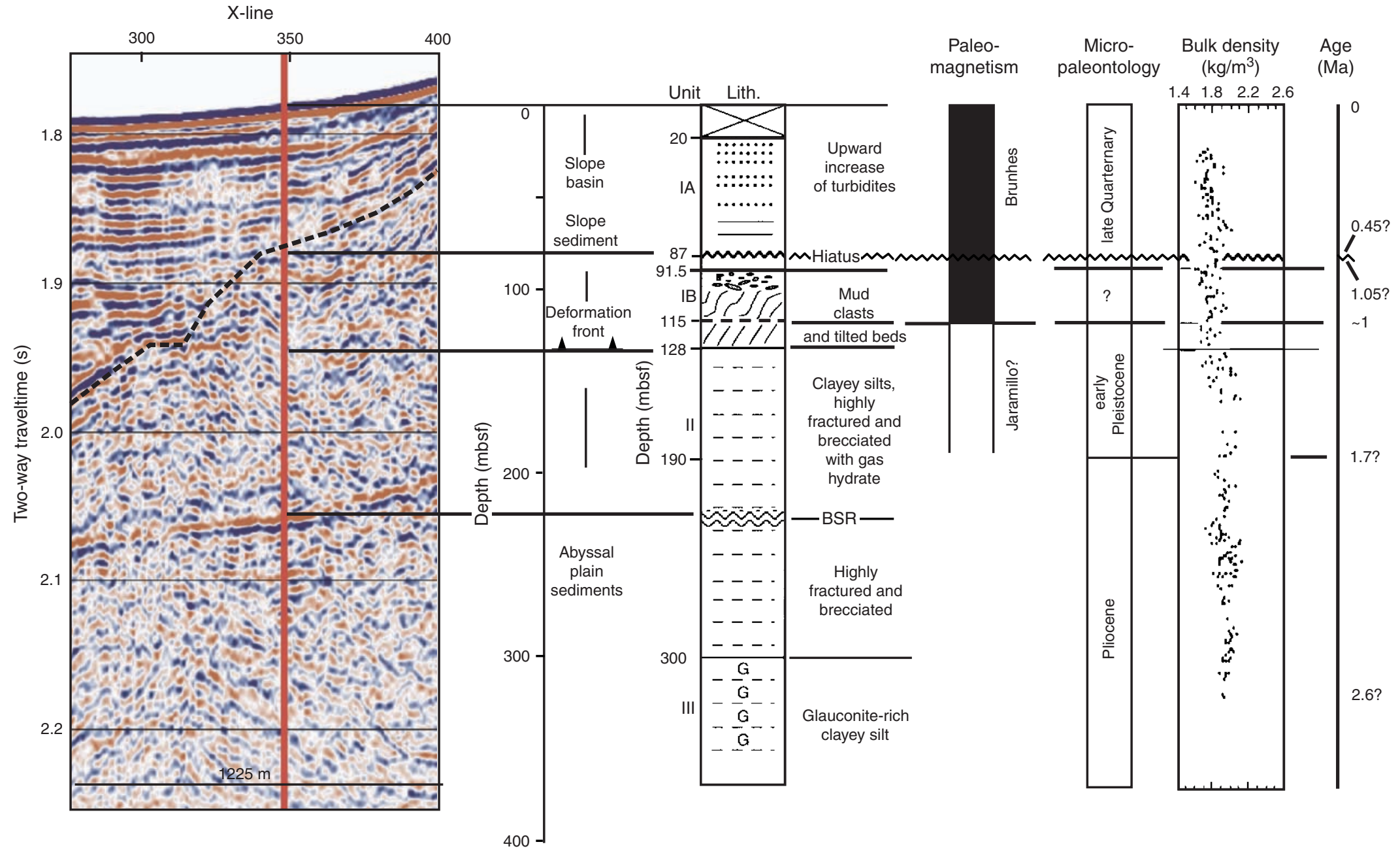


Figure F5. Seismic section from multichannel seismic Line 89-08 over Site 889, showing a prominent bottom-simulating reflector (BSR) event that dominates the seismic profile. $\mathrm{CDP}=$ common depth point.

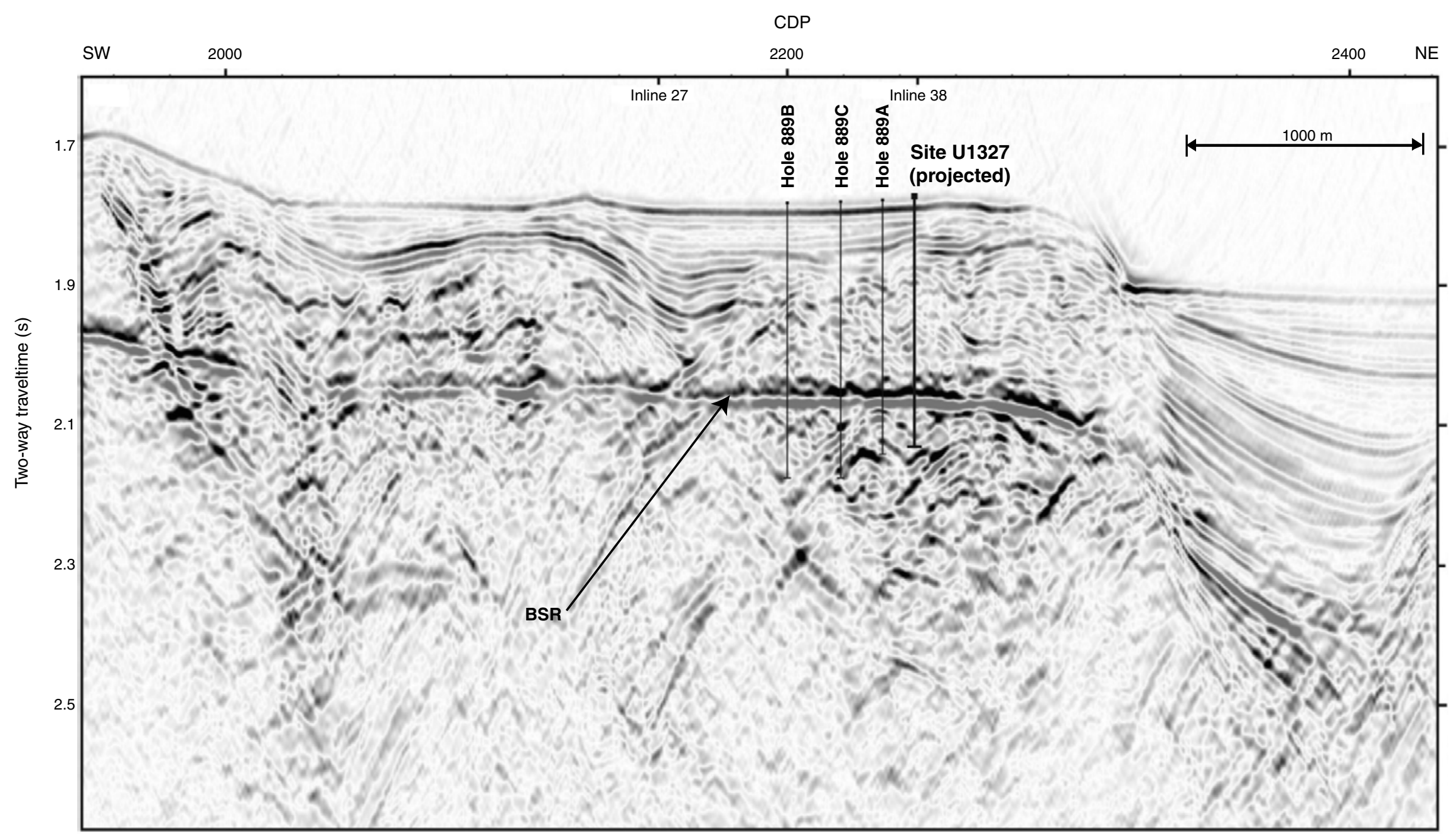


Figure F6. Seismic section from 1999 3-D multichannel seismic (MCS) Inline 38 over Site U1327. A bottom-simulating reflector (BSR) is clearly identifiable where it falls within the accreted sediments. In the deeper slope basins the BSR merges with regular reflectivity and becomes indiscernible. The reflection strength is reduced compared to what was observed in MCS Line 89-08 as attributed to the frequency-dependent behavior of the BSR (Chapman et al., 2002). CDP = common depth point, V.E. = vertical exaggeration.

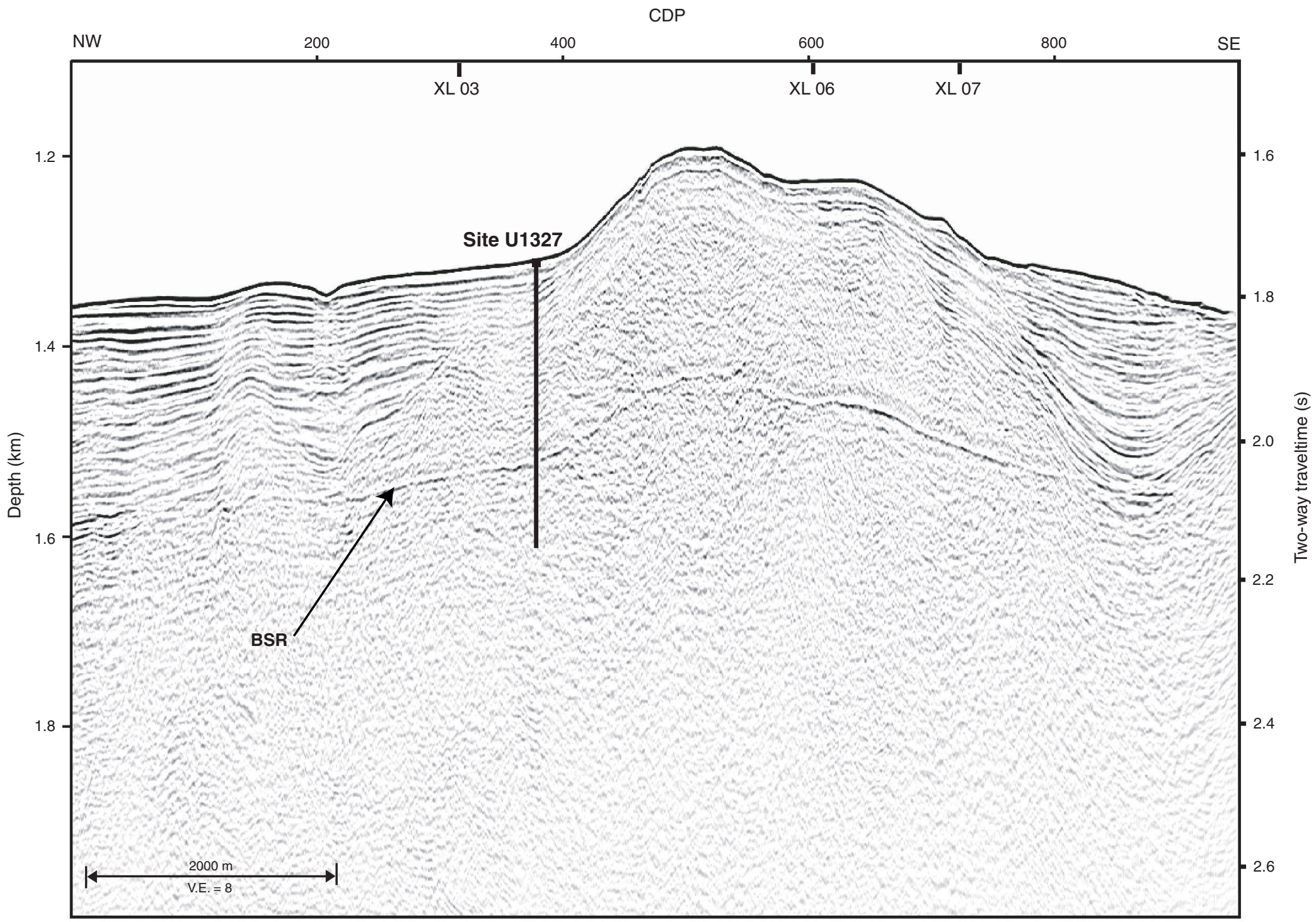


Figure F7. Seismic section from 1999 3-D multichannel seismic (MCS) XLine 3, which crosses Inline 38 in a perpendicular direction. This line is offset by $\sim 100 \mathrm{~m}$ to the northwest from Site U1327. CDP = common depth point, V.E. = vertical exaggeration, BSR $=$ bottom-simulating reflector.

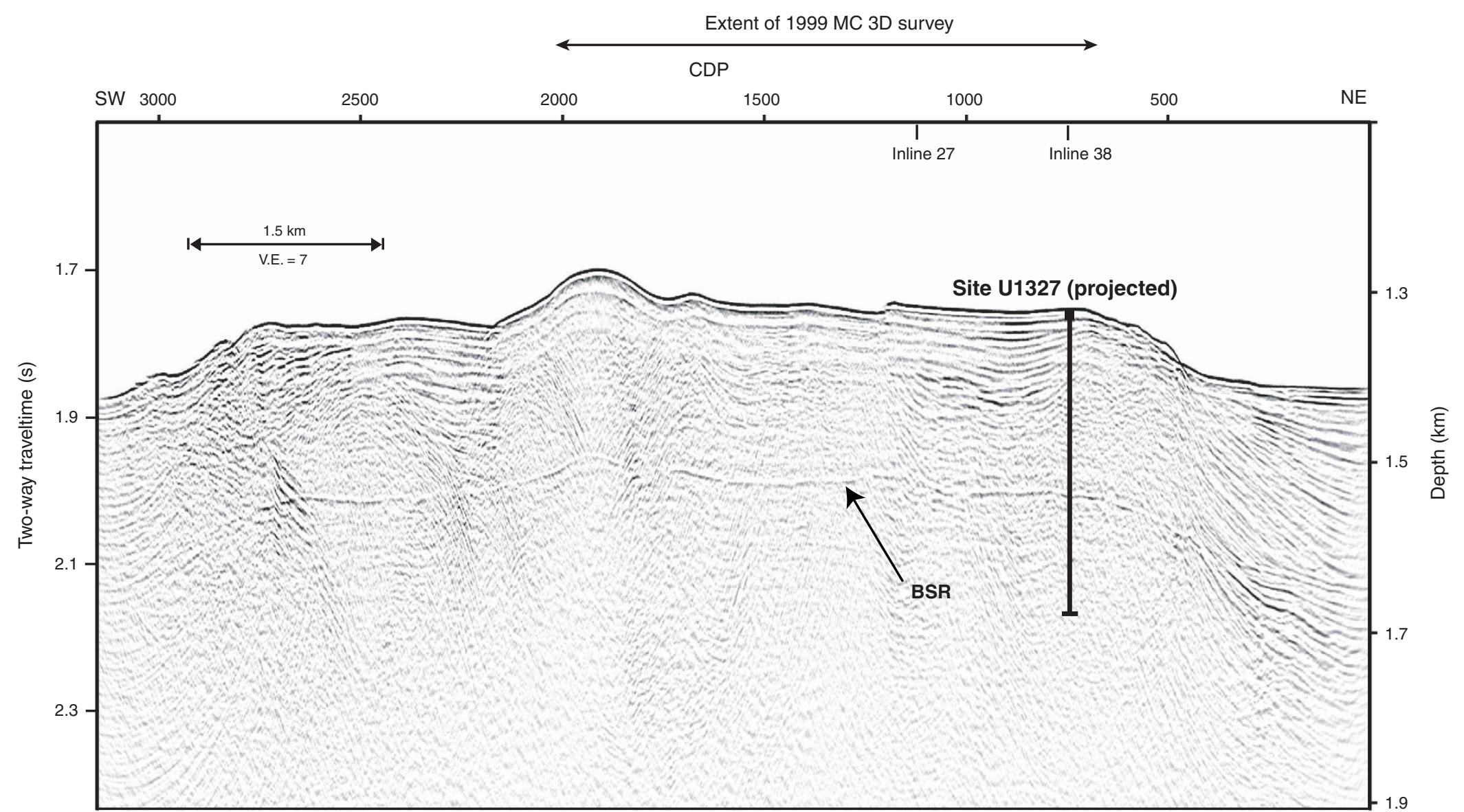


Figure F8. Bottom-simulating reflector (BSR) reflection coefficient as defined from the 1999 3-D multichannel seismic (MCS) data. The BSR is relatively weak in most areas with reflection coefficients smaller than -0.1 . A single bright spot occurs in association with cold vent Site U1328 (see the "Site U1328" chapter for details). Axes are universal transverse mercator (UTM) projection easting and northing coordinates using the WGS-84 reference. $\mathrm{CPD}=$ common depth point.

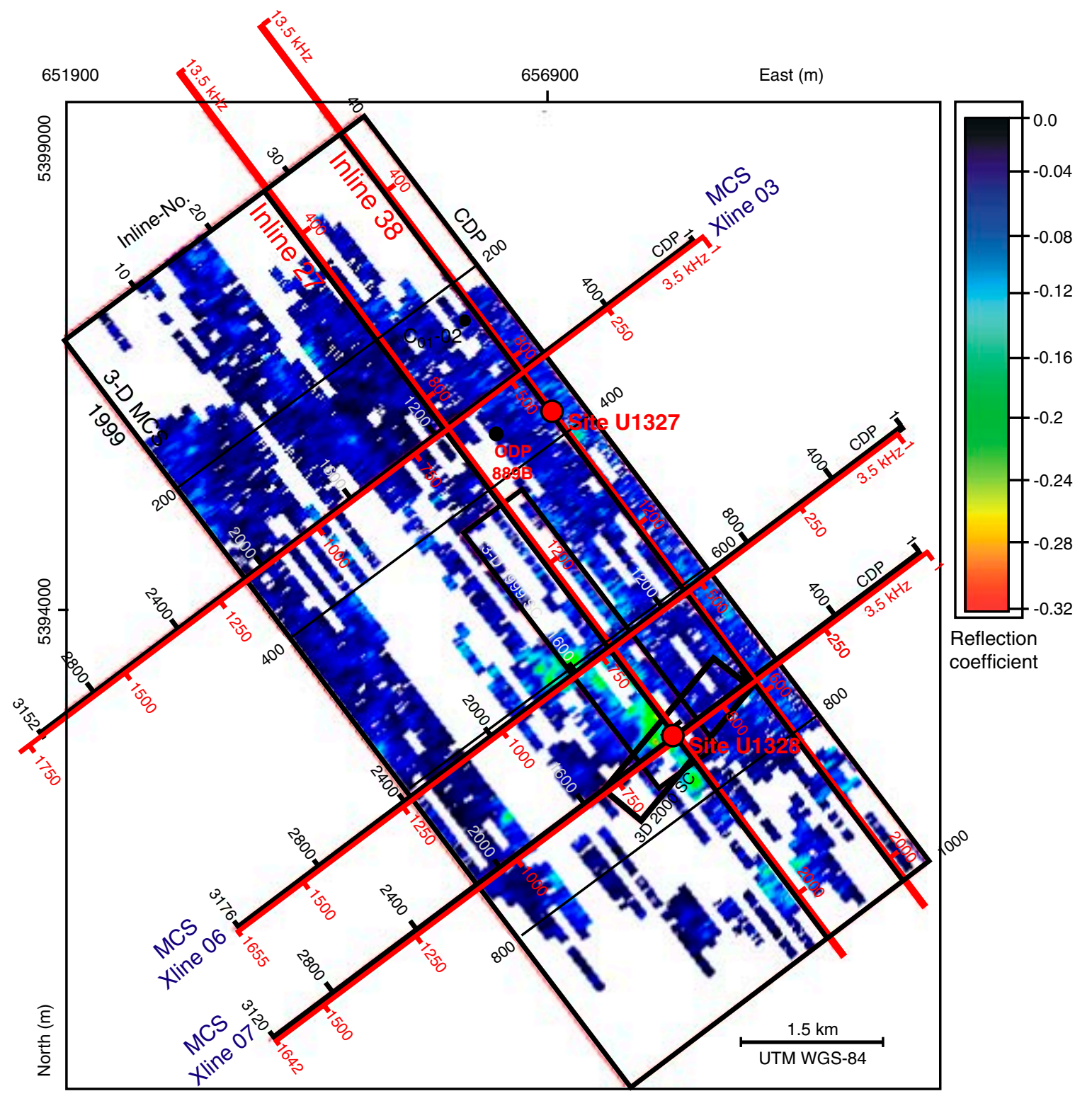


Figure F9. Locations of holes drilled at Site U1327, showing track lines with seismic survey shot points. Axes are universal transverse Mercator (UTM) projection easting and northing coordinates using the WGS-84 reference. $\mathrm{MCS}=$ multichannel seismic.

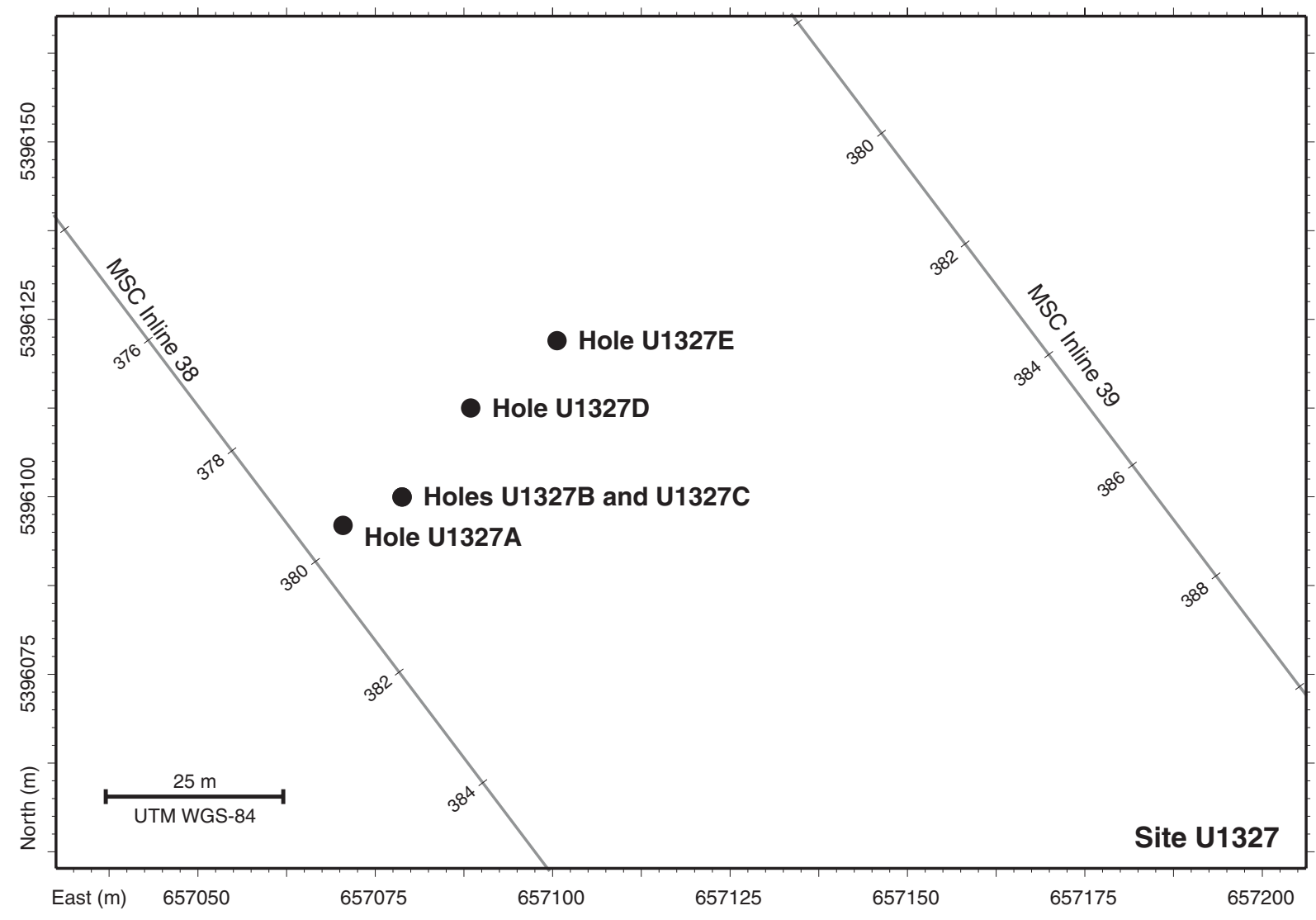


Figure F10. Lithostratigraphic summary for Hole U1327C showing the percentage of clay, silt, sand, biogenic opal (diatoms, radiolarians, siliceous spicules, silicoflagellates), foraminifers, and nannofossils in the major lithology; clay, silt, and sand in the minor lithology; and archive multisensor track color reflectance $\left(\mathrm{a}^{*}\right)$.

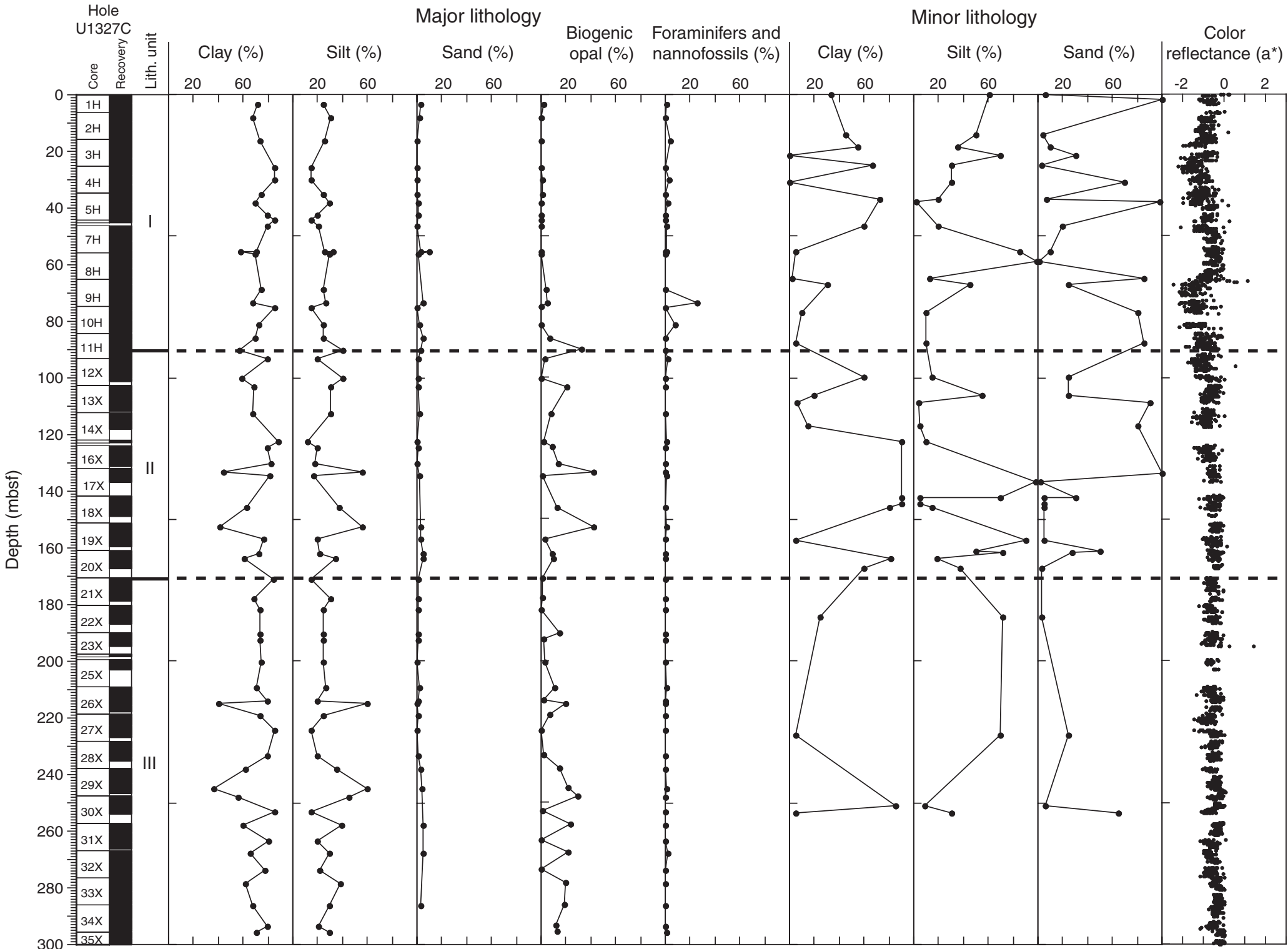


Figure F11. Dark gray silty clay with sandy silt layers in lithostratigraphic Unit I (interval 311-U1327C-3H-4, $65-81 \mathrm{~cm}$ ).

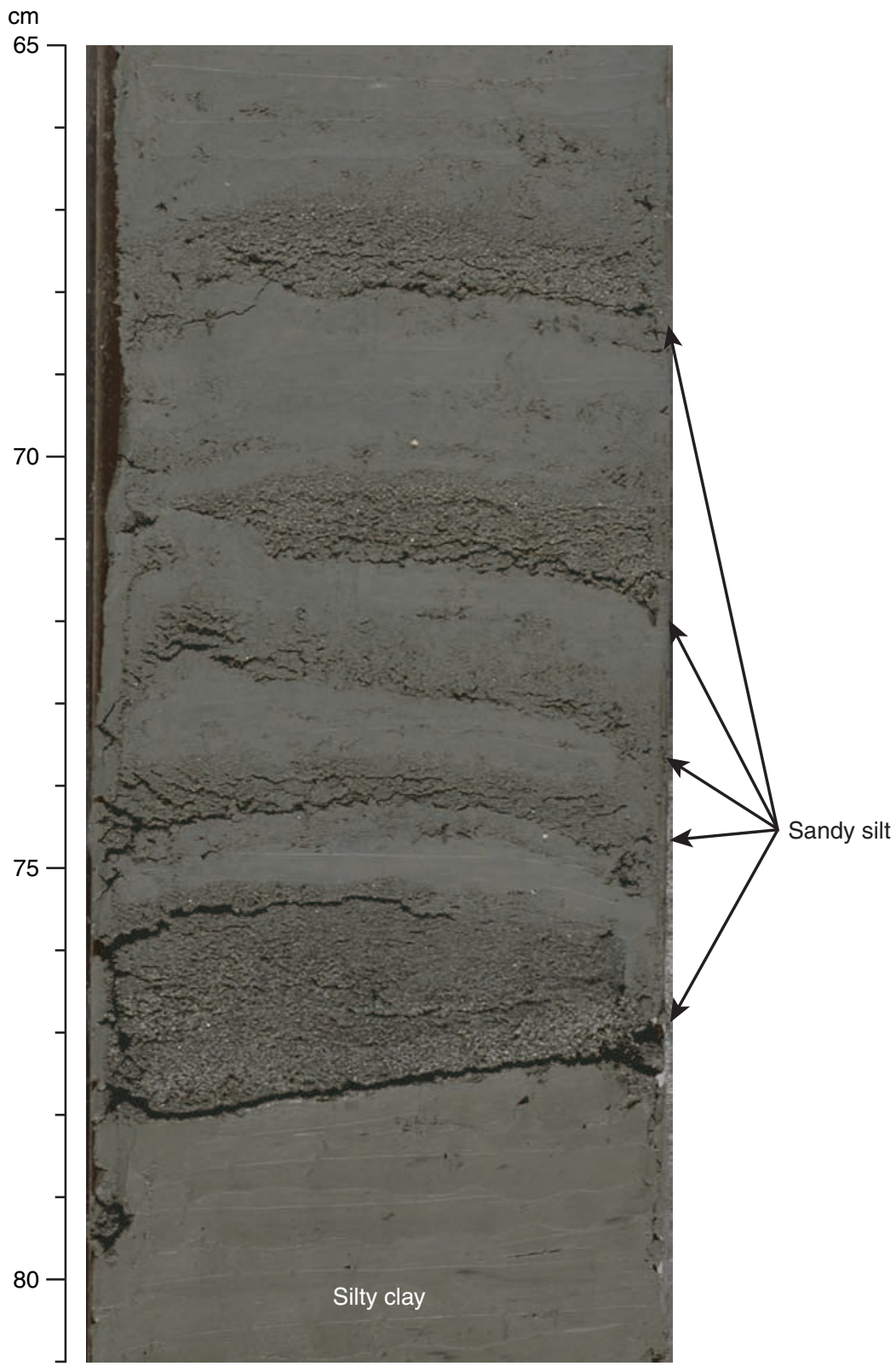


Figure F12. Dark gray silty clay with a $7 \mathrm{~cm}$ thick layer of sand with a sharp, erosional bottom contact in lithostratigraphic Unit I. The sand layer shows a fining-upward sequence and $2 \mathrm{~cm}$ thick parallel lamination on top (interval 311-U1327C-2H-1, 40-57 cm).

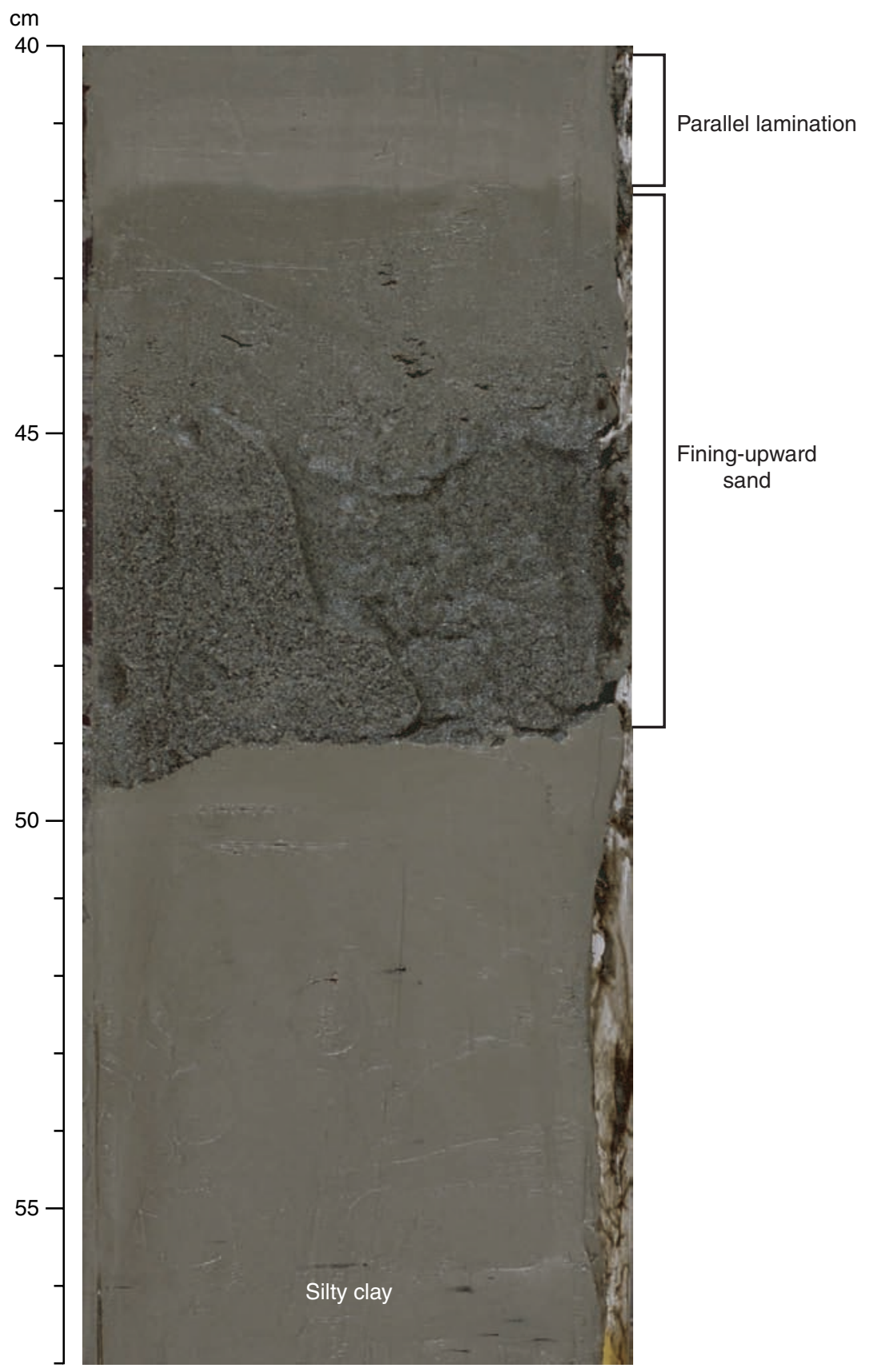


Figure F13. Dark gray silty clay with a $6 \mathrm{~cm}$ thick layer of sand with a sharp, erosional bottom contact in lithostratigraphic Unit I. A rounded centimeter-size rock piece is present in the silty clay above (interval 311U1327C-8H-3, 79-97 cm).

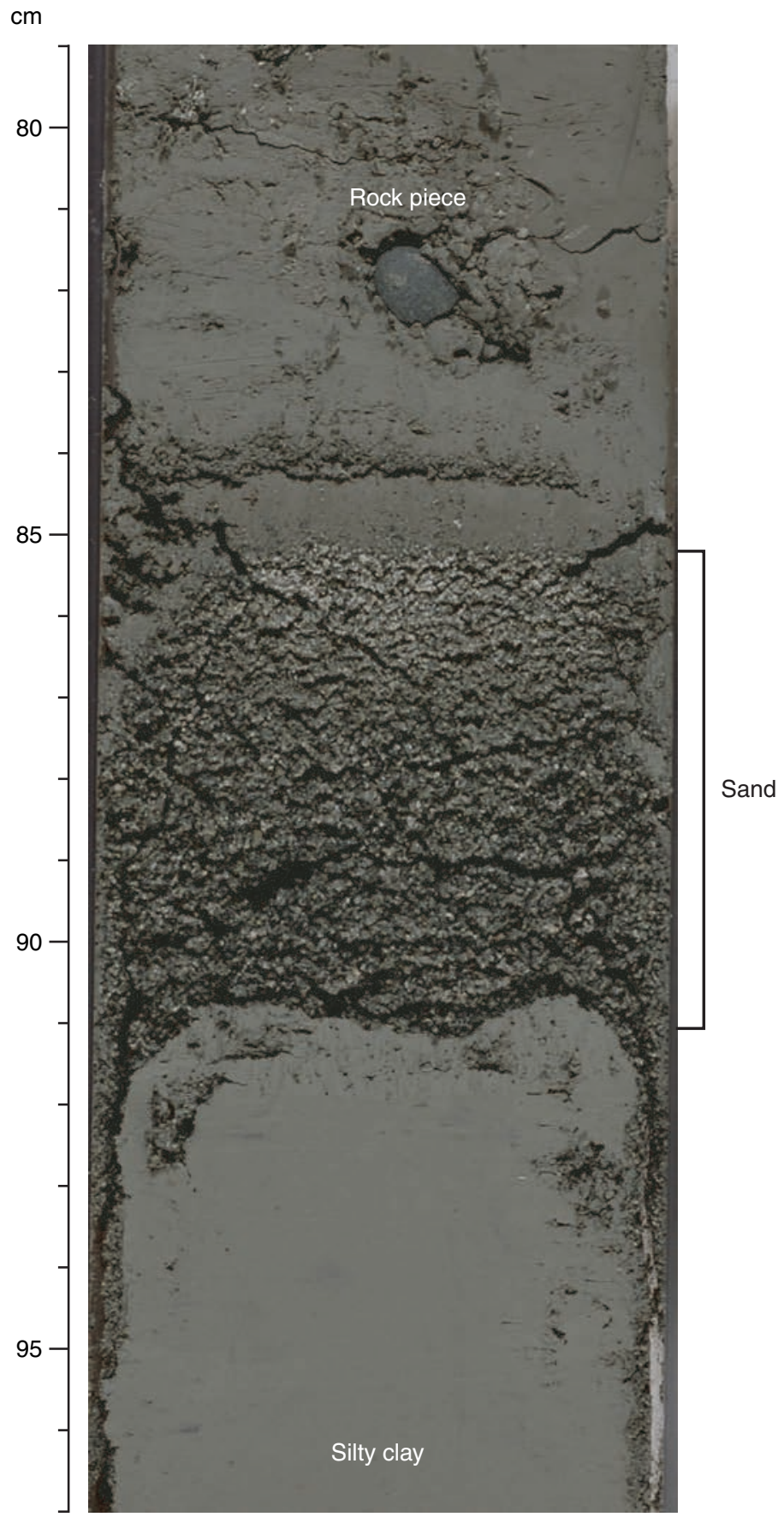


Figure F14. XRD record from a zeolite-rich silt layer in lithostratigraphic Unit I (Sample 311-U1327C-2H-5, 69-70 cm) showing analcime and a form of philipsite as the dominant minerals.

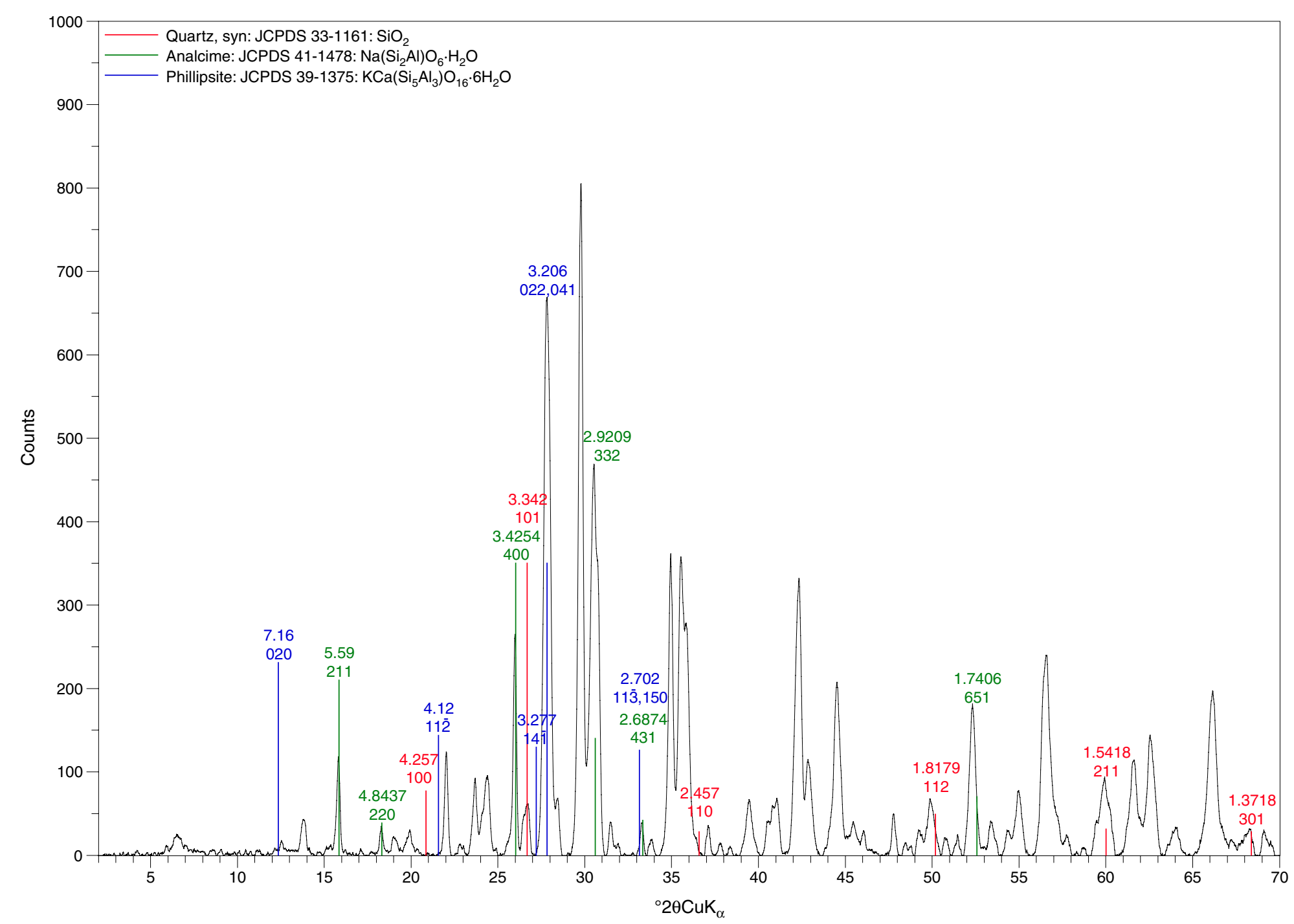


Figure F15. Unlithified authigenic carbonate cement in lithostratigraphic Unit I (interval 311-U1327C-10H-1, $88-110 \mathrm{~cm})$.

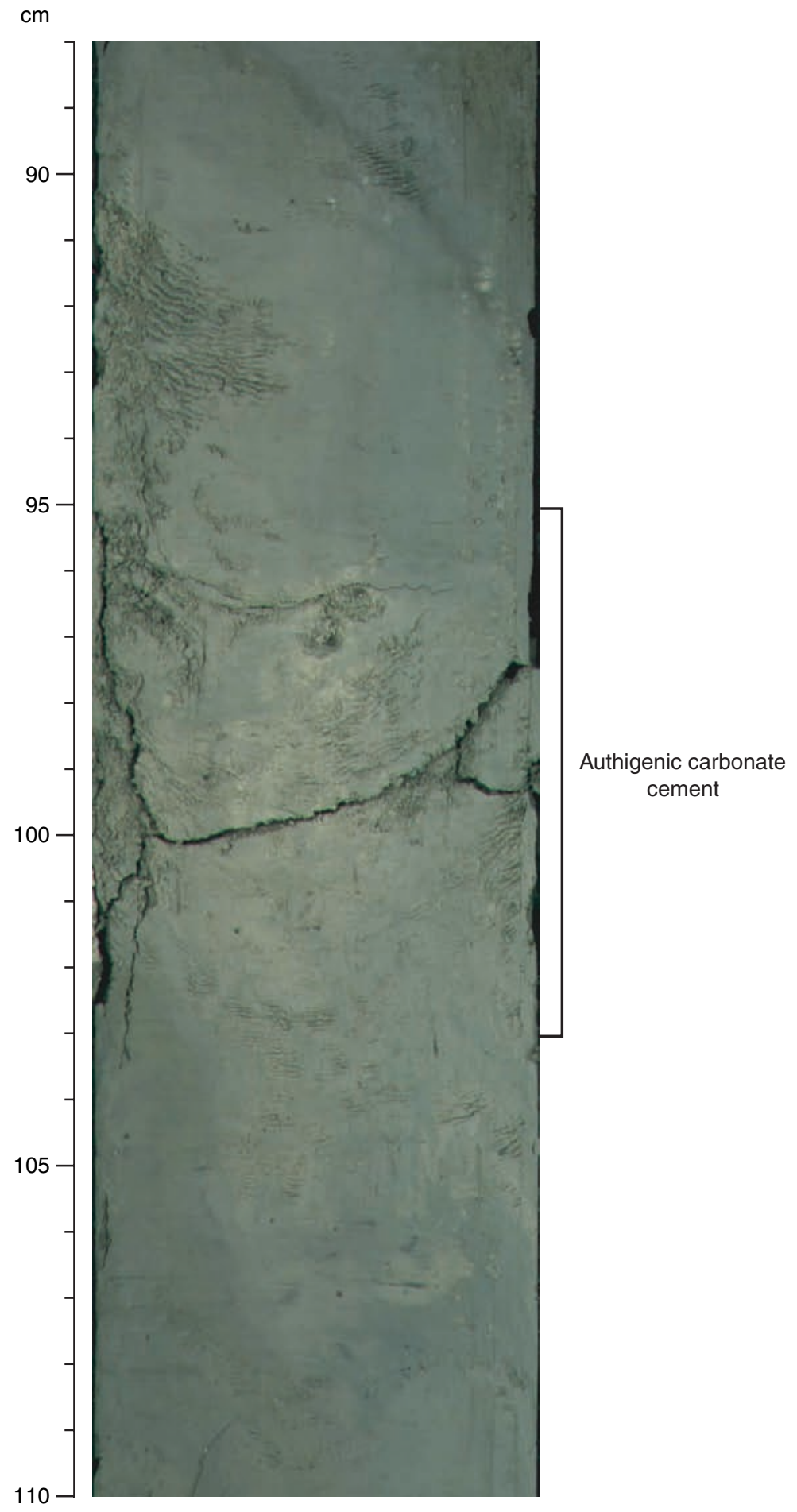


Figure F16. Soft-sediment deformation within silty clay in lithostratigraphic Unit I (interval 311-U1327C-8H$3,15-33 \mathrm{~cm})$.

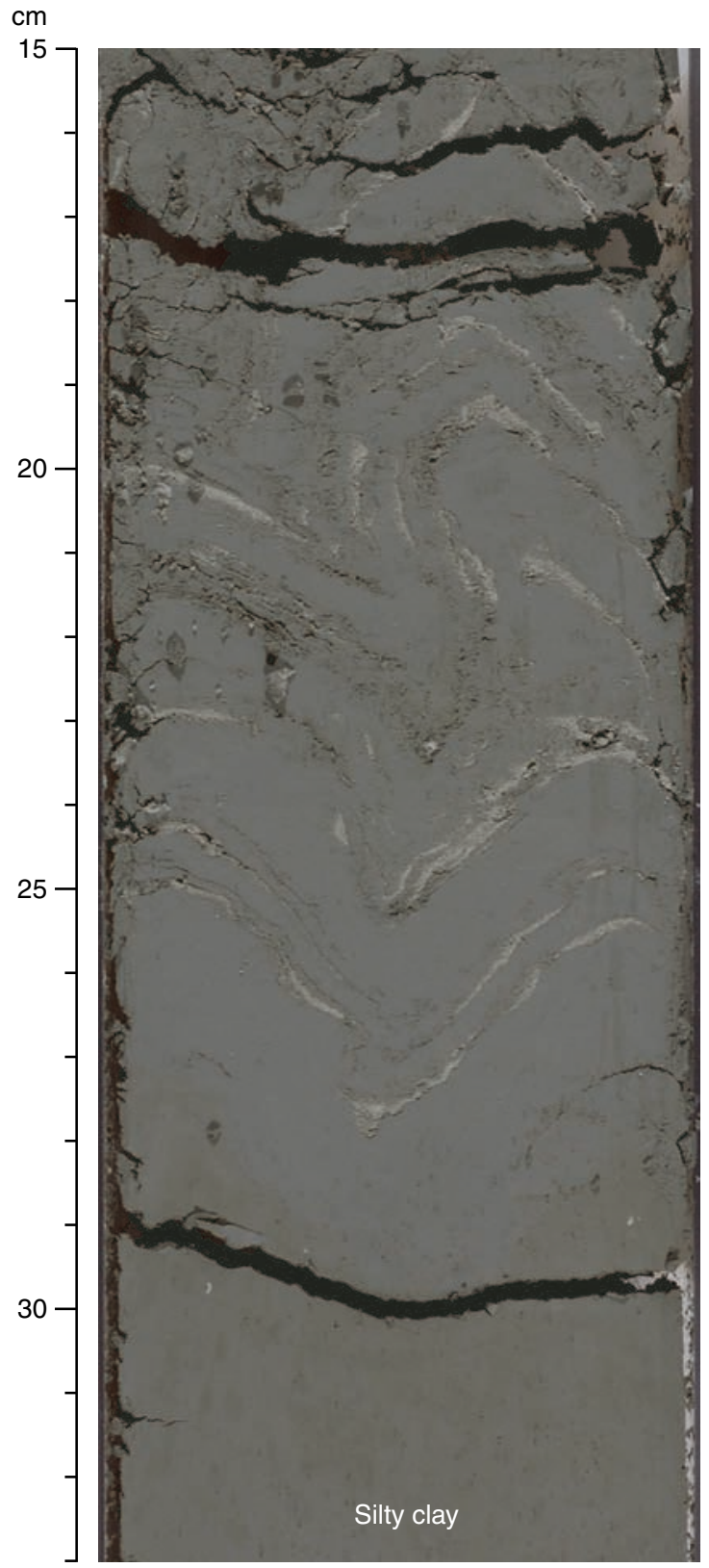


Figure F17. Rounded to subangular rock pebbles of different composition in lithostratigraphic Unit II (interval 311-U1327D-9X-1, 0-31 cm).

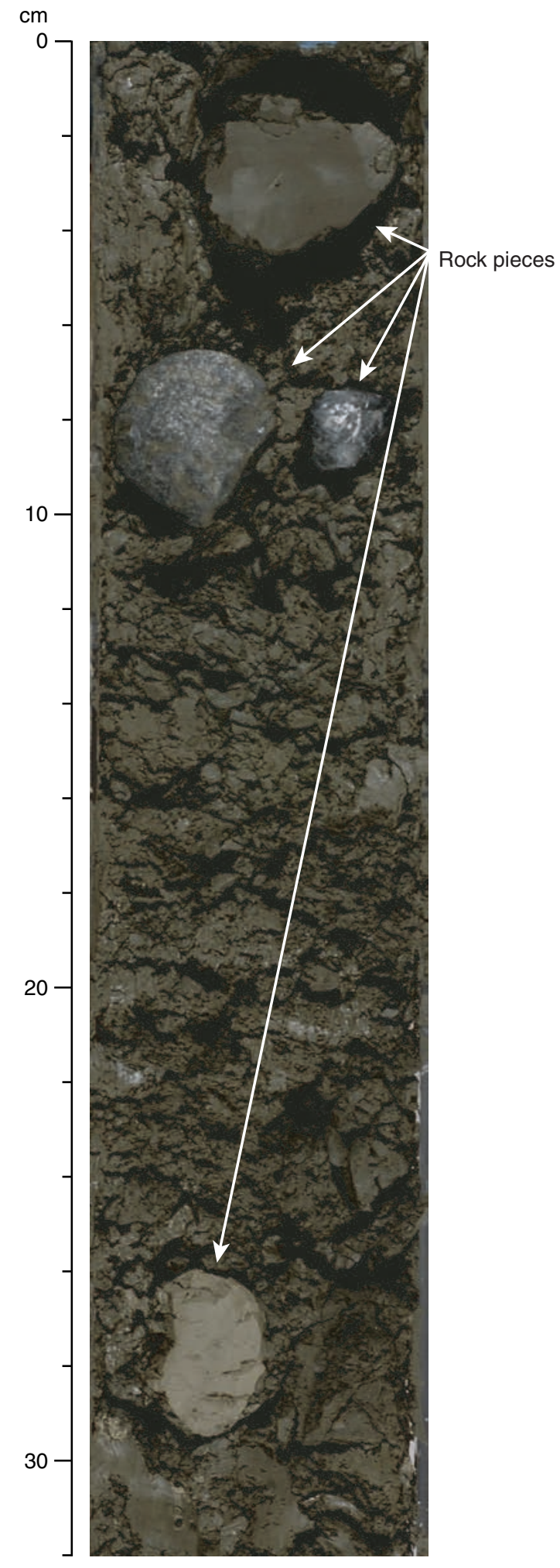


Figure F18. A. Soupy and mousselike structures in lithostratigraphic Unit II (interval 311-U1327C-7X-4, 8-43 $\mathrm{cm})$. B. IR image of the core liner of Core 311-U1327C-7X at 4.51-4.87 m catwalk depth showing the temperature anomaly of another gas hydrate-rich interval. The scale given in the figure is meters measured on the catwalk prior to cutting the core into sections. The measured cold spot corresponds to a sampled piece of hydrate (interval 311-U1327D-7X-2, 57-82 cm).

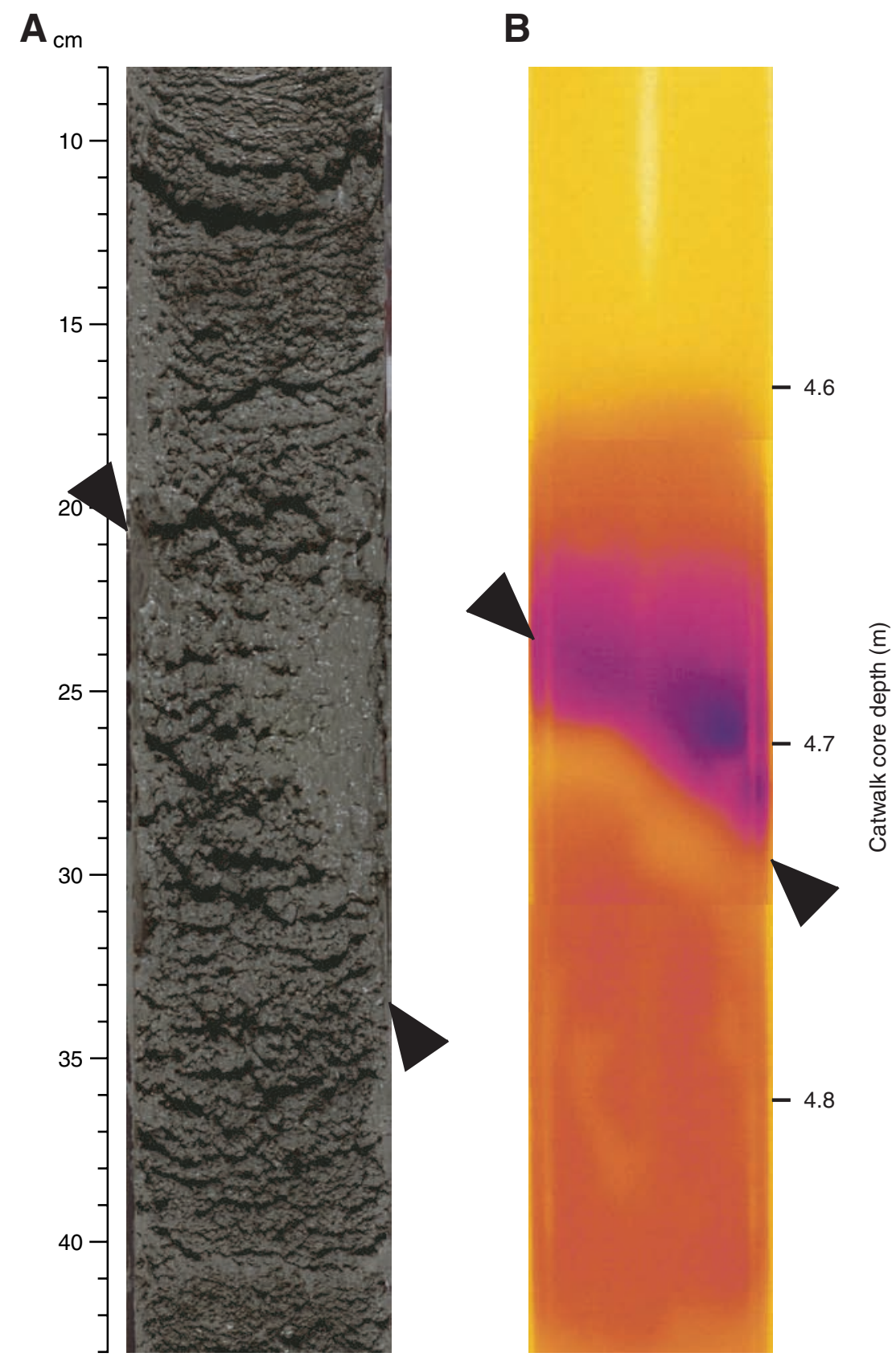


Figure F19. Biscuit structure with broken sediments (drilling slurry) between intact biscuits in lithostratigraphic Unit III (interval 311-U1327C-22X-1, 40-80 cm).

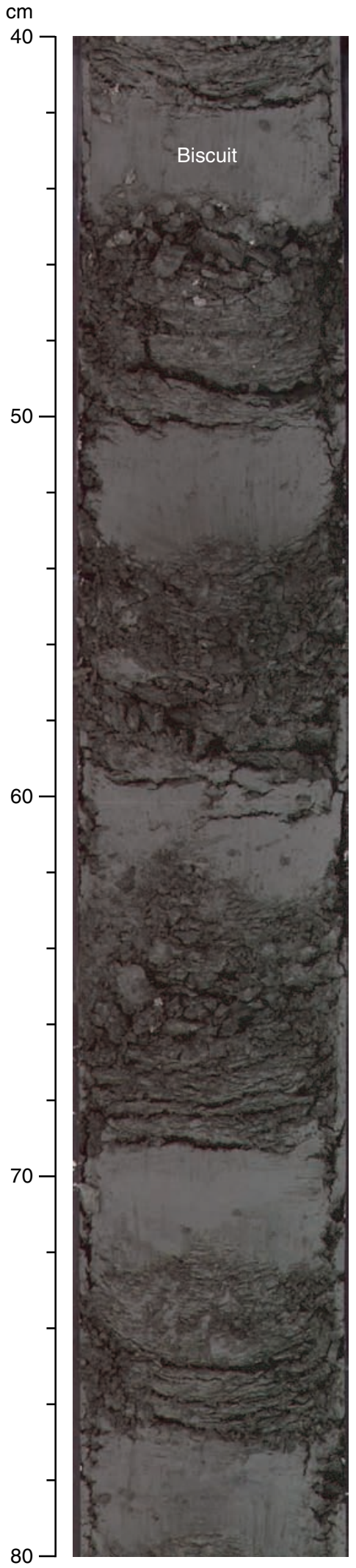


Figure F20. XRD record from a rhodochrosite-rich carbonate cement in lithostratigraphic Unit III (Sample 311-U1327C-29X-4, 59-69 cm).

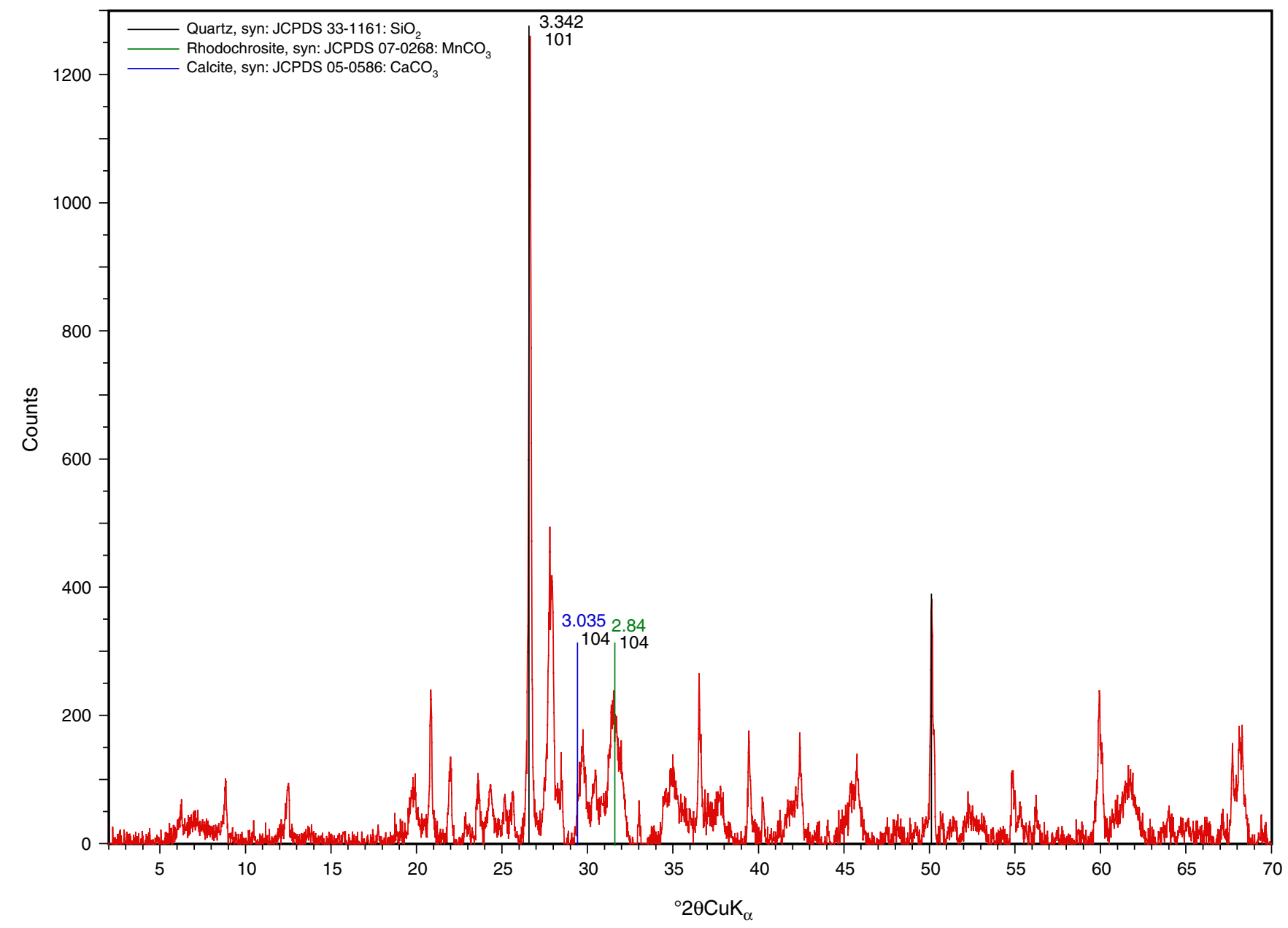


Figure F21. Rock-rich level in a pressure core recovered from lithostratigraphic Unit III (interval 311-U1327C24P-1, 49-71 cm).

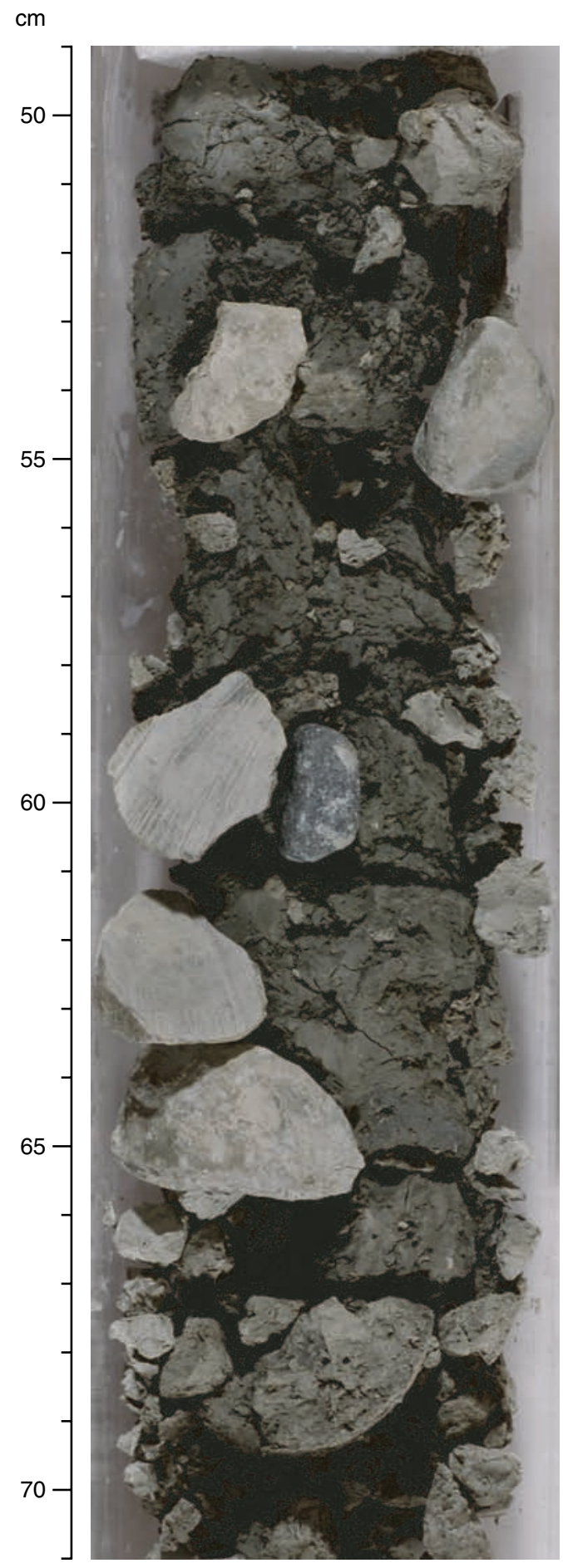


Figure F22. Concentration vs. depth profiles of salinity, chloride, sodium, and potassium in interstitial waters from Holes U1327C, U1327D, and U1327E. For comparison, dissolved chloride data from Sites 889 and 890 are included (data from Westbrook, Carson, Musgrave, et al., 1994). SW = seawater, BSR = seismically inferred bottom-simulating reflector.
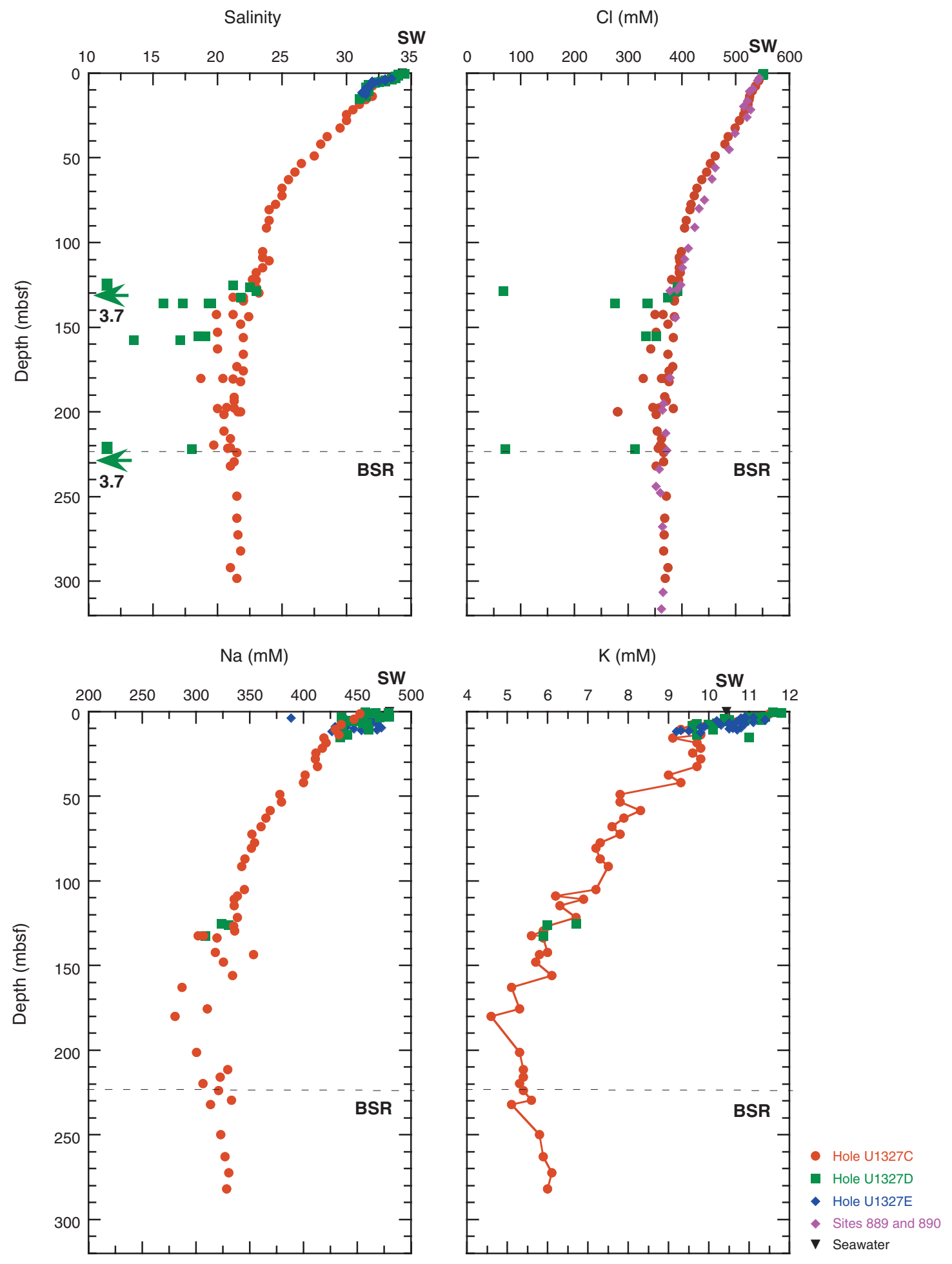
Figure F23. Concentration vs. depth profiles of alkalinity, sulfate, ammonium, and phosphate in interstitial waters from Holes U1327C, U1327D, and U1327E. SW = seawater, BSR = seismically inferred bottom-simulating reflector.
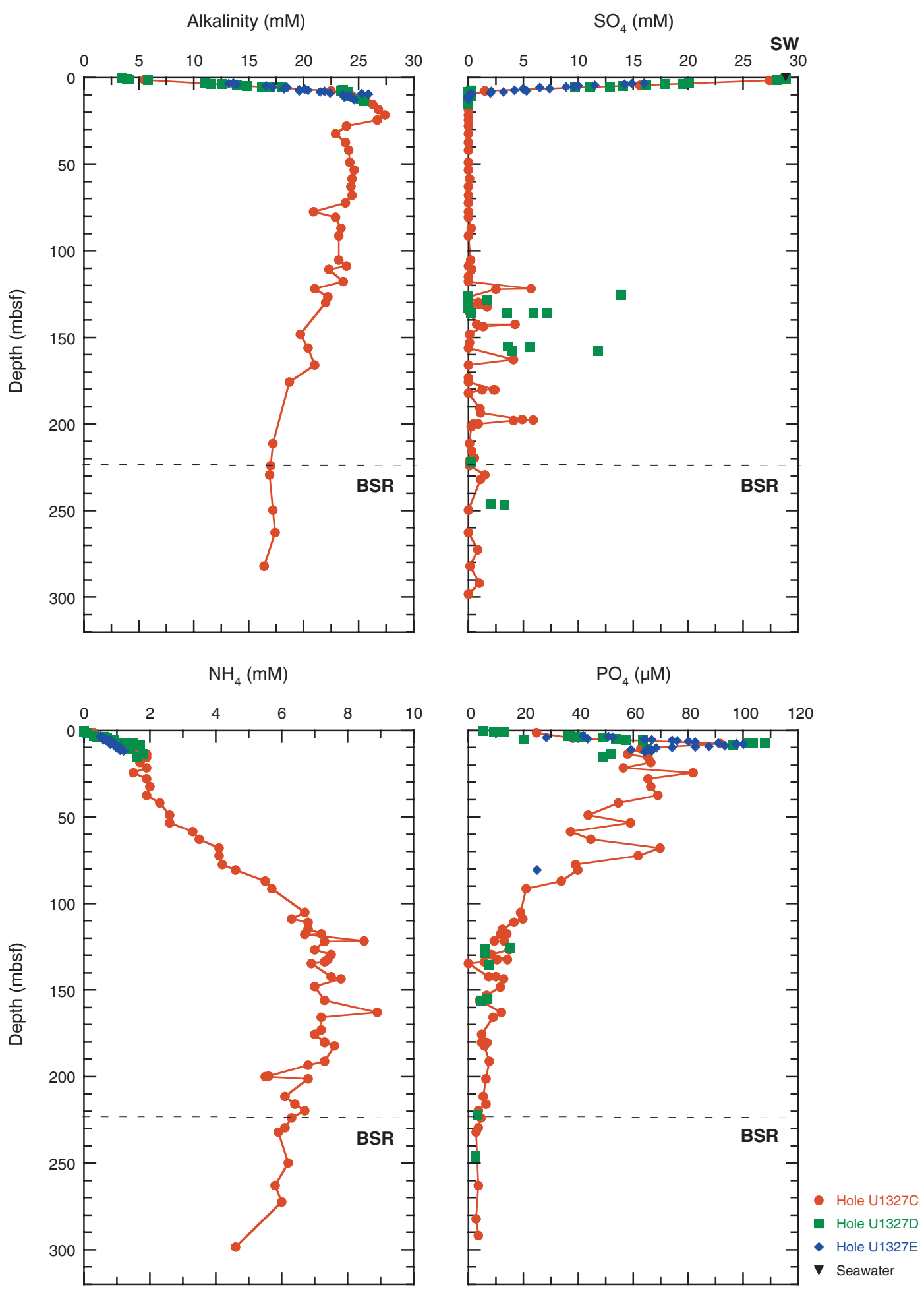
Figure F24. Concentration vs. depth profiles of calcium, magnesium, $\mathrm{Mg} / \mathrm{Ca}$ ratios, and strontium in interstitial waters from Holes U1327C, U1327D, and U1327E. SW = seawater, BSR = seismically inferred bottom-simulating reflector.
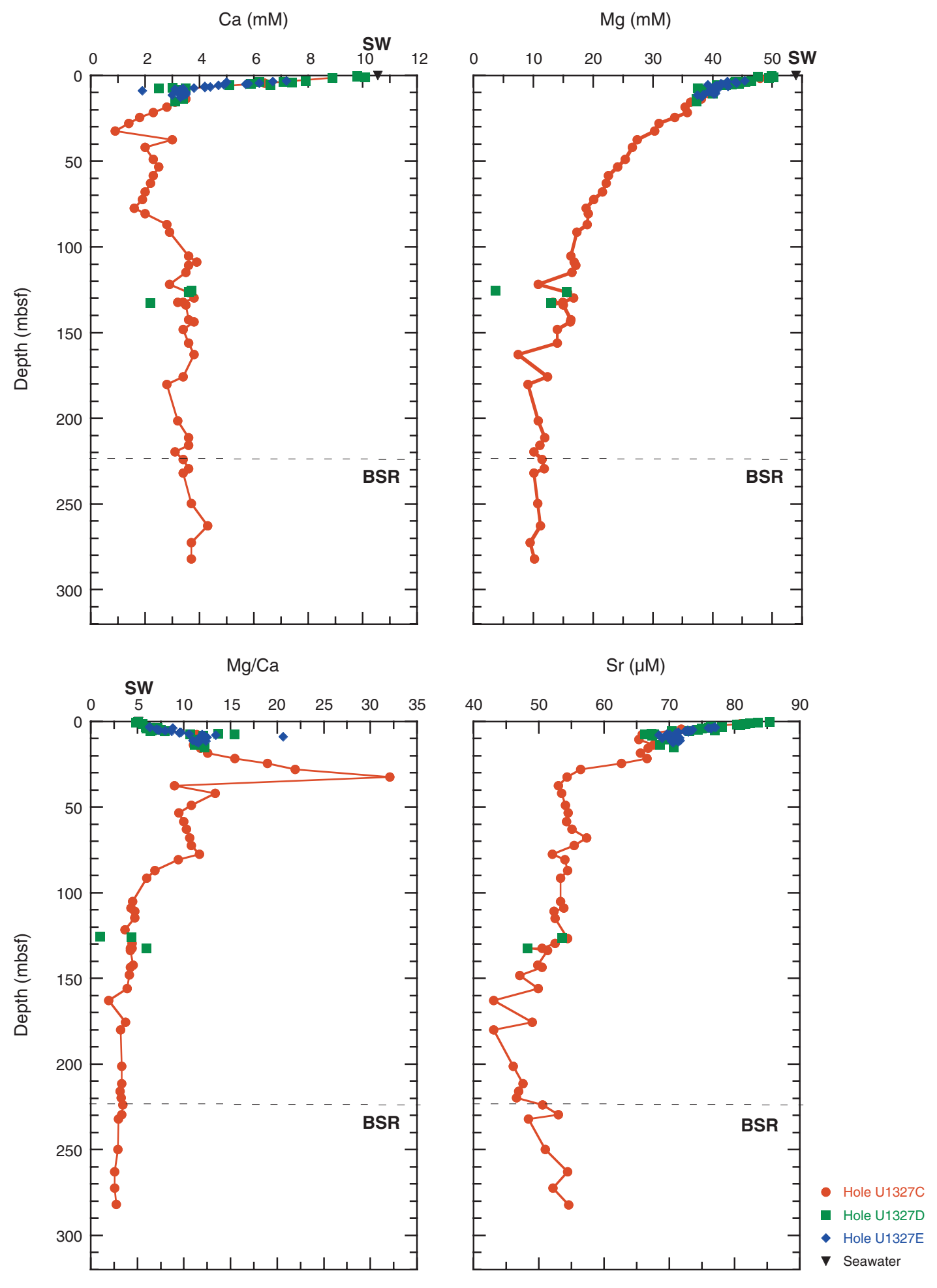
Figure F25. Dissolved sulfate vs. depth profiles from the seafloor to $14 \mathrm{mbsf}$ for Cores 311-U1327D-1H (solid green squares), $2 \mathrm{H}$ (open green squares), and 311-U1327E-1H (blue diamonds). The apparent depth offsets of $\sim 1 \mathrm{~m}$ between Cores 311-U1327D-1H and 311-U1327E-1H, and $\sim 3 \mathrm{~m}$ between Cores 311-U1327D-1H and 2H are discussed in the text. The combined data from Holes U1327D and U1327E place the depth of the sulfate/ methane interface between 9 and 10 mbsf.

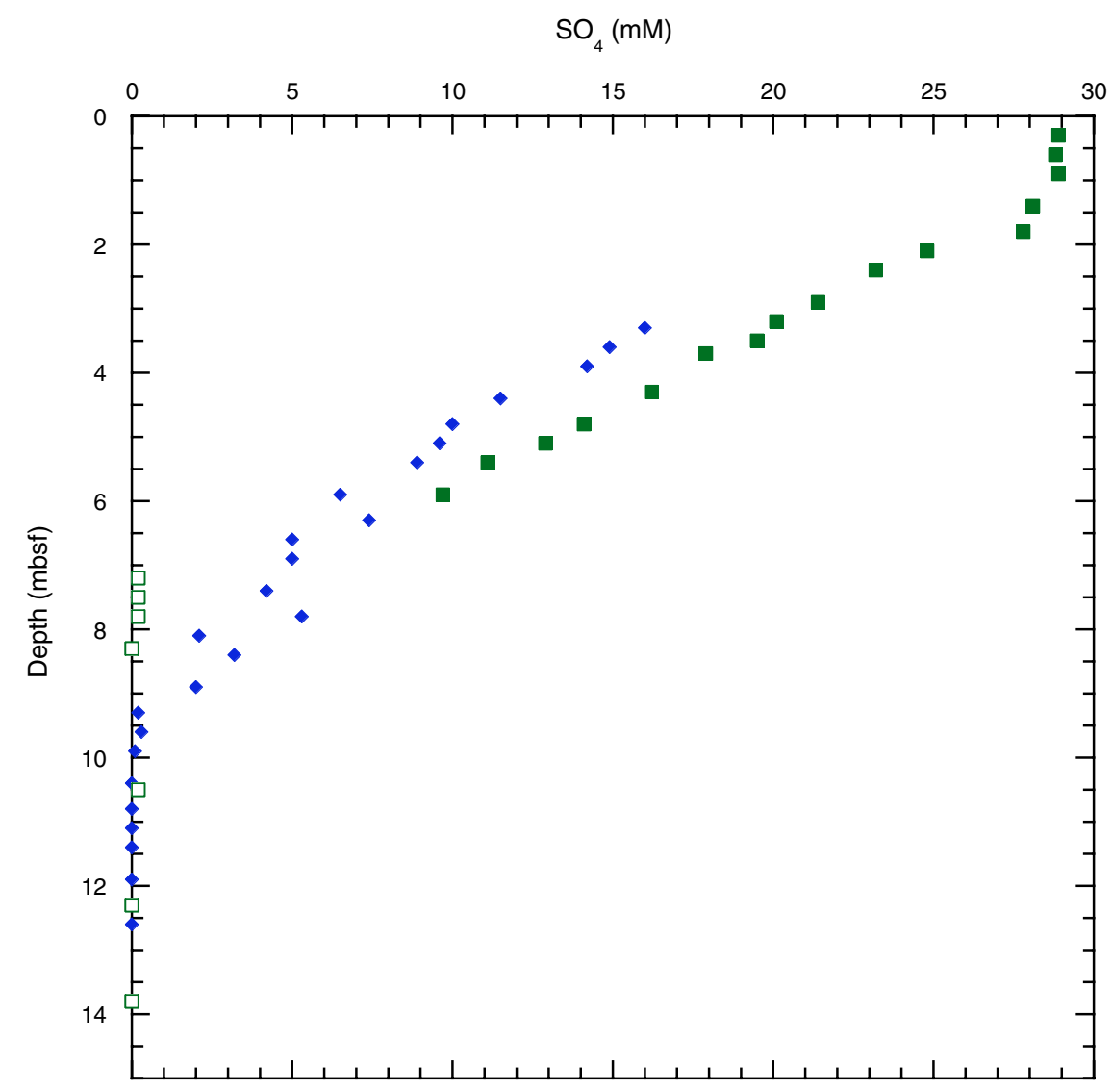


Figure F26. Concentration vs. depth profiles of silica, lithium, and boron in interstitial waters from Hole U1327C. BSR = seismically inferred bottom-simulating reflector.

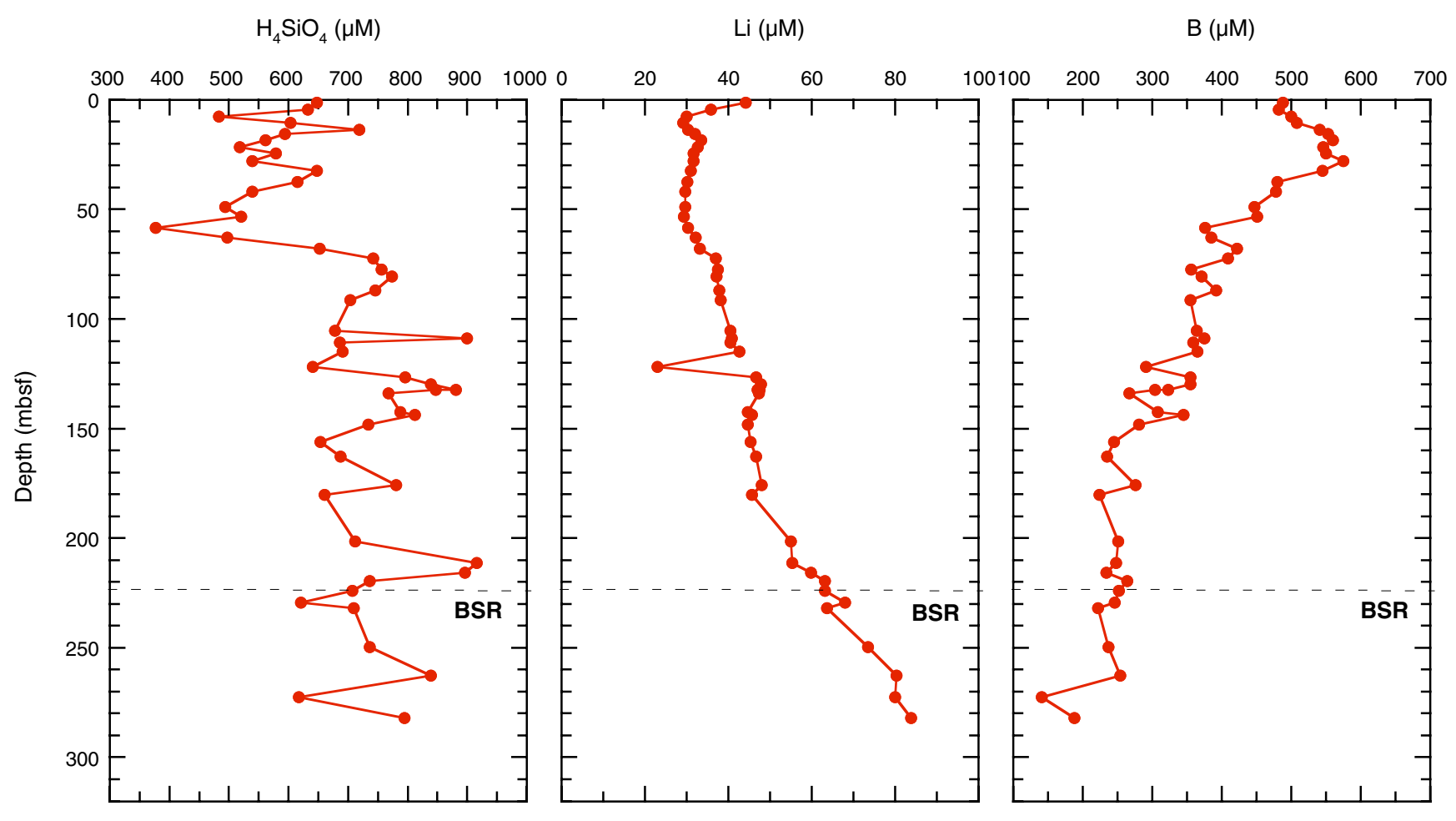


Figure F27. Concentrations of methane and ethane in headspace gas samples from Site U1327. BSR = bottomsimulating reflector.

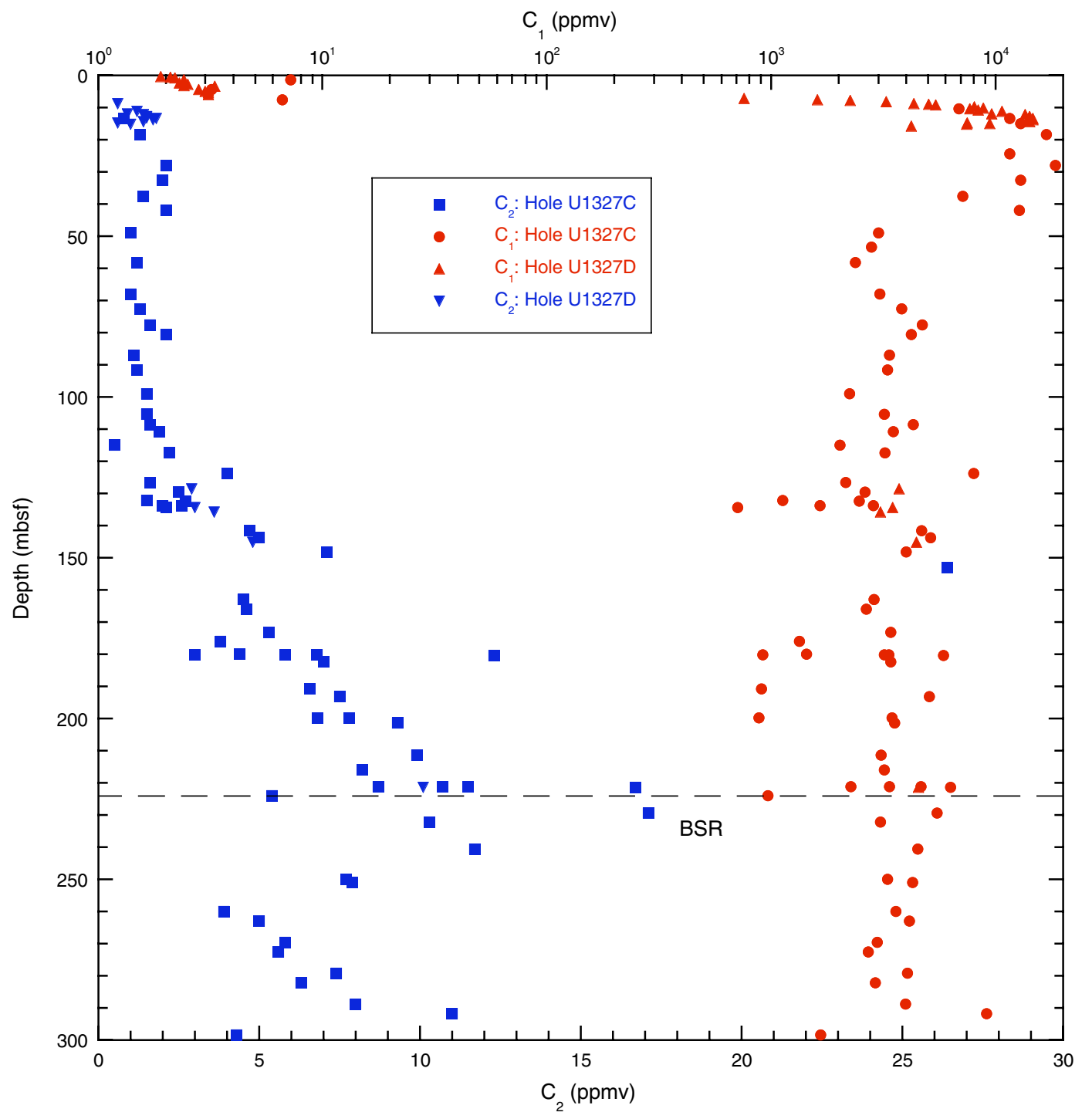


Figure F28. Concentrations of ethane, propane, $i$-butane, and $n$-butane in void gas samples from Site U1327. $\mathrm{BSR}=$ bottom-simulating reflector.

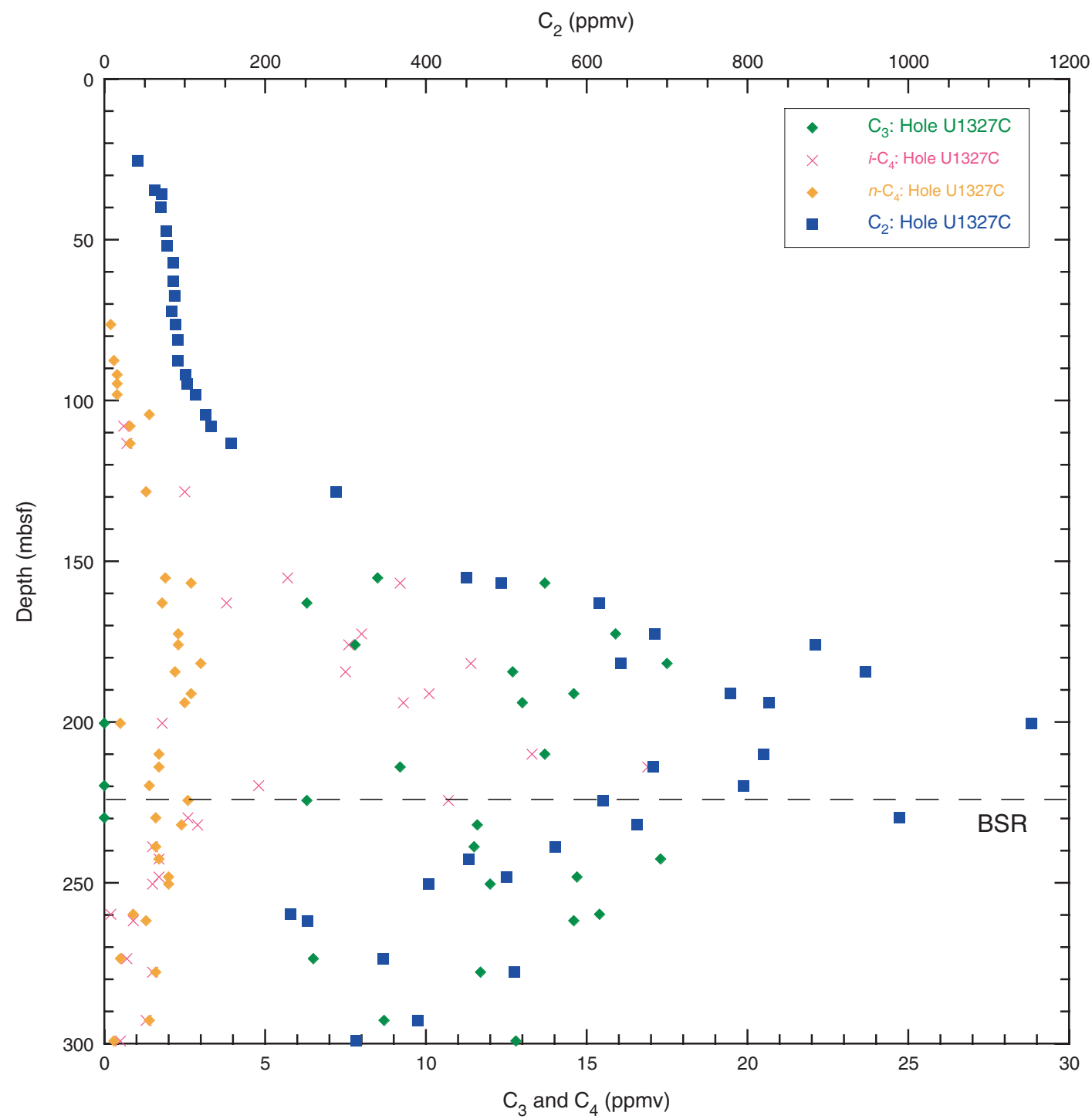


Figure F29. $C_{1} / C_{2}$ ratios in headspace gas (HS), void gas (VAC), and pressure core sampler (PCS) gas samples from Site U1327. BSR = bottom-simulating reflector.

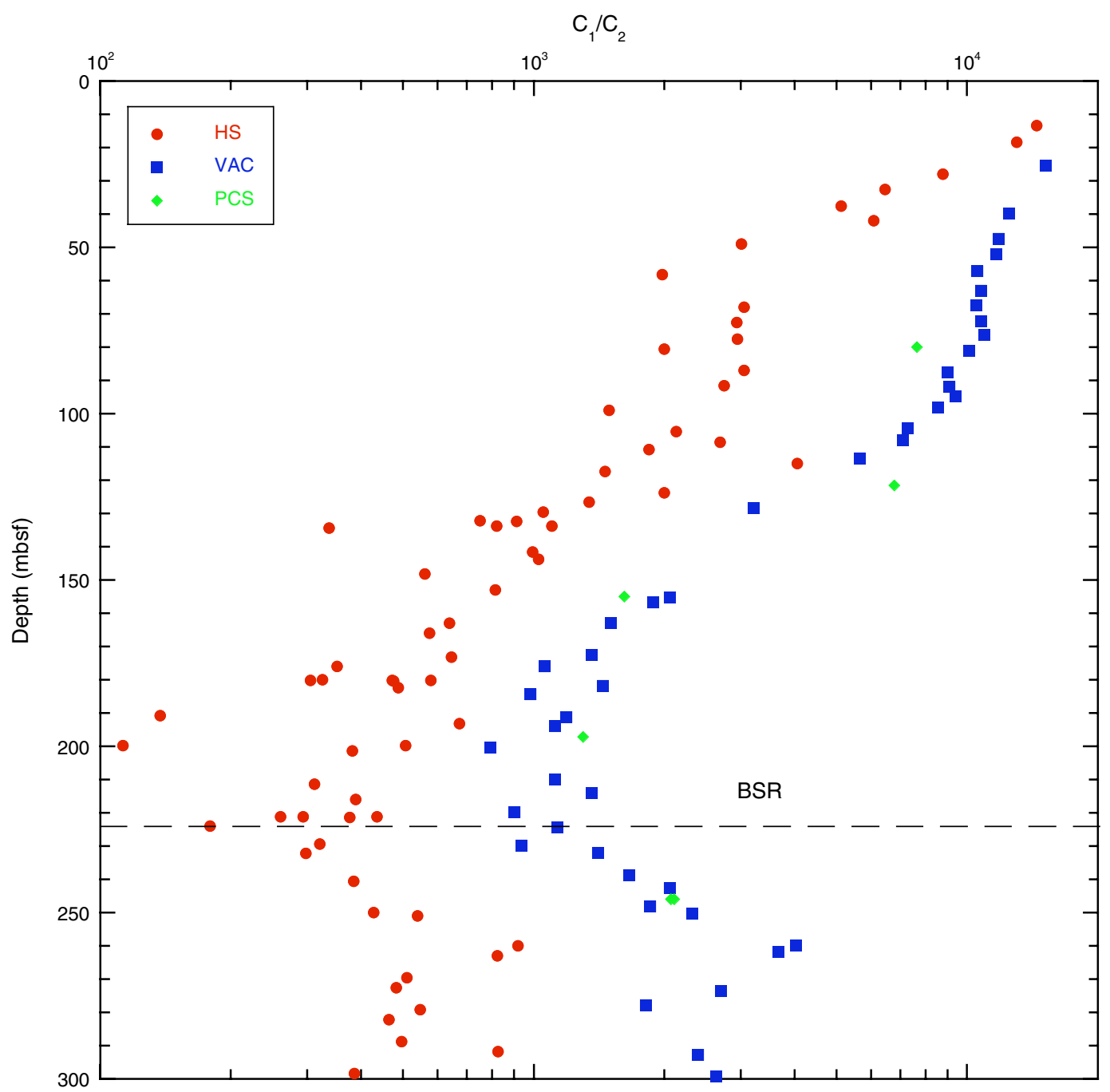


Figure F30. $\mathrm{C}_{1} / \mathrm{C}_{2}$ and $i-\mathrm{C}_{4} / n-\mathrm{C}_{4}$ ratios in void gas (VAC) and pressure core sampler (PCS) gas samples from Site $\mathrm{U} 1327$. BSR = bottom-simulating reflector.

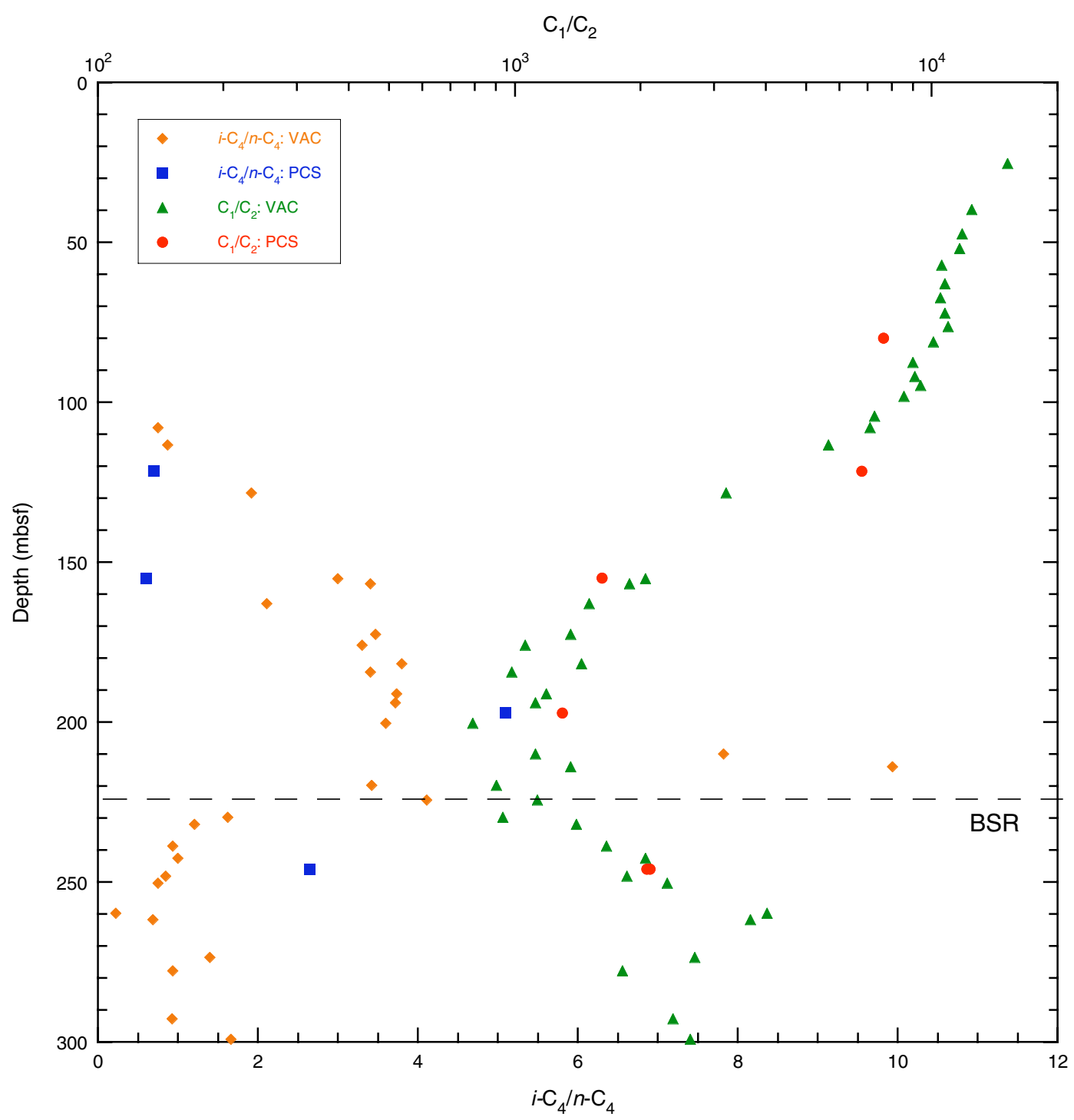


Figure F31. $\mathrm{C}_{1} / \mathrm{C}_{2}$ ratio vs. temperature in headspace gas (HS) and void gas (VAC) samples from Site U1327.

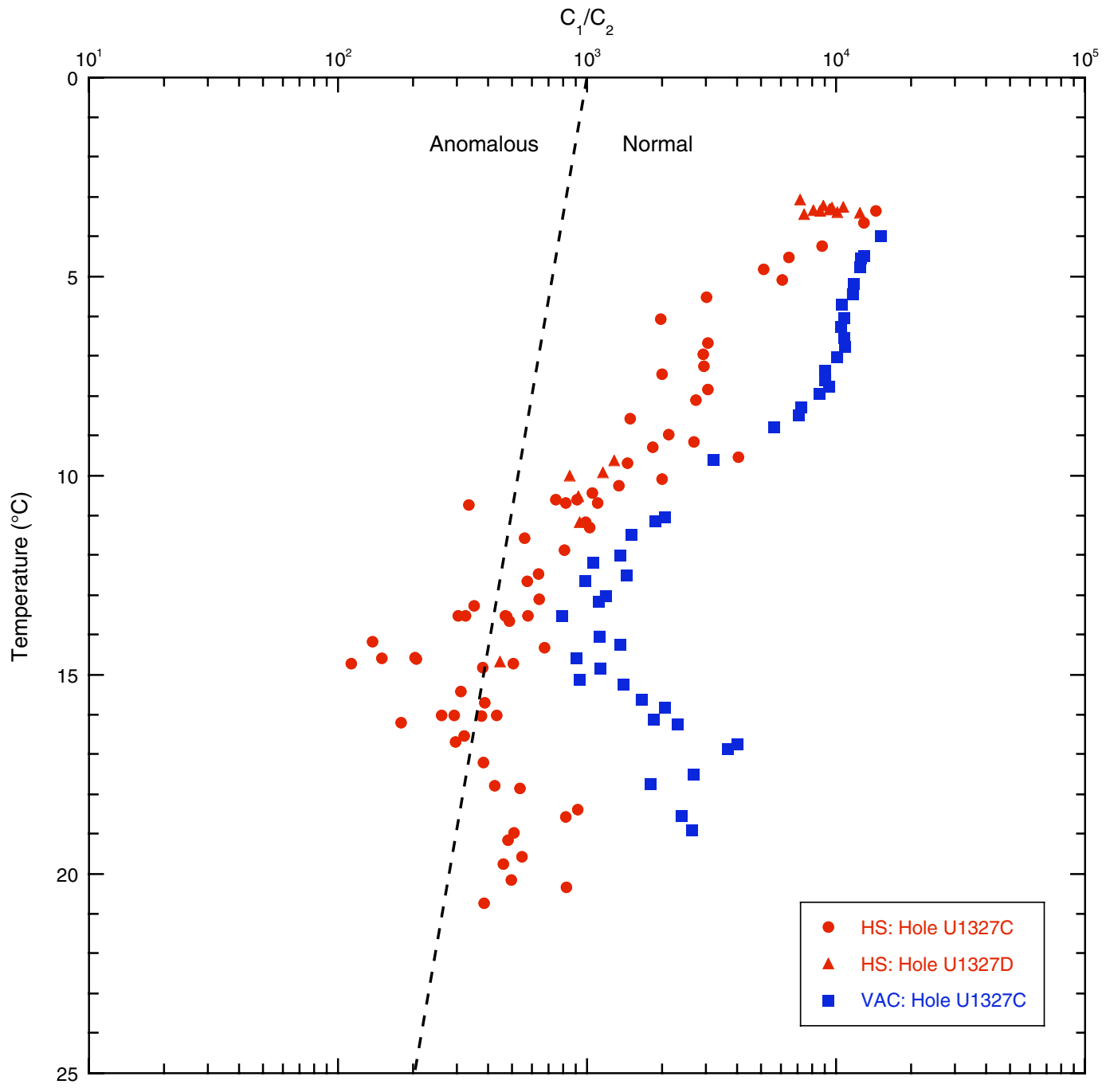


Figure F32. Dissolved sulfate and methane concentrations from Site U1327. SMI = sulfate/methane interface.

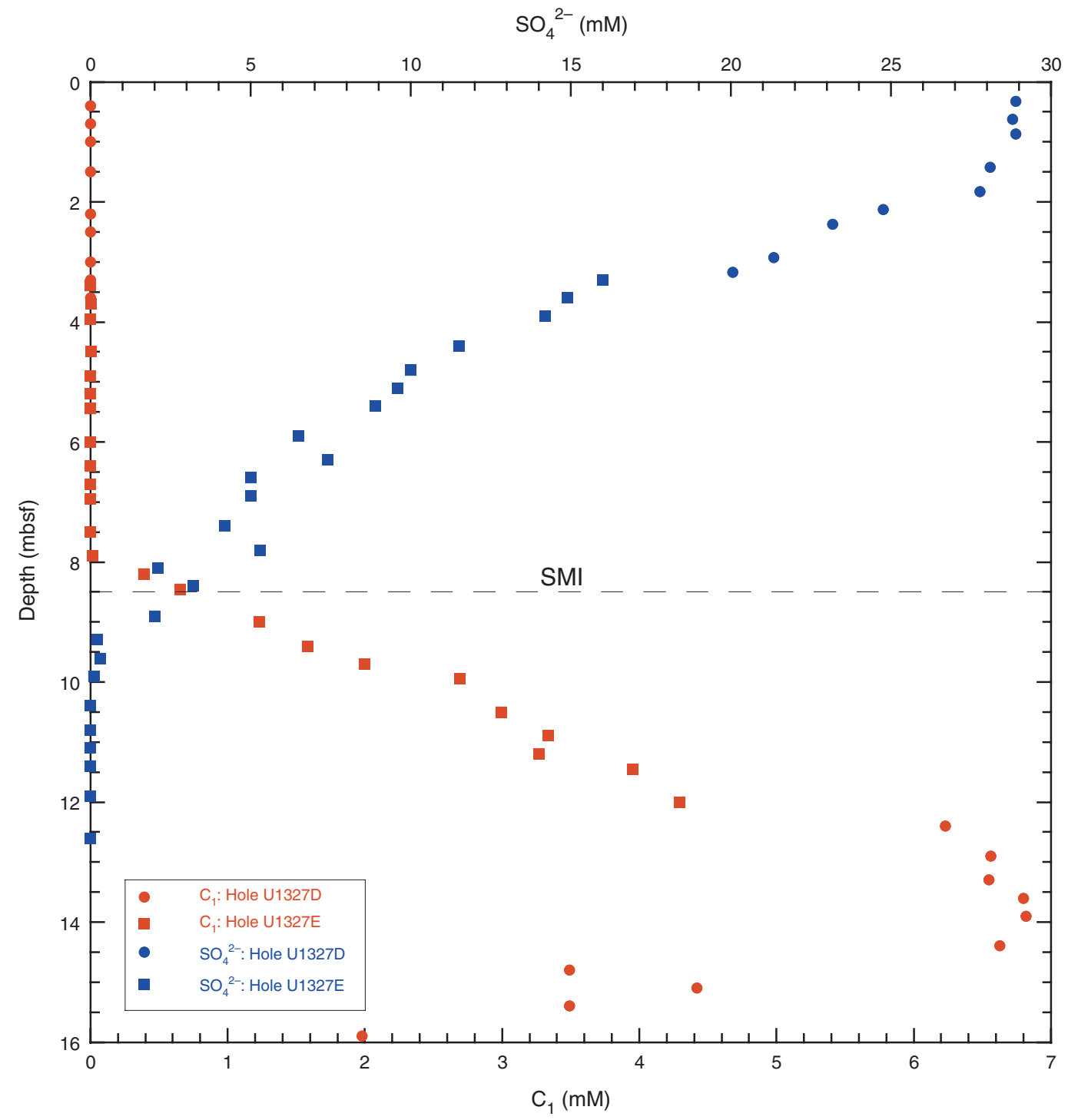


Figure F33. Concentrations of inorganic carbon (IC), calcium carbonate $\left(\mathrm{CaCO}_{3}\right)$, total organic carbon (TOC), and total nitrogen $(\mathrm{TN})$ and $\mathrm{C} / \mathrm{N}$ ratios in sediments from Site U1327. Data are plotted on different depth scales to highlight the overall site (0-300 mbsf) and near-surface (0-13 mbsf) trends.
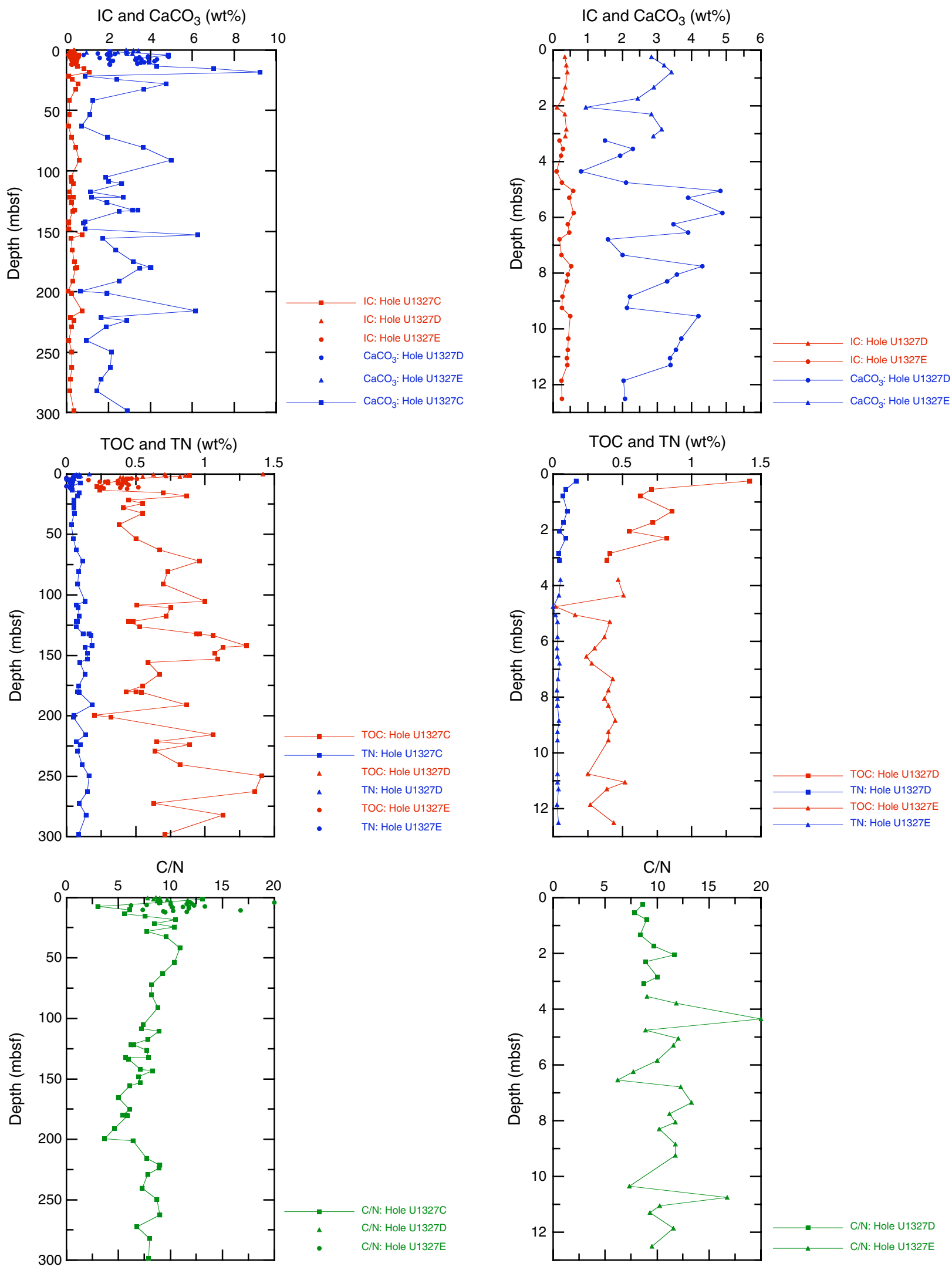
Figure F34. Overview of physical property data from Site U1327. Plotted from left to right are core recovery; logging-while-drilling (LWD) and moisture and density (MAD) porosity; LWD, multisensor track (MST), and MAD bulk density; MAD grain density; LWD and MST contact and noncontact resistivity; MST magnetic susceptibility; thermal conductivity (line shows regional trend from Davis et al., 1990); Torvane and automated vane shear strength; and lithostratigraphic units. APC = advanced piston corer, $\mathrm{XCB}=$ extended core barrel, BSR = bottom-simulating reflector.

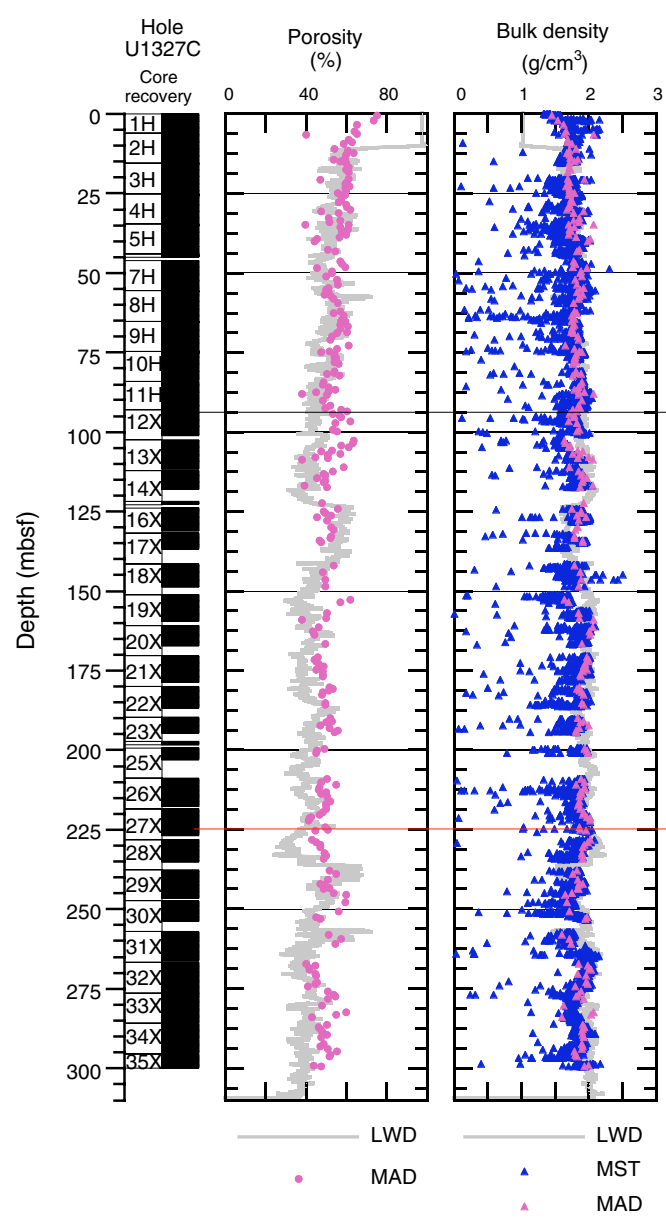

Grain density

$\left(\mathrm{g} / \mathrm{cm}^{3}\right)$

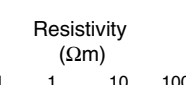

Magnetic susceptibility Thermal conductivity

$\left(x 10^{-7} \mathrm{SI}\right)$

$(\mathrm{W} /[\mathrm{m} \cdot \mathrm{K}])$

Shear strength
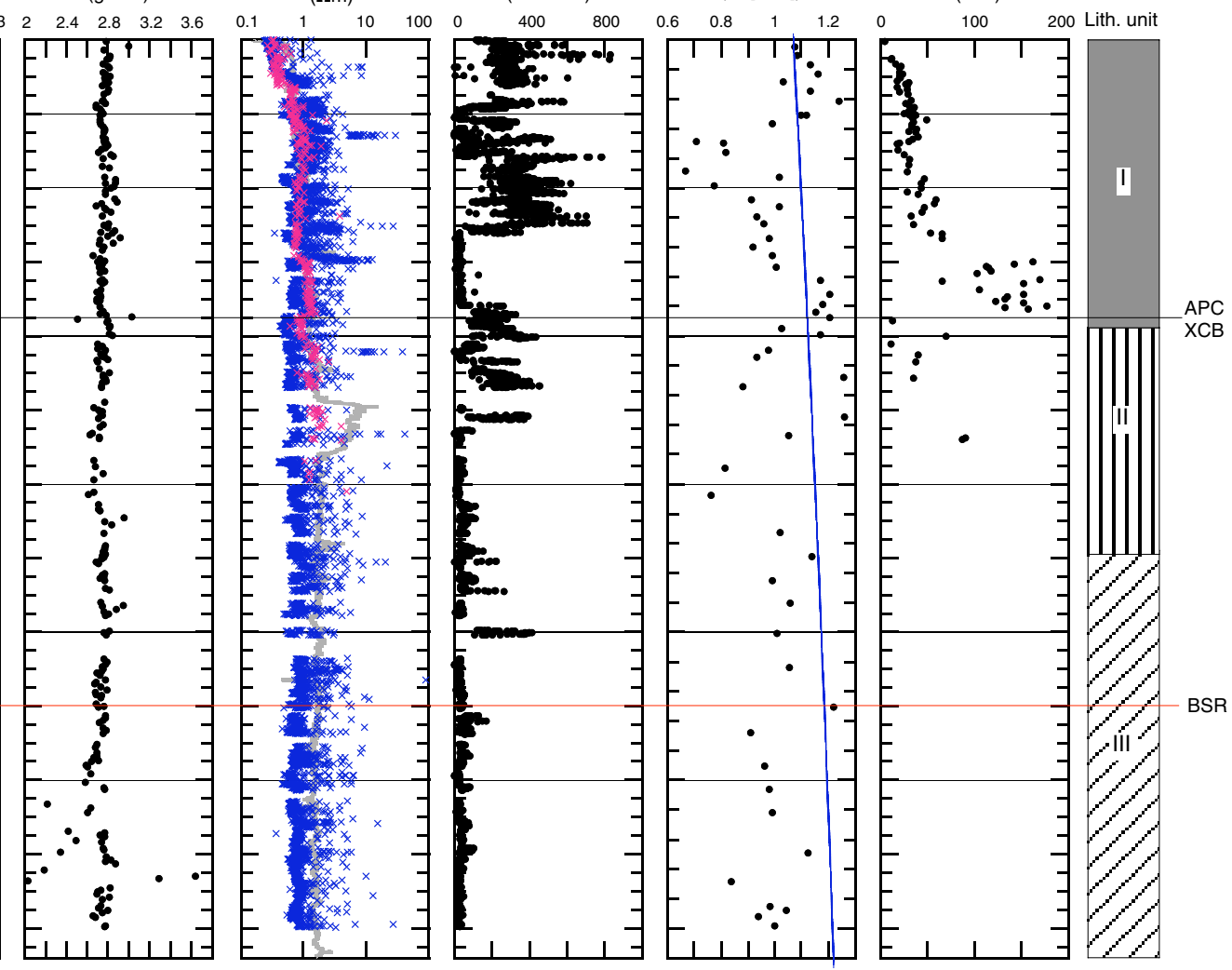

MAD

LWD

MST
noncontac

Contact 
Figure F35. Combined infrared (IR) images of core liner temperature from Holes U1327C and U1327D, compared to logging-while-drilling/measurement-while-drilling (LWD/MWD) resistivity and calculated pore water saturation from Hole U1327A. Core recovery and core handling time are also shown. (This figure is available in an oversized format.)

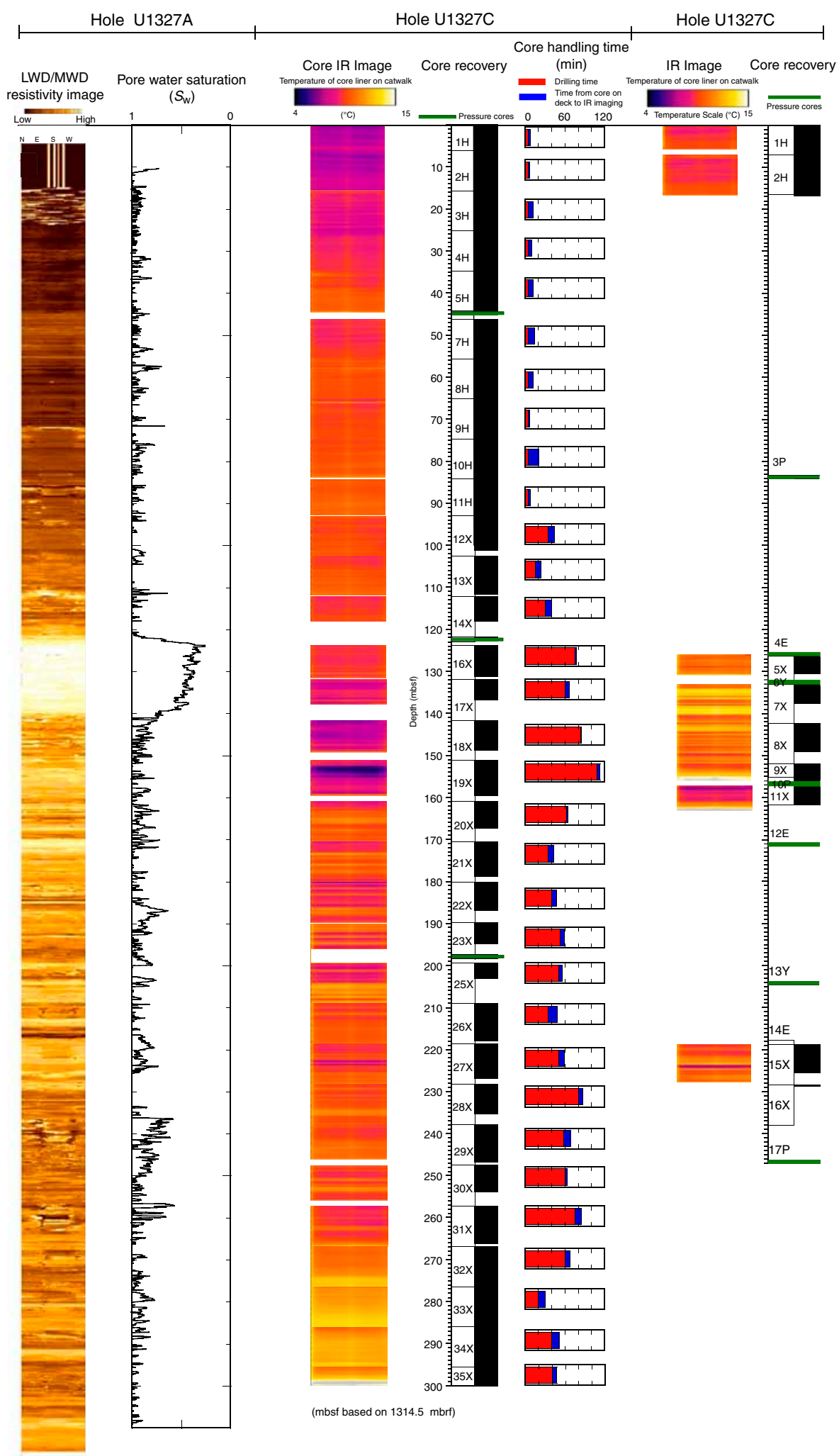


Figure F36. A. Downhole temperature in Hole U1237C based on concatenation of core liner temperatures averaged across each pixel row (see text for details). B. Downhole temperature in Hole U1327D. C. Detail of the temperature profile for 220-230 mbsf. Note the numerous, strong cold temperature anomalies.

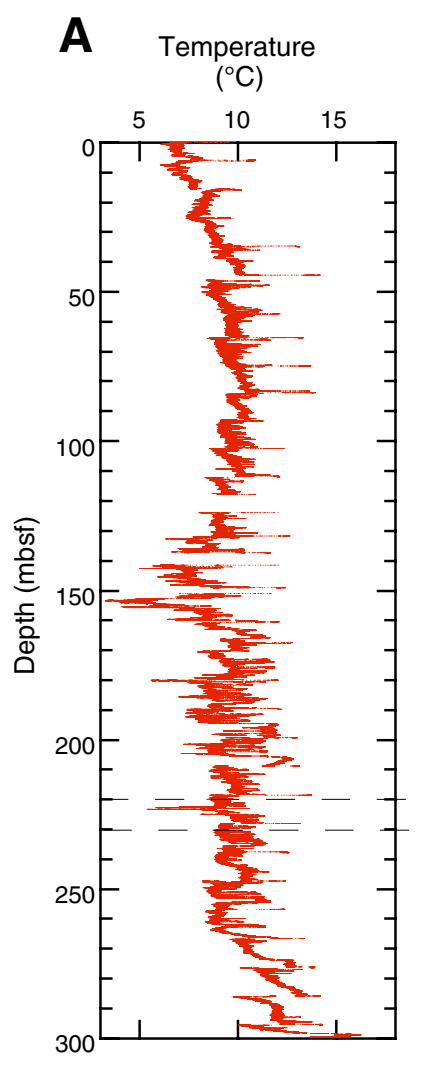

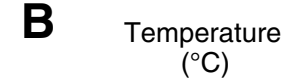

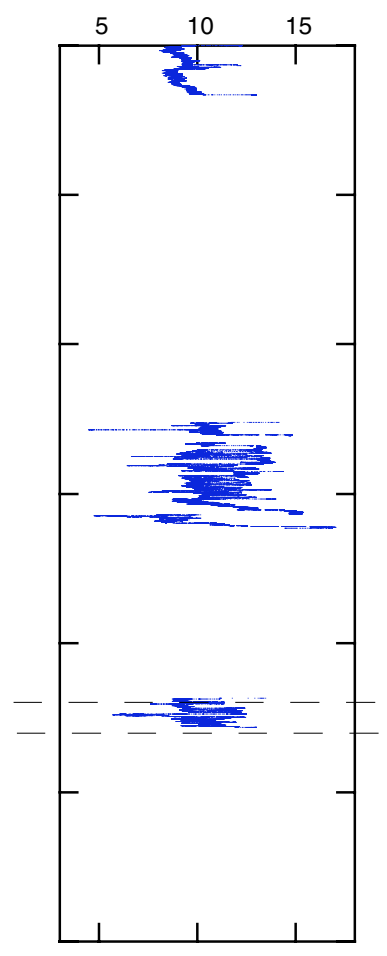

C Temperature

$\left({ }^{\circ} \mathrm{C}\right)$

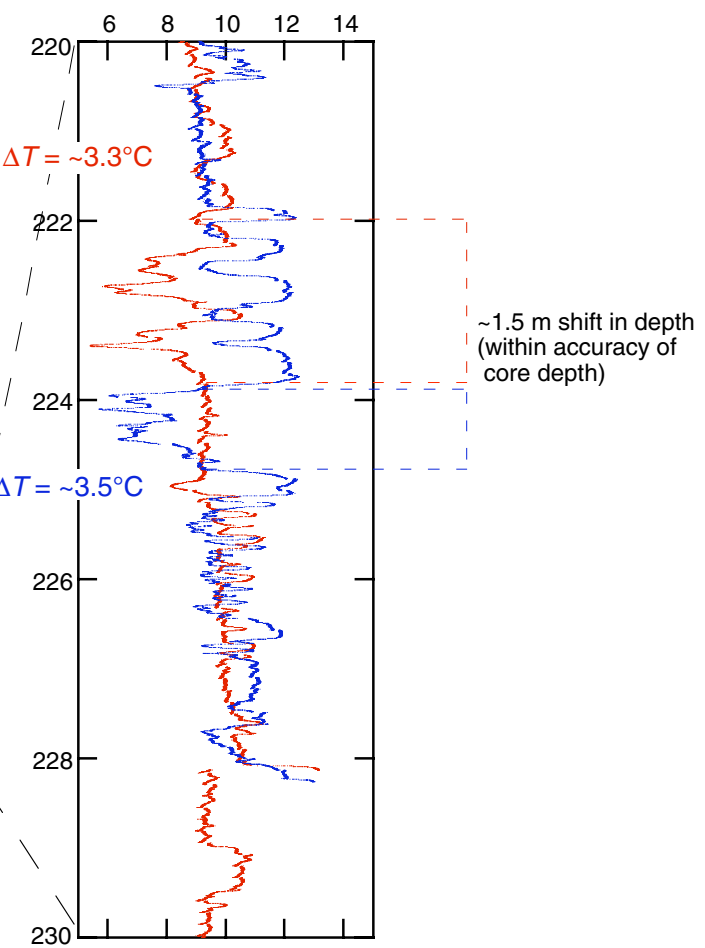


Figure F37. IR images of section ends from Core 311-U1327D-2H, with associated cross-core temperature profiles. The ambient temperature is $13.5^{\circ} \mathrm{C}$.

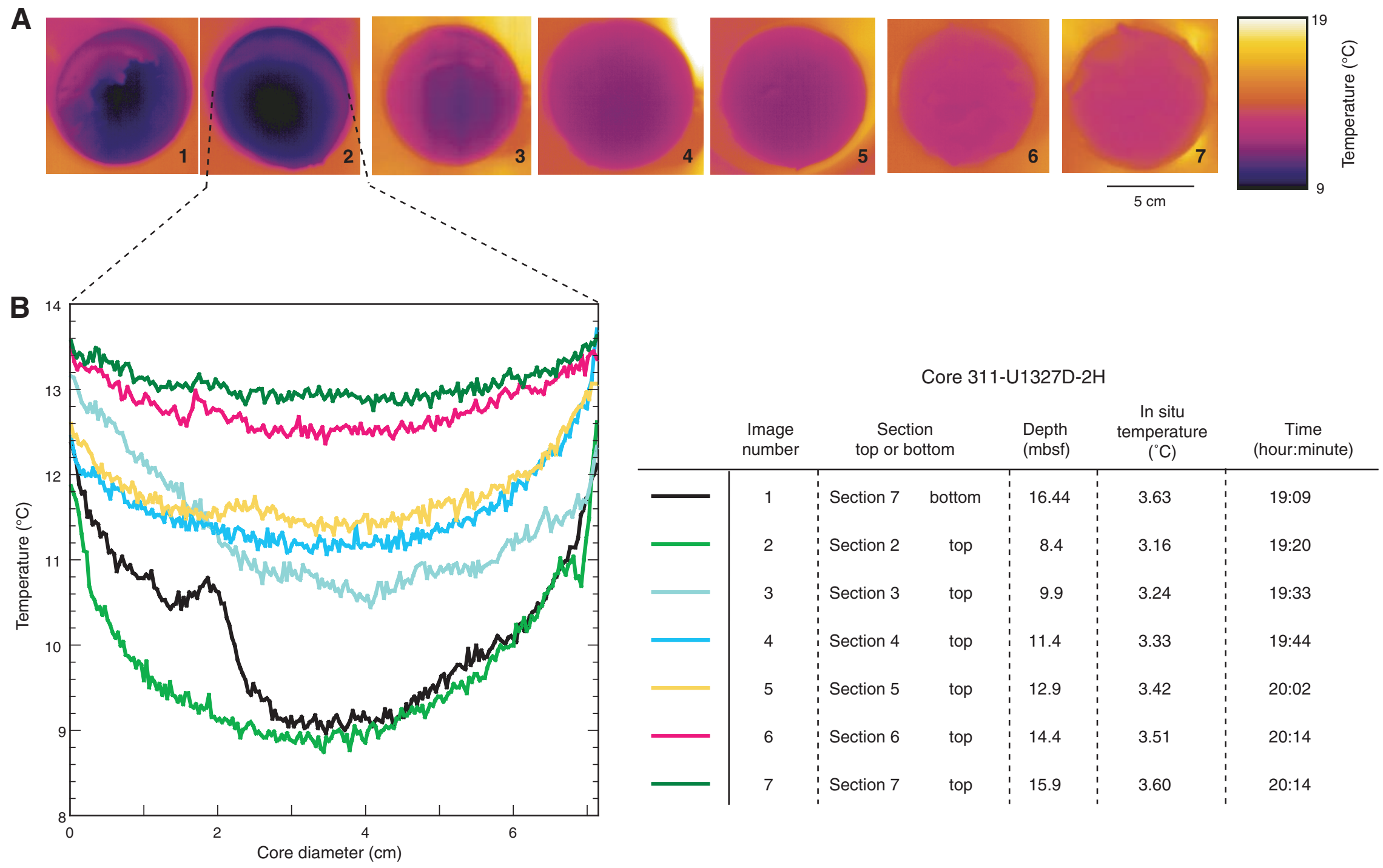


Figure F38. Downhole plot of selected physical properties (porosity, bulk density, resistivity, and magnetic susceptibility) from 100 to $170 \mathrm{mbsf}$, Hole U1327C. LWD = logging while drilling, MAD = moisture and density, MST = multisensor track.
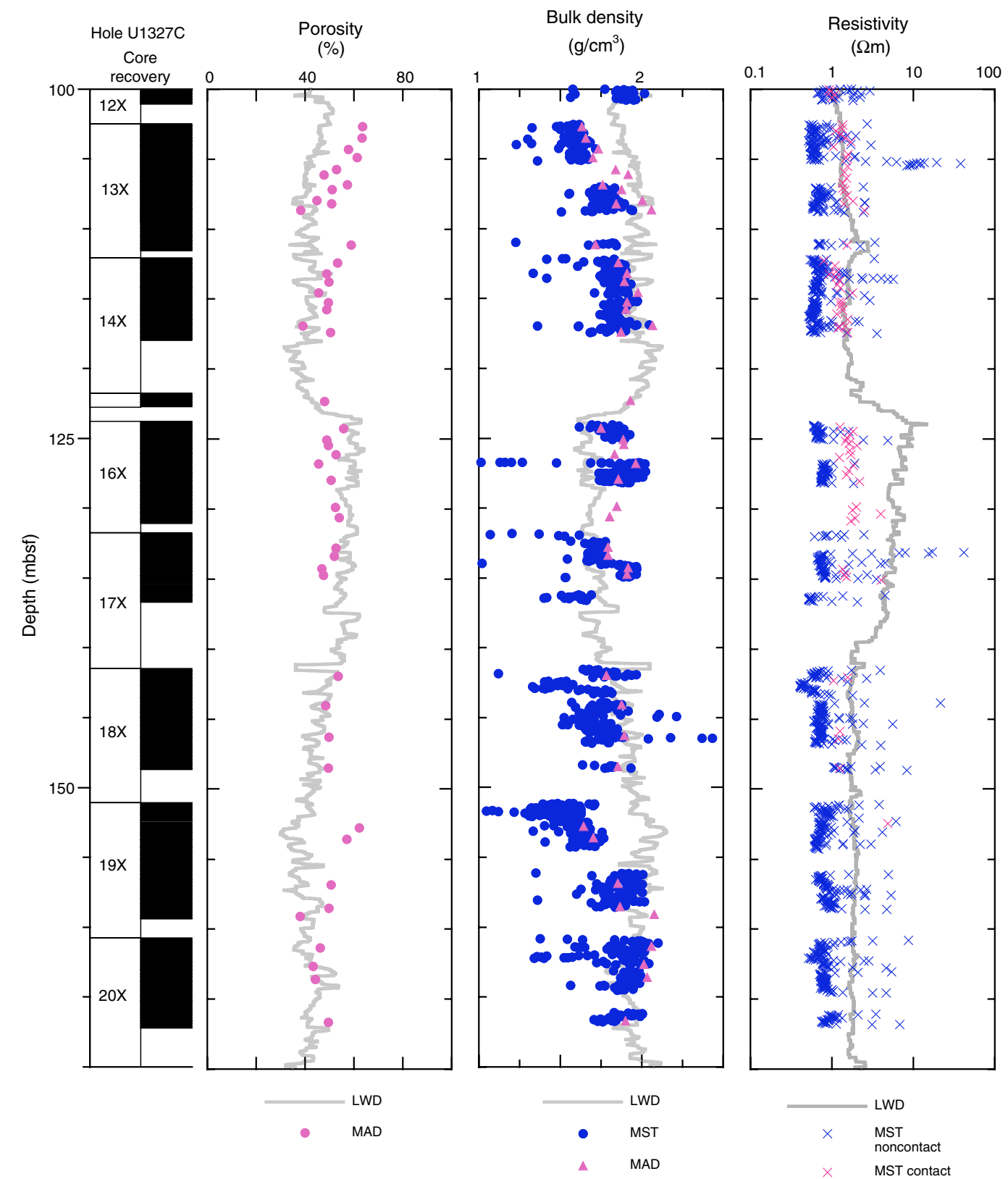
Magnetic susceptibility $\left(\mathrm{x} 10^{-7} \mathrm{SI}\right)$

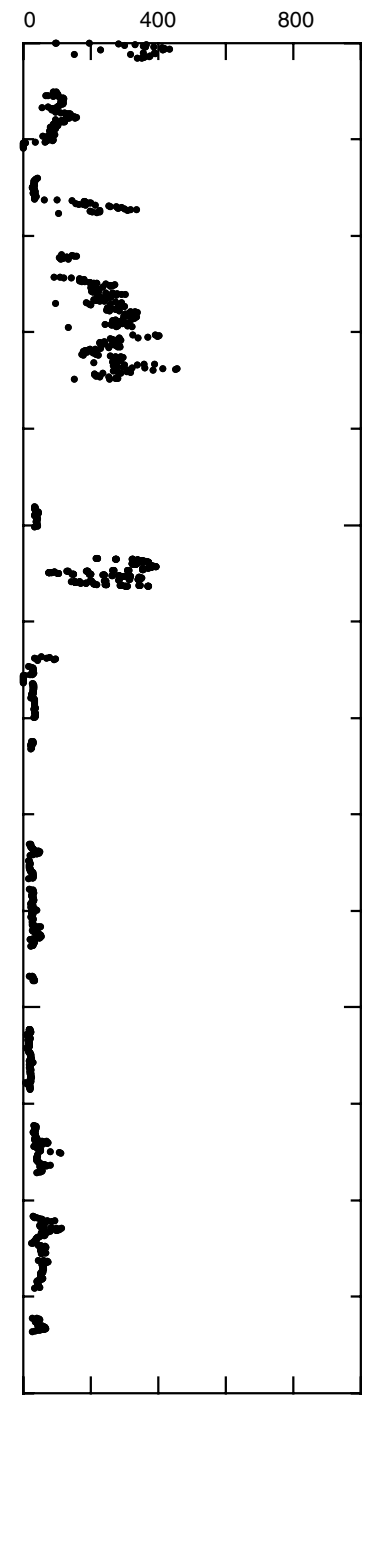


Figure F39. A. Magnetic susceptibility, Holes U1327B and U1327C. Correlation of the data indicates a shift of $3 \mathrm{~m}$ between Holes U1327B and U1327C. This shift in the seafloor baseline has not been applied to the Expedition 311 data in the Janus database. It should be taken into account, however, for detailed data comparisons between these holes. (Continued on next page.)

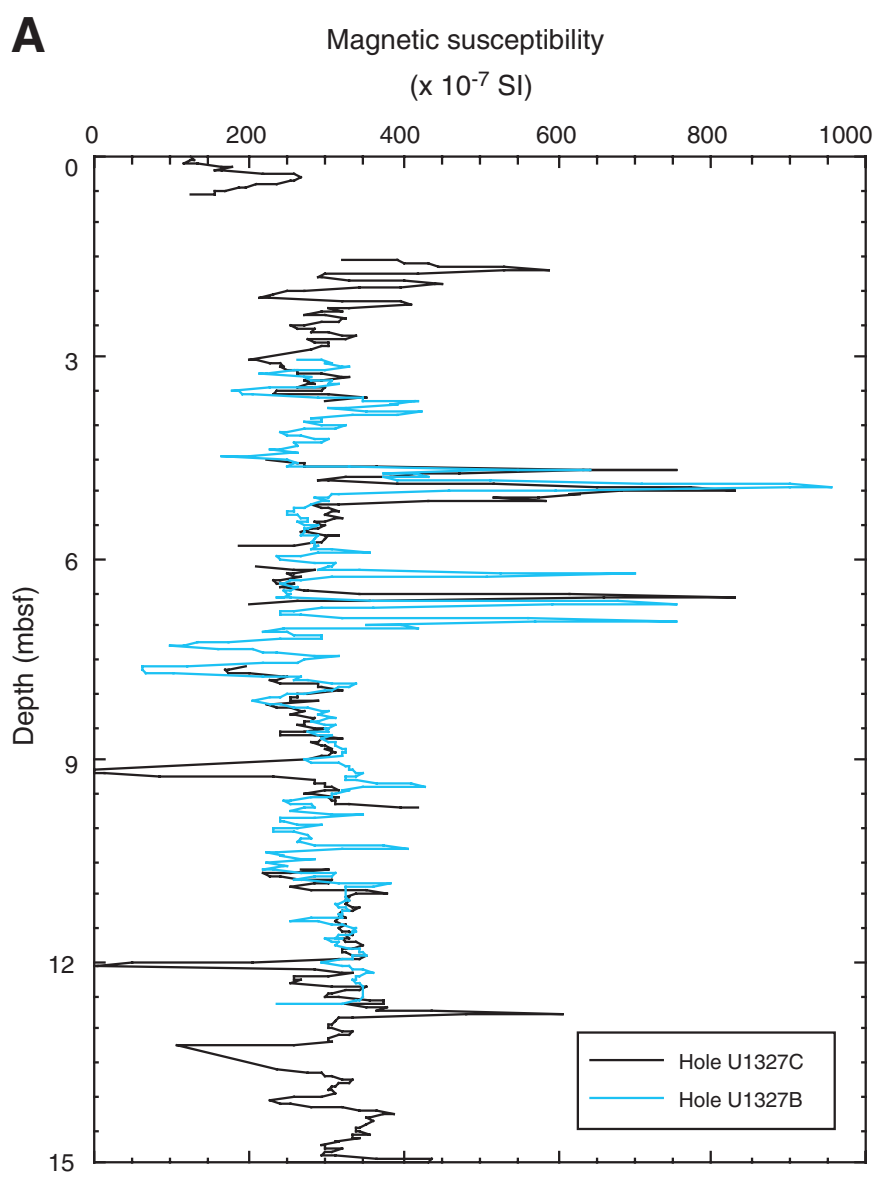


Figure F39 (continued). B. Comparison of the magnetic susceptibility between 120 and 170 mbsf in Holes U1327C and U1327D. Note the large differences between data at the same depth. The core images show that a probable cause for these differences are large, presumably highly magnetic dropstones that are present in Hole U1327D but absent from Hole U1327C.

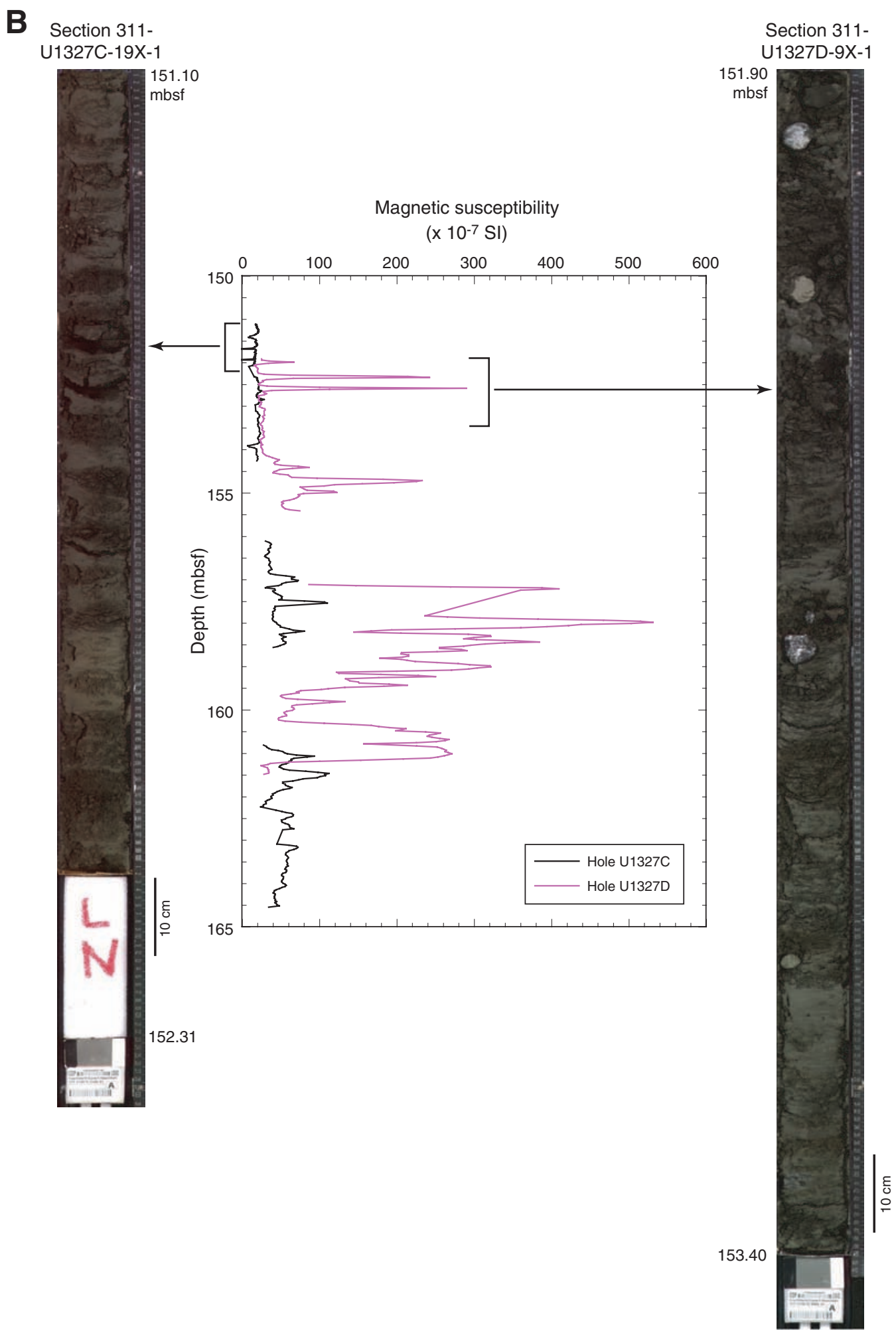


Figure F40. A. $P$-wave velocity measurements made using the multisensor track (MST) and Hamilton frame at Holes U1327B and U1327C. Only MST and $P$-wave sensor (PWS) 3 data were used to determine the best-fit line representing velocity as a function of depth beneath the seafloor. B. Comparison of MST velocity and density from Hole U1327B and U1327C. Compared values are within $2 \mathrm{~cm}$ of each other. C. Comparison of Hamilton frame velocity and MST density. Compared values are within $2 \mathrm{~cm}$ of each other.
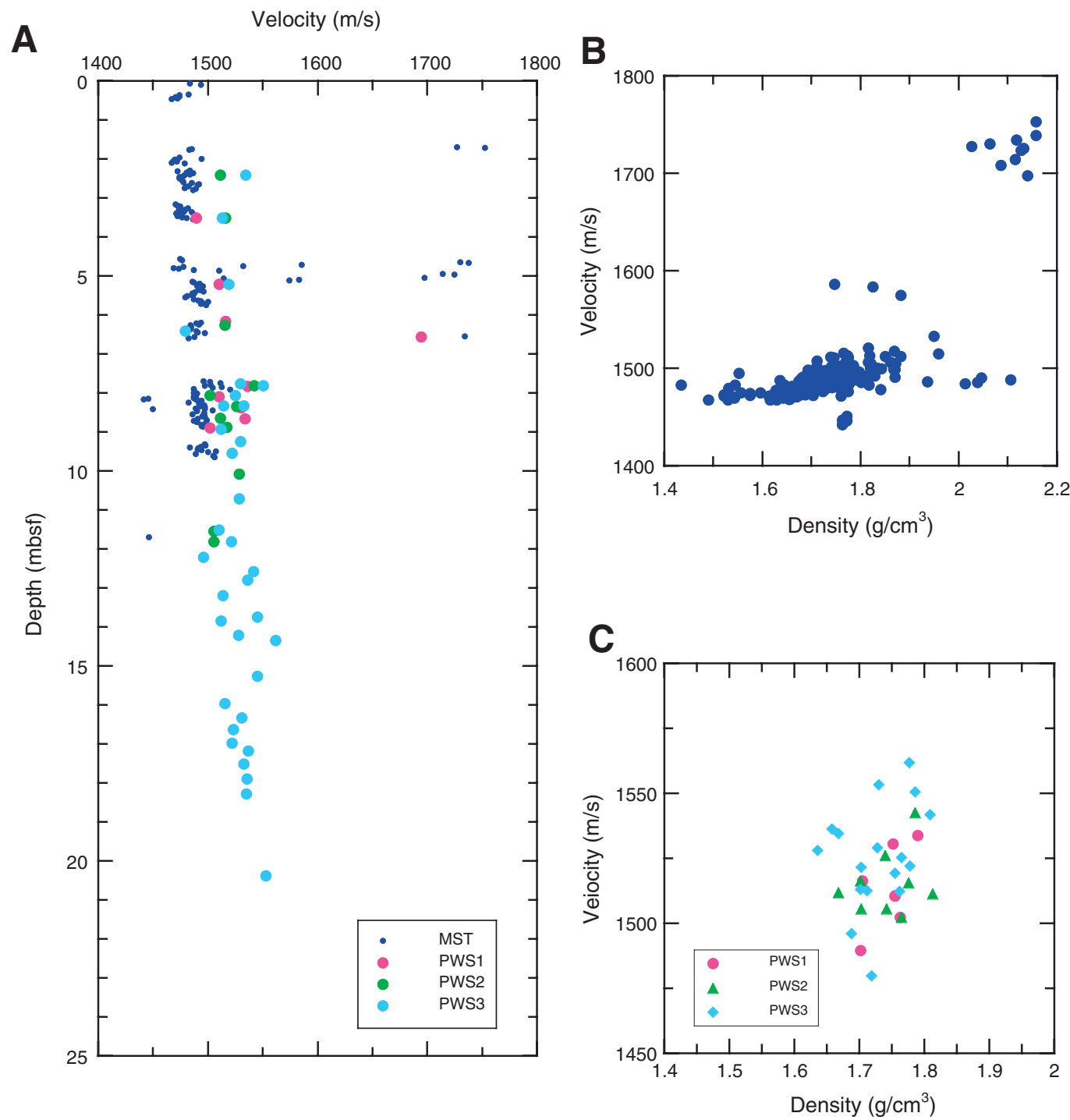
Figure F41. A. Automated vane shear (AVS) and handheld Torvane shear strength measurements from Hole U1327C. XCB = extended core barrel. B. Ratio of shear strength to overburden pressure. This provides information on the degree of sediment underconsolidation or overconsolidation. C. Overburden pressure calculated from MAD bulk density data.

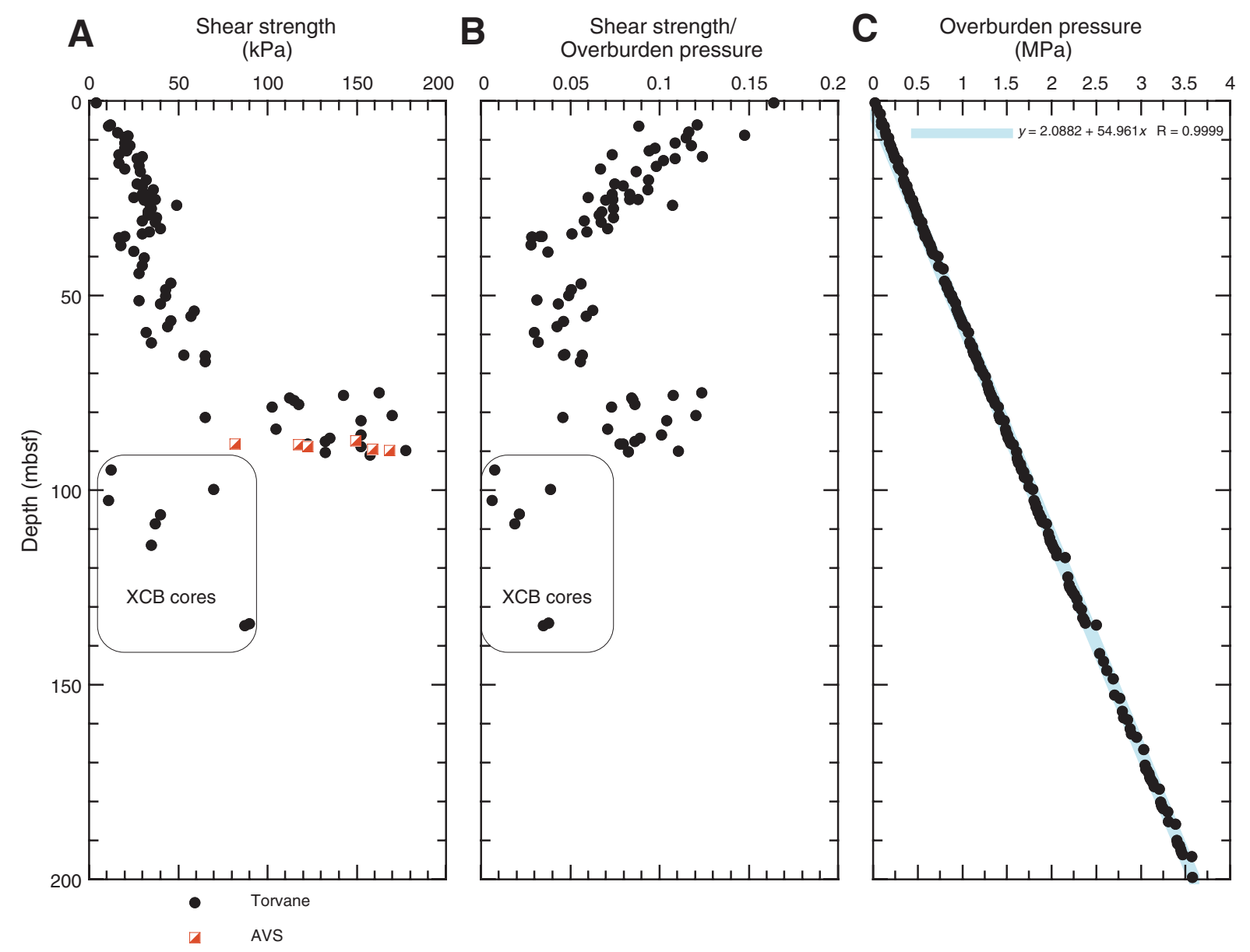


Figure F42. A. Comparison of pore water resistivity, calculated from interstitial water salinity using equations developed by Fofonoff (1985), and bulk volume contact resistivity of sediments from Site U1327. Both sets of values have been corrected to $20^{\circ} \mathrm{C}$. B. Formation factor (ratio of pore water resistivity to sediment resistivity). C. Comparison of porosity derived from moisture and density (MAD) measurements and Archie's equation (Archie's parameters: $m=2.33$ and $a=0.877$ ). (Continued on next page.)

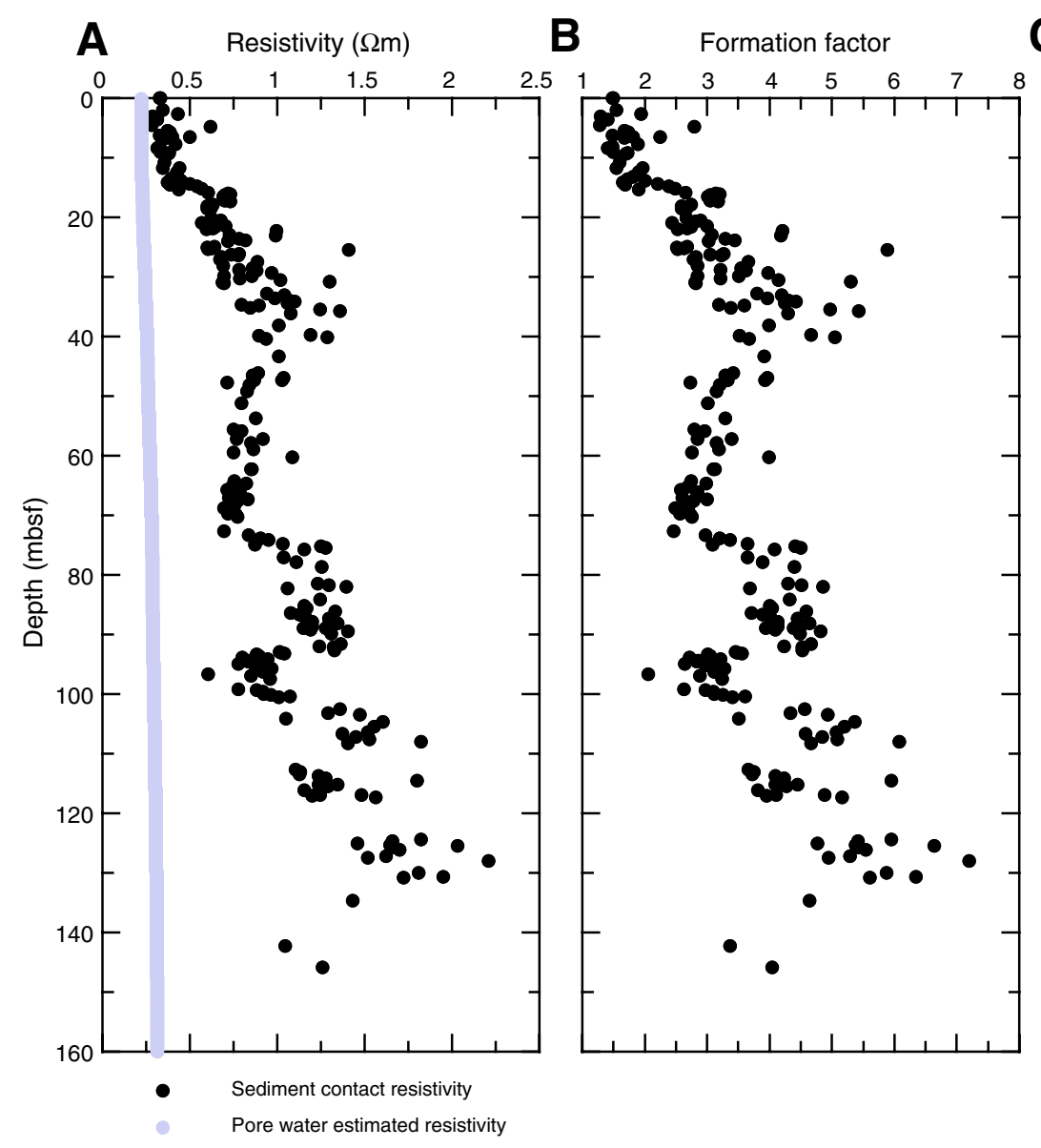

C Porosity

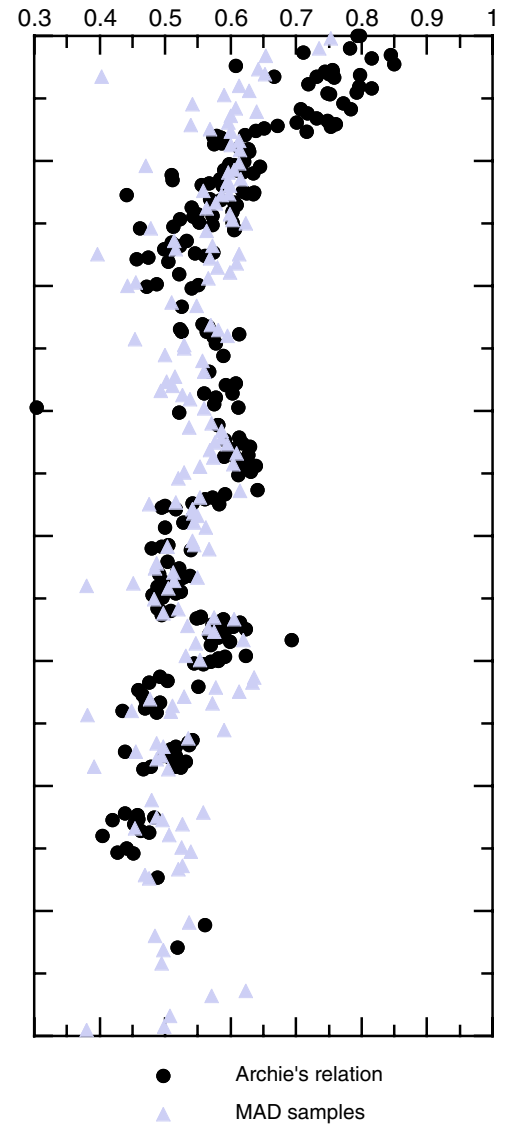


Figure F42 (continued). D. Formation factor vs. MAD porosity. A best-fit solution to Archie's equation gives Archie's parameters as $m=2.33$ and $a=0.877$. Open circles = samples with significant sand content, solid circles $=$ typical hemipelagic sediment .

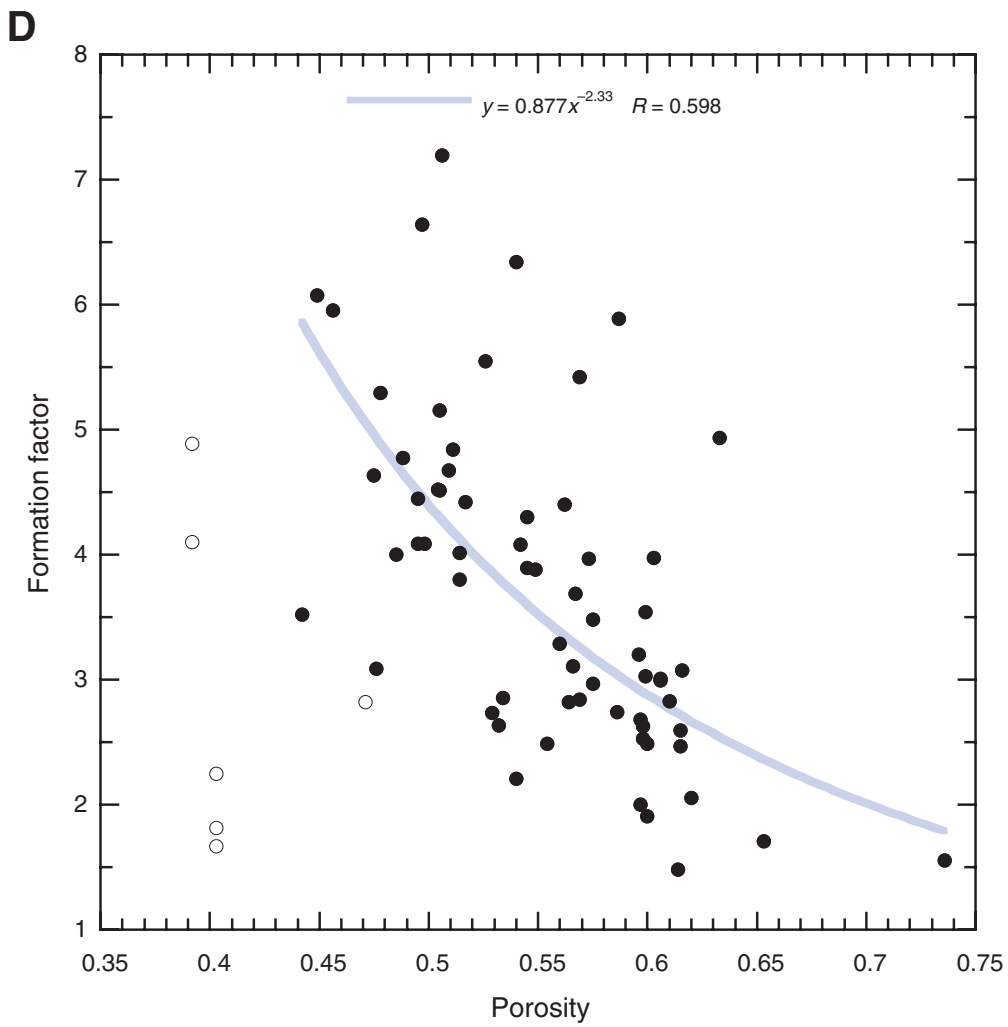


Figure F43. Thermal conductivity measurements (open circles $=$ uncorrected, solid circles $=$ corrected) from Holes U1327C and U1327D. Dashed line $=$ correction factor for in situ temperature and pressure, solid line = regional trend derived by Davis et al. (1990).

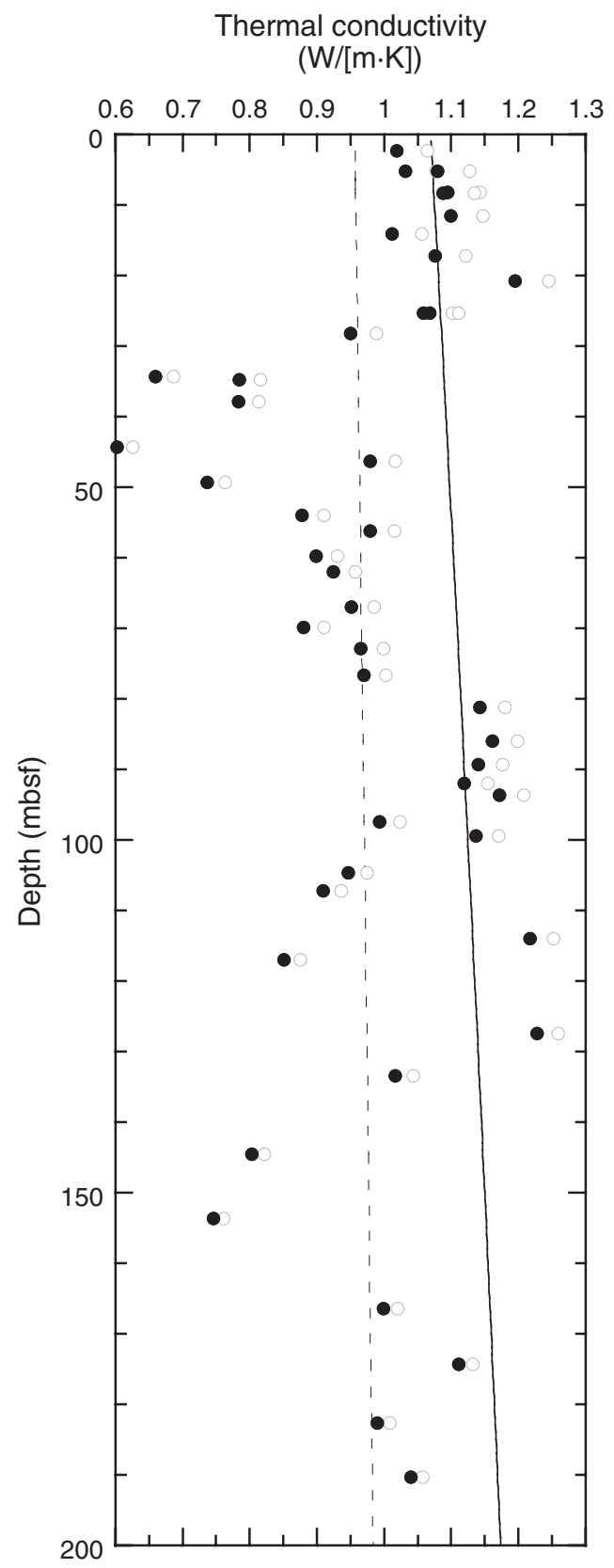


Figure F44. Advanced pressure corer temperature tool (APCT) and Davis-Villinger Temperature-Pressure Probe (DVTPP) in situ temperature measurements from Site U1327. Both temperature and pressure are shown for the DVTPP.
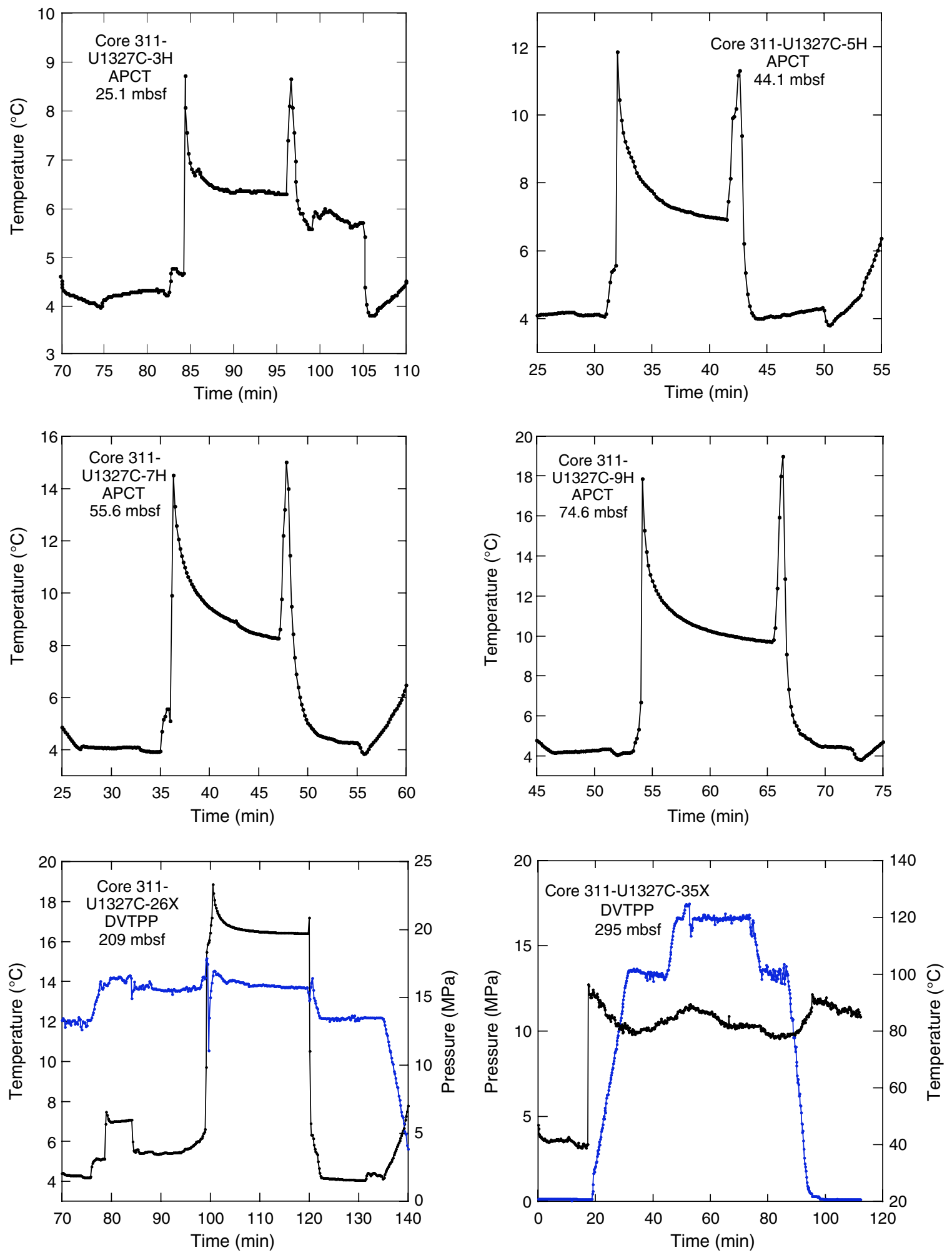
Figure F45. In situ temperature measurements from Site U1327 (black circles; open black circle is a data point that was seriously affected by ship heave and was not used in the calculation of the slope) and Site 889 (blue circles). The best-fit line for the Site U1327 data is shown by the black line, with uncertainties shown by dashed black lines. The slope is $0.059^{\circ} \pm 0.002^{\circ} \mathrm{C} / \mathrm{m}$ with a seafloor intercept of $2.66^{\circ} \pm 0.19^{\circ} \mathrm{C}$. For the combined Sites U1327 and 889 best-fit line, the slope is $0.055^{\circ} \pm 0.004^{\circ} \mathrm{C} / \mathrm{m}$ with a seafloor intercept of $2.62^{\circ} \pm$ $0.38^{\circ} \mathrm{C}$. The seafloor intercept is consistent with regional hydrographic data (see "Physical properties" in the "Site U1329" chapter), which indicate that the water temperature at the seafloor is $2.5^{\circ}-2.8^{\circ} \mathrm{C}$. The dashed red lines are the results for Site U1329. Stability boundaries for gas hydrate at hydrostatic pressure for pore water salinities of 2.1\%, 3.0\%, and 3.5\% are also shown (calculated using CSMHY; Sloan, 1998). At this site, background pore water salinity is $\sim 2.1$ (see "Interstitial water geochemistry"). Depth of the bottom-simulating reflector (BSR) was predicted from seismic data as described in the "Methods" chapter. Base of gas hydrate stability zone (GHSZ) estimated from thermal gradient at 3.5\% salinity.

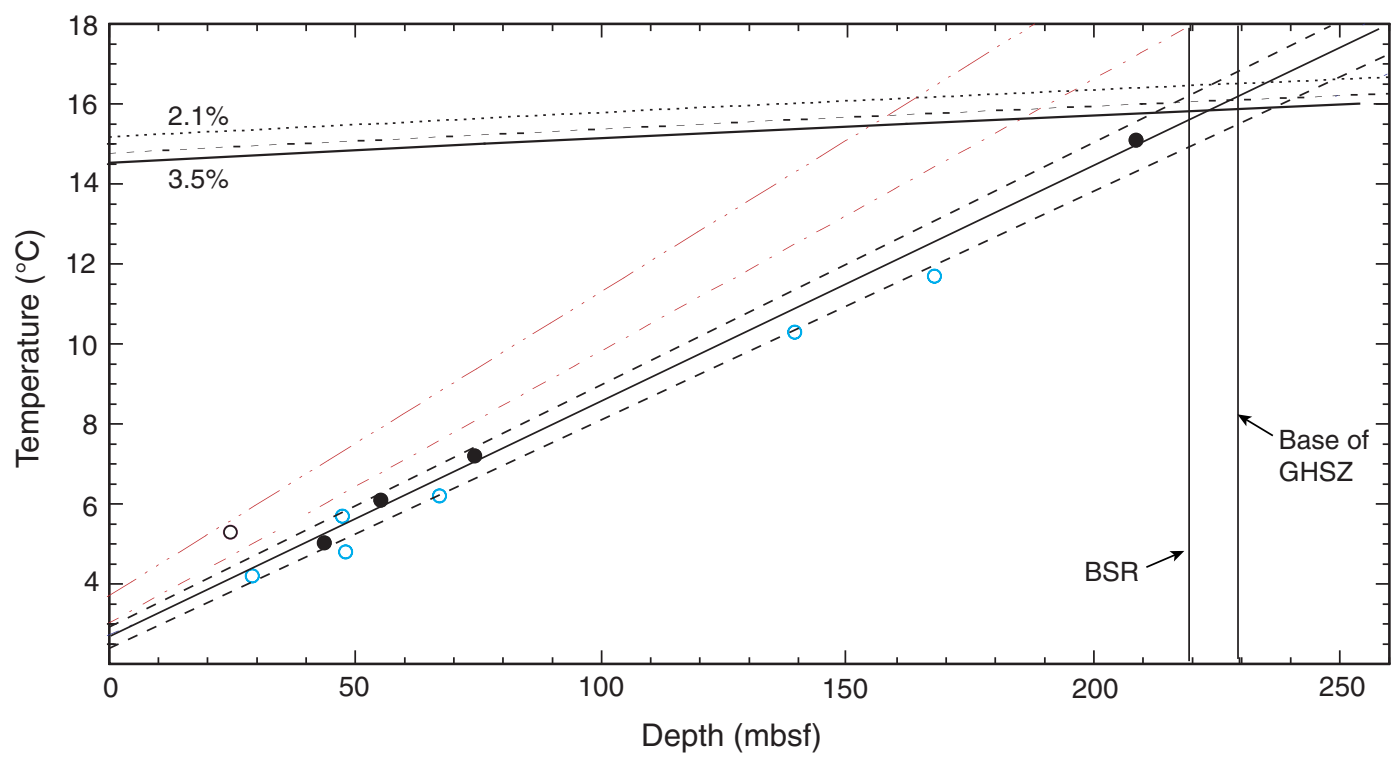


Figure F46. Paleomagnetic data after $20 \mathrm{mT}$ alternating-field demagnetization in Hole U1327C.

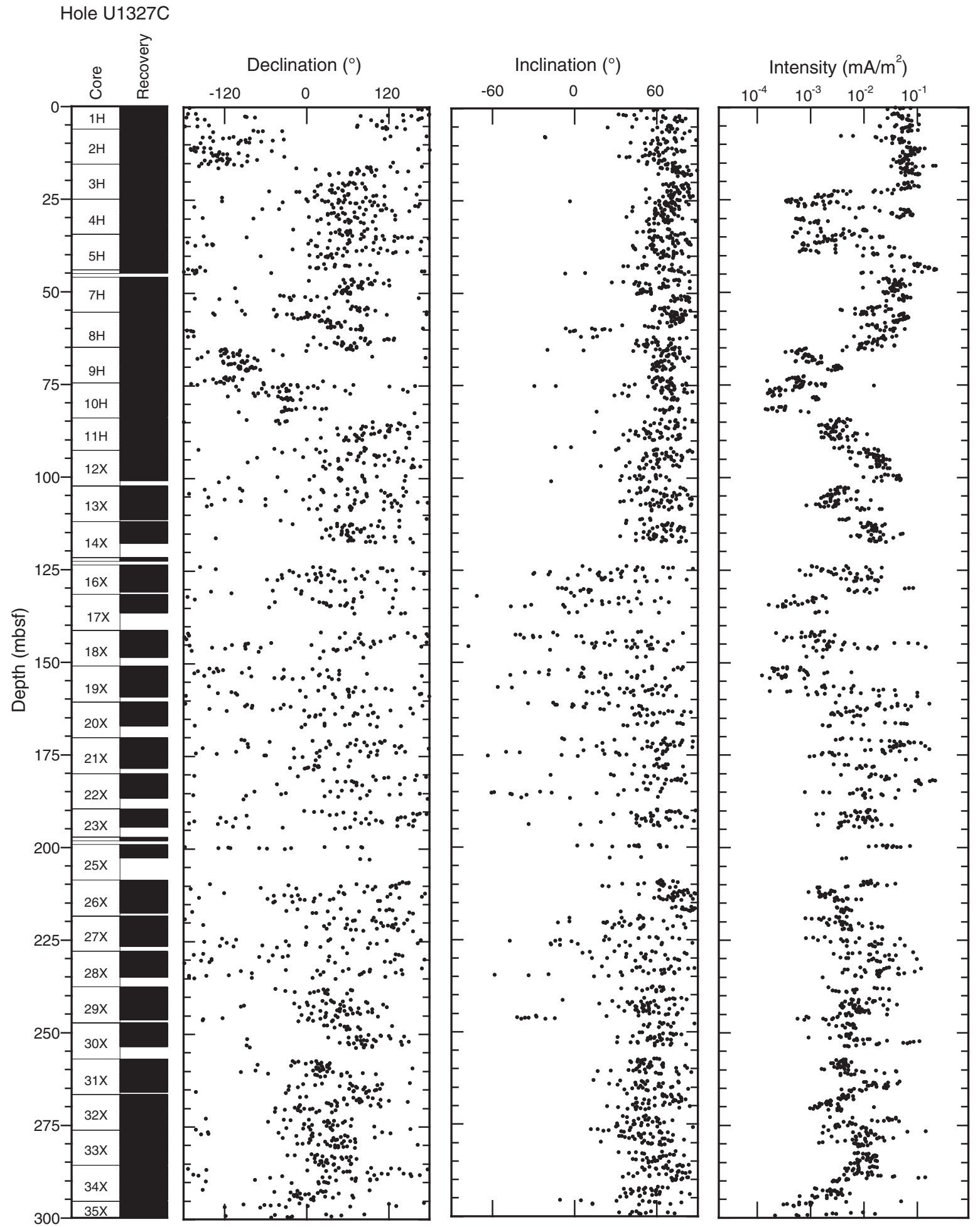


Figure F47. Temperature and pressure vs. elapsed time for each pressure core deployment as recorded by the corer's internal data logger. Deployment and recovery are shaded orange, operation at coring depth is shaded yellow, and autoclave immersion in the ice shuck is shaded blue. Cores 311-U1327D-6Y and 311-U1327E-2P were not immersed in the ice shuck. No data are available for Core 311-U1327D-1Y. (Continued on next three pages).
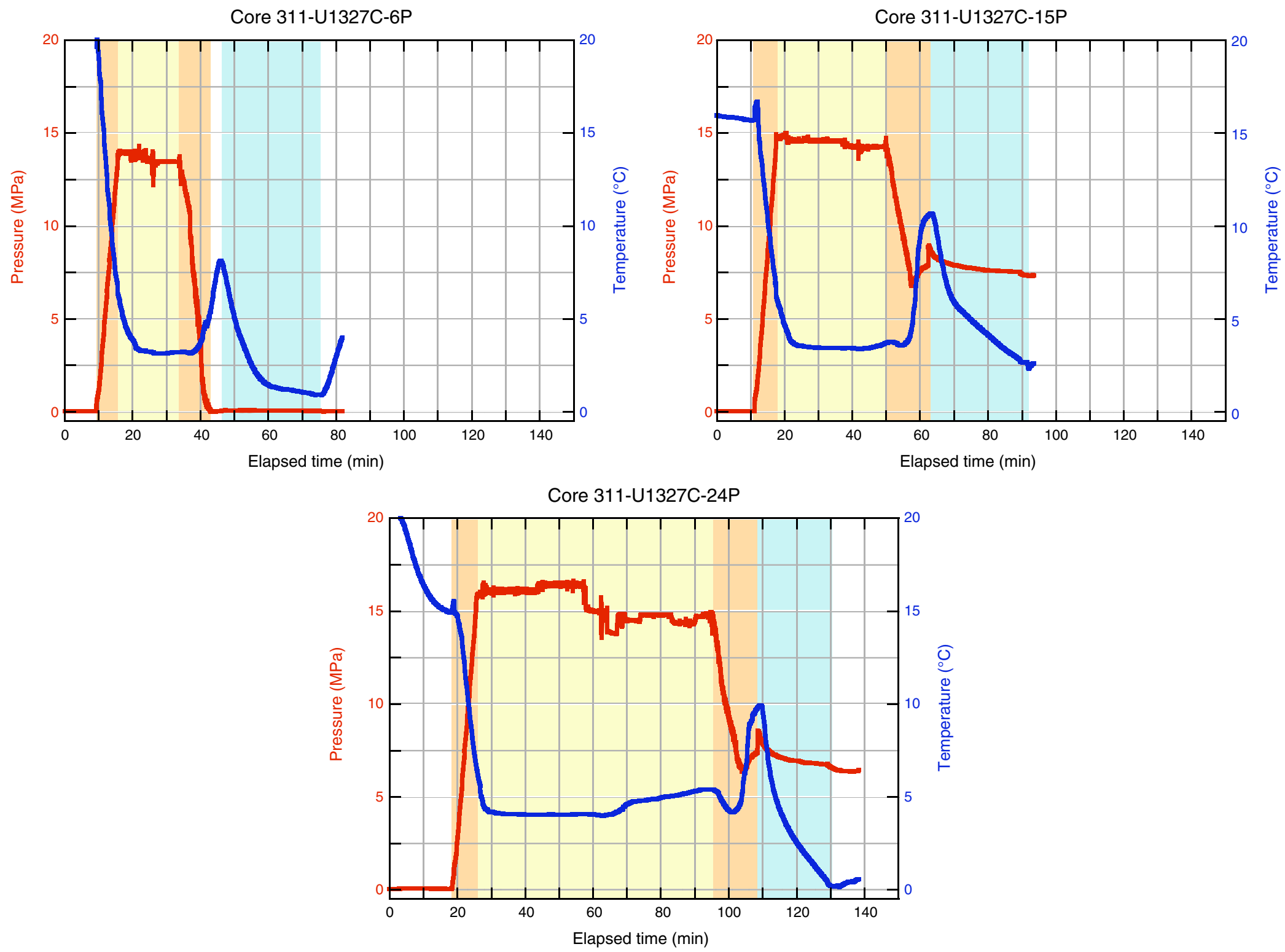

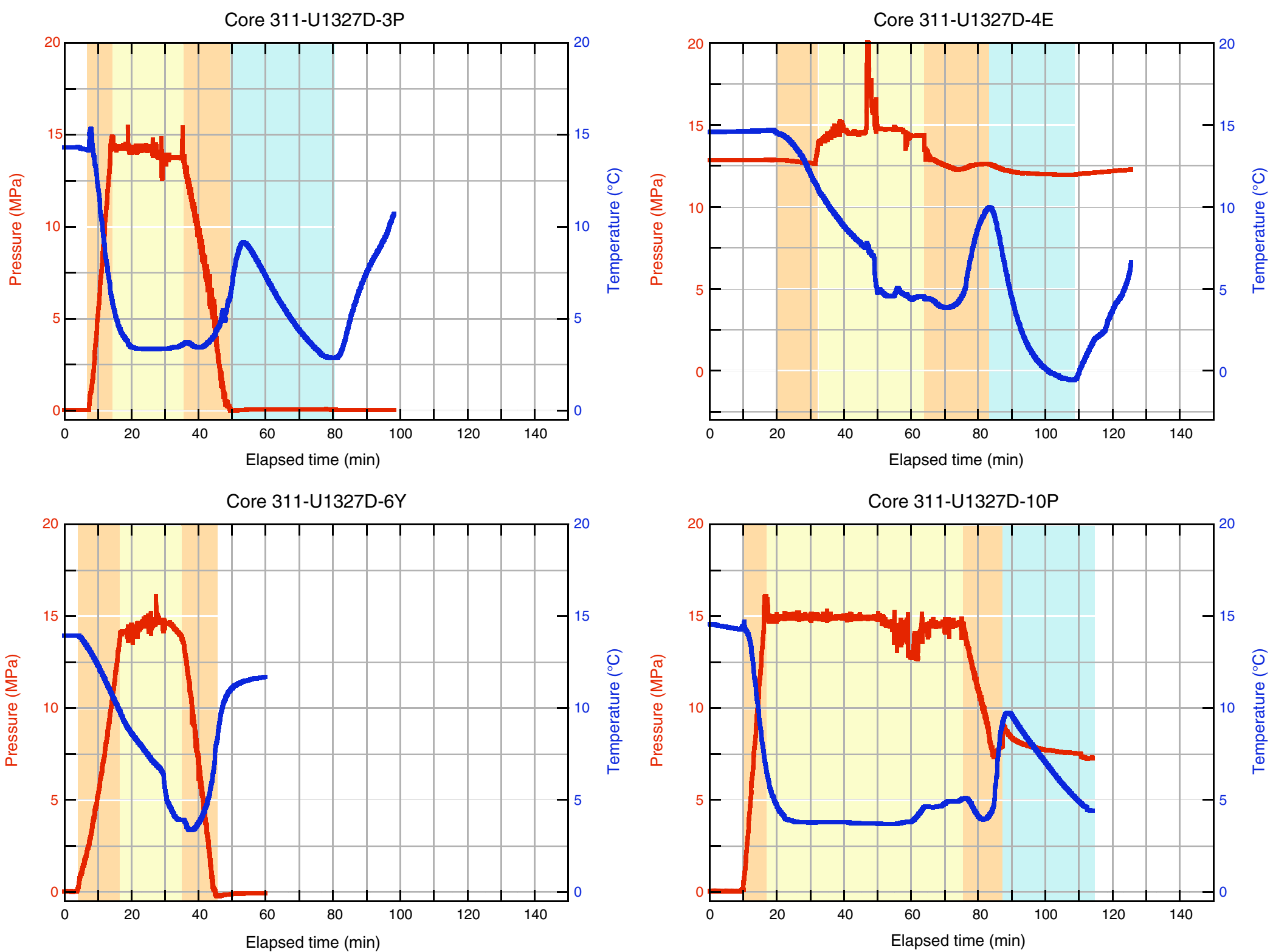
Figure F47 (continued). Temperature and pressure vs. elapsed time. (Continued on next page.)
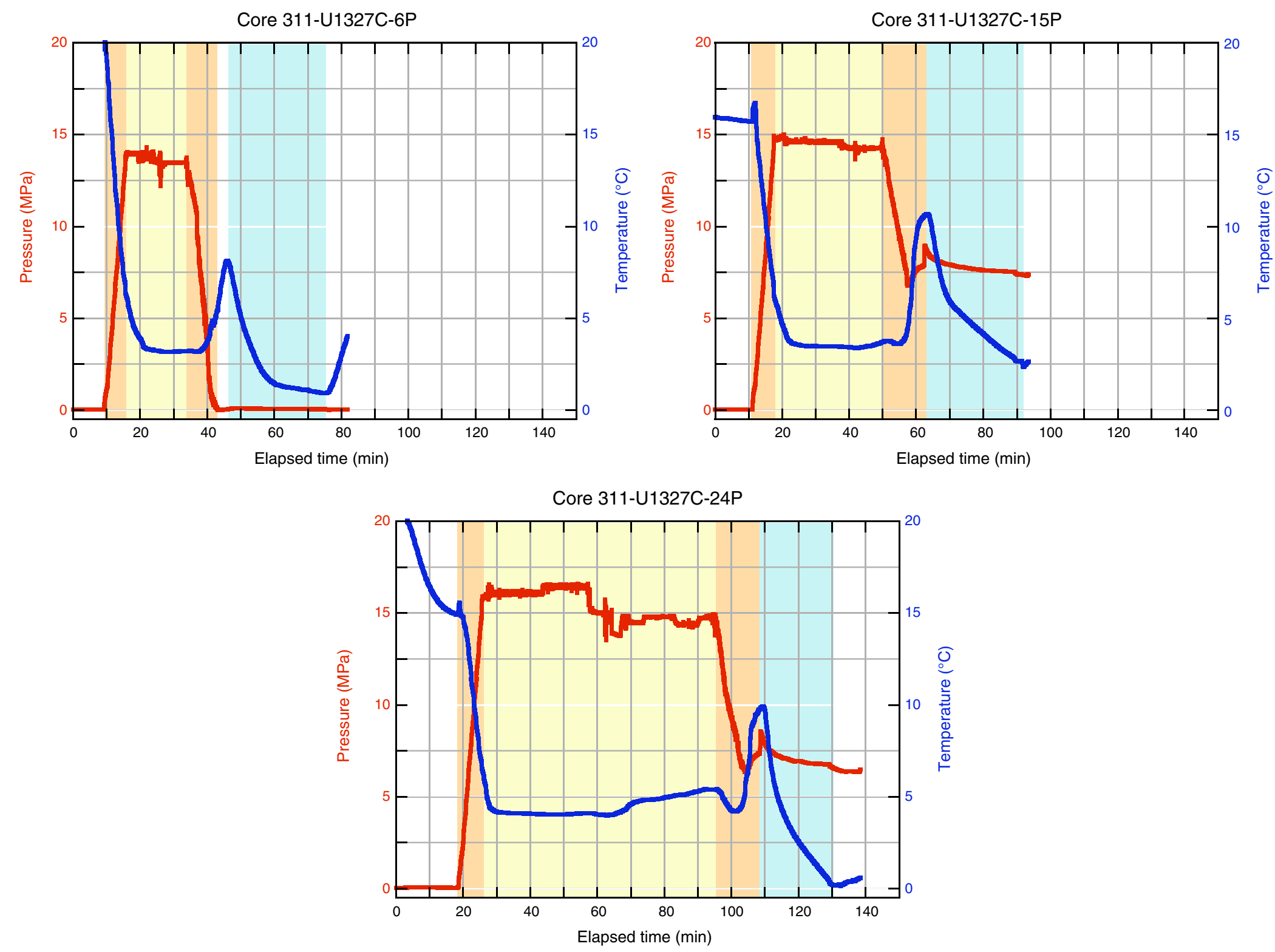
Figure F47 (continued). Temperature and pressure vs. elapsed time.
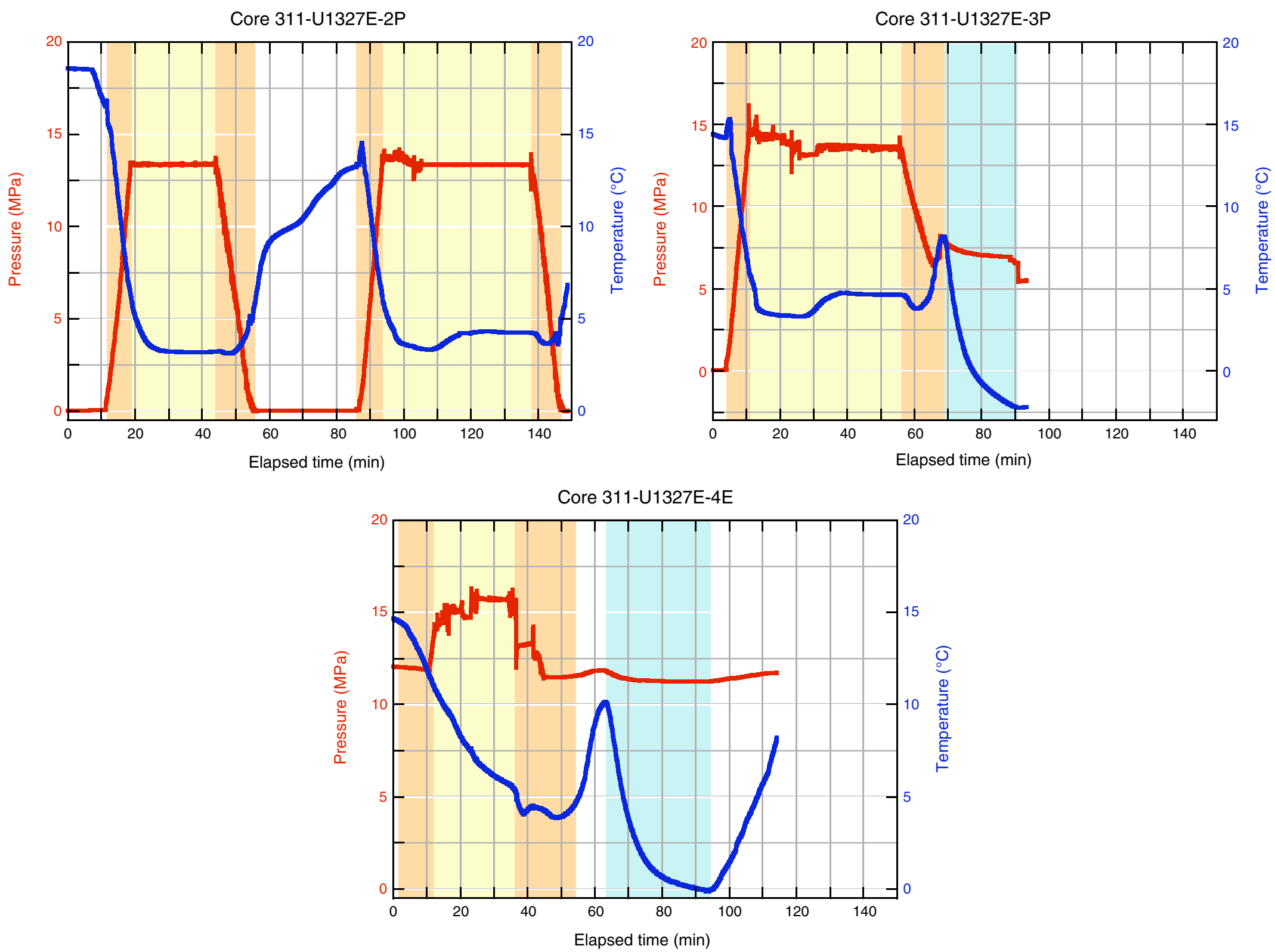
Figure F48. Temperature vs. pressure for all pressure core deployments, showing trajectories relative to gas hydrate stability at 20 and 35 ppt salinity $(\mathrm{Xu}, 2002,2004)$. Circles = final temperature and pressure of autoclave prior to data logger removal, squares = pressure and temperature conditions in the cold laboratory van. No data are available for Core 311-U1327D-13Y.

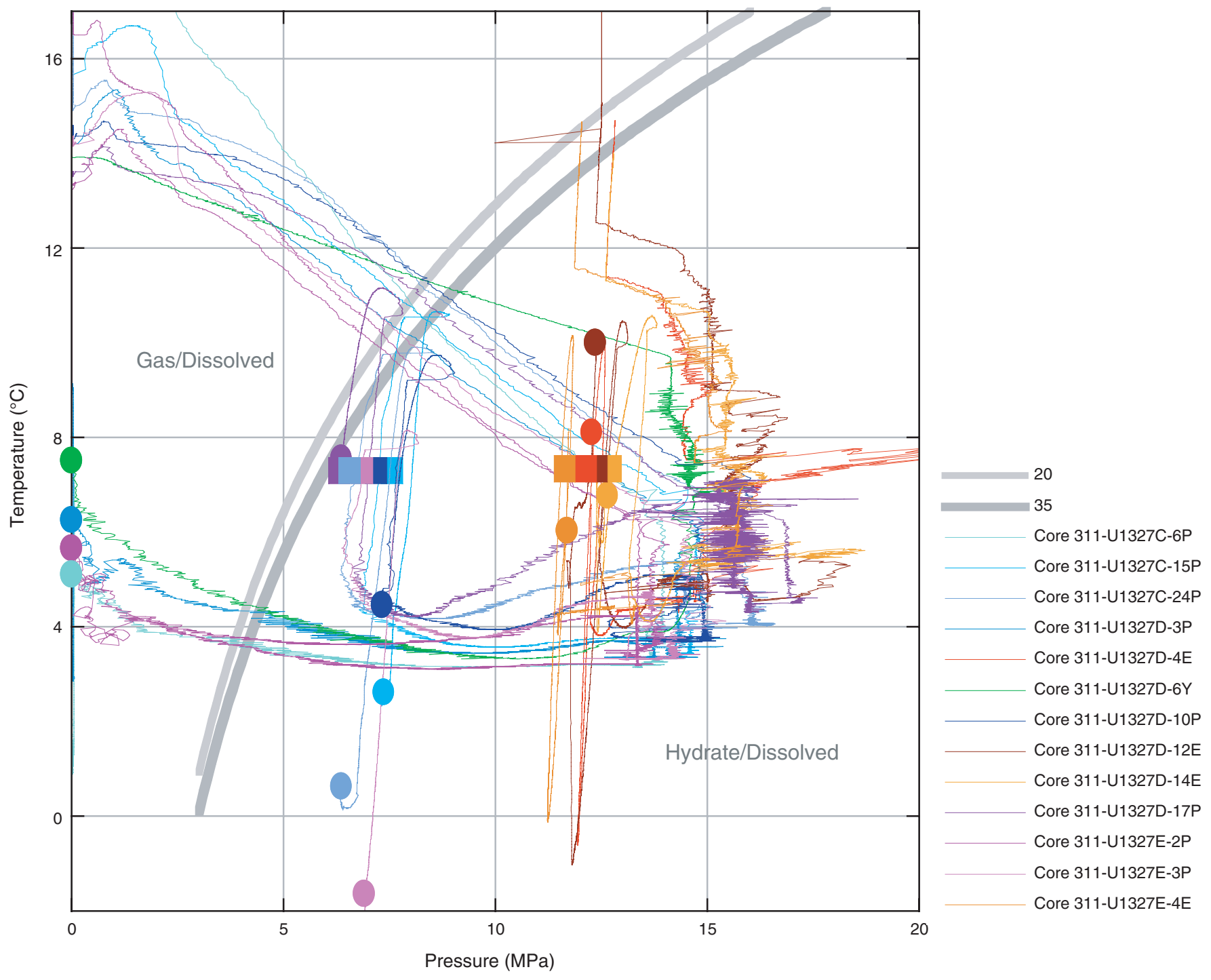


Figure F49. Methane phase diagram, with total methane concentration measured from the five depressurized PCS cores at Site U1327. The seafloor temperature and thermal gradient were taken from "In situ temperature profile," the salinity profile was taken from Table T3, and methane saturation was calculated according to $\mathrm{Xu}(2002,2004)$. BSR = bottom-simulating reflector.

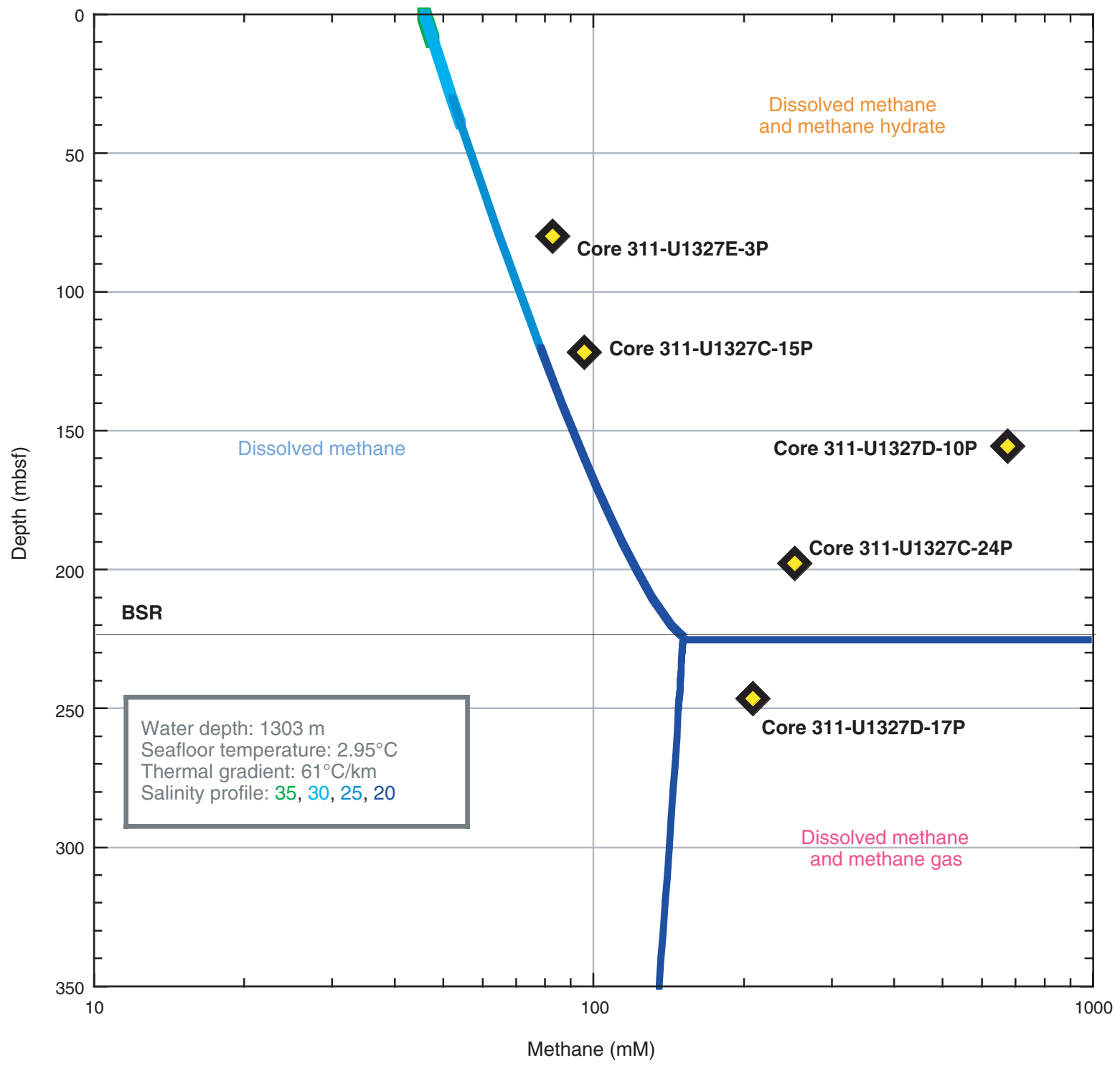


Figure F50. Pressure vs. released gas volume for PCS cores at Site U1327. Arrows = placement of gamma ray density scans. Initial pressure readings are not available for Core 311-1327C-15P because the pressure gauge was off-scale. (Continued on next page.)
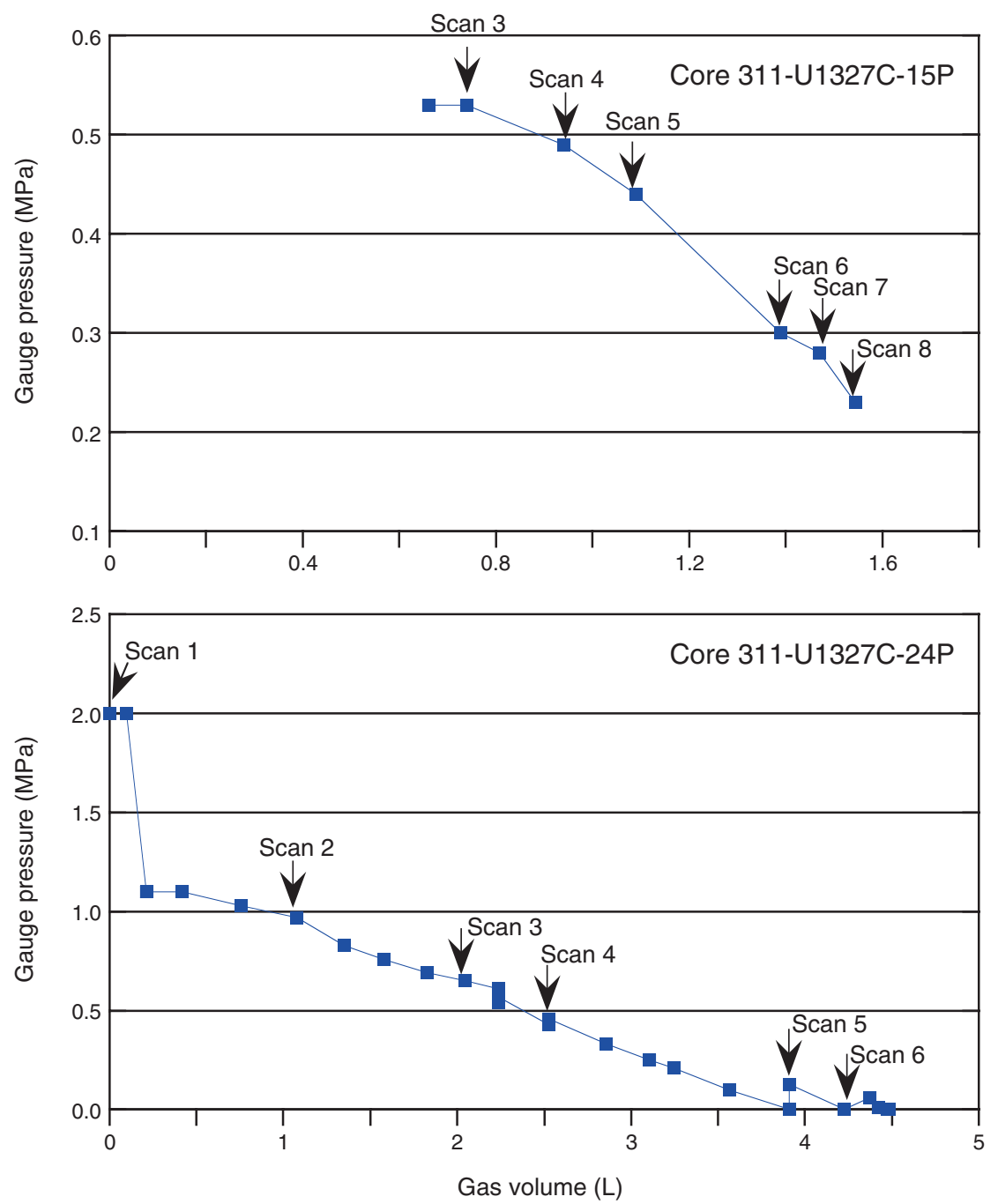
Figure F50 (continued). Pressure vs. released PCS gas.
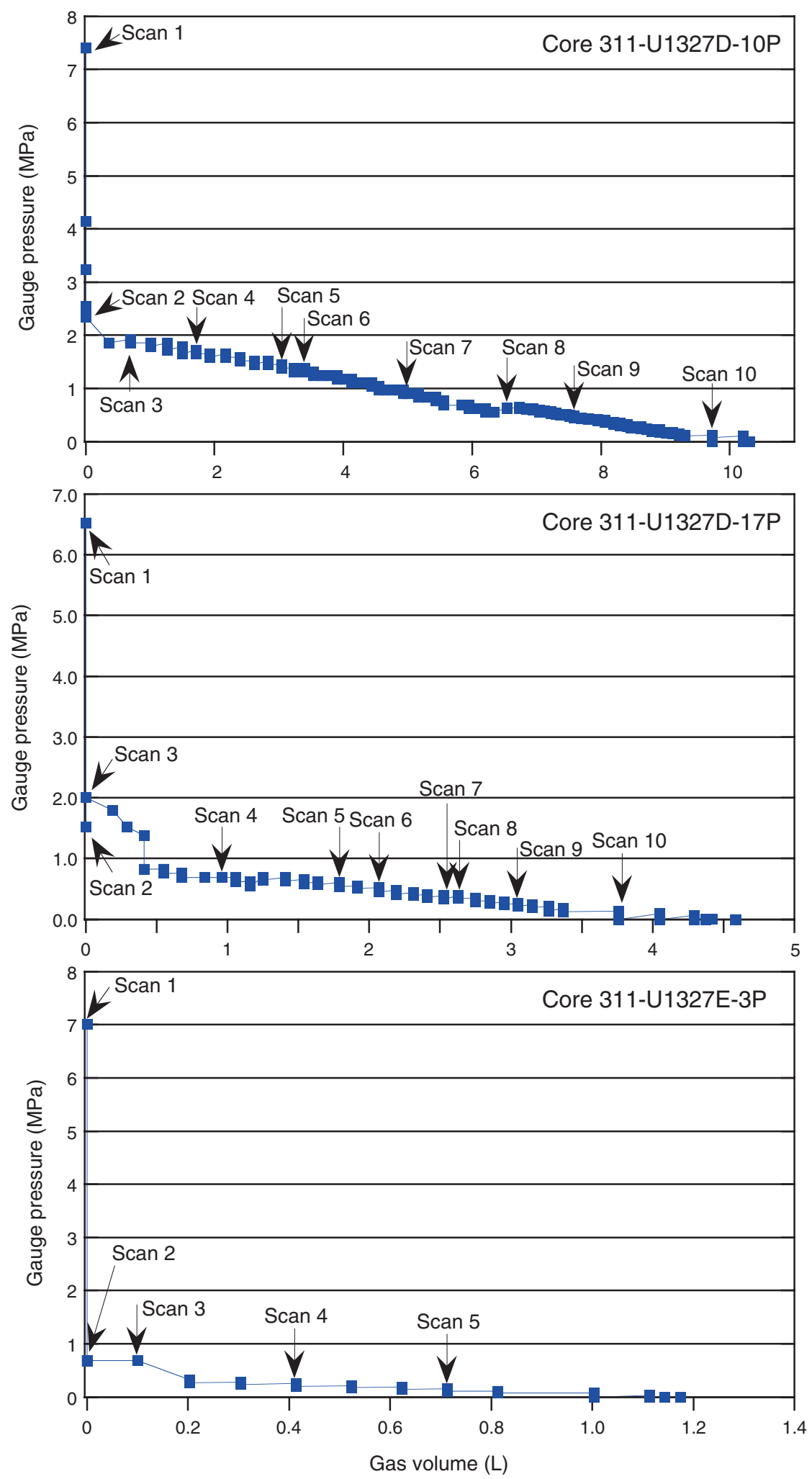
Figure F51. Summary of data collected from PCS cores at Site U1327, including gamma ray density scans collected during degassing, X-ray images collected before and after degassing, line scan images collected after degassing, and chlorinity data collected in selected zones. Gamma ray density scans are shown as differential density plots (i.e., as profiles from which the initial profile has been subtracted). A. Core 311-U1327C-15P. (Continued on next four pages.)

Core 311-U1327C-15P

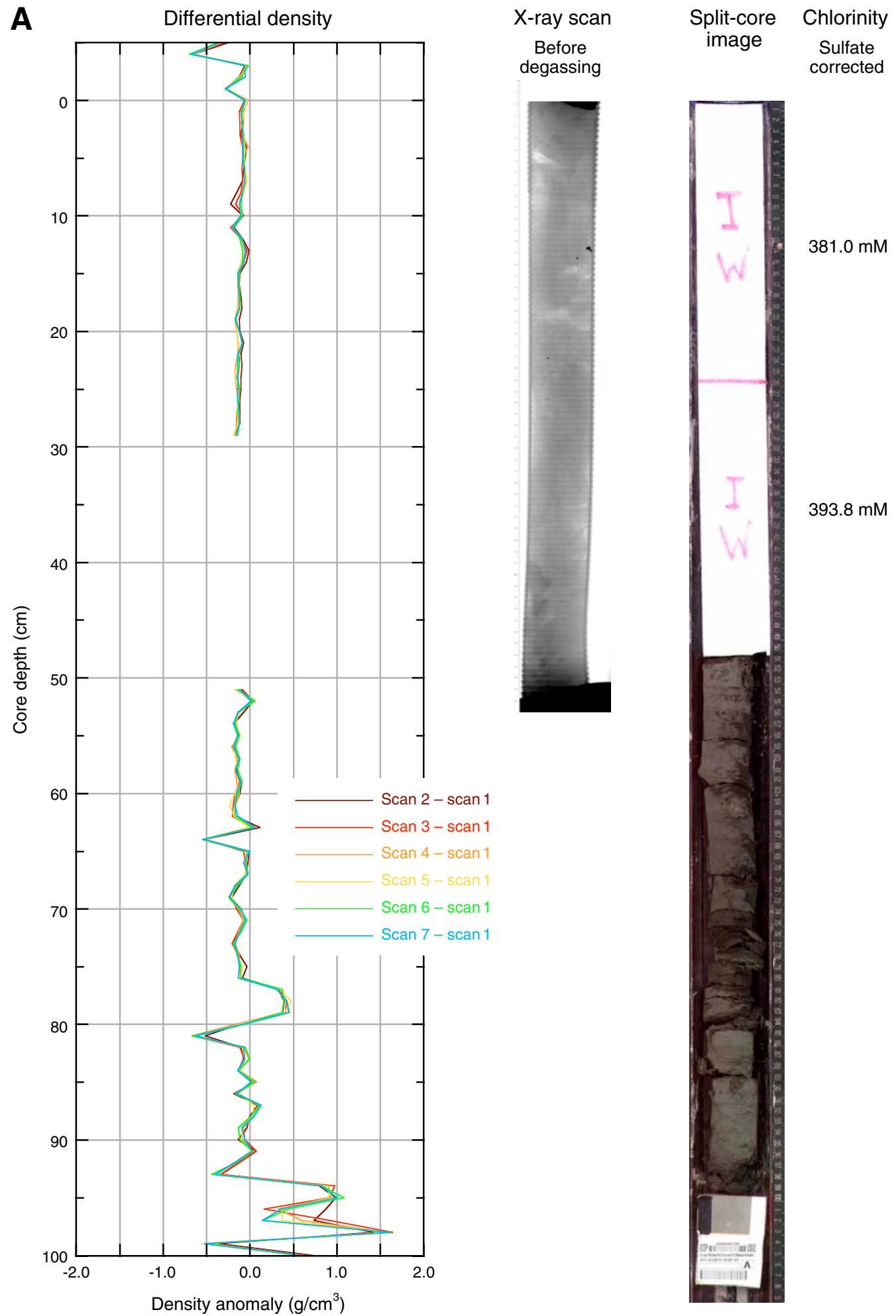


Figure F51 (continued). B. Core 311-U1327C-24P. (Continued on next page.)

Core 311-U1327C-24P

B

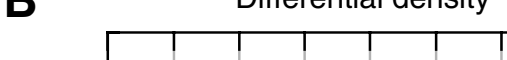

\section{(1)}

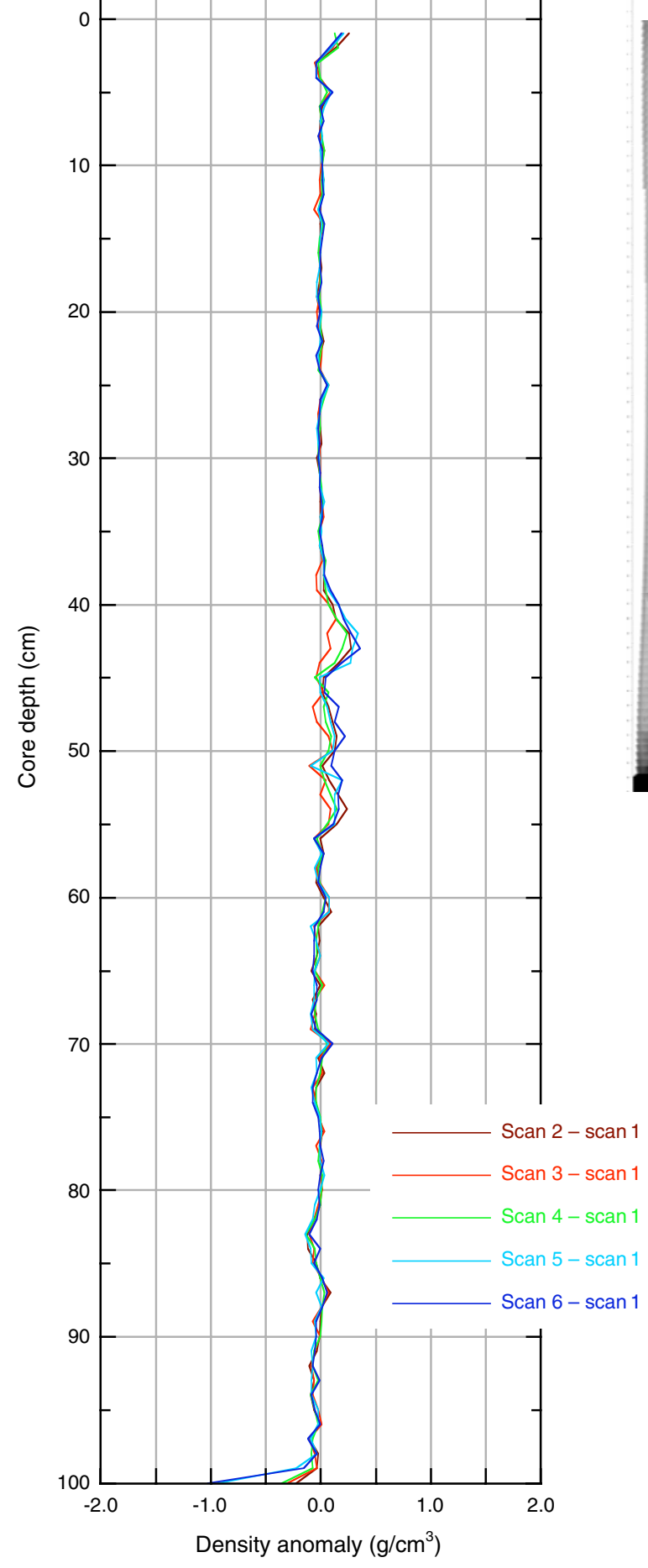

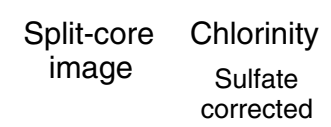

degassing degassing

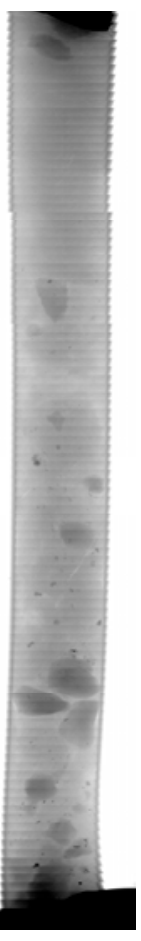

$356.7 \mathrm{mM}$

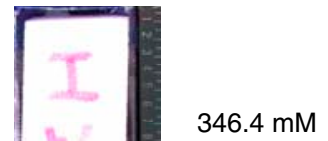

$384.0 \mathrm{mM}$

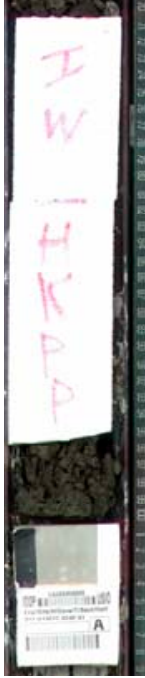


Figure F51 (continued). C. Core 311-U1327D-10P. (Continued on next page.)

Core 311-U1327D-10P

C

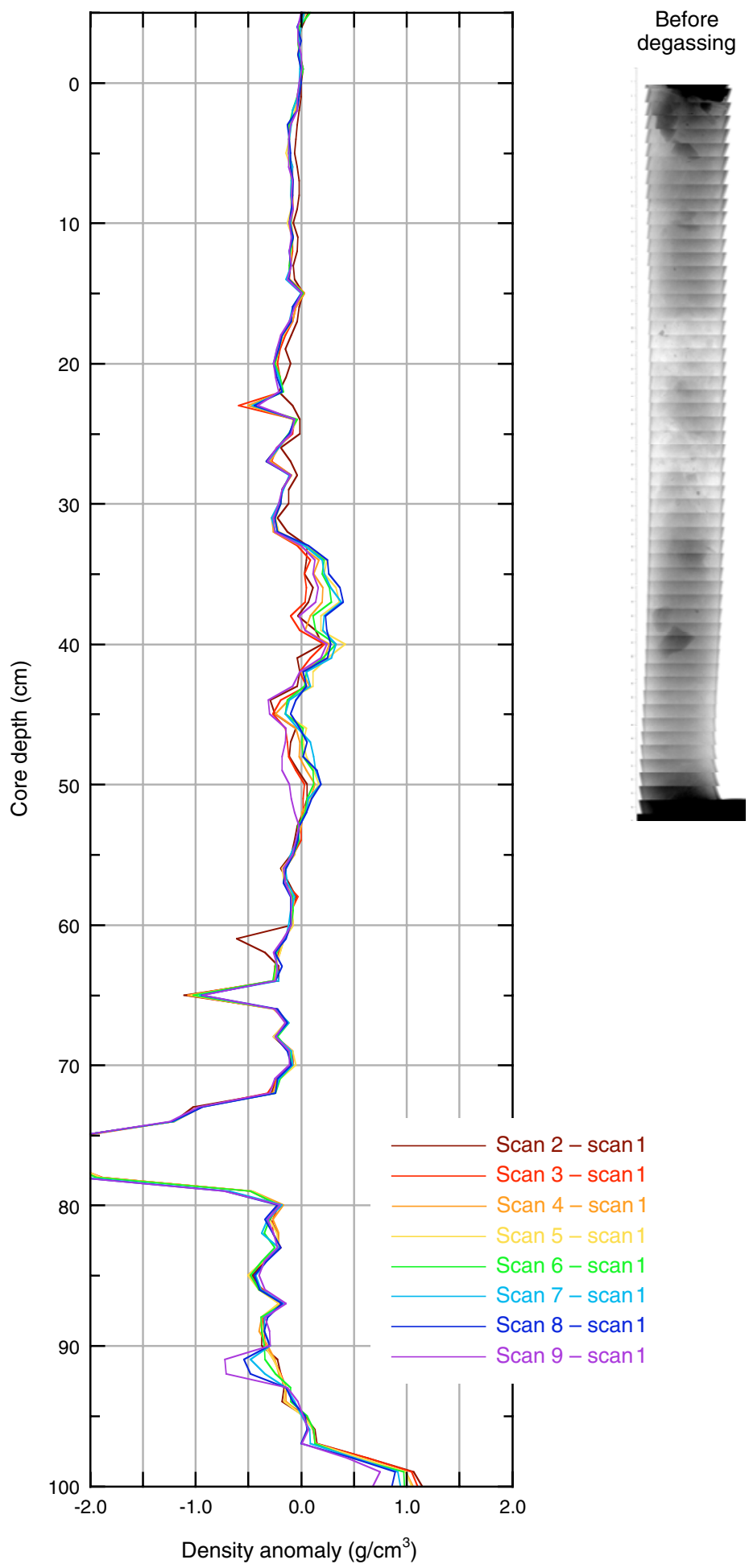

X-ray scan

After
degassing

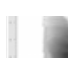

$\begin{array}{cc}\begin{array}{c}\text { Split-core } \\ \text { image }\end{array} & \begin{array}{c}\text { Chlorinity } \\ \text { Sulfate }\end{array}\end{array}$

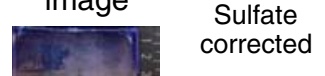

$336.4 \mathrm{mM}$

$333.2 \mathrm{mM}$

$351.7 \mathrm{mM}$

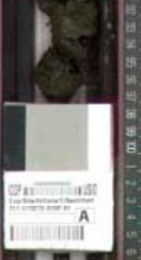


Figure F51 (continued). D. Core 311-U1327D-17P. (Continued on next page.)

Core 311-U1327D-17P

D

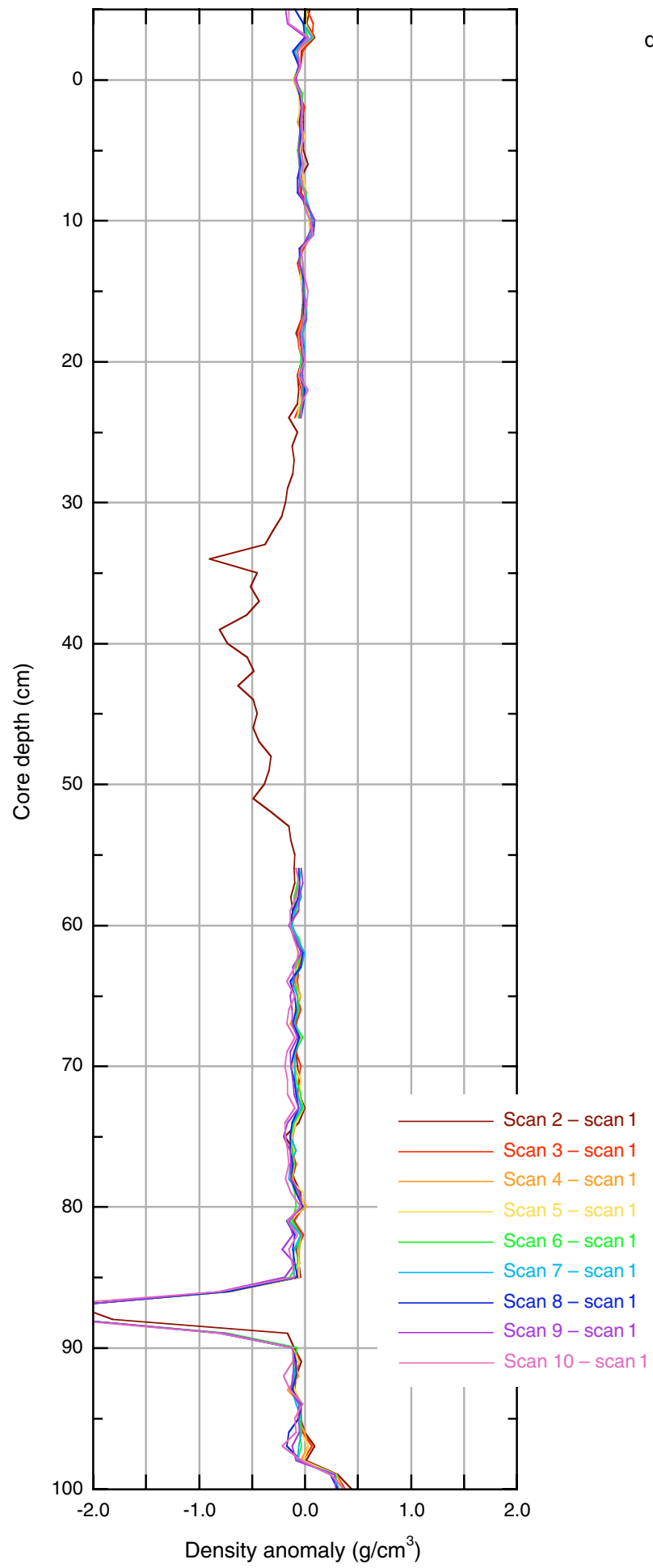

Split-core Chlorinity image Sulfate

Before After degassing degassing

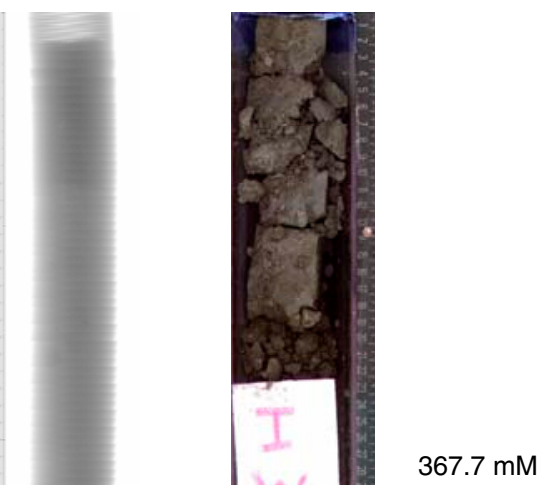

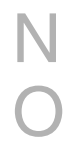
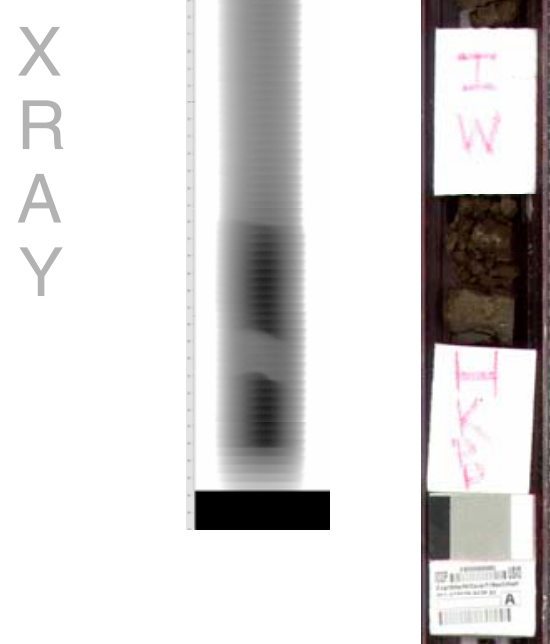

$369.6 \mathrm{mM}$ 
Figure F51 (continued). E. Core 311-U1327E-3P.

Core 311-U1327E-3P

E

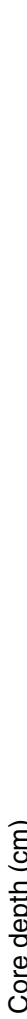

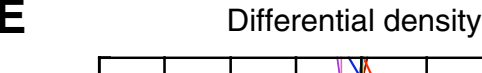

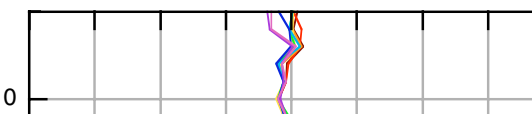

$$
0
$$$$
10
$$

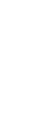

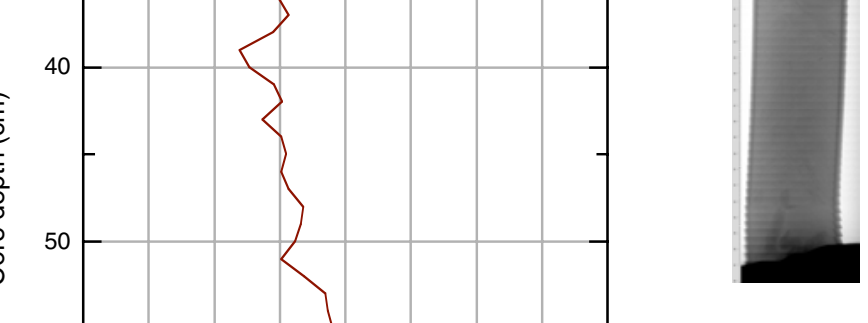$$
100
$$

X-ray scan

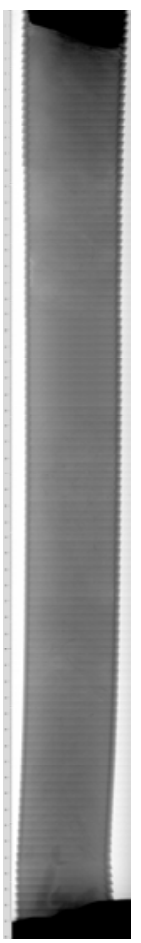

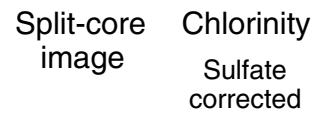

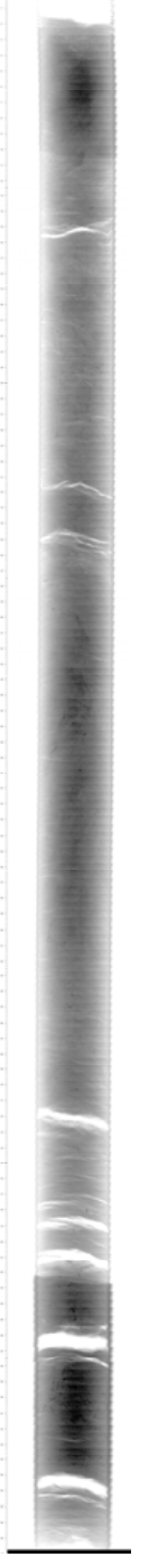

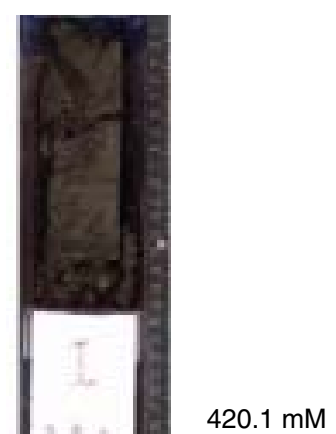


Figure F52. Pressure core data collected at $12 \mathrm{MPa}$ and $7^{\circ} \mathrm{C}$, including gamma ray density, $P$-wave velocity, and X-ray images. X-ray images have been stretched 250\% in the cross-core direction to show detail. A. Core 311-U1327D-12E. (Continued on next page.)

A

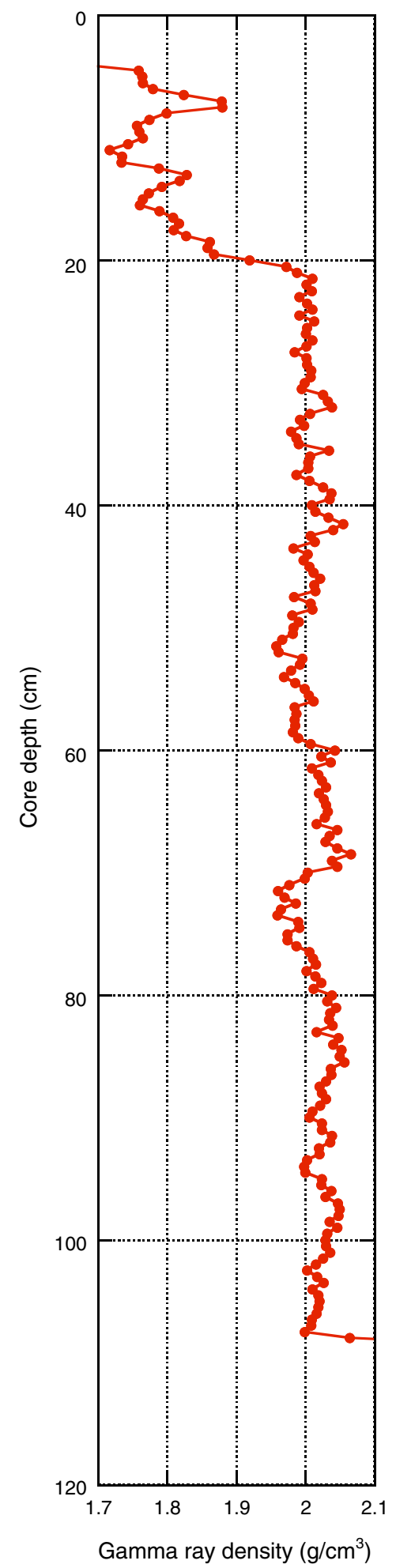

Core 311-U1327D-12E

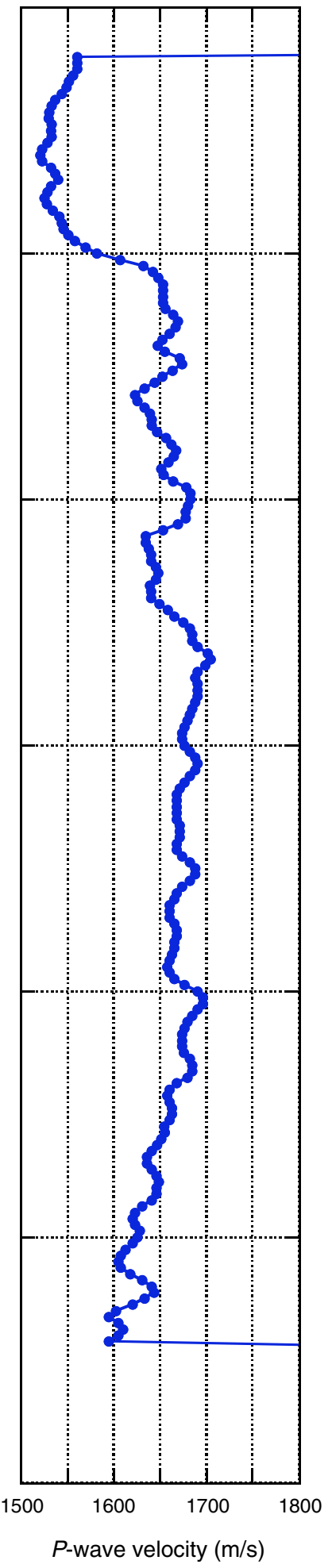

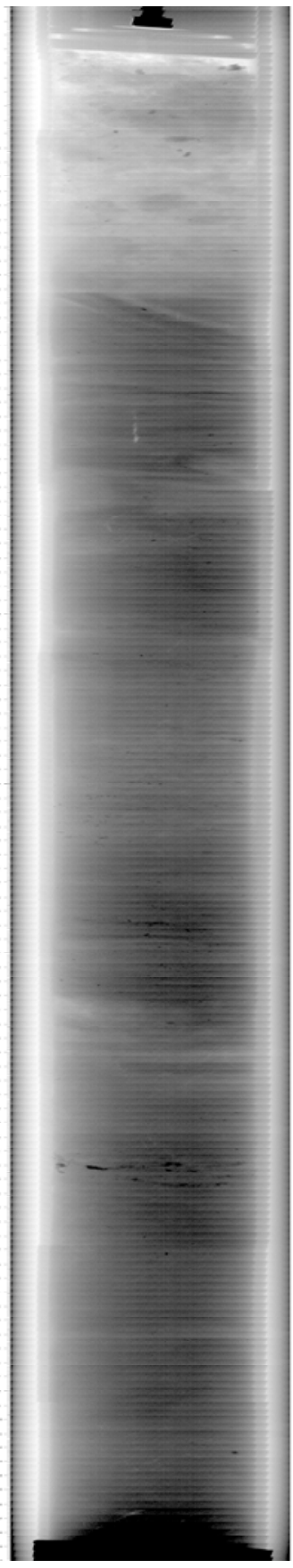


Figure F52 (continued). B. Core 311- U1327D-14E.

B

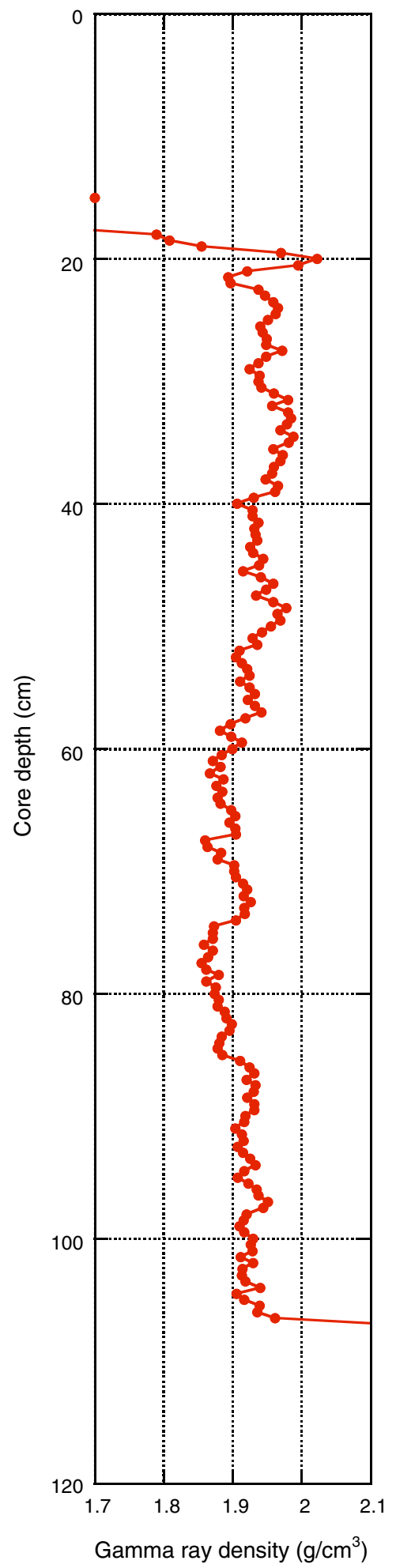

Core 311-U1327D-14E

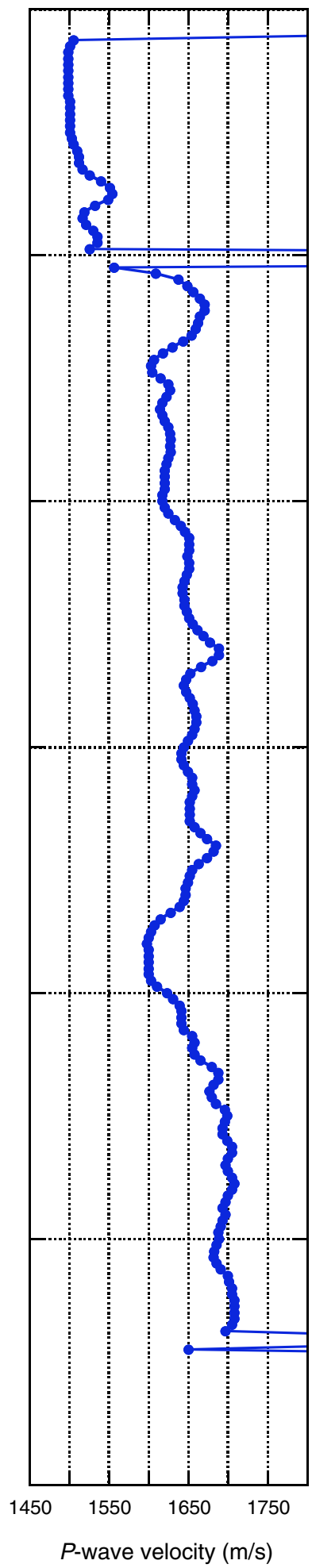

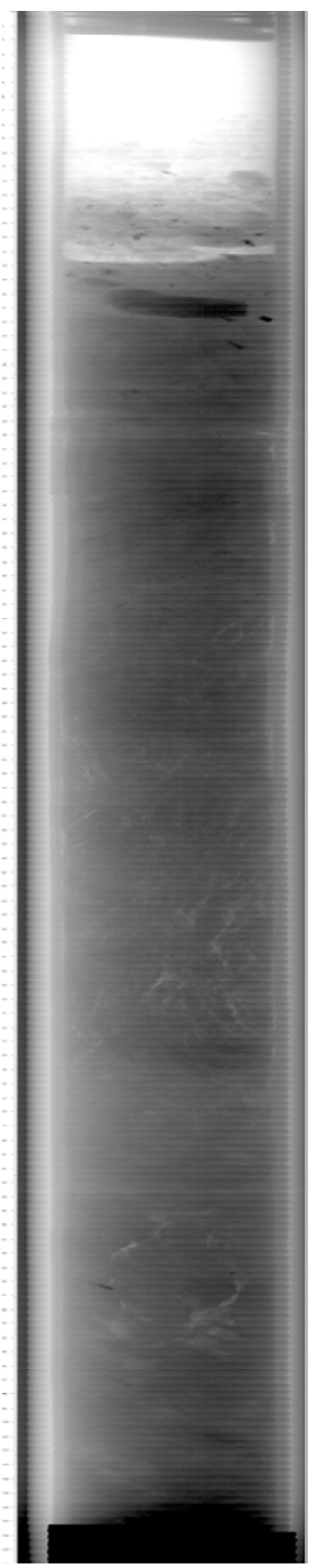


Figure F53. Gamma ray density vs. $P$-wave velocity for Cores 311-U1327D-12E and 14E. Data are also shown for Core 311-U1329E-9E with the two interpreted gas hydrate-containing intervals highlighted. The best-fit line to points showing a "normal" positive correlation between density and $P$-wave velocity is shown in black. The red box encompasses anomalous high-velocity points.

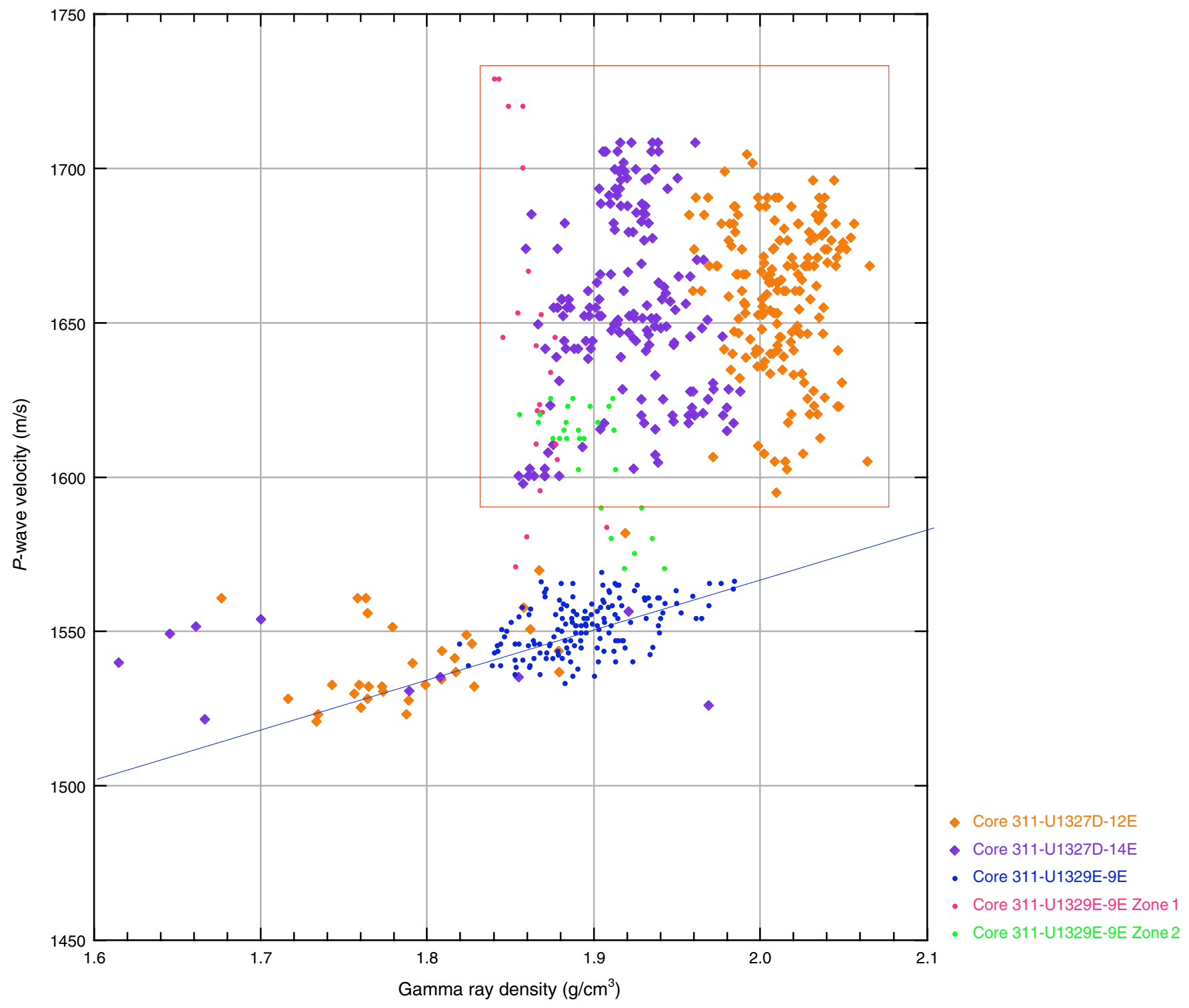


Figure F54. Monitoring and quality control LWD/MWD logs from Hole U1327A.

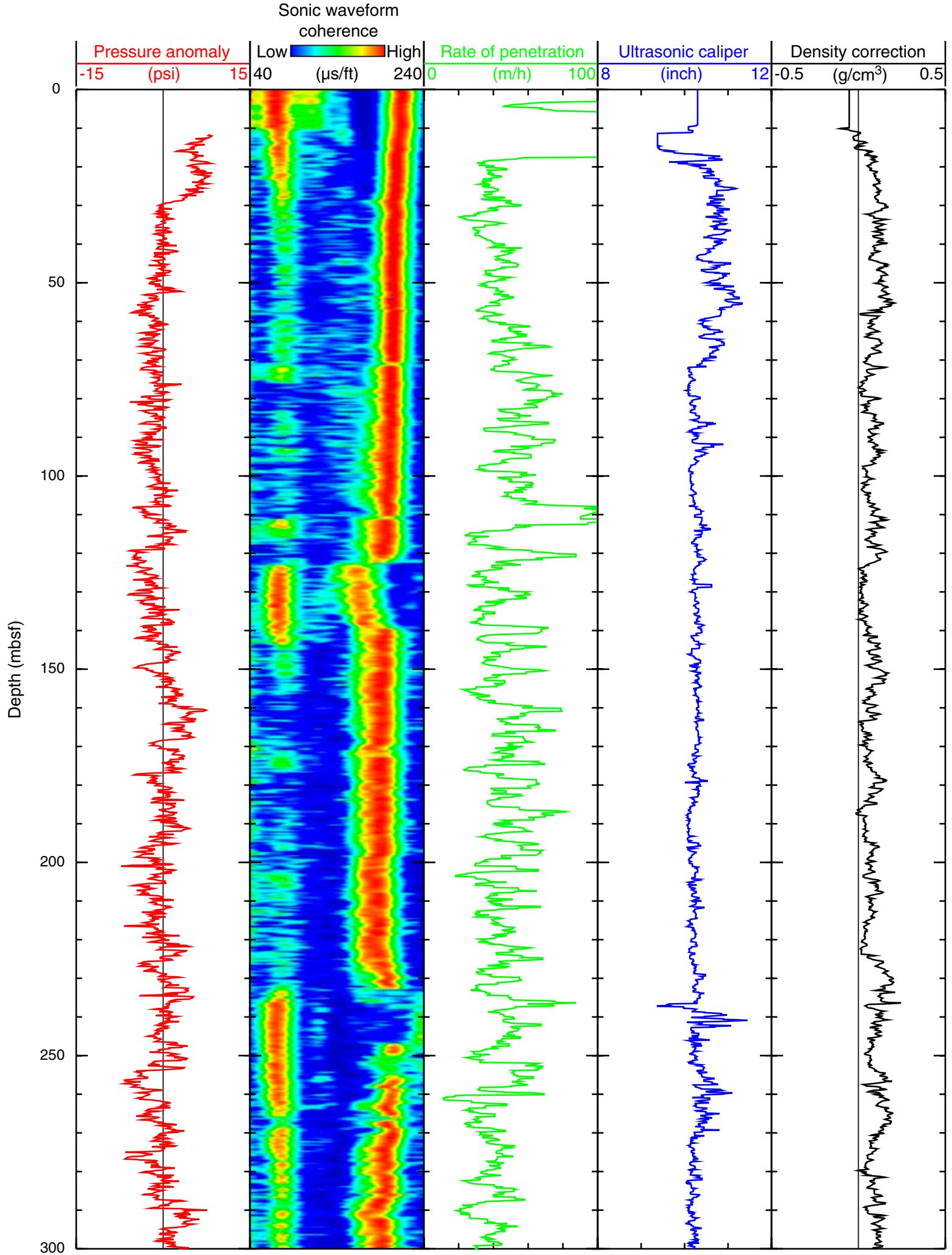


Figure F55. Summary of LWD data from Hole U1327A. P16B = phase-shift resistivity measured by the EcoScope tool at a source-receiver spacing of 16 in $(41 \mathrm{~cm}), \mathrm{A} 40 \mathrm{~B}=$ attenuation resistivity measured by the EcoScope tool at a source-receiver spacing of 40 in $(102 \mathrm{~cm}), \mathrm{RAB}=$ resistivity-at-the-bit image obtained by the GeoVISION tool.

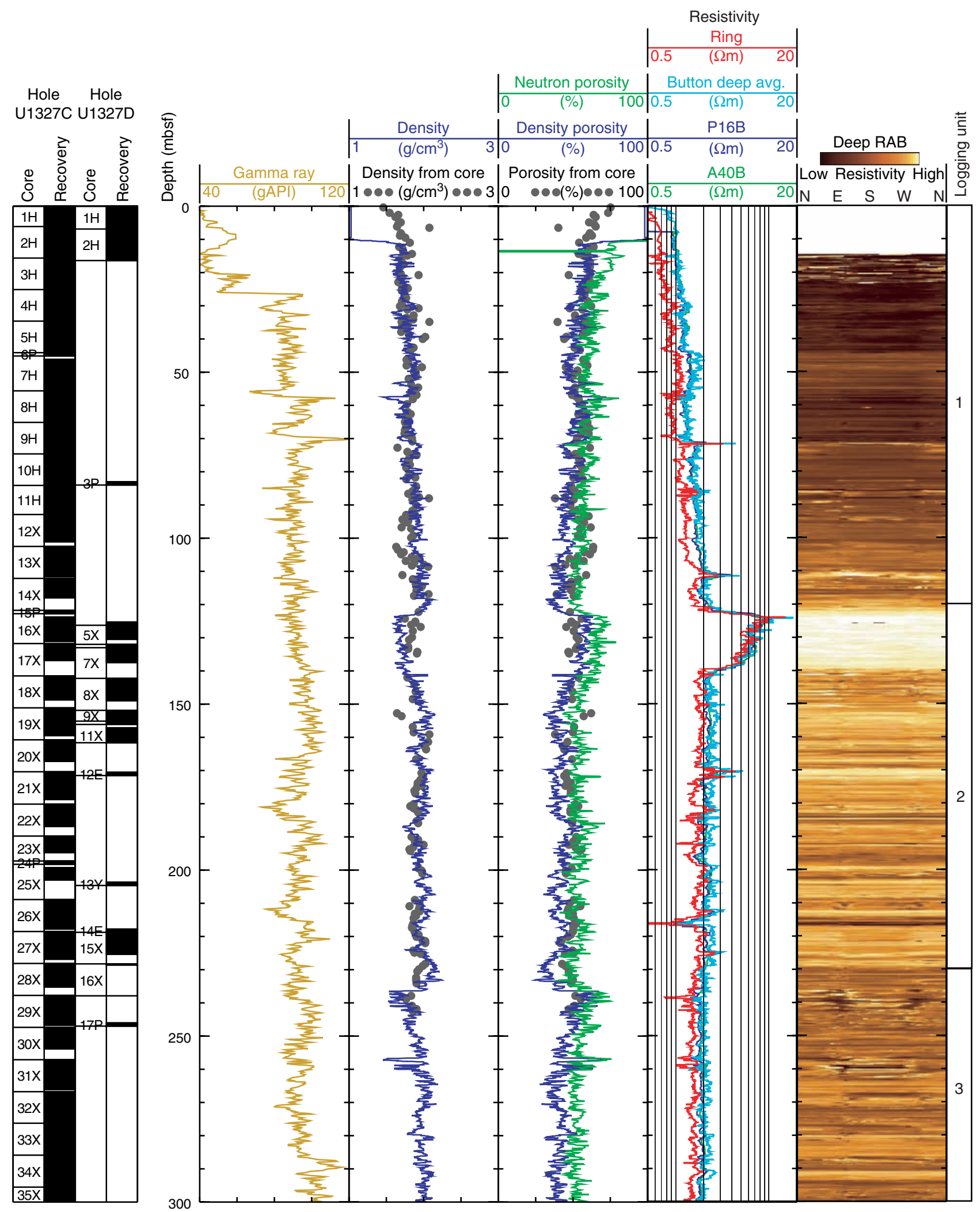


Figure F56. Summary of wireline logging data from Holes U1327D and U1327E. $V_{\mathrm{P}}=P$-wave velocity, $V_{\mathrm{S}}=S$ wave velocity.

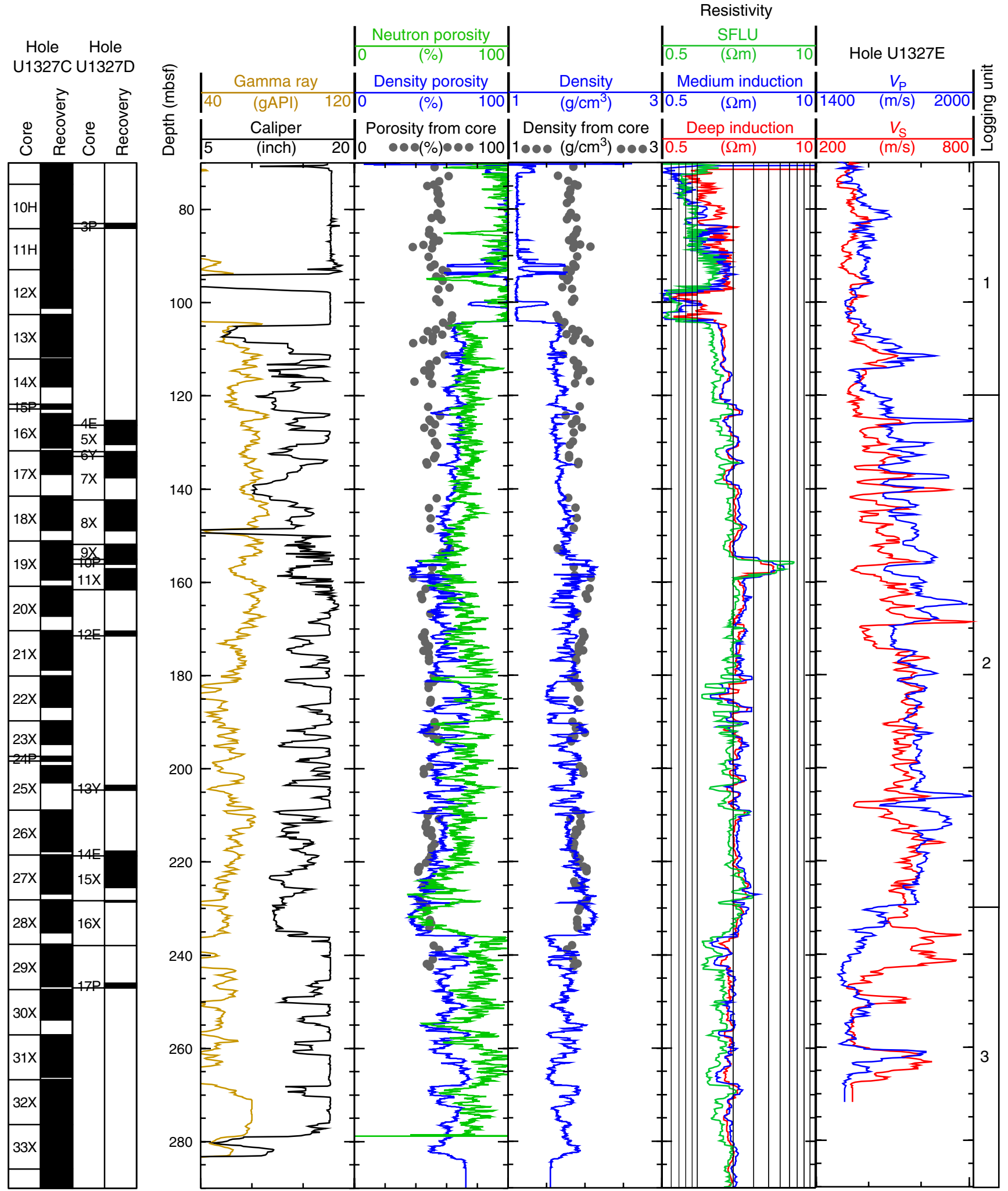


Figure F57. Sonic waveform data, $P$-wave velocity, and $S$-wave velocity obtained with the wireline Dipole Sonic Imager tool in Hole U1327E. SFLU $=$ spherically focused resistivity, $V_{\mathrm{p}}=P$-wave velocity, Mono. $=$ monopole, $V_{\mathrm{S}}=S$-wave velocity, $\mathrm{UD}=$ upper dipole, $\mathrm{LD}=$ lower dipole.

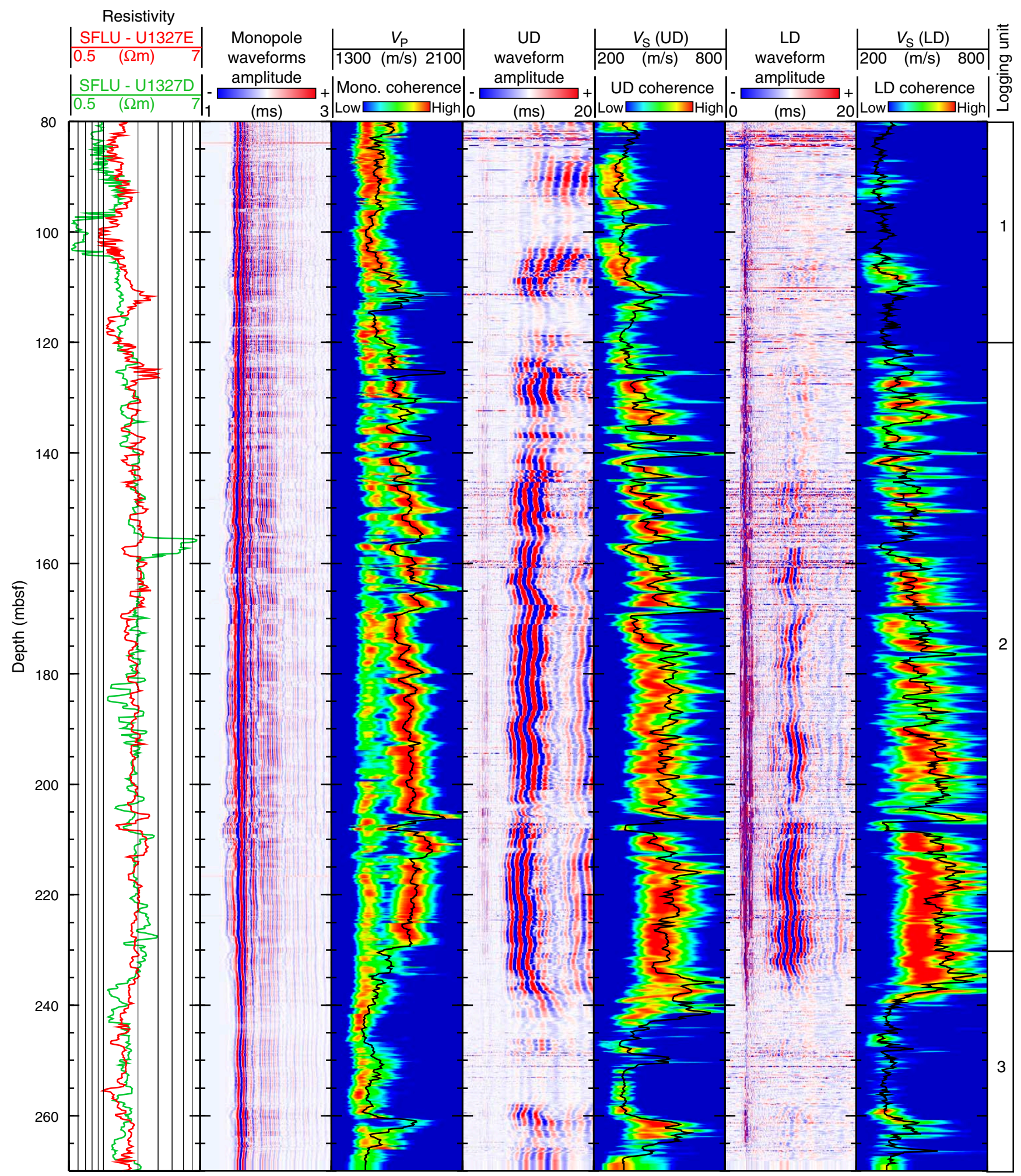


Figure F58. Comparison of logging-while-drilling (LWD; Hole U1327A) and wireline logging (WL; Hole U1327D) data. cal. $=$ caliper, por. $=$ porosity, SFLU = spherically focused resistivity, P16B = phase-shift resistivity measured by the EcoScope tool at a source-receiver spacing of 16 in $(41 \mathrm{~cm})$, avg. = average.

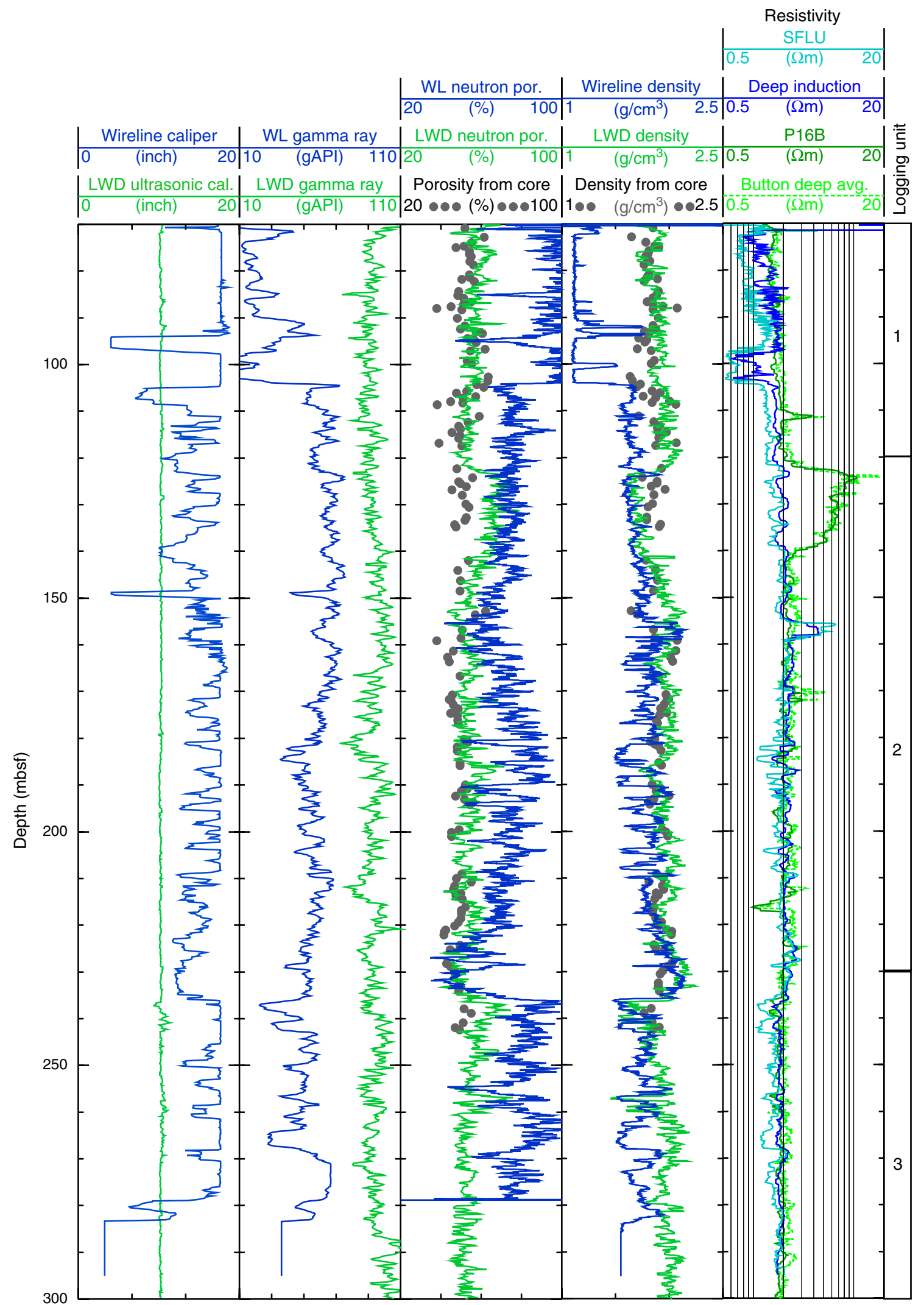


Figure F59. Comparison of wireline logging data from Holes U1327D and U1327E. SFLU = spherically focused resistivity, $V_{\mathrm{p}}=P$-wave velocity, $V_{\mathrm{S}}=S$-wave velocity.

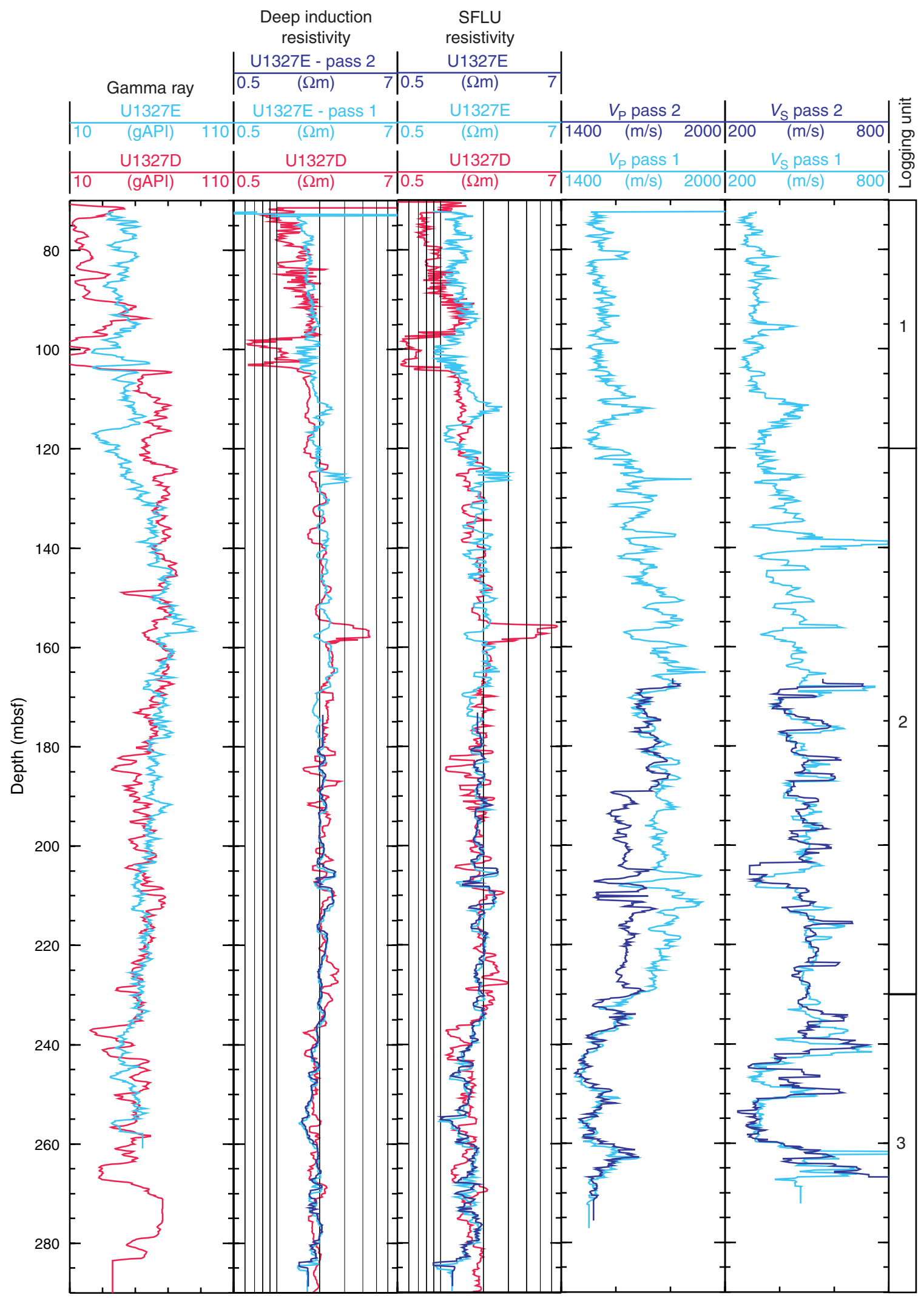


Figure F60. LWD image data from Hole U1327A. RAB = resistivity-at-the-bit image obtained by the GeoVISION tool.

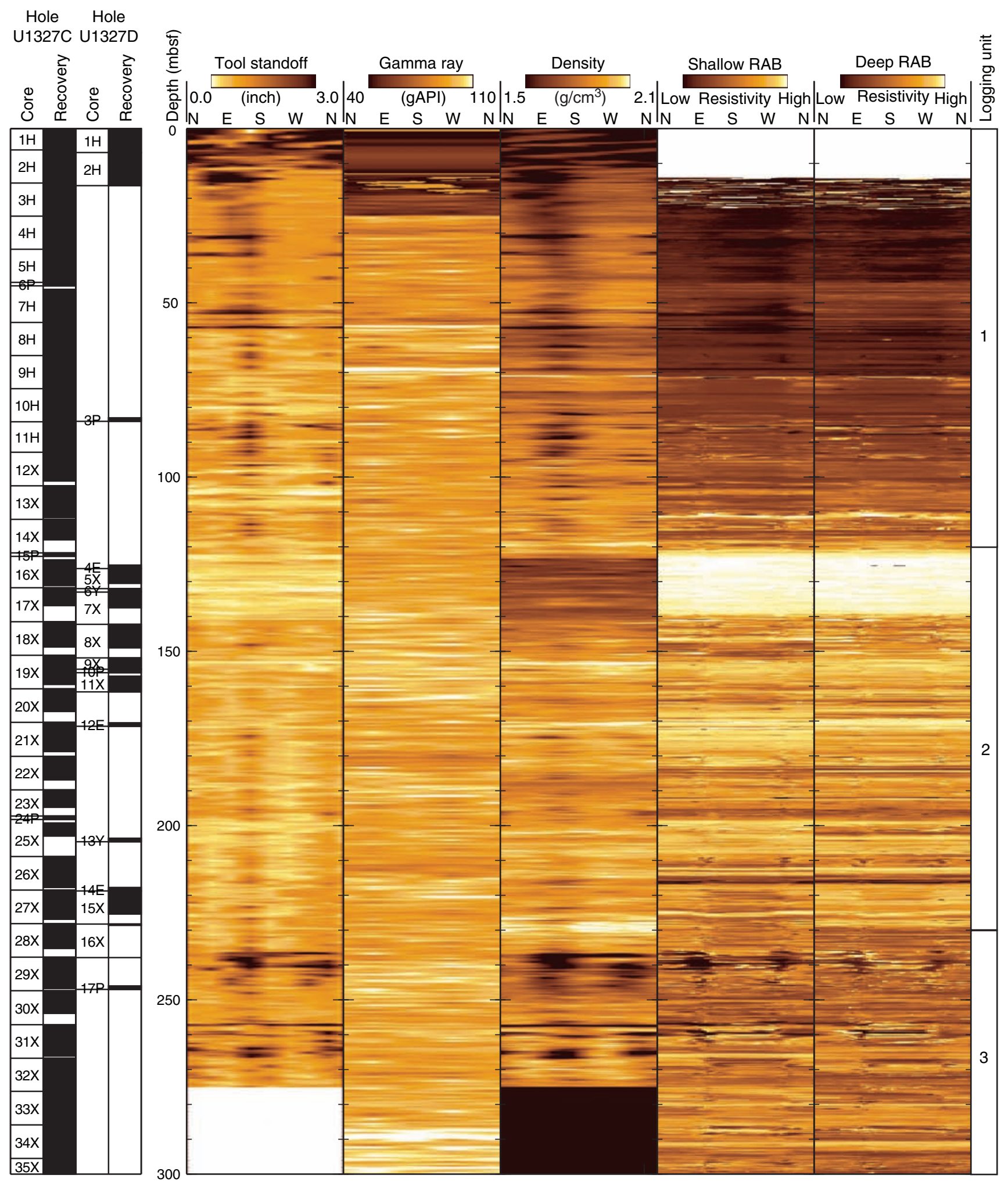


Figure F61. Comparison of LWD porosity logs with core-derived porosity data.

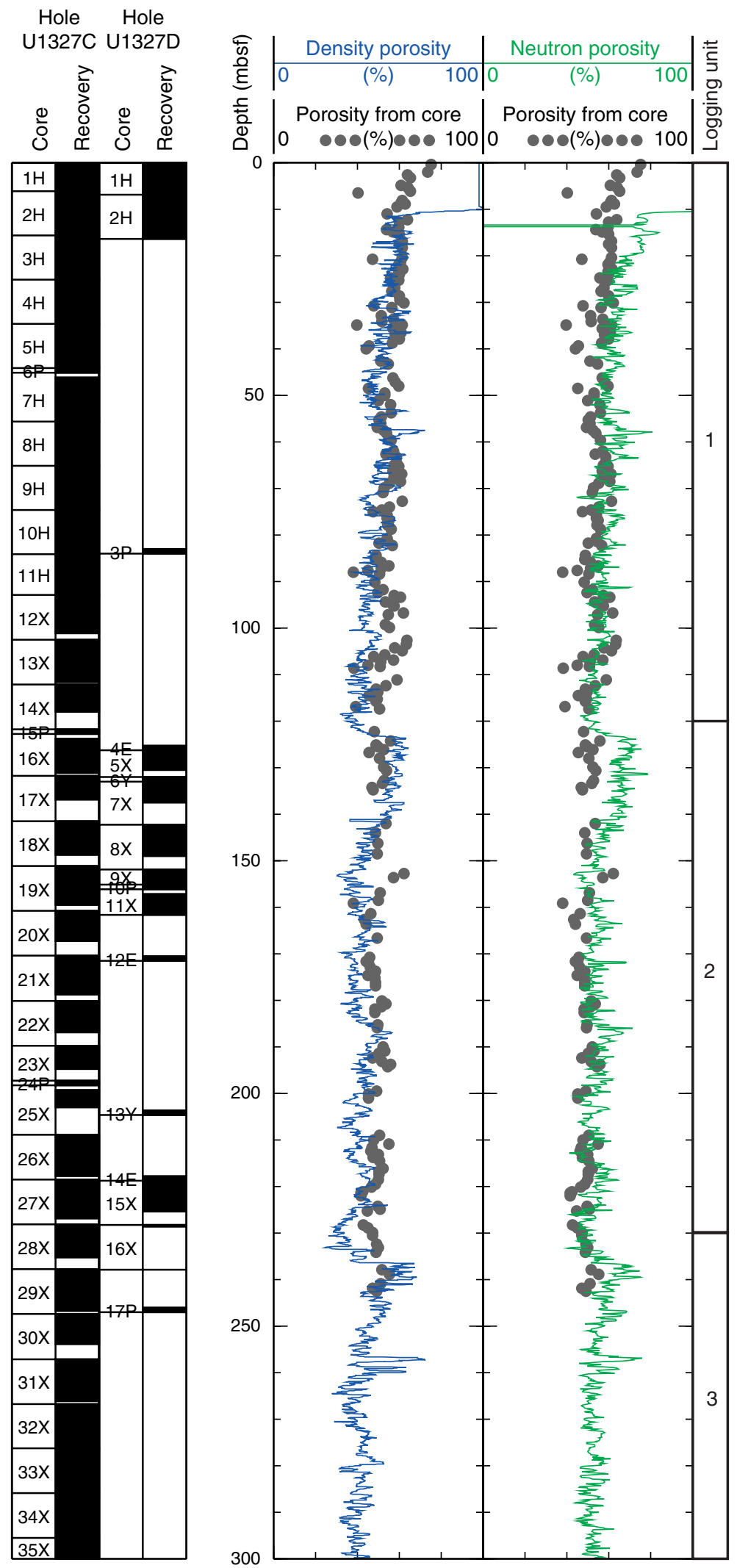


Figure F62. Water saturation from Archie's equation and from LWD porosity and resistivity logs. $R_{\mathrm{w}}=$ formation water resistivity, $m=$ cementation coefficient, $R_{0}=$ computed formation resistivity for $100 \%$ water saturation, $R_{\mathrm{t}}=$ measured resistivity, $S_{\mathrm{w}}=$ water saturation, $\mathrm{RAB}=$ resistivity-at-the-bit image obtained by the GeoVISION tool.

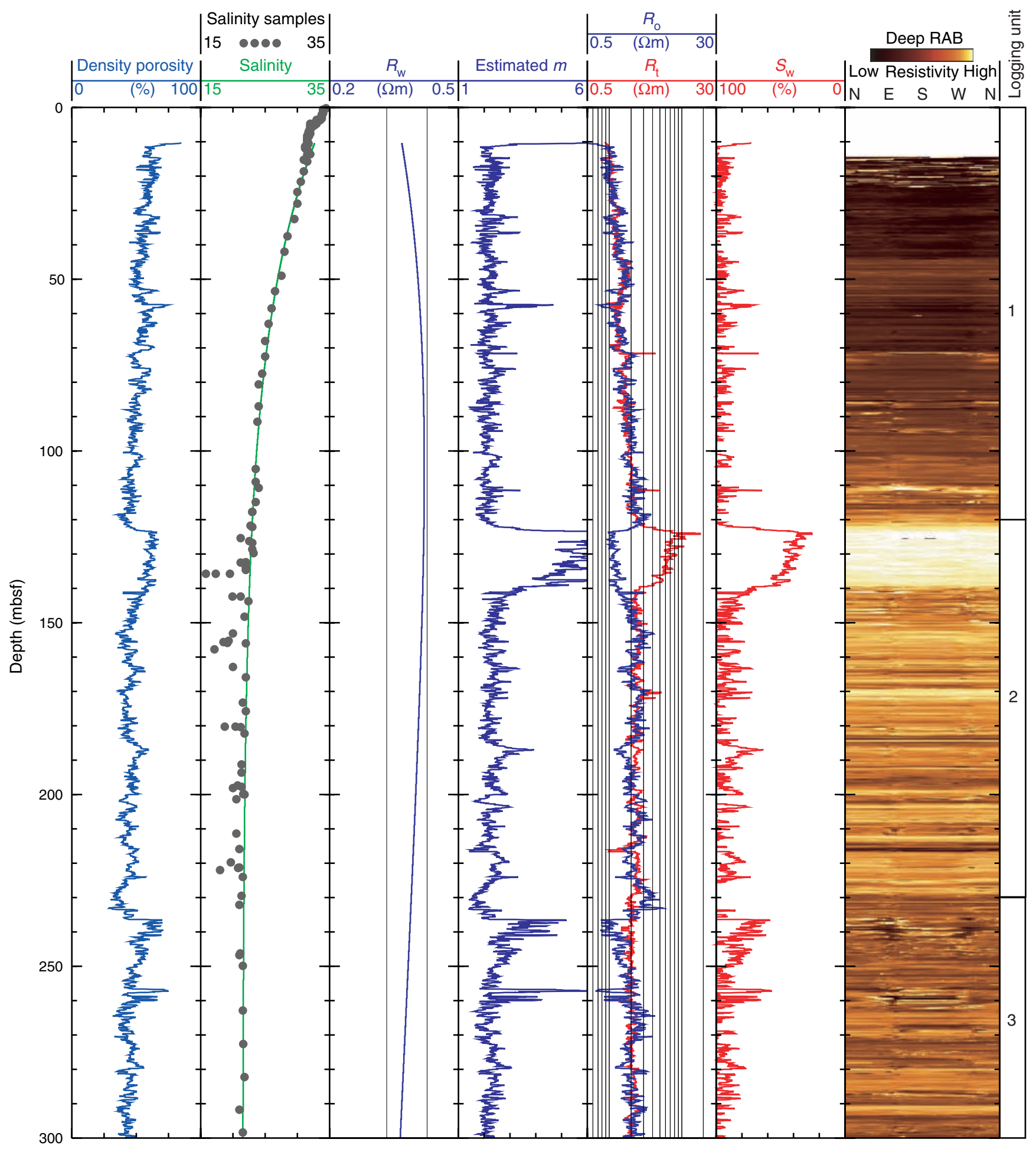


Figure F63. Stacked waveforms recorded at 16 stations by the Well Seismic Tool in the Hole U1327D vertical seismic profile. Red crosses $=$ picked first break times.

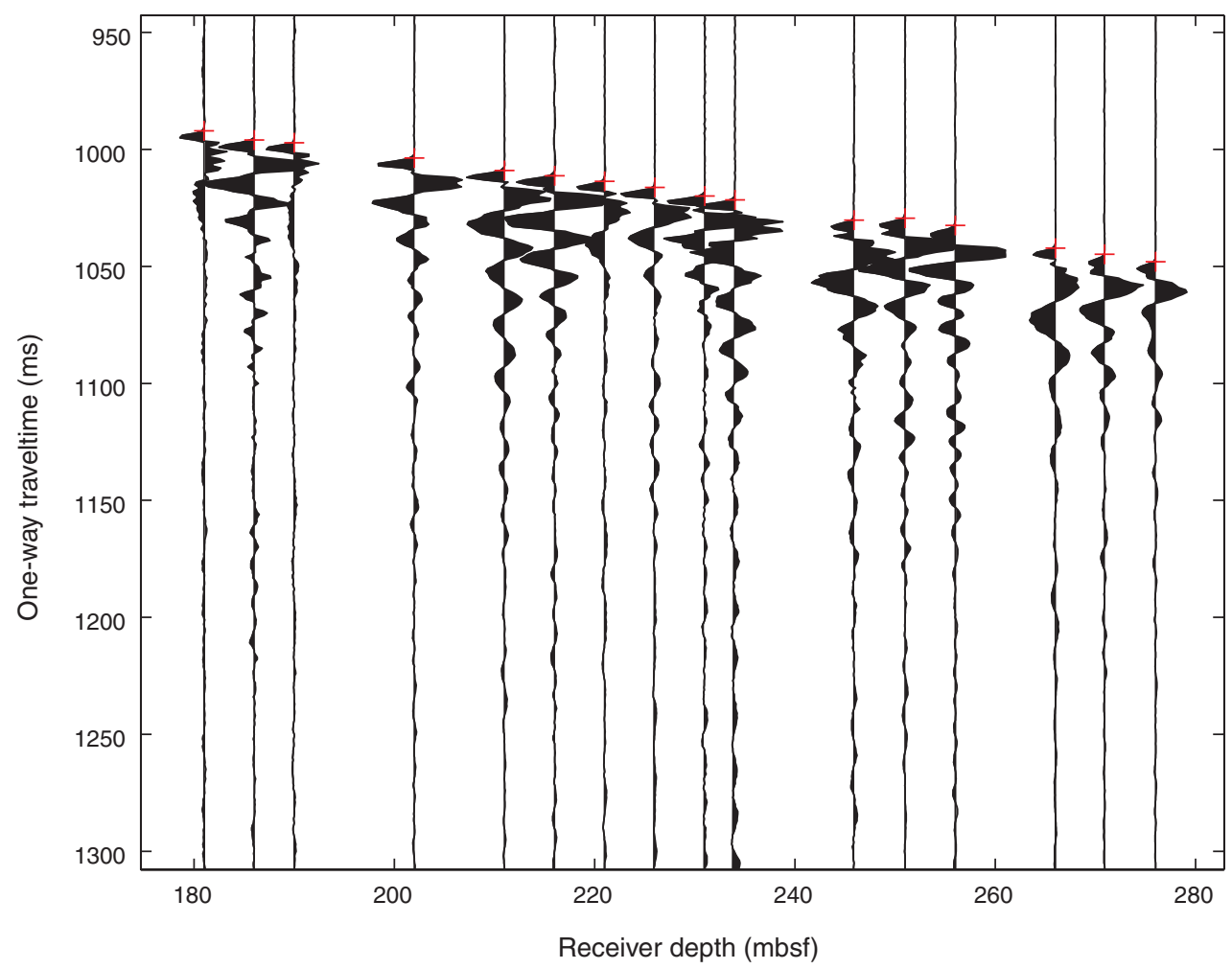


Figure F64. Time vs. depth plot of first break times in the Hole U1327D vertical seismic profile. The best-fit straight lines indicate two regions of high $(1843 \mathrm{~m} / \mathrm{s})$ and low $(1281 \mathrm{~m} / \mathrm{s})$ average interval velocity.

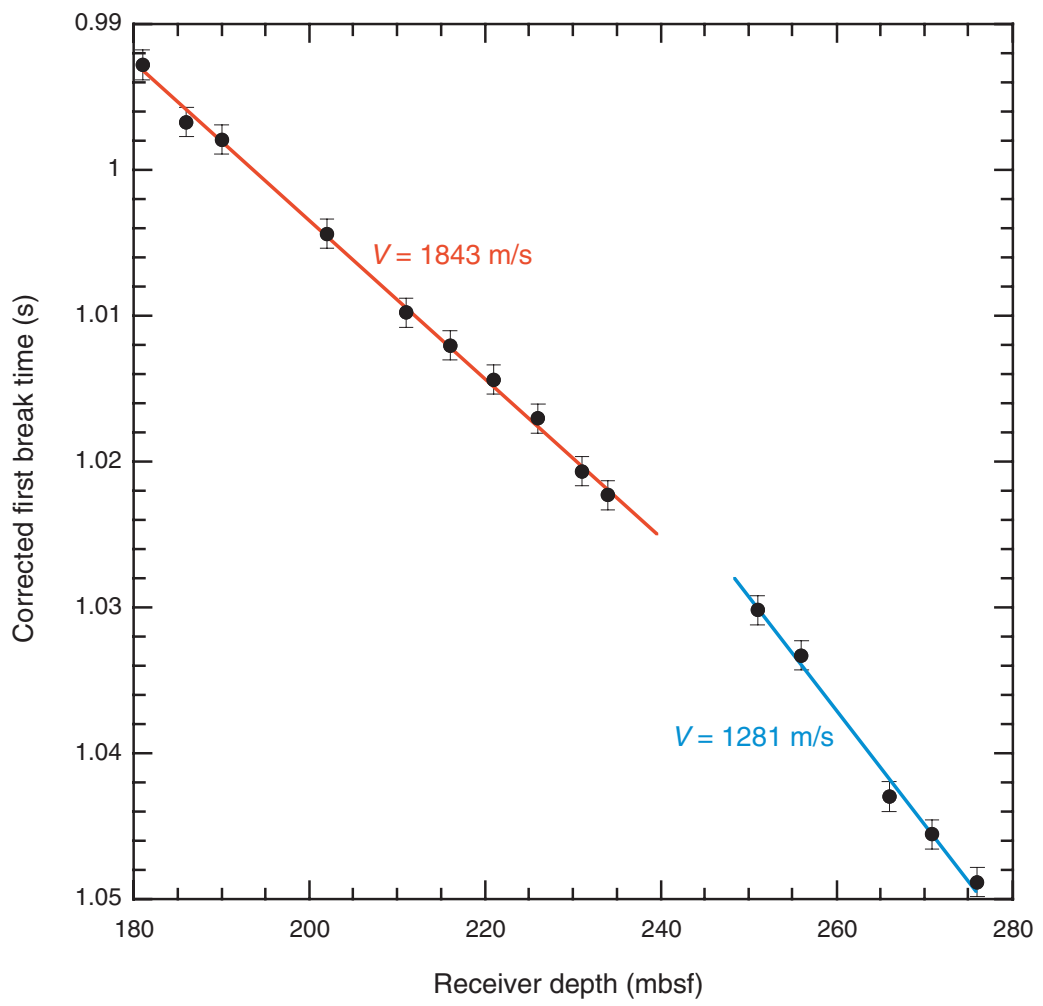


Figure F65. (A) Interval velocity inversion of the first break times in the Hole U1327D vertical seismic profile (VSP), compared to (B) the $P$-wave velocity sonic log from Hole U1327D, and (C) an interval velocity inversion from the Hole $889 \mathrm{~B}$ VSP. Dashed line $= \pm 1$ posterior standard deviation, shaded area $=$ intervals of steep decrease in velocity with depth that correspond to the BSR.

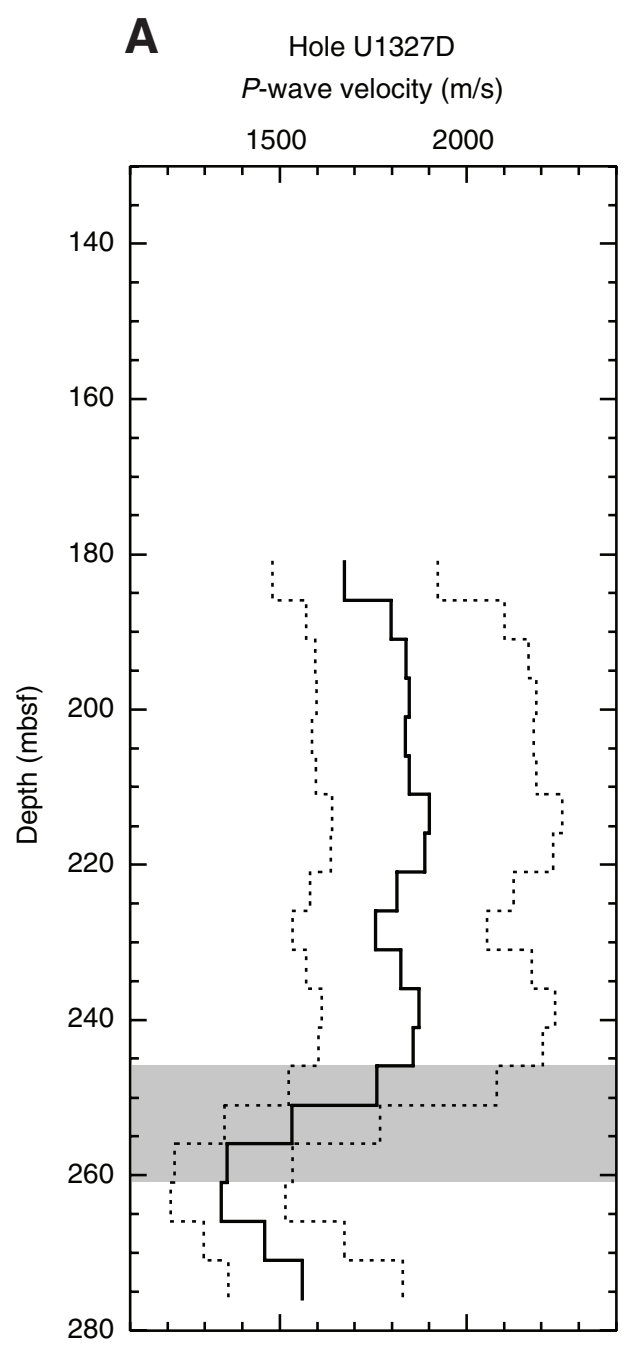

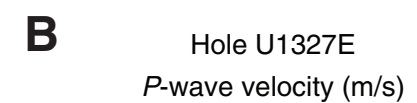

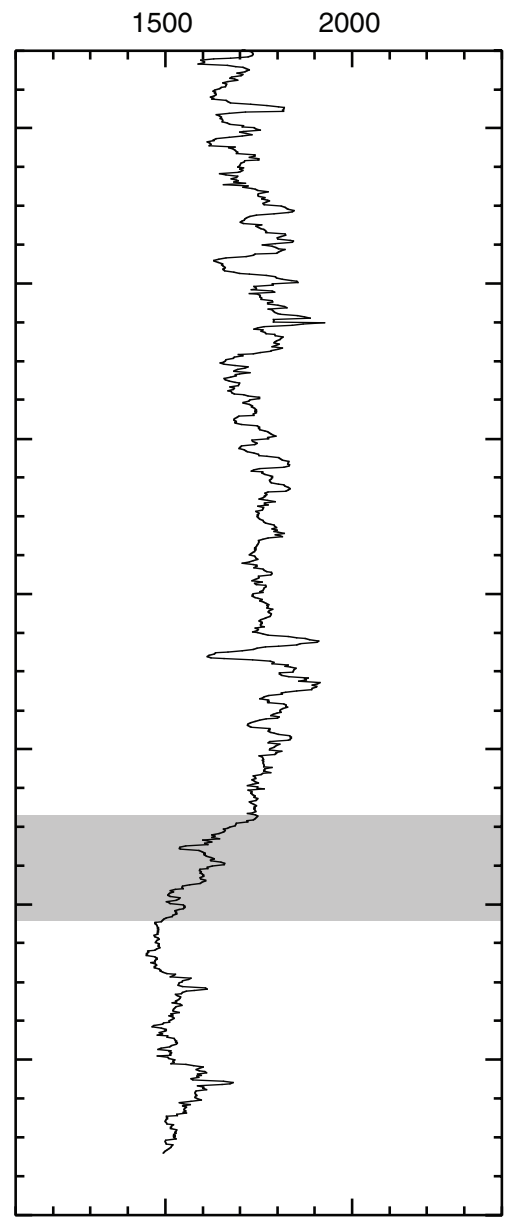

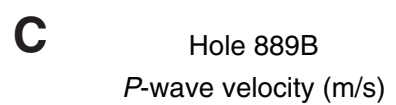

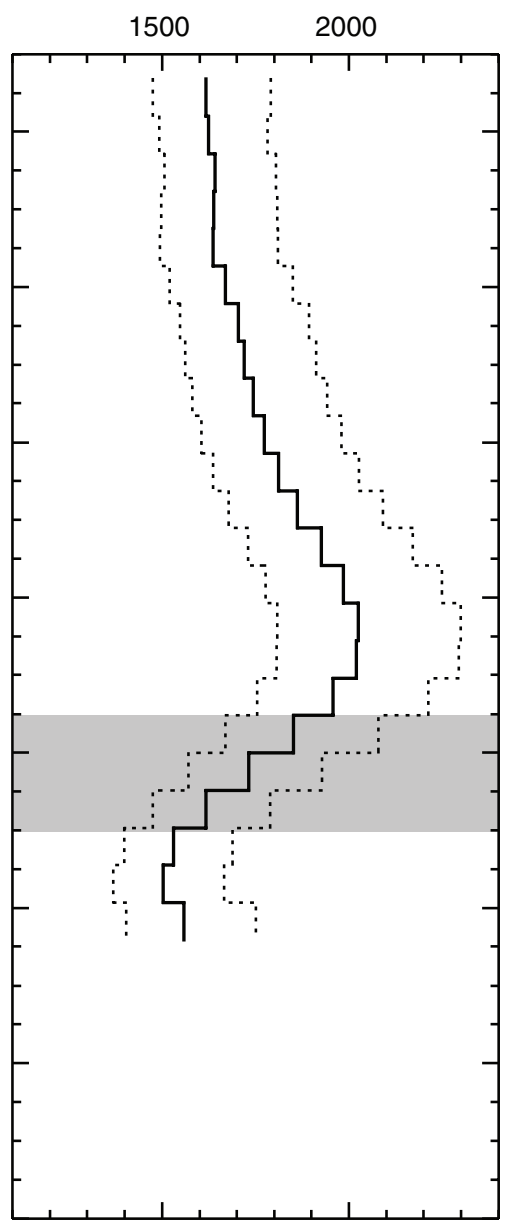


Figure F66. Illustration of the lateral variability in gas hydrate distribution at Site U1327. RAB = resistivity-atthe-bit image obtained by the GeoVISION tool, avg = average, $\mathrm{P} 16 \mathrm{~B}=$ phase-shift resistivity measured by the EcoScope tool at a source-receiver spacing of 16 in $(41 \mathrm{~cm}), \mathrm{A} 40 \mathrm{~B}=$ attenuation resistivity measured by the EcoScope tool at a source-receiver spacing of 40 in $(102 \mathrm{~cm}), \mathrm{IR}=$ infrared, SFLU $=$ spherically focused resistivity, Med. = medium. High hydrate concentrations are marked by light intervals (high resistivity) in the RAB image, purple to red intervals (cold temperatures) in the IR images, and high resistivities in the resistivity logs. The high resistivity interval in Hole U1327A (120-140 mbsf) correlates with the cold interval in the IR images of Hole U1327C (130-160 mbsf), except for a $10 \mathrm{~m}$ depth difference. The resistivity log in Hole U1327D shows a high resistivity interval at 155-160 mbsf, which correlates with a cold interval observed in the IR images from the same hole. The resistivity log in Hole U1327E does not show a high resistivity interval at 155-160 mbsf.

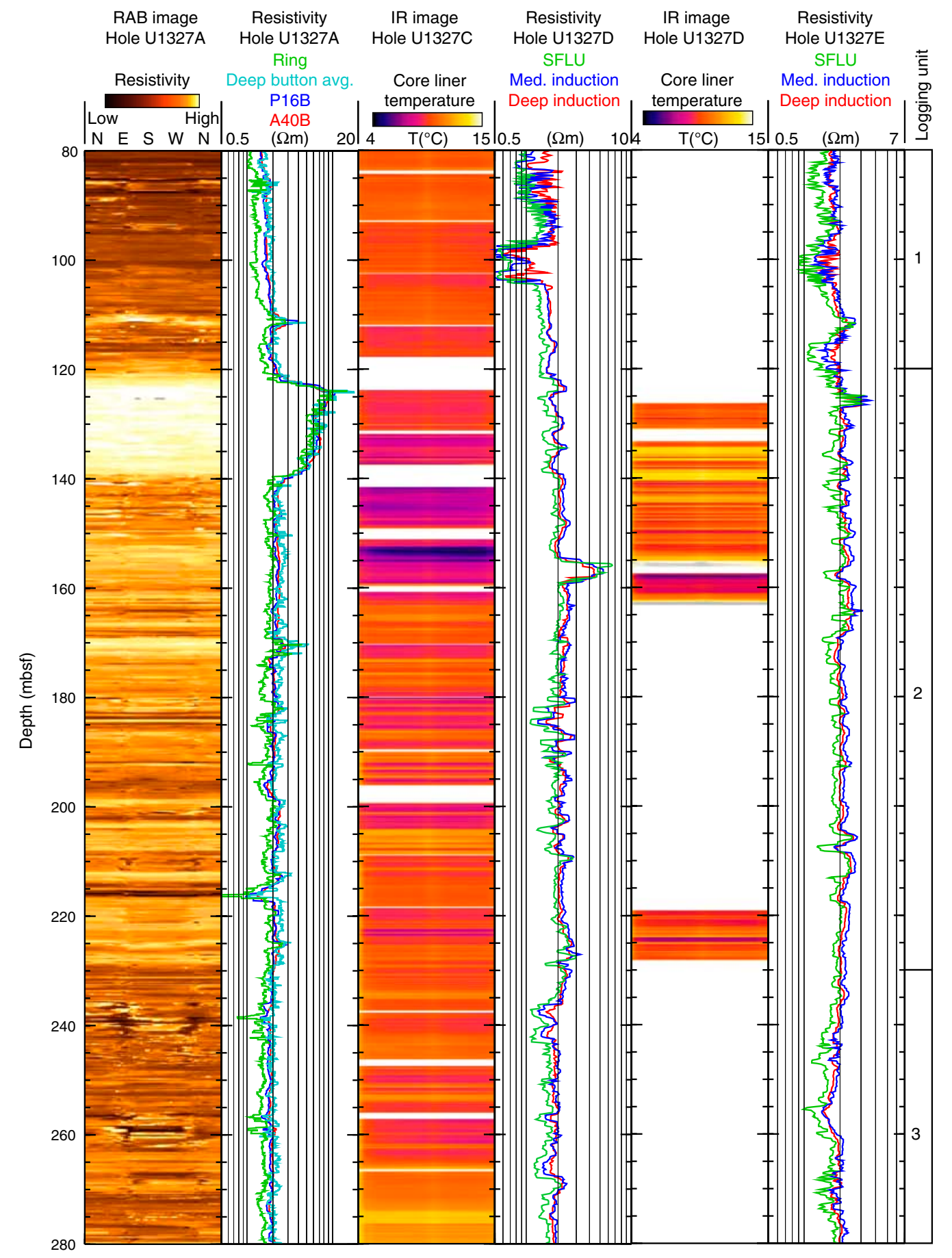


Figure F67. Borehole temperatures recorded with the Temperature/Acceleration/Pressure tool on the triple combination tool string run in Hole U1327D.

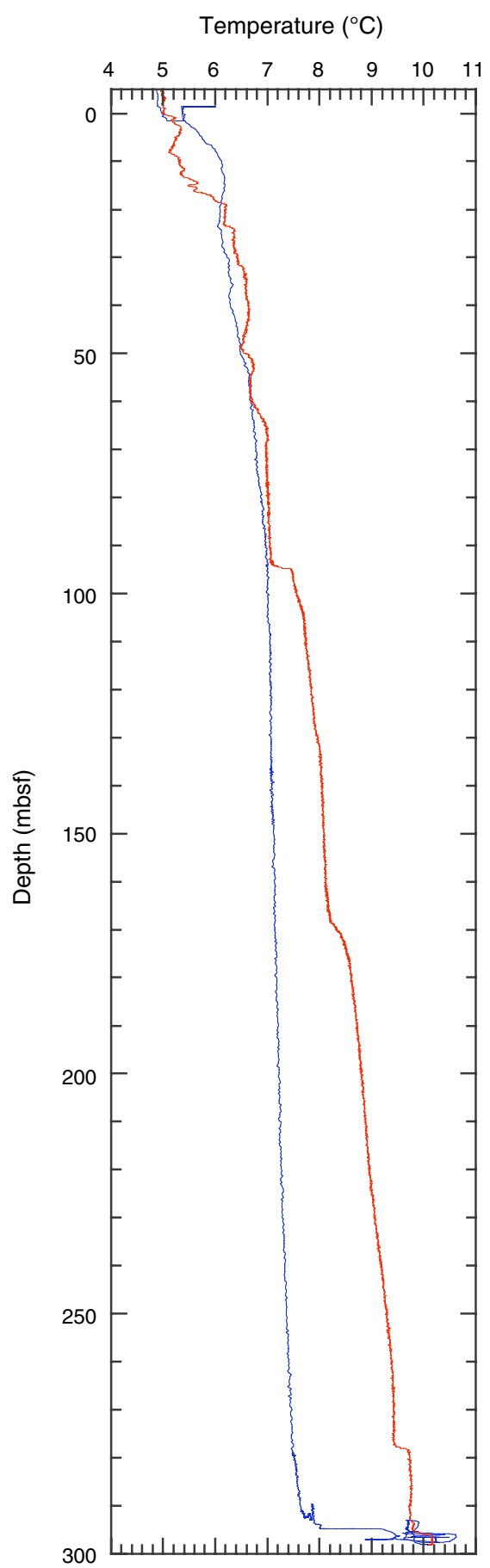


Table T1. Site U1327 coring summary. (See table note. Continued on next page.)

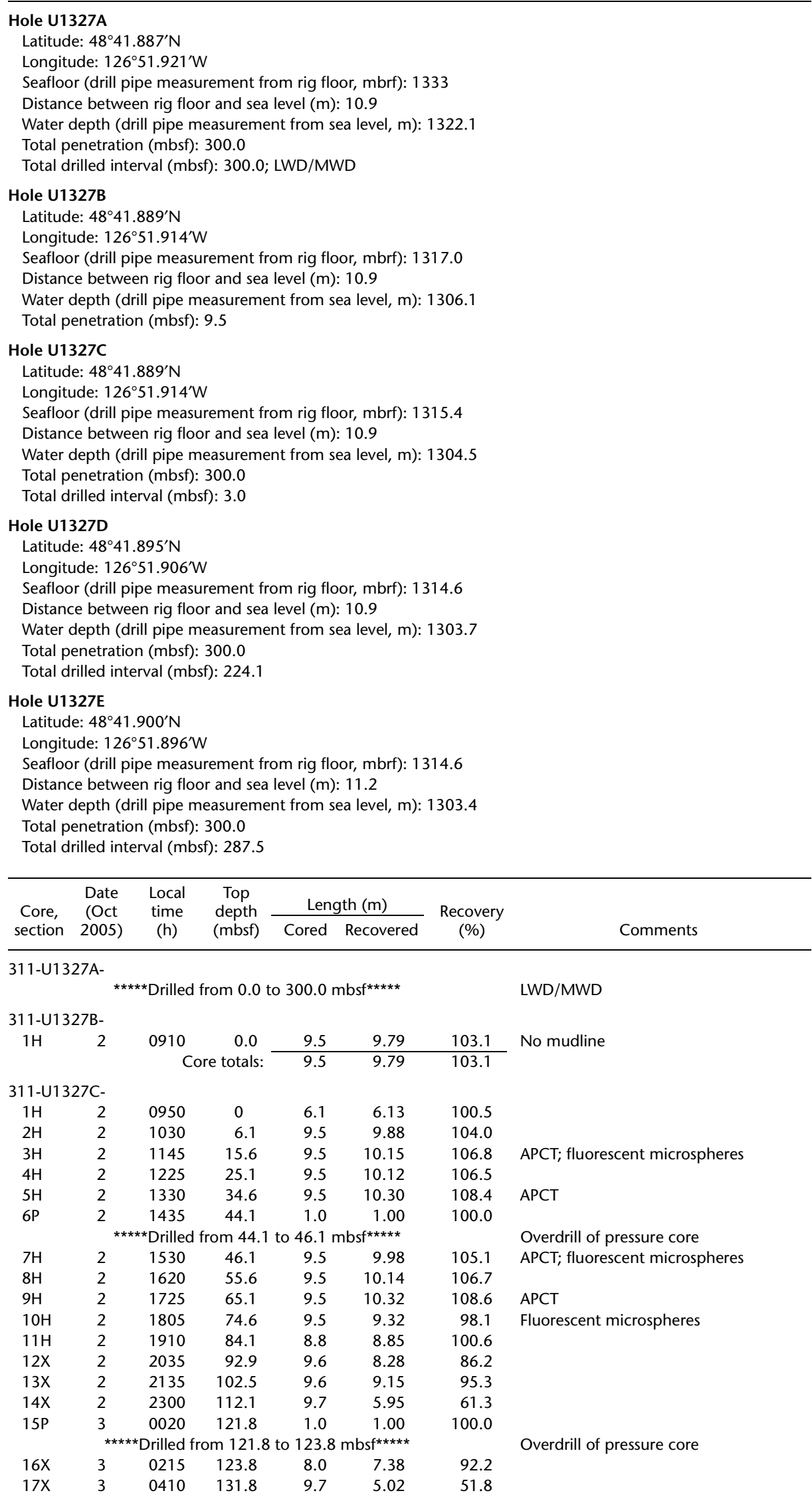


Table T1 (continued).

\begin{tabular}{|c|c|c|c|c|c|c|c|}
\hline \multirow{2}{*}{$\begin{array}{l}\text { Core, } \\
\text { section }\end{array}$} & \multirow{2}{*}{$\begin{array}{l}\text { Date } \\
\text { (Oct } \\
2005 \text { ) }\end{array}$} & \multirow{2}{*}{$\begin{array}{l}\text { Local } \\
\text { time } \\
\text { (h) }\end{array}$} & \multirow{2}{*}{$\begin{array}{c}\text { Top } \\
\text { depth } \\
\text { (mbsf) }\end{array}$} & \multicolumn{2}{|c|}{ Length $(\mathrm{m})$} & \multirow{2}{*}{$\begin{array}{l}\text { Recovery } \\
\text { (\%) }\end{array}$} & \multirow[b]{2}{*}{ Comments } \\
\hline & & & & Cored & Recovered & & \\
\hline $18 \mathrm{X}$ & 3 & 0615 & 141.5 & 9.6 & 7.30 & 76.0 & \\
\hline $19 \mathrm{X}$ & 3 & 0840 & 151.1 & 9.7 & 8.40 & 86.6 & \\
\hline $20 x$ & 3 & 1030 & 160.8 & 9.6 & 6.50 & 67.7 & DVTP at $170.4 \mathrm{mbsf}$ \\
\hline $21 x$ & 3 & 1315 & 170.4 & 9.7 & 8.38 & 86.4 & \\
\hline $22 x$ & 3 & 1435 & 180.1 & 9.6 & 6.72 & 69.1 & \\
\hline $23 x$ & 3 & 1605 & 189.7 & 7.6 & 5.03 & 66.2 & \\
\hline \multirow[t]{2}{*}{$24 \mathrm{P}$} & 3 & 1715 & 197.3 & 1.0 & 1.00 & 100.0 & \\
\hline & \multicolumn{5}{|c|}{ 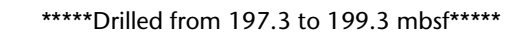 } & & Overdrill of pressure core \\
\hline $25 \mathrm{X}$ & 3 & 1910 & 199.3 & 9.6 & 3.73 & 38.9 & \\
\hline $26 \mathrm{X}$ & 3 & 2040 & 208.9 & 9.6 & 8.91 & 92.8 & DVTPP at $218.5 \mathrm{mbsf}$ \\
\hline $27 X$ & 4 & 0020 & 218.5 & 9.6 & 8.37 & 87.2 & \\
\hline $28 \mathrm{X}$ & 4 & 0235 & 228.1 & 9.6 & 7.12 & 74.2 & \\
\hline $29 x$ & 4 & 0415 & 237.7 & 9.7 & 8.99 & 92.7 & \\
\hline $30 x$ & 4 & 0605 & 247.4 & 9.7 & 6.50 & 67.0 & \\
\hline $31 x$ & 4 & 0745 & 257.1 & 9.6 & 9.08 & 94.6 & \\
\hline $32 \mathrm{x}$ & 4 & 0915 & 266.7 & 9.6 & 9.79 & 102.0 & \\
\hline $33 x$ & 4 & 1000 & 276.3 & 9.6 & 9.49 & 98.9 & \\
\hline $34 X$ & 4 & 1110 & 285.9 & 9.6 & 9.41 & 98.0 & \\
\hline \multirow{2}{*}{$35 x$} & 4 & 1215 & 295.5 & 4.5 & 4.48 & 99.6 & DVTPP at $300.0 \mathrm{mbsf}$ \\
\hline & \multicolumn{3}{|c|}{ Core totals: } & 297.0 & 262.17 & 88.3 & \\
\hline \multicolumn{8}{|c|}{ 311-U1327D- } \\
\hline $1 \mathrm{H}$ & 4 & 1710 & 0.0 & 6.9 & 6.90 & 100.0 & Fluorescent microspheres \\
\hline \multirow[t]{2}{*}{$2 \mathrm{H}$} & 4 & 1855 & 6.9 & 9.5 & 9.83 & 103.5 & Fluorescent microspheres \\
\hline & \multicolumn{5}{|c|}{$* \star * * *$ Drilled from 6.9 to $83.0 \mathrm{mbsf}{ }^{* \star * * *}$} & & \\
\hline \multirow[t]{3}{*}{$3 P$} & 4 & 2320 & 83.0 & 1.0 & 0.00 & 0.0 & \\
\hline & & *Drilled & rom 83.0 & to 85.0 i & nbsf***** & & Overdrill of pressure core \\
\hline & & Drilled & om 85.0 & o 125.3 & $m b s f^{\star \star \star \star *}$ & & \\
\hline $4 \mathrm{E}$ & 6 & 0050 & 125.3 & 1.0 & 1.10 & 110.0 & \\
\hline $5 X$ & 6 & 0210 & 126.3 & 5.7 & 4.14 & 72.6 & \\
\hline $6 \mathrm{Y}$ & 6 & 0340 & 132.0 & 1.0 & 0.84 & 84.0 & \\
\hline $7 X$ & 6 & 0540 & 133.0 & 9.3 & 4.54 & 48.8 & \\
\hline $8 \mathrm{X}$ & 6 & 0740 & 142.3 & 9.6 & 6.64 & 69.2 & \\
\hline $9 \mathrm{X}$ & 6 & 0900 & 151.9 & 3.2 & 3.66 & 114.4 & \\
\hline $10 \mathrm{P}$ & 6 & 1040 & 155.1 & 1.0 & 0.92 & 92.0 & \\
\hline & & Drilled $\mathrm{f}$ & m 155.1 & to 157.1 & $m b s f^{\star \star \star \star *}$ & & Overdrill of pressure core \\
\hline $11 x$ & 6 & 1210 & 157.1 & 4.5 & 4.62 & 102.7 & \\
\hline & & Drilled $\mathrm{f}$ & m 157.1 & to 170.5 & $m b s f^{\star \star \star \star *}$ & & \\
\hline $12 \mathrm{E}$ & 6 & 1540 & 170.5 & 1.0 & 1.14 & 114.0 & \\
\hline & & Drilled $\mathrm{f}$ & $\mathrm{m} 170.5$ & to 203.6 & $m b s f^{* \star * * *}$ & & \\
\hline $13 Y$ & 6 & 2045 & 203.6 & 1.0 & 0.48 & 48.0 & \\
\hline & & Drilled $\mathrm{f}$ & m 203.6 & to 217.7 & $m b s f^{* * * * *}$ & & \\
\hline $14 \mathrm{E}$ & 7 & 0110 & 217.7 & 1.0 & 1.15 & 115.0 & \\
\hline $15 X$ & 7 & 0355 & 218.7 & 9.6 & 6.73 & 70.1 & \\
\hline $16 \mathrm{X}$ & 7 & 0620 & 228.3 & 9.6 & 0.30 & 3.1 & \\
\hline & & Drilled $\mathrm{f}$ & m 228.3 & to 246.0 & mbsf***** & & \\
\hline $17 P$ & 7 & 1030 & 246.0 & 1.0 & 1.00 & 100.0 & \\
\hline & & Drilled $\mathrm{f}$ & m 246.0 & to 247.0 & $m b s f^{\star \star \star \star *}$ & & \\
\hline & & & e totals: & 75.9 & 53.99 & 71.1 & \\
\hline 311-U13 & 27E- & & & & & & \\
\hline & & **Drille & from 0.0 & to $3.0 \mathrm{~m}$ & $b s f^{\star \star \star \star *}$ & & \\
\hline $1 \mathrm{H}$ & 9 & 920 & 3.0 & 9.5 & 9.94 & 104.6 & \\
\hline & & **Drillec & from 3.0 & o $40.0 n$ & lbsf $f_{\star \star \star \star *}$ & & \\
\hline $2 \mathrm{P}$ & 9 & 1300 & 40.0 & 1.0 & 1.00 & 100.0 & Ball activated prematurely, sheared pin \\
\hline & & *Drilled & rom 40.0 & to 80.0 r & $\operatorname{mbsf*\star \star \star *}$ & & \\
\hline $3 P$ & 9 & 1550 & 80.0 & 1.0 & 0.95 & 95.0 & Sheared OS pin \\
\hline & & Drilled & om 80.0 & to 128.0 & $m b s f^{* \star * \star *}$ & & \\
\hline $4 \mathrm{E}$ & 9 & 2040 & 128.0 & 1.0 & 0.48 & 48.0 & \\
\hline & & Drilled $f$ & $\mathrm{~m} 128.0$ & to 129.0 & 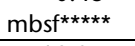 & & \\
\hline & & & e totals: & 12.5 & 12.37 & 99.0 & \\
\hline
\end{tabular}

Note: $\mathrm{LWD} / \mathrm{MWD}=$ logging while drilling/measurement while drilling, APCT = advanced piston corer temperature tool, DVTP $=$ Davis-Villinger Temperature Probe, DVTPP = Davis-Villinger Temperature-Pressure Probe, OS = over shot. 


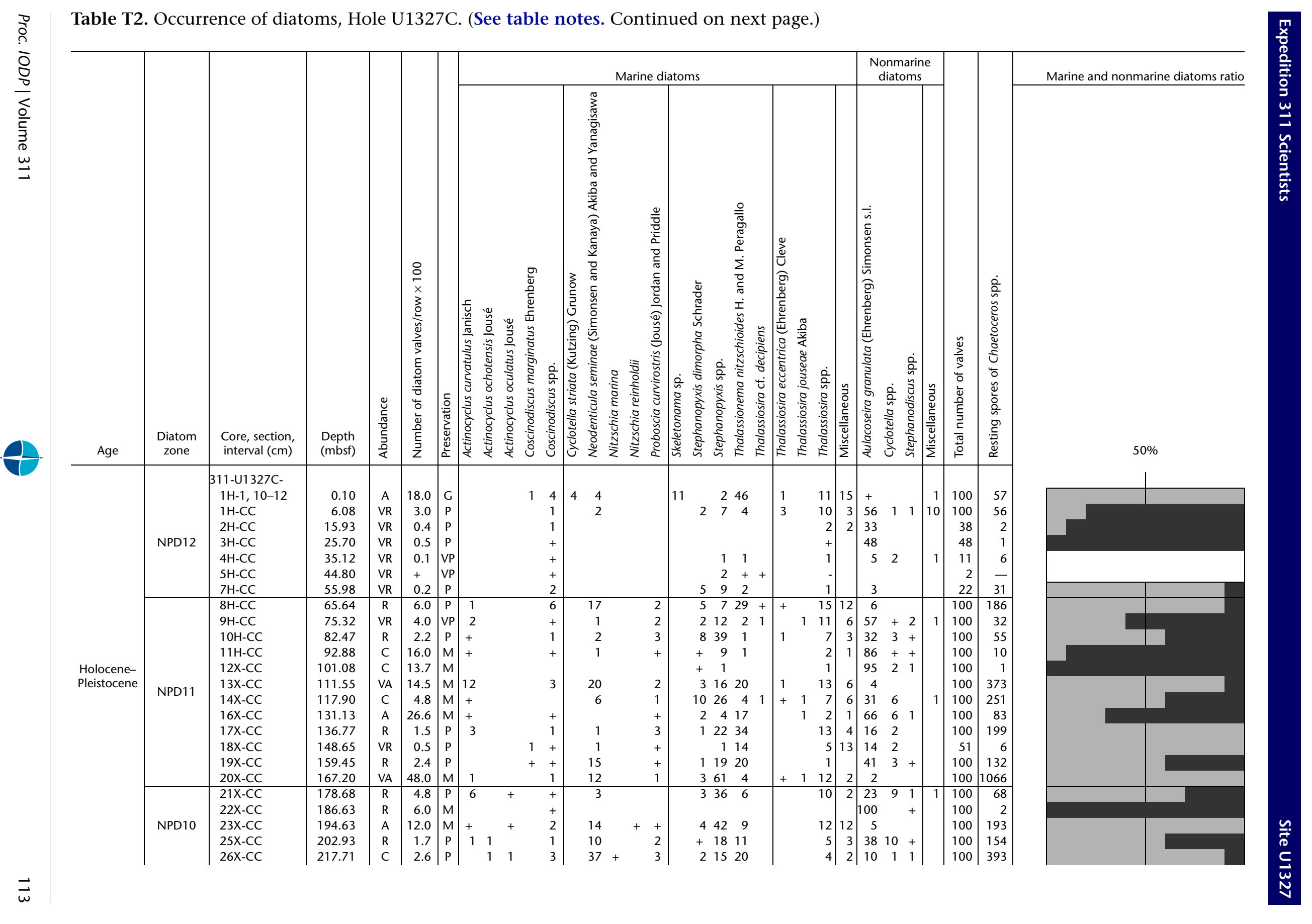




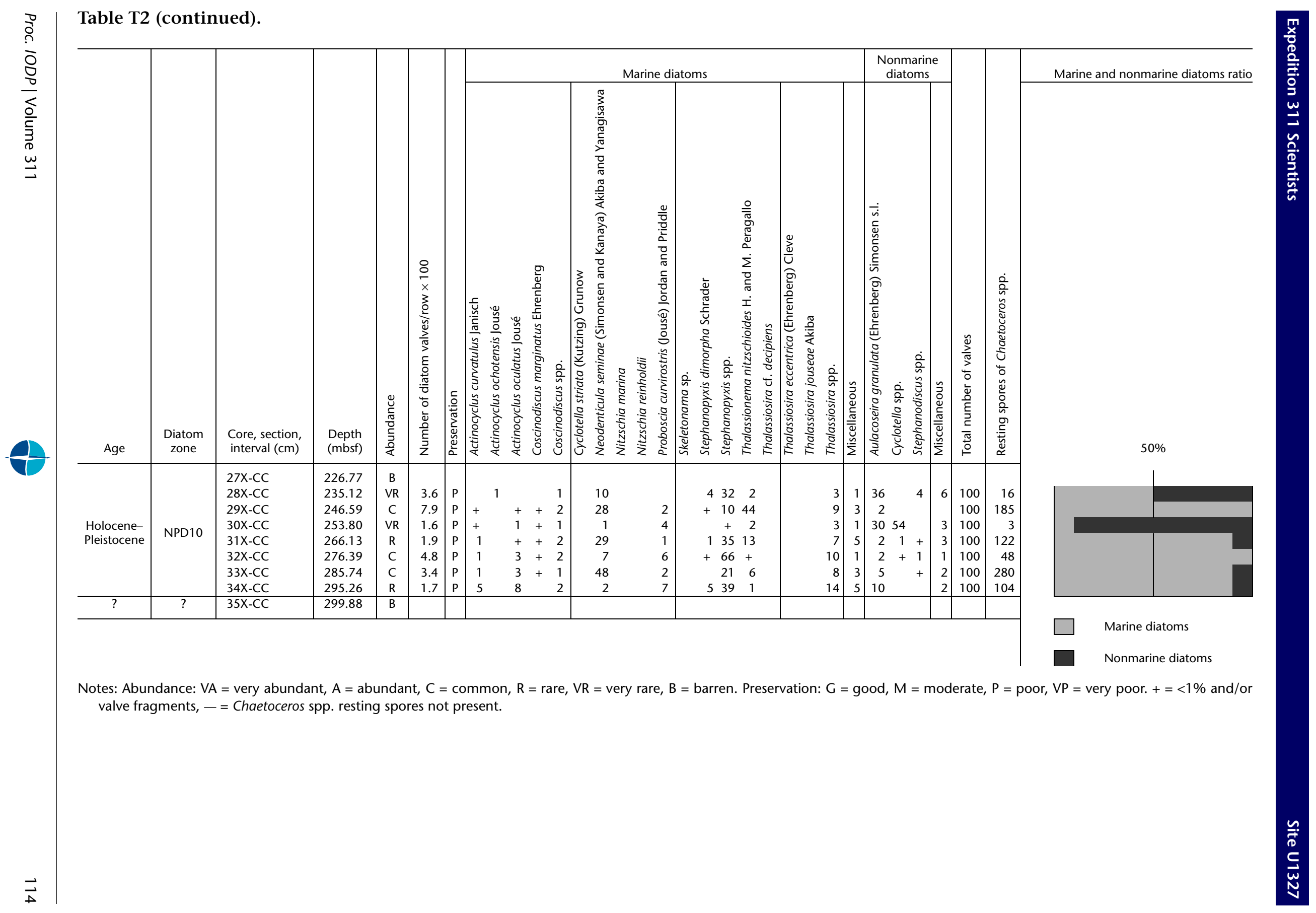




\begin{tabular}{|c|c|c|c|c|c|c|c|c|c|c|c|c|c|c|c|c|c|c|c|}
\hline \multirow{2}{*}{$\begin{array}{l}\text { Core, section, } \\
\text { interval }(\mathrm{cm})\end{array}$} & \multirow{2}{*}{$\begin{array}{l}\text { Depth } \\
\text { (mbsf) }\end{array}$} & \multirow{2}{*}{$\begin{array}{l}\text { Volume } \\
(\mathrm{mL})\end{array}$} & \multirow[b]{2}{*}{$\mathrm{pH}$} & \multirow{2}{*}{$\begin{array}{l}\text { Alkalinity } \\
(\mathrm{mM})\end{array}$} & \multirow[b]{2}{*}{ Salinity } & \multirow{2}{*}{$\underset{(\mathrm{mM})}{\mathrm{Cl}}$} & \multirow{2}{*}{$\begin{array}{l}\mathrm{SO}_{4} \\
(\mathrm{mM})\end{array}$} & \multirow{2}{*}{$\begin{array}{l}\mathrm{PO}_{4} \\
(\mu \mathrm{M})\end{array}$} & \multirow{2}{*}{$\begin{array}{c}\mathrm{NH}_{4} \\
(\mathrm{mM})\end{array}$} & \multirow{2}{*}{$\begin{array}{c}\mathrm{H}_{4} \mathrm{SiO}_{4} \\
(\mu \mathrm{M})\end{array}$} & \multicolumn{4}{|c|}{ Cations (mM) } & \multirow[b]{2}{*}{$\mathrm{Mg} / \mathrm{Ca}$} & & ace ele & ents $(\mu \mathrm{M}$ & \\
\hline & & & & & & & & & & & $\mathrm{Na}$ & $\mathrm{K}$ & $\mathrm{Mg}$ & $\mathrm{Ca}$ & & $\mathrm{Sr}$ & $\mathrm{Li}$ & B & $\mathrm{Ba}$ \\
\hline 311-U1327C- & & & & & & & & & & & & & & & & & & & \\
\hline $1 \mathrm{H}-1,140-150$ & 1.5 & 48 & 7.45 & 5.5 & 34.0 & 548.6 & 27.4 & 24.7 & 0.3 & 648.0 & 452.4 & 11.5 & 48.0 & 8.9 & 5.38 & 80.9 & 44.1 & 488.0 & 0.0 \\
\hline $1 \mathrm{H}-3,140-150$ & 4.5 & 42 & 7.65 & 13.8 & 33.0 & 542.7 & 15.6 & 38.0 & 0.7 & 632.3 & 447.0 & 10.5 & 44.9 & 6.4 & 6.99 & 71.8 & 35.8 & 482.0 & 0.0 \\
\hline $2 \mathrm{H}-1,140-150$ & 7.6 & 40 & 7.80 & 22.5 & 32.0 & 536.7 & 1.5 & 91.8 & 1.4 & 482.8 & 434.9 & 9.6 & 39.7 & 3.5 & 11.36 & 65.8 & 30.0 & 500.3 & 5.2 \\
\hline $2 \mathrm{H}-3,140-150$ & 10.6 & 44 & 7.64 & 24.4 & 31.5 & 531.3 & 0.0 & 62.7 & 1.5 & 603.5 & 429.6 & 9.3 & 39.2 & 3.4 & 11.63 & 65.3 & 29.1 & 507.7 & 9.8 \\
\hline $2 \mathrm{H}-5,140-150$ & 13.6 & 42 & 7.78 & 25.7 & 32.0 & 525.8 & 0.0 & 58.1 & 1.9 & 718.1 & 433.0 & 9.8 & 38.1 & 3.5 & 11.00 & 67.6 & 30.3 & 540.5 & 18.8 \\
\hline $2 \mathrm{H}-7,54-64$ & 15.7 & 40 & 7.71 & 26.3 & 31.5 & 524.8 & 0.0 & 65.4 & 1.9 & 594.1 & 418.8 & 9.1 & 36.3 & 3.1 & 11.76 & 66.7 & 32.0 & 552.9 & 28.4 \\
\hline $3 \mathrm{H}-2,140-150$ & 18.6 & 58 & 7.97 & 26.8 & 31.0 & 522.9 & 0.0 & 66.3 & 1.7 & 560.9 & 421.0 & 9.7 & 35.4 & 2.8 & 12.54 & 65.6 & 33.5 & 559.8 & 34.9 \\
\hline $3 \mathrm{H}-4,140-150$ & 21.6 & 56 & 7.97 & 27.4 & 30.5 & 517.9 & 0.0 & 56.3 & 1.9 & 518.7 & 417.3 & 9.8 & 35.8 & 2.3 & 15.43 & 66.6 & 32.7 & 546.3 & 37.6 \\
\hline $3 \mathrm{H}-6,140-150$ & 24.6 & 63 & 8.06 & 26.7 & 30.0 & 515.4 & 0.0 & 81.8 & 1.5 & 578.2 & 411.6 & 9.6 & 33.7 & 1.8 & 18.96 & 62.7 & 31.6 & 549.4 & 32.3 \\
\hline $4 \mathrm{H}-2,135-150$ & 28.0 & 60 & 8.00 & 23.9 & 30.0 & 507.0 & 0.0 & 65.4 & 1.9 & 539.0 & 411.1 & 9.8 & 31.0 & 1.4 & 21.94 & 56.4 & 31.6 & 575.2 & 20.7 \\
\hline $4 \mathrm{H}-5,135-150$ & 32.5 & 60 & 8.03 & 22.9 & 29.5 & 499.1 & 0.0 & 66.3 & 2.0 & 647.1 & 413.0 & 9.7 & 30.3 & 0.9 & 32.06 & 54.3 & 31.1 & 545.1 & 17.1 \\
\hline $5 \mathrm{H}-2,135-150$ & 37.5 & 52 & 8.11 & 23.8 & 28.5 & 485.7 & 0.0 & 69.0 & 1.9 & 614.5 & 401.5 & 9.0 & 27.4 & 3.0 & 9.04 & 53.0 & 30.1 & 479.6 & 14.0 \\
\hline $5 \mathrm{H}-5,135-150$ & 42.0 & 54 & 8.16 & 24.1 & 28.0 & 479.8 & 0.0 & 54.5 & 2.3 & 538.9 & 399.9 & 9.3 & 26.6 & 2.0 & 13.34 & 53.5 & 29.6 & 478.3 & 14.1 \\
\hline $7 \mathrm{H}-2,135-150$ & 49.0 & 49 & 8.08 & 24.2 & 27.5 & 462.5 & 0.0 & 43.6 & 2.6 & 493.7 & 378.0 & 7.8 & 25.4 & 2.3 & 10.82 & 54.1 & 29.6 & 446.6 & 17.4 \\
\hline 7H-5, 135-150 & 53.5 & 48 & 8.06 & 24.6 & 26.5 & 453.0 & 0.0 & 59.0 & 2.6 & 520.4 & 379.4 & 7.8 & 24.1 & 2.5 & 9.45 & 54.5 & 29.3 & 450.7 & 22.3 \\
\hline $8 \mathrm{H}-2,120-150$ & 58.5 & 50 & 8.32 & 24.4 & 26.0 & 445.6 & 0.1 & 37.2 & 3.3 & 376.3 & 369.6 & 8.3 & 22.8 & 2.3 & 9.89 & 54.3 & 30.4 & 376.7 & 37.6 \\
\hline $8 \mathrm{H}-5,125-150$ & 63.0 & 53 & 8.21 & 24.3 & 25.5 & 437.2 & 0.0 & 44.5 & 3.5 & 497.0 & 364.8 & 7.9 & 22.2 & 2.2 & 10.26 & 55.1 & 32.2 & 385.4 & 42.4 \\
\hline $9 \mathrm{H}-2,120-150$ & 68.0 & 66 & 8.08 & 24.4 & 25.0 & 427.8 & 0.0 & 69.9 & 4.1 & 652.2 & 360.4 & 7.6 & 21.6 & 2.0 & 10.61 & 57.3 & 33.2 & 421.8 & 47.3 \\
\hline $9 \mathrm{H}-5,125-150$ & 72.5 & 61 & 8.15 & 23.8 & 25.0 & 422.8 & 0.0 & 61.8 & 4.1 & 741.8 & 351.9 & 7.8 & 20.1 & 1.9 & 10.76 & 55.4 & 37.0 & 409.1 & 49.7 \\
\hline $10 \mathrm{H}-2,125-150$ & 77.5 & 49 & 8.10 & 20.9 & 24.5 & 416.9 & 0.0 & 39.0 & 4.2 & 756.4 & 354.4 & 7.3 & 18.8 & 1.6 & 11.68 & 52.1 & 37.4 & 355.9 & 43.1 \\
\hline $10 \mathrm{H}-5,125-150$ & 80.6 & 48 & 8.10 & 22.9 & 24.0 & 415.4 & 0.0 & 39.9 & 4.6 & 773.1 & 351.6 & 7.2 & 19.2 & 2.0 & 9.40 & 54.0 & 37.2 & 371.2 & 45.7 \\
\hline $11 \mathrm{H}-2,125-150$ & 87.0 & 58 & 8.19 & 23.4 & 24.0 & 408.0 & 0.2 & 33.6 & 5.5 & 746.1 & 345.6 & 7.3 & 19.0 & 2.8 & 6.87 & 54.6 & 37.8 & 392.0 & 49.3 \\
\hline $11 \mathrm{H}-5,125-150$ & 91.5 & 46 & 8.30 & 23.2 & 23.8 & 404.5 & 0.0 & 20.9 & 5.7 & 703.3 & 342.6 & 7.5 & 17.3 & 2.9 & 5.99 & 53.3 & 38.1 & 355.4 & 52.1 \\
\hline $12 X-3,120-150^{*}$ & 96.1 & - & - & - & - & - & - & - & - & - & - & - & - & - & - & - & - & - & - \\
\hline $12 \mathrm{X}-5,110-150^{*}$ & 98.9 & - & - & - & - & - & - & - & - & - & - & - & - & - & - & - & - & - & - \\
\hline $13 \mathrm{X}-2,115-150$ & 105.3 & 19 & 7.97 & 23.2 & 23.5 & 398.6 & 0.2 & 18.8 & 6.6 & 678.2 & 345.0 & 7.2 & 16.3 & 3.6 & 4.50 & 53.5 & 40.5 & 363.5 & 55.5 \\
\hline $13 X-5,71-101$ & 109.0 & 46 & 8.04 & 23.9 & 23.5 & 396.0 & 0.0 & 19.7 & 6.3 & 900.0 & 338.6 & 6.2 & 16.8 & 3.9 & 4.31 & 53.8 & 40.8 & 375.4 & 51.4 \\
\hline $13 X-6,110-150$ & 110.8 & 16 & 8.08 & 22.3 & 24.0 & 398.0 & 0.3 & 16.3 & 6.7 & 686.3 & 335.6 & 6.9 & 17.1 & 3.6 & 4.71 & 52.7 & 40.5 & 359.1 & 55.3 \\
\hline $14 \mathrm{X}-2,115-150$ & 114.9 & 17 & - & - & 23.5 & 395.0 & 0.0 & 12.3 & 6.8 & 690.8 & 335.4 & 6.3 & 16.5 & 3.5 & 4.73 & 52.5 & 42.7 & 364.6 & 51.8 \\
\hline $14 X-4,102-112$ & 117.7 & 12 & 7.93 & 23.6 & 23.0 & 397.0 & 0.0 & 14.0 & 7.2 & - & - & - & - & - & - & - & - & - & - \\
\hline $14 X-4,112-122$ & 117.8 & 20 & - & - & 23.0 & 395.0 & 0.0 & 11.5 & 6.7 & - & - & - & - & - & - & - & - & - & - \\
\hline $14 \mathrm{X}-4,122-130^{*}$ & 117.9 & - & - & - & - & - & - & - & - & - & - & - & - & - & - & - & - & - & - \\
\hline $15 \mathrm{P}-1,0-25$ & 121.8 & 16 & 7.97 & 17.3 & 25.0 & 416.0 & 5.7 & 8.2 & 6.8 & 544.7 & 366.4 & 7.5 & 19.3 & 4.4 & 52.01 & 52.0 & 23.8 & 322.0 & 20.3 \\
\hline $15 \mathrm{P}-1,25-50$ & 122.1 & 10 & - & - & 24.0 & 408.0 & 2.5 & 12.3 & 6.7 & - & - & - & - & - & - & - & - & - & - \\
\hline $16 \mathrm{X}-2,120-150$ & 126.7 & 35 & 8.03 & 22.2 & 23.0 & 391.0 & 0.0 & 14.8 & 7.0 & 796.1 & 335.1 & 6.0 & 15.7 & 3.6 & 4.39 & 54.4 & 46.7 & 354.9 & 50.1 \\
\hline $16 X-4,120-150$ & 129.7 & 28 & 7.87 & 21.4 & 23.5 & 395.0 & 0.9 & 8.2 & 7.3 & 838.6 & 336.0 & 5.9 & 16.7 & 3.8 & 4.43 & 53.5 & 47.8 & 355.3 & 46.7 \\
\hline $17 X-2,0-10$ & 132.4 & 12 & - & - & 22.0 & 383.0 & 0.2 & 14.0 & - & 880.6 & 306.9 & 5.6 & 14.9 & 3.4 & 4.41 & 50.7 & 47.5 & 323.3 & 45.2 \\
\hline $17 X-2,10-20$ & 132.5 & 14 & - & - & 22.0 & 387.0 & 1.7 & 9.8 & 7.0 & 805.5 & 312.5 & 6.2 & 15.7 & 3.6 & 4.38 & 50.6 & 45.7 & 312.6 & 47.0 \\
\hline $17 X-3,64-74$ & 133.9 & 6 & - & - & 22.0 & 386.0 & 0.0 & 5.7 & 7.3 & 767.5 & 319.5 & 5.9 & 15.0 & 3.5 & 4.25 & 51.3 & 47.4 & 267.5 & 46.6 \\
\hline $17 X-4,65-76$ & 134.6 & 7 & - & - & 22.0 & 386.0 & 0.0 & - & 6.9 & - & - & - & - & - & - & - & - & - & - \\
\hline $18 \mathrm{X}-2,0-10$ & 142.4 & 5 & - & - & 21.5 & 370.0 & 0.7 & 7.3 & 7.3 & 787.3 & 318.1 & 6.0 & 16.3 & 3.6 & 4.54 & 50.7 & 44.6 & 307.9 & 36.6 \\
\hline $18 \mathrm{X}-2,0-10$ & 142.4 & 13 & - & - & 22.0 & 381.0 & 4.3 & 9.0 & & - & - & - & - & - & - & - & - & - & - \\
\hline $18 X-2,120-150$ & 143.7 & 8 & - & - & 23.0 & 394.0 & 1.4 & 12.3 & 7.5 & 811.9 & 353.5 & 5.8 & 16.2 & 3.8 & 4.27 & 52.2 & 45.7 & 345.1 & 39.8 \\
\hline $18 X-5,120-150$ & 148.2 & 25 & 8.08 & 19.7 & 21.8 & 375.0 & 0.1 & 11.5 & 6.9 & 733.7 & 325.5 & 5.7 & 14.0 & 3.4 & 4.13 & 47.3 & 44.6 & 281.1 & 42.4 \\
\hline $19 \times-2,69-79$ & 153.1 & 11 & - & - & 20.0 & 353.0 & 0.1 & 6.5 & & - & - & - & - & - & - & - & - & - & - \\
\hline $19 X-4,120-150$ & 156.0 & 24 & 8.15 & 20.4 & 22.0 & 384.0 & 0.0 & 4.0 & 7.3 & 653.4 & 334.0 & 6.1 & 14.0 & 3.6 & 3.94 & 49.9 & 45.3 & 244.9 & 43.8 \\
\hline $20 \times-2,48-78$ & 162.9 & 18 & - & - & 22.0 & 373.0 & 4.1 & 10.7 & 7.6 & 610.7 & 314.3 & 5.8 & 14.1 & 4.8 & 2.93 & 49.3 & 43.9 & 265.7 & 39.1 \\
\hline $20 X-4,120-150$ & 165.9 & 21 & 7.97 & 21.0 & 22.0 & 374.0 & 0.0 & 9.0 & 7.2 & - & - & - & - & - & - & - & - & - & - \\
\hline $21 \times-2,113-143$ & 173.2 & 4 & - & - & 21.5 & 383.0 & 0.0 & - & 7.2 & - & - & - & - & - & - & - & - & - & - \\
\hline
\end{tabular}




\begin{tabular}{|c|c|c|c|c|c|c|c|c|c|c|c|c|c|c|c|c|c|c|c|}
\hline \multirow{2}{*}{$\begin{array}{l}\text { Core, section, } \\
\text { interval }(\mathrm{cm})\end{array}$} & \multirow{2}{*}{$\begin{array}{l}\text { Depth } \\
\text { (mbsf) }\end{array}$} & \multirow{2}{*}{$\begin{array}{l}\text { Volume } \\
(\mathrm{mL})\end{array}$} & \multirow[b]{2}{*}{$\mathrm{pH}$} & \multirow{2}{*}{$\begin{array}{l}\text { Alkalinity } \\
(\mathrm{mM})\end{array}$} & \multirow[b]{2}{*}{ Salinity } & \multirow{2}{*}{$\underset{(\mathrm{mM})}{\mathrm{Cl}}$} & \multirow{2}{*}{$\begin{array}{c}\mathrm{SO}_{4} \\
(\mathrm{mM})\end{array}$} & \multirow{2}{*}{$\begin{array}{l}\mathrm{PO}_{4} \\
(\mu \mathrm{M})\end{array}$} & \multirow{2}{*}{$\begin{array}{c}\mathrm{NH}_{4} \\
(\mathrm{mM})\end{array}$} & \multirow{2}{*}{$\begin{array}{c}\mathrm{H}_{4} \mathrm{SiO}_{4} \\
(\mu \mathrm{M})\end{array}$} & \multicolumn{4}{|c|}{ Cations (mM) } & \multirow[b]{2}{*}{$\mathrm{Mg} / \mathrm{Ca}$} & & race ele & nents $(\mu \mathrm{N}$ & \\
\hline & & & & & & & & & & & $\mathrm{Na}$ & K & $\mathrm{Mg}$ & $\mathrm{Ca}$ & & $\mathrm{Sr}$ & $\mathrm{Li}$ & B & $\mathrm{Ba}$ \\
\hline $21 X-4,81-150$ & 175.7 & 33 & 8.12 & 18.7 & 22.0 & 375.8 & 0.0 & 4.8 & 7.0 & 780.1 & 310.6 & 5.3 & 12.4 & 3.4 & 3.71 & 49.0 & 48.0 & 276.5 & 41.4 \\
\hline $22 X-1,0-17$ & 180.2 & 17 & - & - & 20.0 & 347.1 & 2.4 & 5.7 & 6.7 & 618.4 & 296.9 & 5.1 & 12.8 & 3.5 & 3.68 & 46.7 & 44.1 & 242.9 & 39.6 \\
\hline $22 X-1,17-26$ & 180.3 & 6 & - & - & 21.5 & 377.8 & 2.3 & 6.5 & 6.7 & - & - & - & - & - & - & - & - & - & - \\
\hline $22 \mathrm{X}-1,26-37$ & 180.4 & 6 & - & - & 21.8 & 376.3 & 1.2 & 4.8 & 7.0 & - & - & - & - & - & - & - & - & - & - \\
\hline $22 X-2,85-118$ & 182.3 & 8 & - & - & 21.8 & 376.3 & 0.0 & 5.7 & 7.6 & - & - & - & - & - & - & - & - & - & - \\
\hline $23 X-1,131-161$ & 191.2 & 9 & - & - & 21.8 & 374.8 & 1.0 & 7.3 & 7.1 & - & - & - & - & - & - & - & - & - & - \\
\hline $23 \mathrm{X}-3,62-89$ & 193.6 & 16 & - & - & 21.8 & 378.3 & 1.1 & - & 6.5 & - & - & - & - & - & - & - & - & - & - \\
\hline $24 \mathrm{P}-1,0-12$ & 197.4 & 12 & - & - & 23.0 & 382.7 & 4.9 & - & - & - & - & - & - & - & - & - & - & - & - \\
\hline 24P-1, 39-48 & 197.7 & 8 & - & - & 24.0 & 398.1 & 5.9 & - & - & - & - & - & - & - & - & - & - & - & - \\
\hline $24 \mathrm{P}-1,70-80$ & 198.1 & 22 & - & - & 22.0 & 409.0 & 4.1 & - & - & - & - & - & - & - & - & - & - & - & - \\
\hline $25 X-1,51-61$ & 199.9 & 5 & - & - & 22.0 & 288.2 & 0.9 & - & 5.4 & - & - & - & - & - & - & - & - & - & - \\
\hline $25 X-1,61-71$ & 200.0 & 3 & - & - & 22.0 & 285.2 & 0.5 & - & 5.4 & - & - & - & - & - & - & - & - & - & - \\
\hline $25 \times-3,0-25$ & 201.4 & 22 & - & - & 20.5 & 354.0 & 0.2 & 6.3 & 6.7 & 708.0 & 302.0 & 5.3 & 11.1 & 3.3 & 3.38 & 46.4 & 54.8 & 252.3 & 47.4 \\
\hline $26 \mathrm{X}-2,84-114$ & 211.4 & 36 & 7.99 & 17.2 & 20.5 & 354.5 & 0.1 & 5.4 & 6.1 & 914.2 & 330.1 & 5.4 & 12.0 & 3.6 & 3.36 & 47.7 & 55.3 & 247.9 & 51.5 \\
\hline $26 X-5,120-150$ & 215.9 & 33 & - & - & 21.0 & 363.4 & 0.3 & 6.3 & 6.4 & 888.2 & 323.9 & 5.4 & 11.6 & 3.6 & 3.19 & 47.3 & 59.6 & 236.5 & 49.8 \\
\hline $27 X-1,108-138$ & 219.7 & 33 & - & - & 20.0 & 363.9 & 0.5 & 3.6 & 6.5 & 725.9 & 309.7 & 5.4 & 10.9 & 3.2 & 3.37 & 47.3 & 62.5 & 267.4 & 51.8 \\
\hline $27 X-3,0-10$ & 221.3 & 4 & - & - & 21.0 & 365.9 & 0.2 & - & - & - & - & - & - & - & - & - & - & - & - \\
\hline $27 \mathrm{X}-3,10-20$ & 221.4 & 3 & - & - & 20.8 & 357.0 & 0.1 & - & - & - & - & - & - & - & - & - & - & - & - \\
\hline $27 X-4,114-144$ & 224.0 & 24 & 8.15 & 17.0 & 21.5 & 366.9 & 0.1 & 4.5 & 6.3 & 705.8 & 321.2 & 5.4 & 11.7 & 3.4 & 3.44 & 50.7 & 63.0 & 252.7 & 57.6 \\
\hline $28 \mathrm{X}-1,120-150$ & 229.5 & 21 & 7.99 & 16.2 & 22.0 & 375.8 & 1.5 & 3.6 & 5.8 & 596.9 & 340.8 & 5.8 & 14.0 & 3.9 & 3.56 & 54.8 & 65.8 & 256.4 & 55.9 \\
\hline $28 X-3,96-125$ & 232.1 & 17 & - & - & 21.5 & 359.8 & 1.1 & 2.7 & 5.7 & 688.0 & 320.2 & 5.3 & 11.8 & 3.7 & 3.20 & 49.9 & 62.3 & 230.5 & 52.7 \\
\hline $29 \mathrm{X}-2,120-150^{*}$ & 240.6 & - & - & - & - & - & - & - & - & - & - & - & - & - & - & - & - & - & - \\
\hline $30 X-2,88-118$ & 249.9 & 20 & 8.13 & 17.2 & 21.5 & 370.4 & 0.0 & - & 6.2 & 736.1 & 323.1 & 5.8 & 10.7 & 3.7 & 2.88 & 51.0 & 73.5 & 236.8 & 68.3 \\
\hline $31 X-4,120-150$ & 262.9 & 40 & 8.09 & 17.4 & 21.5 & 367.4 & 0.0 & 3.6 & 5.8 & 838.4 & 326.8 & 5.9 & 11.2 & 4.3 & 1.98 & 54.4 & 80.4 & 254.2 & 73.8 \\
\hline $32 X-4,120-150$ & 272.6 & 20 & - & - & 22.0 & 372.3 & 0.8 & - & 5.8 & 603.7 & 335.0 & 6.2 & 10.8 & 3.9 & 2.78 & 53.2 & 78.5 & 150.1 & 71.5 \\
\hline $33 X-4,120-150$ & 282.2 & 33 & 8.31 & 16.4 & 21.8 & 367.4 & 0.2 & 2.7 & - & 790.6 & 329.3 & 6.1 & 10.4 & 3.8 & 2.76 & 54.8 & 83.6 & 189.4 & 72.2 \\
\hline $34 X-4,120-150$ & 291.8 & 12 & - & - & 21.5 & 380.3 & 1.0 & 3.6 & - & - & - & - & - & - & - & - & - & - & - \\
\hline $35 X-2,120-150$ & 298.4 & 33 & - & - & 21.5 & 369.4 & 0.0 & - & 4.6 & - & - & - & - & - & - & - & - & - & - \\
\hline 311-U1327D- & & & & & & & & & & & & & & & & & & & \\
\hline $1 \mathrm{H}-1,25-40$ & 0.3 & 70 & 7.62 & 3.5 & 34.5 & 551.6 & 28.9 & 5.4 & 0.0 & - & 457.6 & 11.6 & 49.9 & 9.8 & 5.07 & 85.4 & - & - & - \\
\hline $1 \mathrm{H}-1,55-70$ & 0.6 & 72 & 7.65 & 3.9 & 34.0 & 550.6 & 28.8 & 9.1 & 0.0 & - & 466.7 & 11.8 & 47.6 & 9.8 & 4.83 & 83.6 & - & - & - \\
\hline $1 \mathrm{H}-1,80-95$ & 0.9 & 70 & 7.66 & 4.1 & 34.0 & 550.1 & 28.9 & 12.7 & 0.0 & - & 479.0 & 12.2 & 50.3 & 10.1 & 4.98 & 82.3 & - & - & - \\
\hline $1 \mathrm{H}-1,135-150$ & 1.4 & 60 & 7.58 & 5.8 & 34.0 & 550.1 & 28.1 & 20.0 & 0.1 & - & 461.7 & 12.1 & 49.4 & 8.9 & 5.54 & 81.7 & - & - & - \\
\hline $1 \mathrm{H}-2,25-40$ & 1.8 & 74 & 7.71 & 6.5 & 34.0 & - & 27.8 & 22.7 & 0.2 & - & 459.3 & 12.0 & 50.1 & 9.6 & 5.22 & 80.8 & - & - & - \\
\hline $1 \mathrm{H}-2,55-70$ & 2.1 & 62 & 7.71 & 6.5 & 33.8 & - & 24.8 & 32.7 & 0.2 & - & 467.2 & 11.1 & 46.6 & 9.3 & 5.02 & 80.3 & - & - & - \\
\hline $1 \mathrm{H}-2,80-95$ & 2.4 & 70 & 7.66 & 8.6 & 33.8 & - & 23.2 & 34.5 & 0.2 & - & 469.6 & 11.6 & 47.7 & 8.7 & 5.48 & 80.9 & - & - & - \\
\hline $1 \mathrm{H}-2,135-150$ & 2.9 & 60 & 7.79 & 10.4 & 33.8 & - & 21.4 & 37.2 & 0.4 & - & 447.6 & 11.6 & 45.0 & 7.1 & 6.37 & 76.4 & - & - & - \\
\hline $1 \mathrm{H}-3,10-25$ & 3.2 & 68 & 7.88 & 11.0 & 33.8 & - & 20.1 & 36.3 & 0.3 & - & 479.5 & 11.4 & 46.5 & 7.9 & 5.88 & 78.1 & - & - & - \\
\hline $1 \mathrm{H}-3,40-55$ & 3.5 & 58 & 7.71 & 11.5 & 33.5 & - & 19.5 & 39.1 & 0.4 & - & 470.9 & 11.2 & 45.5 & 7.1 & 6.38 & 76.3 & - & - & - \\
\hline $1 \mathrm{H}-3,65-80$ & 3.7 & 50 & 7.78 & 12.6 & 33.5 & - & 17.9 & 40.9 & 0.6 & - & 435.7 & 11.0 & 43.9 & 6.2 & 7.14 & 76.1 & - & - & - \\
\hline $1 \mathrm{H}-3,120-135$ & 4.3 & 40 & 7.79 & 13.9 & 33.0 & - & 16.2 & 49.1 & 0.7 & - & 454.7 & 10.5 & 43.8 & 7.4 & 5.96 & 75.0 & - & - & - \\
\hline $1 \mathrm{H}-4,25-40$ & 4.8 & 45 & 7.59 & 14.8 & 33.0 & - & 14.1 & 53.6 & 0.7 & - & 449.4 & 10.5 & 44.4 & 5.9 & 7.52 & 74.3 & - & - & - \\
\hline $1 \mathrm{H}-4,55-70$ & 5.1 & 21 & 7.75 & 16.2 & 32.7 & - & 12.9 & 20.0 & 0.9 & - & 448.9 & 11.3 & 43.2 & 6.6 & 6.56 & 77.0 & - & - & - \\
\hline $1 \mathrm{H}-4,80-95$ & 5.4 & 65 & 7.74 & 16.9 & 32.5 & - & 11.1 & 57.2 & 0.8 & - & 442.4 & 10.9 & 42.2 & 6.6 & 6.39 & 73.1 & - & - & - \\
\hline $1 \mathrm{H}-4,135-150$ & 5.9 & 50 & 7.79 & 18.0 & 32.2 & - & 9.7 & 63.6 & 0.9 & - & 446.2 & 10.4 & 40.7 & 5.1 & 7.93 & 70.4 & - & - & - \\
\hline $2 \mathrm{H}-1,25-40$ & 7.2 & 57 & 7.94 & 23.6 & 31.7 & - & 0.2 & 108.1 & 1.2 & - & 455.2 & 10.2 & 40.3 & 3.0 & 13.66 & 67.2 & - & - & - \\
\hline $2 \mathrm{H}-1,55-70$ & 7.5 & 31 & 7.84 & 23.4 & 31.7 & - & 0.2 & 101.8 & 1.3 & - & 459.5 & 9.7 & 37.5 & 3.5 & 10.66 & 67.7 & - & - & - \\
\hline $2 \mathrm{H}-1,80-95$ & 7.8 & 44 & 7.87 & 23.6 & 31.7 & - & 0.2 & 103.6 & 1.5 & - & 459.4 & 10.0 & 39.3 & 2.5 & 15.42 & 66.2 & - & - & - \\
\hline $2 \mathrm{H}-1,135-150$ & 8.3 & 53 & 7.75 & 24.0 & 31.5 & - & 0.0 & 96.3 & 1.7 & - & 436.1 & 9.6 & 38.3 & 3.2 & 12.09 & 67.3 & - & - & - \\
\hline $2 \mathrm{H}-3,55-70$ & 10.5 & 50 & 7.88 & 24.0 & 31.7 & - & 0.2 & 64.5 & 1.4 & - & 460.6 & 10.1 & 40.0 & 3.4 & 11.64 & 69.7 & - & - & - \\
\hline
\end{tabular}




\begin{tabular}{|c|c|c|c|c|c|c|c|c|c|c|c|c|c|c|c|c|c|c|c|}
\hline \multirow{2}{*}{$\begin{array}{l}\text { Core, section, } \\
\text { interval }(\mathrm{cm})\end{array}$} & \multirow{2}{*}{$\begin{array}{l}\text { Depth } \\
\text { (mbsf) }\end{array}$} & \multirow{2}{*}{$\begin{array}{l}\text { Volume } \\
(\mathrm{mL})\end{array}$} & \multirow[b]{2}{*}{$\mathrm{pH}$} & \multirow{2}{*}{$\begin{array}{l}\text { Alkalinity } \\
(\mathrm{mM})\end{array}$} & \multirow[b]{2}{*}{ Salinity } & \multirow{2}{*}{$\underset{(\mathrm{mM})}{\mathrm{Cl}}$} & \multirow{2}{*}{$\begin{array}{l}\mathrm{SO}_{4} \\
(\mathrm{mM})\end{array}$} & \multirow{2}{*}{$\begin{array}{l}\mathrm{PO}_{4} \\
(\mu \mathrm{M})\end{array}$} & \multirow{2}{*}{$\begin{array}{l}\mathrm{NH}_{4} \\
(\mathrm{mM})\end{array}$} & \multirow{2}{*}{$\begin{array}{c}\mathrm{H}_{4} \mathrm{SiO}_{4} \\
(\mu \mathrm{M})\end{array}$} & \multicolumn{4}{|c|}{ Cations (mM) } & \multirow[b]{2}{*}{$\mathrm{Mg} / \mathrm{Ca}$} & \multicolumn{4}{|c|}{ Trace elements $(\mu \mathrm{M})$} \\
\hline & & & & & & & & & & & $\mathrm{Na}$ & K & $\mathrm{Mg}$ & $\mathrm{Ca}$ & & $\mathrm{Sr}$ & $\mathrm{Li}$ & $B$ & $\mathrm{Ba}$ \\
\hline $2 \mathrm{H}-4,80-95$ & 12.3 & 20 & 7.80 & 25.2 & 31.5 & - & 0.0 & - & - & - & - & - & - & - & - & - & - & - & - \\
\hline $2 \mathrm{H}-5,55-70$ & 13.8 & 45 & 7.75 & 25.5 & 31.5 & - & 0.0 & 51.8 & 1.8 & - & 441.2 & 9.7 & 37.3 & 3.4 & 11.12 & 68.6 & - & - & - \\
\hline $2 \mathrm{H}-6,80-95$ & 15.3 & 40 & - & - & 31.0 & - & 0.0 & 49.1 & 1.6 & - & 434.0 & 11.0 & 37.3 & 3.1 & 12.20 & 70.7 & - & - & - \\
\hline $4 \mathrm{E}-1,0-20$ & 125.4 & 20 & - & - & 27.5 & - & 13.9 & 9.3 & - & - & 398.7 & 8.5 & 27.8 & 7.0 & 3.97 & 54.0 & - & - & - \\
\hline $4 \mathrm{E}-1,95-110$ & 126.3 & 10 & - & - & 22.5 & 391.6 & 0.0 & 5.9 & - & - & 330.4 & 6.0 & 15.6 & 3.6 & 4.38 & 53.6 & - & - & - \\
\hline $5 X-2,74-84$ & 128.6 & 8 & - & - & 23.0 & 391.6 & 0.0 & - & - & - & - & - & - & - & - & - & - & - & - \\
\hline $5 X-2,84-94$ & 128.7 & 1 & - & - & 5.5 & 97.0 & 1.7 & 5.9 & - & - & - & - & - & - & - & - & - & - & - \\
\hline $6 \mathrm{Y}-1,49-68$ & 132.6 & 12 & - & - & 21.8 & 373.8 & 0.0 & - & - & - & 308.4 & 5.9 & 13.0 & 2.2 & 5.94 & 48.3 & - & - & - \\
\hline $7 X-3,38-48$ & 135.8 & 3 & - & - & 20.8 & 380.3 & 5.9 & - & - & - & - & - & - & - & - & - & - & - & - \\
\hline $7 X-3,48-54$ & 135.8 & 5 & - & - & 19.5 & 336.7 & 0.2 & 7.6 & - & - & - & - & - & - & - & - & - & - & - \\
\hline $7 X-3,48-54$ & 135.8 & 4 & - & - & 18.0 & 310.4 & 3.5 & - & - & - & - & - & - & - & - & - & - & - & - \\
\hline $10 \mathrm{P}-1,18-28$ & 155.3 & 5 & - & - & 23.0 & 391.5 & 7.2 & 5.9 & - & - & - & - & - & - & - & - & - & - & - \\
\hline $10 \mathrm{P}-1,45-55$ & 155.6 & 2 & - & - & 20.5 & 361.6 & 3.6 & - & - & - & - & - & - & - & - & - & - & - & - \\
\hline $10 \mathrm{P}-1,78-88$ & 155.9 & 4 & & - & 22.0 & 391.5 & 5.6 & 4.3 & - & - & - & - & - & - & - & - & - & - & - \\
\hline $11 \mathrm{X}-1,67-70$ & 157.7 & 4 & - & - & 19.5 & - & 4.0 & - & - & - & - & - & - & - & - & - & - & - & - \\
\hline $11 X-1,70-72$ & 157.7 & 1 & - & - & 22.0 & - & 11.8 & - & - & - & - & - & - & - & - & - & - & - & - \\
\hline $15 X-3,49-59$ & 222.0 & 2 & - & - & 3.7 & 74.1 & 0.2 & - & - & - & - & - & - & - & - & - & - & - & - \\
\hline $15 X-3,49-59$ & 222.0 & 1 & - & - & 18.0 & 315.4 & 0.2 & 3.4 & - & - & - & - & - & - & - & - & - & - & - \\
\hline $17 \mathrm{P}-1,25-35$ & 246.3 & 4 & - & - & 22.0 & 382.7 & 2.0 & 2.6 & - & - & - & - & - & - & - & - & - & - & - \\
\hline $17 P-1,70-80$ & 246.8 & 3 & - & - & 22.5 & 391.2 & 3.3 & 2.6 & - & - & - & - & - & - & - & - & - & - & - \\
\hline 311-U1327E- & & & & & & & & & & & & & & & & & & & \\
\hline $1 \mathrm{H}-1,25-40$ & 3.3 & 40 & 7.74 & 13.6 & 33.5 & - & 16.0 & 41.8 & 0.5 & - & 452.5 & 10.9 & 45.4 & 7.2 & 6.27 & 76.9 & - & - & - \\
\hline $1 \mathrm{H}-1,55-70$ & 3.6 & 40 & 7.62 & 13.2 & 33.0 & - & 14.9 & 50.9 & 0.5 & - & 452.4 & 11.2 & 42.5 & 6.7 & 6.32 & 77.1 & - & - & - \\
\hline $1 \mathrm{H}-1,80-95$ & 3.9 & 60 & 7.67 & 13.9 & 33.0 & - & 14.2 & 52.6 & 0.5 & - & 388.6 & 10.8 & 43.9 & 5.0 & 8.79 & 76.0 & - & - & - \\
\hline $1 \mathrm{H}-1,135-150$ & 4.4 & 40 & - & - & 33.0 & - & 11.5 & 28.4 & 0.6 & - & 439.4 & 10.9 & 44.0 & 6.2 & 7.05 & 76.4 & - & - & - \\
\hline $1 \mathrm{H}-2,25-40$ & 4.8 & 55 & 7.74 & 16.6 & 32.0 & - & 10.0 & 43.4 & 0.6 & - & 463.2 & 11.4 & 41.4 & 5.8 & 7.18 & 73.6 & - & - & - \\
\hline $1 \mathrm{H}-2,55-70$ & 5.1 & 65 & - & - & 32.5 & - & 9.6 & 64.3 & 0.7 & - & 444.3 & 11.4 & 41.6 & 5.7 & 7.34 & 72.8 & - & - & - \\
\hline $1 \mathrm{H}-2,80-95$ & 5.4 & 60 & 7.69 & 17.2 & 32.0 & - & 8.9 & 66.8 & 0.6 & - & 440.5 & 10.2 & 39.2 & 4.9 & 7.98 & 73.3 & - & - & - \\
\hline $1 \mathrm{H}-2,135-150$ & 5.9 & 56 & 7.64 & 18.5 & 32.0 & - & 6.5 & 74.3 & 0.8 & - & 435.7 & 10.7 & 40.7 & 4.7 & 8.70 & 72.4 & - & - & - \\
\hline $1 \mathrm{H}-3,25-40$ & 6.3 & 56 & 7.81 & 18.2 & 32.0 & - & 7.4 & 75.9 & 0.8 & - & 452.1 & 10.8 & 40.4 & 4.2 & 9.57 & 72.9 & - & - & - \\
\hline $1 \mathrm{H}-3,55-70$ & 6.6 & 62 & 7.80 & 20.1 & 32.0 & - & 5.0 & 80.1 & 0.8 & - & 468.3 & 11.1 & 42.6 & 4.4 & 9.67 & 71.4 & - & - & - \\
\hline $1 \mathrm{H}-3,80-95$ & 6.9 & 56 & 7.78 & 19.6 & 31.8 & - & 5.0 & 82.6 & 0.8 & - & 461.2 & 10.5 & 40.3 & 4.2 & 9.53 & 71.1 & - & - & - \\
\hline $1 \mathrm{H}-3,135-150$ & 7.4 & 60 & - & 20.4 & 31.8 & - & 4.2 & 90.9 & 0.9 & - & 468.7 & 10.9 & 40.1 & 3.8 & 10.57 & 69.7 & - & - & - \\
\hline $1 \mathrm{H}-4,25-40$ & 7.8 & 66 & 7.93 & 19.6 & 31.8 & - & 5.3 & 97.6 & 0.8 & - & 462.9 & 10.5 & 40.2 & 3.4 & 11.97 & 70.1 & - & - & - \\
\hline $1 \mathrm{H}-4,55-70$ & 8.1 & 70 & 7.94 & 21.9 & 31.8 & - & 2.1 & 100.1 & 0.8 & - & 440.2 & 10.3 & 40.9 & 3.1 & 13.40 & 68.4 & - & - & - \\
\hline $1 \mathrm{H}-4,80-95$ & 8.4 & 50 & 7.97 & 21.5 & 31.8 & - & 3.2 & 97.6 & 0.9 & - & 439.2 & 10.6 & 40.2 & 3.3 & 12.18 & 70.9 & - & - & - \\
\hline $1 \mathrm{H}-4,135-150$ & 8.9 & 56 & 7.96 & 22.4 & 31.5 & - & 2.0 & 93.4 & 1.0 & - & 429.5 & 9.9 & 39.7 & 1.9 & 20.66 & 69.8 & - & - & - \\
\hline $1 \mathrm{H}-5,25-40$ & 9.3 & 64 & 7.88 & 25.3 & 31.5 & - & 0.2 & 87.6 & 1.0 & - & 439.8 & 9.8 & 39.7 & 3.2 & 12.48 & 69.9 & - & - & - \\
\hline $1 \mathrm{H}-5,55-70$ & 9.6 & 64 & 7.94 & 25.9 & 31.5 & - & 0.3 & 82.6 & 1.0 & - & 472.3 & 10.8 & 39.3 & 3.2 & 12.35 & 71.6 & - & - & - \\
\hline $1 \mathrm{H}-5,80-95$ & 9.9 & 66 & 8.04 & 23.6 & 31.5 & - & 0.1 & 74.3 & 1.1 & - & 456.4 & 10.6 & 40.4 & 3.5 & 11.61 & 68.9 & - & - & - \\
\hline $1 \mathrm{H}-5,135-150$ & 10.4 & 56 & 7.84 & 24.1 & 31.5 & - & 0.0 & 68.4 & 1.0 & - & 447.2 & 10.5 & 40.5 & 3.5 & 11.58 & 70.2 & - & - & - \\
\hline $1 \mathrm{H}-6,25-40$ & 10.8 & 58 & 7.79 & 24.3 & 31.5 & - & 0.0 & 65.1 & 1.1 & - & 468.5 & 10.7 & 40.2 & 3.4 & 11.73 & 71.1 & - & - & - \\
\hline $1 \mathrm{H}-6,55-70$ & 11.1 & 52 & 7.78 & 23.7 & 31.5 & - & 0.0 & 59.3 & 1.1 & - & 453.8 & 9.3 & 38.5 & 3.5 & 10.96 & 71.7 & - & - & - \\
\hline $1 \mathrm{H}-6,80-95$ & 11.4 & 54 & 7.76 & 24.3 & 31.2 & - & 0.0 & 66.8 & 1.1 & - & 436.8 & 9.5 & 37.5 & 3.0 & 12.37 & 70.3 & - & - & - \\
\hline $1 \mathrm{H}-6,135-150$ & 11.9 & 60 & 7.70 & 24.5 & 31.2 & - & 0.0 & 66.8 & 1.2 & - & 426.3 & 9.2 & 38.3 & 3.4 & 11.31 & 71.4 & - & - & - \\
\hline $1 \mathrm{H}-7,50-65$ & 12.6 & 60 & 7.70 & 24.6 & 31.5 & - & 0.0 & 64.3 & - & - & 438.5 & 9.8 & 38.2 & 3.3 & 11.54 & 70.6 & - & - & - \\
\hline $3 P-1,18-30$ & 80.2 & 20 & - & - & 24.5 & 421.0 & 0.2 & - & - & - & - & - & - & - & - & - & - & - & - \\
\hline $3 P-1,75-85$ & 80.8 & 8 & - & - & 24.0 & 415.0 & 0.4 & 24.7 & - & - & - & - & - & - & - & - & - & - & - \\
\hline
\end{tabular}


Table T4. Concentrations of solutes corrected for drill-fluid contamination in interstitial waters, Site U1327. (See table notes. Continued on next two pages.)

\begin{tabular}{|c|c|c|c|c|c|c|c|c|c|c|c|c|c|c|c|c|c|c|c|}
\hline \multirow{2}{*}{$\begin{array}{l}\text { Core, section, } \\
\text { interval }(\mathrm{cm})\end{array}$} & \multirow{2}{*}{$\begin{array}{l}\text { Depth } \\
\text { (mbsf) }\end{array}$} & \multirow{2}{*}{$\begin{array}{l}\text { Volume } \\
(\mathrm{mL})\end{array}$} & \multirow[b]{2}{*}{$\mathrm{pH}$} & \multirow{2}{*}{$\begin{array}{c}\text { Alkalinity } \\
(\mathrm{mM})\end{array}$} & \multirow[b]{2}{*}{ Salinity } & \multirow{2}{*}{$\underset{(\mathrm{mM})}{\mathrm{Cl}}$} & \multirow{2}{*}{$\begin{array}{l}\mathrm{SO}_{4} \\
(\mathrm{mM})\end{array}$} & \multirow{2}{*}{$\begin{array}{l}\mathrm{PO}_{4} \\
(\mu \mathrm{M})\end{array}$} & \multirow{2}{*}{$\begin{array}{c}\mathrm{NH}_{4} \\
(\mathrm{mM})\end{array}$} & \multirow{2}{*}{$\begin{array}{c}\mathrm{H}_{4} \mathrm{SiO}_{4} \\
(\mu \mathrm{M})\end{array}$} & \multicolumn{4}{|c|}{ Cations (mM) } & \multirow[b]{2}{*}{$\mathrm{Mg} / \mathrm{Ca}$} & \multicolumn{4}{|c|}{ Trace elements $(\mu \mathrm{M})$} \\
\hline & & & & & & & & & & & $\mathrm{Na}$ & K & $\mathrm{Mg}$ & $\mathrm{Ca}$ & & $\mathrm{Sr}$ & $\mathrm{Li}$ & B & $\mathrm{Ba}$ \\
\hline 311-U1327C- & & & & & & & & & & & & & & & & & & & \\
\hline $1 \mathrm{H}-1,140-150$ & 1.5 & 48 & 7.45 & 5.5 & 34.0 & 548.6 & 27.4 & 24.7 & 0.3 & 648.0 & 452.4 & 11.5 & 48.0 & 8.9 & 5.38 & 80.9 & 44.1 & 488.0 & 0.0 \\
\hline $1 \mathrm{H}-3,140-150$ & 4.5 & 42 & 7.65 & 13.8 & 33.0 & 542.7 & 15.6 & 38.0 & 0.7 & 632.3 & 447.0 & 10.5 & 44.9 & 6.4 & 6.99 & 71.8 & 35.8 & 482.0 & 0.0 \\
\hline $2 \mathrm{H}-1,140-150$ & 7.6 & 40 & 7.80 & 22.5 & 32.0 & 536.7 & 1.5 & 91.8 & 1.4 & 482.8 & 434.9 & 9.6 & 39.7 & 3.5 & 11.36 & 65.8 & 30.0 & 500.3 & 5.2 \\
\hline $2 \mathrm{H}-3,140-150$ & 10.6 & 44 & 7.64 & 24.4 & 31.5 & 531.3 & 0.0 & 62.7 & 1.5 & 603.5 & 429.6 & 9.3 & 39.2 & 3.4 & 11.63 & 65.3 & 29.1 & 507.7 & 9.8 \\
\hline $2 \mathrm{H}-5,140-150$ & 13.6 & 42 & 7.78 & 25.7 & 32.0 & 525.8 & 0.0 & 58.1 & 1.9 & 718.1 & 433.0 & 9.8 & 38.1 & 3.5 & 11.00 & 67.6 & 30.3 & 540.5 & 18.8 \\
\hline $2 \mathrm{H}-7,54-64$ & 15.7 & 40 & 7.71 & 26.3 & 31.5 & 524.8 & 0.0 & 65.4 & 1.9 & 594.1 & 418.8 & 9.1 & 36.3 & 3.1 & 11.76 & 66.7 & 32.0 & 552.9 & 28.4 \\
\hline $3 \mathrm{H}-2,140-150$ & 18.6 & 58 & 7.97 & 26.8 & 31.0 & 522.9 & 0.0 & 66.3 & 1.7 & 560.9 & 421.0 & 9.7 & 35.4 & 2.8 & 12.54 & 65.6 & 33.5 & 559.8 & 34.9 \\
\hline $3 \mathrm{H}-4,140-150$ & 21.6 & 56 & 7.97 & 27.4 & 30.5 & 517.9 & 0.0 & 56.3 & 1.9 & 518.7 & 417.3 & 9.8 & 35.8 & 2.3 & 15.43 & 66.6 & 32.7 & 546.3 & 37.6 \\
\hline $3 \mathrm{H}-6,140-150$ & 24.6 & 63 & 8.06 & 26.7 & 30.0 & 515.4 & 0.0 & 81.8 & 1.5 & 578.2 & 411.6 & 9.6 & 33.7 & 1.8 & 18.96 & 62.7 & 31.6 & 549.4 & 32.3 \\
\hline $4 \mathrm{H}-2,135-150$ & 28.0 & 60 & 8.00 & 23.9 & 30.0 & 507.0 & 0.0 & 65.4 & 1.9 & 539.0 & 411.1 & 9.8 & 31.0 & 1.4 & 21.94 & 56.4 & 31.6 & 575.2 & 20.7 \\
\hline $4 \mathrm{H}-5,135-150$ & 32.5 & 60 & 8.03 & 22.9 & 29.5 & 499.1 & 0.0 & 66.3 & 2.0 & 647.1 & 413.0 & 9.7 & 30.3 & 0.9 & 32.06 & 54.3 & 31.1 & 545.1 & 17.1 \\
\hline $5 \mathrm{H}-2,135-150$ & 37.5 & 52 & 8.11 & 23.8 & 28.5 & 485.7 & 0.0 & 69.0 & 1.9 & 614.5 & 401.5 & 9.0 & 27.4 & 3.0 & 8.99 & 53.0 & 30.1 & 479.6 & 14.0 \\
\hline $5 \mathrm{H}-5,135-150$ & 42.0 & 54 & 8.16 & 24.1 & 28.0 & 479.8 & 0.0 & 54.5 & 2.3 & 538.9 & 399.9 & 9.3 & 26.6 & 2.0 & 13.34 & 53.5 & 29.6 & 478.3 & 14.1 \\
\hline 7H-2, 135-150 & 49.0 & 49 & 8.08 & 24.2 & 27.5 & 462.5 & 0.0 & 43.6 & 2.6 & 493.7 & 378.0 & 7.8 & 25.4 & 2.3 & 10.82 & 54.1 & 29.6 & 446.6 & 17.4 \\
\hline 7H-5, 135-150 & 53.5 & 48 & 8.06 & 24.6 & 26.5 & 453.0 & 0.0 & 59.0 & 2.6 & 520.4 & 379.4 & 7.8 & 24.1 & 2.5 & 9.45 & 54.5 & 29.3 & 450.7 & 22.3 \\
\hline $8 \mathrm{H}-2,120-150$ & 58.5 & 50 & 8.32 & 24.4 & 26.0 & 445.6 & 0.0 & 37.2 & 3.3 & 377.3 & 369.1 & 8.3 & 22.6 & 2.3 & 9.98 & 54.2 & 30.4 & 376.4 & 37.8 \\
\hline $8 \mathrm{H}-5,125-150$ & 63.0 & 53 & 8.21 & 24.3 & 25.5 & 437.2 & 0.0 & 44.5 & 3.5 & 497.0 & 364.8 & 7.9 & 22.2 & 2.2 & 10.26 & 55.1 & 32.2 & 385.4 & 42.4 \\
\hline $9 \mathrm{H}-2,120-150$ & 68.0 & 66 & 8.08 & 24.4 & 25.0 & 427.8 & 0.0 & 69.9 & 4.1 & 652.2 & 360.4 & 7.6 & 21.6 & 2.0 & 10.61 & 57.3 & 33.2 & 421.8 & 47.3 \\
\hline $9 \mathrm{H}-5,125-150$ & 72.5 & 61 & 8.15 & 23.8 & 25.0 & 422.8 & 0.0 & 61.8 & 4.1 & 741.8 & 351.9 & 7.8 & 20.1 & 1.9 & 10.76 & 55.4 & 37.0 & 409.1 & 49.7 \\
\hline $10 \mathrm{H}-2,125-150$ & 77.5 & 49 & 8.10 & 20.9 & 24.5 & 416.9 & 0.0 & 39.0 & 4.2 & 756.4 & 354.4 & 7.3 & 18.8 & 1.6 & 11.68 & 52.1 & 37.4 & 355.9 & 43.1 \\
\hline $10 \mathrm{H}-5,125-150$ & 80.6 & 48 & 8.10 & 22.9 & 24.0 & 415.4 & 0.0 & 39.9 & 4.6 & 773.1 & 351.6 & 7.2 & 19.2 & 2.0 & 9.40 & 54.0 & 37.2 & 371.2 & 45.7 \\
\hline $11 \mathrm{H}-2,125-150$ & 87.0 & 58 & 8.19 & 23.4 & 24.0 & 408.0 & 0.0 & 33.8 & 5.5 & 746.1 & 345.6 & 7.3 & 19.0 & 2.8 & 6.87 & 54.6 & 37.8 & 392.0 & 49.3 \\
\hline $11 \mathrm{H}-5,125-150$ & 91.5 & 46 & 8.30 & 23.2 & 23.8 & 404.5 & 0.0 & 20.9 & 5.7 & 703.3 & 342.6 & 7.5 & 17.3 & 2.9 & 5.99 & 53.3 & 38.1 & 355.4 & 52.1 \\
\hline $12 X-3,120-150^{*}$ & 96.1 & - & - & - & - & - & - & - & - & - & - & - & - & - & - & - & - & - & - \\
\hline $12 \mathrm{X}-5,110-150^{*}$ & 98.9 & - & - & - & - & - & - & - & - & - & - & - & - & - & - & - & - & - & - \\
\hline $13 X-2,115-150$ & 105.3 & 19 & 7.97 & 23.2 & 23.5 & 398.6 & 0.0 & 18.9 & 6.7 & 678.2 & 345.0 & 7.2 & 16.3 & 3.6 & 4.50 & 53.5 & 40.5 & 363.5 & 55.5 \\
\hline $13 X-5,71-101$ & 109.0 & 46 & 8.04 & 23.9 & 23.5 & 394.9 & 0.0 & 19.7 & 6.3 & 900.0 & 338.6 & 6.2 & 16.8 & 3.9 & 4.31 & 53.8 & 40.8 & 375.4 & 51.4 \\
\hline $13 X-6,110-150$ & 110.8 & 16 & 8.08 & 22.3 & 24.0 & 396.3 & 0.0 & 16.5 & 6.8 & 686.3 & 335.6 & 6.9 & 17.1 & 3.6 & 4.71 & 52.7 & 40.5 & 359.1 & 55.3 \\
\hline $14 \mathrm{X}-2,115-150$ & 114.9 & 17 & - & - & 23.5 & 395.0 & 0.0 & 12.3 & 6.8 & 690.8 & 335.4 & 6.3 & 16.5 & 3.5 & 4.73 & 52.5 & 42.7 & 364.6 & 51.8 \\
\hline $14 X-4,102-112$ & 117.7 & 12 & 7.93 & 23.6 & 23.0 & 397.0 & 0.0 & 14.0 & 7.2 & - & - & - & - & - & - & - & - & - & - \\
\hline $14 \mathrm{X}-4,112-122$ & 117.8 & 20 & - & - & 23.0 & 395.0 & 0.0 & 11.5 & 6.7 & - & - & - & - & - & - & - & - & - & - \\
\hline $14 \mathrm{X}-4,122-130^{*}$ & 117.9 & - & - & - & - & - & - & - & - & - & - & - & - & - & - & - & - & - & - \\
\hline $15 \mathrm{P}-1,0-25$ & 121.8 & 16 & 7.97 & 21.0 & 22.7 & 381.0 & 0.0 & 9.4 & 8.5 & 641.2 & 338.7 & 6.7 & 10.8 & 2.9 & 3.68 & 43.5 & 23.0 & 290.7 & 25.3 \\
\hline $15 \mathrm{P}-1,25-50$ & 122.1 & 10 & - & & 23.0 & 393.8 & 0.0 & 13.2 & 7.3 & - & - & - & - & - & - & - & - & - & - \\
\hline $16 \mathrm{X}-2,120-150$ & 126.7 & 35 & 8.03 & 22.2 & 23.0 & 391.0 & 0.0 & 14.8 & 7.0 & 796.1 & 335.1 & 6.0 & 15.7 & 3.6 & 4.39 & 54.4 & 46.7 & 354.9 & 50.1 \\
\hline $16 X-4,120-150$ & 129.7 & 28 & 7.87 & 22.0 & 23.2 & 389.9 & 0.0 & 8.3 & 7.5 & 838.6 & 336.0 & 5.9 & 16.7 & 3.8 & 4.43 & 53.5 & 47.8 & 355.3 & 46.7 \\
\hline $17 X-2,0-10$ & 132.4 & 12 & - & - & 22.0 & 383.0 & 0.0 & 14.1 & - & 880.6 & 306.9 & 5.6 & 14.9 & 3.4 & 4.41 & 50.7 & 47.5 & 323.3 & 45.2 \\
\hline $17 X-2,10-20$ & 132.5 & 14 & - & - & 21.2 & 376.3 & 0.0 & 10.3 & 7.4 & 846.5 & 302.1 & 5.9 & 13.3 & 3.2 & 4.23 & 48.3 & 46.9 & 304.1 & 50.0 \\
\hline $17 X-3,64-74$ & 133.9 & 6 & - & - & 22.0 & 386.0 & 0.0 & 5.7 & 7.3 & 767.5 & 319.5 & 5.9 & 15.0 & 3.5 & 4.25 & 51.3 & 47.4 & 267.5 & 46.6 \\
\hline $17 X-4,65-76$ & 134.6 & 7 & - & - & 22.0 & 386.0 & 0.0 & - & 6.9 & - & - & - & - & - & - & - & - & - & - \\
\hline $18 \mathrm{X}-2,0-10$ & 142.4 & 5 & - & - & 21.2 & 365.1 & 0.0 & 7.4 & 7.5 & 787.3 & 318.1 & 6.0 & 16.3 & 3.6 & 4.54 & 50.7 & 44.6 & 307.9 & 36.6 \\
\hline $18 X-2,0-10$ & 142.4 & 13 & - & - & 19.9 & 350.1 & 0.0 & 10.0 & & - & - & - & - & - & - & - & - & - & - \\
\hline $18 X-2,120-150$ & 143.7 & 8 & - & - & 22.4 & 385.9 & 0.0 & 12.8 & 7.8 & 811.9 & 353.5 & 5.8 & 16.2 & 3.8 & 4.27 & 52.2 & 45.7 & 345.1 & 39.8 \\
\hline $18 X-5,120-150$ & 148.2 & 25 & 8.08 & 19.7 & 21.8 & 374.2 & 0.0 & 11.5 & 7.0 & 733.7 & 325.5 & 5.7 & 14.0 & 3.4 & 4.13 & 47.3 & 44.6 & 281.1 & 42.4 \\
\hline $19 \times-2,69-79$ & 153.1 & 11 & - & - & 20.0 & 352.2 & 0.0 & 6.5 & 0.0 & - & - & - & - & - & - & - & - & - & - \\
\hline $19 X-4,120-150$ & 156.0 & 24 & 8.15 & 20.4 & 22.0 & 384.0 & 0.0 & 4.0 & 7.3 & 653.4 & 334.0 & 6.1 & 14.0 & 3.6 & 3.94 & 49.9 & 45.3 & 244.9 & 43.8 \\
\hline $20 X-2,48-78$ & 162.9 & 18 & - & - & 20.0 & 342.3 & 0.0 & 11.9 & 8.9 & 686.9 & 286.9 & 5.1 & 7.5 & 3.8 & 1.94 & 43.1 & 46.6 & 235.2 & 45.6 \\
\hline $20 X-4,120-150$ & 165.9 & 21 & 7.97 & 21.0 & 22.0 & 374.0 & 0.0 & 9.0 & 7.2 & - & - & - & - & - & - & - & - & - & - \\
\hline
\end{tabular}


Table T4 (continued).

\begin{tabular}{|c|c|c|c|c|c|c|c|c|c|c|c|c|c|c|c|c|c|c|c|}
\hline \multirow{2}{*}{$\begin{array}{l}\text { Core, section, } \\
\text { interval }(\mathrm{cm})\end{array}$} & \multirow{2}{*}{$\begin{array}{l}\text { Depth } \\
\text { (mbsf) }\end{array}$} & \multirow{2}{*}{$\begin{array}{l}\text { Volume } \\
(\mathrm{mL})\end{array}$} & \multirow[b]{2}{*}{$\mathrm{pH}$} & \multirow{2}{*}{$\begin{array}{c}\text { Alkalinity } \\
(\mathrm{mM})\end{array}$} & \multirow[b]{2}{*}{ Salinity } & \multirow{2}{*}{$\underset{(\mathrm{mM})}{\mathrm{Cl}}$} & \multirow{2}{*}{$\begin{array}{l}\mathrm{SO}_{4} \\
(\mathrm{mM})\end{array}$} & \multirow{2}{*}{$\begin{array}{l}\mathrm{PO}_{4} \\
(\mu \mathrm{M})\end{array}$} & \multirow{2}{*}{$\begin{array}{c}\mathrm{NH}_{4} \\
(\mathrm{mM})\end{array}$} & \multirow{2}{*}{$\begin{array}{c}\mathrm{H}_{4} \mathrm{SiO}_{4} \\
(\mu \mathrm{M})\end{array}$} & \multicolumn{4}{|c|}{ Cations (mM) } & & & ace ele & ents $(\mu \mathrm{M}$ & \\
\hline & & & & & & & & & & & $\mathrm{Na}$ & K & $\mathrm{Mg}$ & $\mathrm{Ca}$ & $\mathrm{Mg} / \mathrm{Ca}$ & $\mathrm{Sr}$ & $\mathrm{Li}$ & $B$ & $\mathrm{Ba}$ \\
\hline $21 X-2,113-143$ & 173.2 & 4 & - & - & 21.5 & 383.0 & 0.0 & - & 7.2 & - & - & - & - & - & - & - & - & - & - \\
\hline $21 X-4,81-150$ & 175.7 & 33 & 8.12 & 18.7 & 22.0 & 375.8 & 0.0 & 4.8 & 7.0 & 780.1 & 310.6 & 5.3 & 12.4 & 3.4 & 3.71 & 49.0 & 48.0 & 276.5 & 41.4 \\
\hline $22 X-1,0-17$ & 180.2 & 17 & - & - & 18.7 & 328.1 & 0.0 & 5.9 & 7.3 & 660.4 & 280.4 & 4.6 & 9.1 & 2.8 & 3.20 & 43.1 & 45.6 & 224.3 & 43.1 \\
\hline $22 X-1,17-26$ & 180.3 & 6 & - & - & 20.4 & 362.3 & 0.0 & 6.8 & 7.3 & - & - & - & - & - & - & - & - & - & - \\
\hline $22 \mathrm{X}-1,26-37$ & 180.4 & 6 & - & - & 21.2 & 368.2 & 0.0 & 4.9 & 7.3 & - & - & - & - & - & - & - & - & - & - \\
\hline $22 X-2,85-118$ & 182.3 & 8 & - & - & 21.8 & 376.3 & 0.0 & 5.7 & 7.6 & - & - & - & - & - & - & - & - & - & - \\
\hline $23 X-1,131-161$ & 191.2 & 9 & - & - & 21.3 & 368.1 & 0.0 & 7.5 & 7.3 & - & - & - & - & - & - & - & - & - & - \\
\hline $23 X-3,62-89$ & 193.6 & 16 & - & - & 21.3 & 371.1 & 0.0 & - & 6.8 & - & - & - & - & - & - & - & - & - & - \\
\hline $24 \mathrm{P}-1,0-12$ & 197.4 & 12 & - & - & 20.7 & 346.4 & 0.0 & - & - & - & - & - & - & - & - & - & - & - & - \\
\hline $24 \mathrm{P}-1,39-48$ & 197.7 & 8 & - & - & 21.3 & 356.7 & 0.0 & - & - & - & - & - & - & - & - & - & - & - & - \\
\hline $24 \mathrm{P}-1,70-80$ & 198.1 & 22 & - & - & 20.0 & 384.0 & 0.0 & - & - & - & - & - & - & - & - & - & - & - & - \\
\hline $25 X-1,51-61$ & 199.9 & 5 & - & - & 21.6 & 279.5 & 0.0 & - & 5.6 & - & - & - & - & - & - & - & - & - & - \\
\hline $25 X-1,61-71$ & 200.0 & 3 & - & - & 21.8 & 280.9 & 0.0 & - & 5.5 & - & - & - & - & - & - & - & - & - & - \\
\hline $25 X-3,0-25$ & 201.4 & 22 & - & - & 20.5 & 352.4 & 0.0 & 6.4 & 6.8 & 712.3 & 300.6 & 5.3 & 10.8 & 3.2 & 3.33 & 46.1 & 55.0 & 250.8 & 47.7 \\
\hline $26 \mathrm{X}-2,84-114$ & 211.4 & 36 & 7.99 & 17.2 & 20.5 & 353.9 & 0.0 & 5.4 & 6.1 & 916.3 & 329.7 & 5.4 & 11.9 & 3.6 & 3.34 & 47.6 & 55.4 & 247.4 & 51.6 \\
\hline $26 X-5,120-150$ & 215.9 & 33 & - & - & 21.0 & 361.4 & 0.0 & 6.4 & 6.4 & 895.7 & 322.3 & 5.4 & 11.1 & 3.6 & 3.13 & 46.9 & 59.9 & 234.4 & 50.4 \\
\hline $27 X-1,108-138$ & 219.7 & 33 & - & - & 19.7 & 360.3 & 0.0 & 3.6 & 6.7 & 736.7 & 306.5 & 5.3 & 10.1 & 3.1 & 3.26 & 46.6 & 63.2 & 264.0 & 52.8 \\
\hline $27 X-3,0-10$ & 221.3 & 4 & - & - & 21.0 & 364.3 & 0.0 & - & - & - & - & - & - & - & - & - & - & - & - \\
\hline $27 X-3,10-20$ & 221.4 & 3 & - & - & 20.8 & 356.3 & 0.0 & - & - & - & - & - & - & - & - & - & - & - & - \\
\hline $27 X-4,114-144$ & 224.0 & 24 & 8.15 & 17.0 & 21.5 & 366.4 & 0.0 & 4.5 & 6.3 & 707.3 & 320.8 & 5.4 & 11.5 & 3.4 & 3.42 & 50.6 & 63.1 & 252.2 & 57.7 \\
\hline $28 \mathrm{X}-1,120-150$ & 229.5 & 21 & 7.99 & 16.9 & 21.3 & 365.8 & 0.0 & 3.6 & 6.1 & 621.2 & 333.2 & 5.6 & 11.8 & 3.6 & 3.31 & 53.0 & 68.0 & 245.9 & 58.9 \\
\hline $28 X-3,96-125$ & 232.1 & 17 & - & - & 21.0 & 351.7 & 0.0 & 2.7 & 5.9 & 709.6 & 313.7 & 5.1 & 10.1 & 3.4 & 2.96 & 48.4 & 63.7 & 221.7 & 54.8 \\
\hline $29 X-2,120-150^{*}$ & 240.6 & - & - & - & - & - & - & - & - & - & - & - & - & - & - & - & - & - & - \\
\hline $30 X-2,88-118$ & 249.9 & 20 & 8.13 & 17.2 & 21.5 & 370.4 & 0.0 & - & 6.2 & 736.1 & 323.1 & 5.8 & 10.7 & 3.7 & 2.88 & 51.0 & 73.5 & 236.8 & 68.3 \\
\hline $31 X-4,120-150$ & 262.9 & 40 & 8.09 & 17.4 & 21.5 & 367.4 & 0.0 & 3.6 & 5.8 & 838.4 & 326.8 & 5.9 & 11.2 & 4.3 & 2.58 & 54.4 & 80.4 & 254.2 & 73.8 \\
\hline $32 X-4,120-150$ & 272.6 & 20 & - & - & 21.6 & 366.8 & 0.0 & - & 6.0 & 617.1 & 330.7 & 6.1 & 9.5 & 3.7 & 2.58 & 52.2 & 80.0 & 141.2 & 73.6 \\
\hline $33 X-4,120-150$ & 282.2 & 33 & 8.31 & 16.4 & 21.8 & 366.3 & 0.0 & 2.7 & - & 794.1 & 328.4 & 6.0 & 10.2 & 3.7 & 2.72 & 54.6 & 83.9 & 188.0 & 72.6 \\
\hline $34 X-4,120-150$ & 291.8 & 12 & - & - & 21.0 & 373.8 & 0.0 & 3.6 & - & - & - & - & - & - & - & - & - & - & - \\
\hline $35 X-2,120-150$ & 298.4 & 33 & - & - & 21.5 & 369.4 & 0.0 & - & 4.6 & - & - & - & - & - & - & - & - & - & - \\
\hline 311-U1327D- & & & & & & & & & & & & & & & & & & & \\
\hline $1 \mathrm{H}-1,25-40$ & 0.3 & 70 & 7.62 & 3.5 & 34.5 & 551.6 & 28.9 & 5.4 & 0.0 & - & 457.6 & 11.6 & 49.9 & 9.8 & 5.07 & 85.4 & - & - & - \\
\hline $1 \mathrm{H}-1,55-70$ & 0.6 & 72 & 7.65 & 3.9 & 34.0 & 550.6 & 28.8 & 9.1 & 0.0 & - & 466.7 & 11.8 & 47.6 & 9.8 & 4.83 & 83.6 & - & - & - \\
\hline $1 \mathrm{H}-1,80-95$ & 0.9 & 70 & 7.66 & 4.1 & 34.0 & 550.1 & 28.9 & 12.7 & 0.0 & - & 479.0 & 12.2 & 50.3 & 10.1 & 4.98 & 82.3 & - & - & - \\
\hline $1 \mathrm{H}-1,135-150$ & 1.4 & 60 & 7.58 & 5.8 & 34.0 & 550.1 & 28.1 & 20.0 & 0.1 & - & 461.7 & 12.1 & 49.4 & 8.9 & 5.54 & 81.7 & - & - & - \\
\hline $1 \mathrm{H}-2,25-40$ & 1.8 & 74 & 7.71 & 6.5 & 34.0 & - & 27.8 & 22.7 & 0.2 & - & 459.3 & 12.0 & 50.1 & 9.6 & 5.22 & 80.8 & - & - & - \\
\hline $1 \mathrm{H}-2,55-70$ & 2.1 & 62 & 7.71 & 6.5 & 33.8 & - & 24.8 & 32.7 & 0.2 & - & 467.2 & 11.1 & 46.6 & 9.3 & 5.02 & 80.3 & - & - & - \\
\hline $1 \mathrm{H}-2,80-95$ & 2.4 & 70 & 7.66 & 8.6 & 33.8 & - & 23.2 & 34.5 & 0.2 & - & 469.6 & 11.6 & 47.7 & 8.7 & 5.48 & 80.9 & - & - & - \\
\hline $1 \mathrm{H}-2,135-150$ & 2.9 & 60 & 7.79 & 10.4 & 33.8 & - & 21.4 & 37.2 & 0.4 & - & 447.6 & 11.6 & 45.0 & 7.1 & 6.37 & 76.4 & - & - & - \\
\hline $1 \mathrm{H}-3,10-25$ & 3.2 & 68 & 7.88 & 11.0 & 33.8 & - & 20.1 & 36.3 & 0.3 & - & 479.5 & 11.4 & 46.5 & 7.9 & 5.88 & 78.1 & - & - & - \\
\hline $1 \mathrm{H}-3,40-55$ & 3.5 & 58 & 7.71 & 11.5 & 33.5 & - & 19.5 & 39.1 & 0.4 & - & 470.9 & 11.2 & 45.5 & 7.1 & 6.38 & 76.3 & - & - & - \\
\hline $1 \mathrm{H}-3,65-80$ & 3.7 & 50 & 7.78 & 12.6 & 33.5 & - & 17.9 & 40.9 & 0.6 & - & 435.7 & 11.0 & 43.9 & 6.2 & 7.14 & 76.1 & - & - & - \\
\hline $1 \mathrm{H}-3,120-135$ & 4.3 & 40 & 7.79 & 13.9 & 33.0 & - & 16.2 & 49.1 & 0.7 & - & 454.7 & 10.5 & 43.8 & 7.4 & 5.96 & 75.0 & - & - & - \\
\hline $1 \mathrm{H}-4,25-40$ & 4.8 & 45 & 7.59 & 14.8 & 33.0 & - & 14.1 & 53.6 & 0.7 & - & 449.4 & 10.5 & 44.4 & 5.9 & 7.52 & 74.3 & - & - & - \\
\hline $1 \mathrm{H}-4,55-70$ & 5.1 & 21 & 7.75 & 16.2 & 32.7 & - & 12.9 & 20.0 & 0.9 & - & 448.9 & 11.3 & 43.2 & 6.6 & 6.56 & 77.0 & - & - & - \\
\hline $1 \mathrm{H}-4,80-95$ & 5.4 & 65 & 7.74 & 16.9 & 32.5 & - & 11.1 & 57.2 & 0.8 & - & 442.4 & 10.9 & 42.2 & 6.6 & 6.39 & 73.1 & - & - & - \\
\hline $1 \mathrm{H}-4,135-150$ & 5.9 & 50 & 7.79 & 18.0 & 32.2 & - & 9.7 & 63.6 & 0.9 & - & 446.2 & 10.4 & 40.7 & 5.1 & 7.93 & 70.4 & - & - & - \\
\hline $2 \mathrm{H}-1,25-40$ & 7.2 & 57 & 7.94 & 23.6 & 31.7 & - & 0.2 & 108.1 & 1.2 & - & 455.2 & 10.2 & 40.3 & 3.0 & 13.66 & 67.2 & - & - & - \\
\hline $2 \mathrm{H}-1,55-70$ & 7.5 & 31 & 7.84 & 23.4 & 31.7 & - & 0.2 & 101.8 & 1.3 & - & 459.5 & 9.7 & 37.5 & 3.5 & 10.66 & 67.7 & - & - & - \\
\hline $2 \mathrm{H}-1,80-95$ & 7.8 & 44 & 7.87 & 23.6 & 31.7 & - & 0.2 & 103.6 & 1.5 & - & 459.4 & 10.0 & 39.3 & 2.5 & 15.42 & 66.2 & - & - & - \\
\hline $2 \mathrm{H}-1,135-150$ & 8.3 & 53 & 7.75 & 24.0 & 31.5 & - & 0.0 & 96.3 & 1.7 & - & 436.1 & 9.6 & 38.3 & 3.2 & 12.09 & 67.3 & - & - & - \\
\hline $2 \mathrm{H}-3,55-70$ & 10.5 & 50 & 7.88 & 24.0 & 31.7 & - & 0.0 & 65.0 & 1.4 & - & 460.6 & 10.1 & 40.0 & 3.4 & 11.64 & 69.7 & - & - & - \\
\hline $2 \mathrm{H}-4,80-95$ & 12.3 & 20 & 7.80 & 25.2 & 31.5 & - & 0.0 & - & - & - & - & - & - & - & - & - & - & - & - \\
\hline
\end{tabular}


Table T4 (continued).

\begin{tabular}{|c|c|c|c|c|c|c|c|c|c|c|c|c|c|c|c|c|c|c|c|}
\hline \multirow{2}{*}{$\begin{array}{l}\text { Core, section, } \\
\text { interval }(\mathrm{cm})\end{array}$} & \multirow{2}{*}{$\begin{array}{l}\text { Depth } \\
\text { (mbsf) }\end{array}$} & \multirow{2}{*}{$\begin{array}{l}\text { Volume } \\
(\mathrm{mL})\end{array}$} & \multirow[b]{2}{*}{$\mathrm{pH}$} & \multirow{2}{*}{$\begin{array}{l}\text { Alkalinity } \\
(\mathrm{mM})\end{array}$} & \multirow[b]{2}{*}{ Salinity } & \multirow{2}{*}{$\begin{array}{c}\mathrm{Cl} \\
(\mathrm{mM})\end{array}$} & \multirow{2}{*}{$\begin{array}{c}\mathrm{SO}_{4} \\
(\mathrm{mM})\end{array}$} & \multirow{2}{*}{$\begin{array}{l}\mathrm{PO}_{4} \\
(\mu \mathrm{M})\end{array}$} & \multirow{2}{*}{$\begin{array}{l}\mathrm{NH}_{4} \\
(\mathrm{mM})\end{array}$} & \multirow{2}{*}{$\begin{array}{c}\mathrm{H}_{4} \mathrm{SiO}_{4} \\
(\mu \mathrm{M})\end{array}$} & \multicolumn{4}{|c|}{ Cations (mM) } & \multirow[b]{2}{*}{$\mathrm{Mg} / \mathrm{Ca}$} & \multicolumn{4}{|c|}{ Trace elements $(\mu \mathrm{M})$} \\
\hline & & & & & & & & & & & $\mathrm{Na}$ & $\mathrm{K}$ & $\mathrm{Mg}$ & $\mathrm{Ca}$ & & $\mathrm{Sr}$ & $\mathrm{Li}$ & $B$ & $\mathrm{Ba}$ \\
\hline $2 \mathrm{H}-5,55-70$ & 13.8 & 45 & 7.75 & 25.5 & 31.5 & - & 0.0 & 51.8 & 1.8 & - & 441.2 & 9.7 & 37.3 & 3.4 & 11.12 & 68.6 & - & - & - \\
\hline $2 \mathrm{H}-6,80-95$ & 15.3 & 40 & - & - & 31.0 & - & 0.0 & 49.1 & 1.6 & - & 434.0 & 11.0 & 37.3 & 3.1 & 12.20 & 70.7 & - & - & - \\
\hline $4 \mathrm{E}-1,0-20$ & 125.4 & 20 & - & - & 21.2 & - & 0.0 & 15.0 & - & - & 323.8 & 6.7 & 3.6 & 3.7 & 0.97 & 23.6 & - & - & - \\
\hline $4 \mathrm{E}-1,95-110$ & 126.3 & 10 & - & - & 22.5 & 391.6 & 0.0 & 5.9 & - & - & 330.4 & 6.0 & 15.6 & 3.6 & 4.38 & 53.6 & - & - & - \\
\hline $5 X-2,74-84$ & 128.6 & 8 & - & - & 23.0 & 391.6 & 0.0 & - & - & - & - & - & - & - & - & - & - & - & - \\
\hline $5 X-2,84-94$ & 128.7 & 1 & - & - & 3.7 & 67.8 & 0.0 & 6.1 & - & - & - & - & - & - & - & - & - & - & - \\
\hline $6 Y-1,49-68$ & 132.6 & 12 & - & - & 21.8 & 373.8 & 0.0 & - & - & - & 308.4 & 5.9 & 13.0 & 2.2 & 5.94 & 48.3 & - & - & - \\
\hline $7 X-3,38-48$ & 135.8 & 3 & - & - & 17.3 & 334.6 & 0.0 & - & - & - & - & - & - & - & - & - & - & - & - \\
\hline $7 X-3,48-54$ & 135.8 & 5 & - & - & 19.5 & 335.0 & 0.0 & 7.6 & - & - & - & - & - & - & - & - & - & - & - \\
\hline $7 X-3,48-54$ & 135.8 & 4 & - & - & 15.8 & 275.4 & 0.0 & - & - & - & - & - & - & - & - & - & - & - & - \\
\hline 10P-1, 18-28 & 155.3 & 5 & - & - & 19.3 & 336.4 & 0.0 & 6.9 & - & - & - & - & - & - & - & - & - & - & - \\
\hline $10 \mathrm{P}-1,45-55$ & 155.6 & 2 & - & - & 18.5 & 333.2 & 0.0 & - & - & - & - & - & - & - & - & - & - & - & - \\
\hline $10 \mathrm{P}-1,78-88$ & 155.9 & 4 & & - & 19.1 & 351.7 & 0.0 & 4.5 & - & - & - & - & - & - & - & - & - & - & - \\
\hline $11 X-1,67-70$ & 157.7 & 4 & - & - & 17.1 & - & 0.0 & - & - & - & - & - & - & - & - & - & - & - & - \\
\hline $11 X-1,70-72$ & 157.7 & 1 & - & - & 13.5 & - & 0.0 & - & - & - & - & - & - & - & - & - & - & - & - \\
\hline $15 X-3,49-59$ & 222.0 & 2 & - & - & 3.7 & 70.4 & 0.0 & - & - & - & - & - & - & - & - & - & - & - & - \\
\hline $15 X-3,49-59$ & 222.0 & 1 & - & - & 18.0 & 313.4 & 0.0 & 3.4 & - & - & - & - & - & - & - & - & - & - & - \\
\hline $17 \mathrm{P}-1,25-35$ & 246.3 & 4 & - & - & 21.1 & 369.7 & 0.0 & 2.6 & - & - & - & - & - & - & - & - & - & - & - \\
\hline $17 \mathrm{P}-1,70-80$ & 246.8 & 3 & - & - & 21.0 & 369.6 & 0.0 & 2.5 & - & - & - & - & - & - & - & - & - & - & - \\
\hline \multicolumn{20}{|l|}{ 311-U1327E- } \\
\hline $1 \mathrm{H}-1,25-40$ & 3.3 & 40 & 7.74 & 13.6 & 33.5 & - & 16.0 & 41.8 & 0.5 & - & 452.5 & 10.9 & 45.4 & 7.2 & 6.27 & 76.9 & - & - & - \\
\hline $1 \mathrm{H}-1,55-70$ & 3.6 & 40 & 7.62 & 13.2 & 33.0 & - & 14.9 & 50.9 & 0.5 & - & 452.4 & 11.2 & 42.5 & 6.7 & 6.32 & 77.1 & - & - & - \\
\hline $1 \mathrm{H}-1,80-95$ & 3.9 & 60 & 7.67 & 13.9 & 33.0 & - & 14.2 & 52.6 & 0.5 & - & 388.6 & 10.8 & 43.9 & 5.0 & 8.79 & 76.0 & - & - & - \\
\hline $1 \mathrm{H}-1,135-150$ & 4.4 & 40 & - & - & 33.0 & - & 11.5 & 28.4 & 0.6 & - & 439.4 & 10.9 & 44.0 & 6.2 & 7.05 & 76.4 & - & - & - \\
\hline $1 \mathrm{H}-2,25-40$ & 4.8 & 55 & 7.74 & 16.6 & 32.0 & - & 10.0 & 43.4 & 0.6 & - & 463.2 & 11.4 & 41.4 & 5.8 & 7.18 & 73.6 & - & - & - \\
\hline $1 \mathrm{H}-2,55-70$ & 5.1 & 65 & - & - & 32.5 & - & 9.6 & 64.3 & 0.7 & - & 444.3 & 11.4 & 41.6 & 5.7 & 7.34 & 72.8 & - & - & - \\
\hline $1 \mathrm{H}-2,80-95$ & 5.4 & 60 & 7.69 & 17.2 & 32.0 & - & 8.9 & 66.8 & 0.6 & - & 440.5 & 10.2 & 39.2 & 4.9 & 7.98 & 73.3 & - & - & - \\
\hline $1 \mathrm{H}-2,135-150$ & 5.9 & 56 & 7.64 & 18.5 & 32.0 & - & 6.5 & 74.3 & 0.8 & - & 435.7 & 10.7 & 40.7 & 4.7 & 8.70 & 72.4 & - & - & - \\
\hline $1 \mathrm{H}-3,25-40$ & 6.3 & 56 & 7.81 & 18.2 & 32.0 & - & 7.4 & 75.9 & 0.8 & - & 452.1 & 10.8 & 40.4 & 4.2 & 9.57 & 72.9 & - & - & - \\
\hline $1 \mathrm{H}-3,55-70$ & 6.6 & 62 & 7.80 & 20.1 & 32.0 & - & 5.0 & 80.1 & 0.8 & - & 468.3 & 11.1 & 42.6 & 4.4 & 9.67 & 71.4 & - & - & - \\
\hline $1 \mathrm{H}-3,80-95$ & 6.9 & 56 & 7.78 & 19.6 & 31.8 & - & 5.0 & 82.6 & 0.8 & - & 461.2 & 10.5 & 40.3 & 4.2 & 9.53 & 71.1 & - & - & - \\
\hline $1 \mathrm{H}-3,135-150$ & 7.4 & 60 & - & 20.4 & 31.8 & - & 4.2 & 90.9 & 0.9 & - & 468.7 & 10.9 & 40.1 & 3.8 & 10.57 & 69.7 & - & - & - \\
\hline $1 \mathrm{H}-4,25-40$ & 7.8 & 66 & 7.93 & 19.6 & 31.8 & - & 5.3 & 97.6 & 0.8 & - & 462.9 & 10.5 & 40.2 & 3.4 & 11.97 & 70.1 & - & - & - \\
\hline $1 \mathrm{H}-4,55-70$ & 8.1 & 70 & 7.94 & 21.9 & 31.8 & - & 2.1 & 100.1 & 0.8 & - & 440.2 & 10.3 & 40.9 & 3.1 & 13.40 & 68.4 & - & - & - \\
\hline $1 \mathrm{H}-4,80-95$ & 8.4 & 50 & 7.97 & 21.5 & 31.8 & - & 3.2 & 97.6 & 0.9 & - & 439.2 & 10.6 & 40.2 & 3.3 & 12.18 & 70.9 & - & - & - \\
\hline $1 \mathrm{H}-4,135-150$ & 8.9 & 56 & 7.96 & 22.4 & 31.5 & - & 2.0 & 93.4 & 1.0 & - & 429.5 & 9.9 & 39.7 & 1.9 & 20.66 & 69.8 & - & - & - \\
\hline $1 \mathrm{H}-5,25-40$ & 9.3 & 64 & 7.88 & 25.3 & 31.5 & - & 0.2 & 87.6 & 1.0 & - & 439.8 & 9.8 & 39.7 & 3.2 & 12.48 & 69.9 & - & - & - \\
\hline $1 \mathrm{H}-5,55-70$ & 9.6 & 64 & 7.94 & 25.9 & 31.5 & - & 0.3 & 82.6 & 1.0 & - & 472.3 & 10.8 & 39.3 & 3.2 & 12.35 & 71.6 & - & - & - \\
\hline $1 \mathrm{H}-5,80-95$ & 9.9 & 66 & 8.04 & 23.6 & 31.5 & - & 0.1 & 74.3 & 1.1 & - & 456.4 & 10.6 & 40.4 & 3.5 & 11.61 & 68.9 & - & - & - \\
\hline $1 \mathrm{H}-5,135-150$ & 10.4 & 56 & 7.84 & 24.1 & 31.5 & - & 0.0 & 68.4 & 1.0 & - & 447.2 & 10.5 & 40.5 & 3.5 & 11.58 & 70.2 & - & - & - \\
\hline $1 \mathrm{H}-6,25-40$ & 10.8 & 58 & 7.79 & 24.3 & 31.5 & - & 0.0 & 65.1 & 1.1 & - & 468.5 & 10.7 & 40.2 & 3.4 & 11.73 & 71.1 & - & - & - \\
\hline $1 \mathrm{H}-6,55-7-$ & 11.1 & 52 & 7.78 & 23.7 & 31.5 & - & 0.0 & 59.3 & 1.1 & - & 453.8 & 9.3 & 38.5 & 3.5 & 10.96 & 71.7 & - & - & - \\
\hline $1 \mathrm{H}-6,80-95$ & 11.4 & 54 & 7.76 & 24.3 & 31.2 & - & 0.0 & 66.8 & 1.1 & - & 436.8 & 9.5 & 37.5 & 3.0 & 12.37 & 70.3 & - & - & - \\
\hline $1 \mathrm{H}-6,135-150$ & 11.9 & 60 & 7.70 & 24.5 & 31.2 & - & 0.0 & 66.8 & 1.2 & - & 426.3 & 9.2 & 38.3 & 3.4 & 11.31 & 71.4 & - & - & - \\
\hline $1 \mathrm{H}-7,50-65$ & 12.6 & 60 & 7.70 & 24.6 & 31.5 & - & 0.0 & 64.3 & - & - & 438.5 & 9.8 & 38.2 & 3.3 & 11.54 & 70.6 & - & - & - \\
\hline $3 \mathrm{P}-1,18-30$ & 80.2 & 20 & - & - & 24.4 & 420.1 & 0.0 & - & - & - & - & - & - & - & - & - & - & - & - \\
\hline $3 \mathrm{P}-1,80-85$ & 80.8 & 8 & - & - & 23.9 & 413.2 & 0.0 & 25.0 & - & - & - & - & - & - & - & - & - & - & - \\
\hline
\end{tabular}


Table T5. Headspace gas concentrations of hydrocarbons, Holes U1327C, U1327D, and U1327E. (See table note. Continued on next two pages.)

\begin{tabular}{|c|c|c|c|c|c|c|c|}
\hline $\begin{array}{l}\text { Core, section, } \\
\text { interval }(\mathrm{cm})\end{array}$ & $\begin{array}{l}\text { Depth } \\
\text { (mbsf) }\end{array}$ & $\mathrm{C}_{1} / \mathrm{C}_{2}$ & $\begin{array}{c}\mathrm{C}_{1} \\
\text { (ppmv) }\end{array}$ & $\begin{array}{c}\mathrm{C}_{2} \\
(\mathrm{ppmv})\end{array}$ & $\begin{array}{c}\mathrm{C}_{2=} \\
(\mathrm{ppmv})\end{array}$ & $\begin{array}{c}\mathrm{C}_{3} \\
(\mathrm{ppmv})\end{array}$ & $\begin{array}{c}\mathrm{C}_{1} \\
(\mathrm{mM})^{*}\end{array}$ \\
\hline \multicolumn{8}{|l|}{ 311-U1327C- } \\
\hline $1 \mathrm{H}-2,0-5$ & 1.5 & & 7 & 0 & 0 & 0 & 0.00 \\
\hline $1 \mathrm{H}-4,0-5$ & 4.5 & & 3 & 0 & 0 & 0 & 0.00 \\
\hline $2 \mathrm{H}-2,0-5$ & 7.6 & & 7 & 0 & 0 & 0 & 0.00 \\
\hline $2 \mathrm{H}-4,0-5$ & 10.6 & & 6,861 & 0 & 0 & 0 & 3.14 \\
\hline $2 \mathrm{H}-6,0-5$ & 13.6 & 14,455 & 11,564 & 0.8 & 0 & 0 & 5.36 \\
\hline $2 \mathrm{H}-7,0-5$ & 15.1 & & 12,974 & 0 & 0 & 0 & 6.04 \\
\hline $3 \mathrm{H}-3,0-5$ & 18.6 & 12,987 & 16,884 & 1.3 & 0 & 0 & 7.93 \\
\hline $3 \mathrm{H}-7,0-5$ & 24.6 & & 11,539 & 0 & 0 & 0 & 5.52 \\
\hline $4 \mathrm{H}-3,0-5$ & 28.1 & 8,792 & 18,464 & 2.1 & 0 & 0 & 8.92 \\
\hline $4 \mathrm{H}-6,0-5$ & 32.6 & 6,472 & 12,944 & 2.0 & 0 & 0 & 6.33 \\
\hline $5 \mathrm{H}-3,0-5$ & 37.6 & 5,113 & 7,159 & 1.4 & 0 & 0 & 3.55 \\
\hline $5 \mathrm{H}-6,0-5$ & 42.1 & 6,078 & 12,764 & 2.1 & 0 & 0 & 6.42 \\
\hline $7 \mathrm{H}-3,0-5$ & 49.1 & 3,017 & 3,017 & 1.0 & 0 & 0 & 1.55 \\
\hline $7 \mathrm{H}-6,0-5$ & 53.6 & & 2,808 & 0 & 0 & 0 & 1.46 \\
\hline $8 \mathrm{H}-2,110-115$ & 58.2 & 1,981 & 2,377 & 1.2 & 0 & 0 & 1.26 \\
\hline $9 \mathrm{H}-3,0-5$ & 68.1 & 3,056 & 3,056 & 1.0 & 0 & 0 & 1.67 \\
\hline $9 \mathrm{H}-6,0-5$ & 72.6 & 2,938 & 3,819 & 1.3 & 0 & 0 & 2.12 \\
\hline $10 \mathrm{H}-3,0-5$ & 77.6 & 2,954 & 4,727 & 1.6 & 0 & 0 & 2.66 \\
\hline $10 \mathrm{H}-6,0-5$ & 80.8 & 2,004 & 4,208 & 2.1 & 0 & 0 & 2.40 \\
\hline $11 \mathrm{H}-3,0-5$ & 87.1 & 3,060 & 3,366 & 1.1 & 0 & 0 & 1.96 \\
\hline $11 \mathrm{H}-6,0-5$ & 91.6 & 2,746 & 3,295 & 1.2 & 0 & 0 & 1.95 \\
\hline $12 X-5,145-150$ & 99.1 & 1,492 & 2,238 & 1.5 & 0 & 0 & 1.36 \\
\hline $13 X-3,0-5$ & 105.5 & 2,133 & 3,199 & 1.5 & 0 & 0 & 1.99 \\
\hline $13 X-5,66-71$ & 108.8 & 2,692 & 4,306 & 1.6 & 0 & 0 & 2.71 \\
\hline $13 X-7,0-5$ & 111.0 & 1,843 & 3,502 & 1.9 & 0 & 0 & 2.22 \\
\hline $14 X-3,0-5$ & 115.1 & 4,051 & 2,026 & 0.5 & 0 & 0 & 1.31 \\
\hline $14 X-4,97-102$ & 117.6 & 1,460 & 3,213 & 2.2 & 0 & 0 & 2.09 \\
\hline $16 X-1,10-21$ & 123.9 & 2,003 & 8,012 & 4.0 & 0 & 0 & 5.32 \\
\hline $16 X-3,0-5$ & 126.7 & 1,341 & 2,146 & 1.6 & 0 & 0 & 1.43 \\
\hline $16 X-5,0-5$ & 129.7 & 1,052 & 2,629 & 2.5 & 0 & 0 & 1.75 \\
\hline $17 X-2,5-6$ & 132.4 & 751 & 1,127 & 1.5 & 0 & 0 & 0.75 \\
\hline $17 X-2,20-25$ & 132.5 & 914 & 2,468 & 2.7 & 0 & 0 & 1.65 \\
\hline $17 X-3,64-66$ & 133.8 & 822 & 1,644 & 2.0 & 0 & 0 & 1.10 \\
\hline $17 X-4,0-5$ & 133.9 & 1,101 & 2,861 & 2.6 & 0 & 0 & 1.91 \\
\hline $17 X-4,65-67$ & 134.6 & 337 & 707 & 2.1 & 0 & 0 & 0.47 \\
\hline $18 X-1,22-27$ & 141.7 & 993 & 4,667 & 4.7 & 0 & 0 & 3.14 \\
\hline $18 X-3,0-5$ & 143.9 & 1,027 & 5,135 & 5.0 & 0 & 0 & 3.46 \\
\hline $18 X-6,0-5$ & 148.4 & 562 & 3,988 & 7.1 & 0 & 0 & 2.69 \\
\hline $19 X-3,0-5$ & 153.1 & 815 & 21,512 & 26.4 & 0 & 0 & 14.58 \\
\hline $20 X-3,0-5$ & 163.1 & 638 & 2,871 & 4.5 & 0 & 0 & 1.95 \\
\hline $20 X-5,0-5$ & 166.1 & 575 & 2,647 & 4.6 & 0 & 0 & 1.80 \\
\hline $21 X-3,0-5$ & 173.3 & 645 & 3,419 & 5.3 & 0 & 0 & 2.32 \\
\hline $21 X-5,0-5$ & 176.0 & 351 & 1,335 & 3.8 & 0 & 0 & 0.90 \\
\hline $22 X-1,7-9$ & 180.2 & 326 & 1,436 & 4.4 & 0 & 0 & 0.97 \\
\hline $22 X-1,15-17$ & 180.3 & 471 & 3,202 & 6.8 & 0 & 0 & 2.16 \\
\hline $22 X-1,17-19$ & 180.3 & 578 & 3,353 & 5.8 & 0 & 0 & 2.27 \\
\hline $22 X-1,27-29$ & 180.4 & 305 & 916 & 3.0 & 0 & 0 & 0.62 \\
\hline $22 X-1,35-37$ & 180.5 & 476 & 5,852 & 12.3 & 0 & 0 & 3.96 \\
\hline $22 X-3,0-5$ & 182.5 & 487 & 3,412 & 7.0 & 0 & 0 & 2.30 \\
\hline $23 X-1,126-131$ & 191.0 & 138 & 905 & 6.6 & 0 & 0 & 0.61 \\
\hline $23 X-3,57-62$ & 193.4 & 674 & 5,057 & 7.5 & 0 & 0 & 3.40 \\
\hline $25 X-1,49-51$ & 199.8 & 113 & 882 & 7.8 & 0 & 0 & 0.59 \\
\hline $25 X-1,69-71$ & 200.0 & 506 & 3,453 & 6.8 & 0 & 0 & 2.32 \\
\hline $25 X-3,25-30$ & 201.5 & 381 & 3,545 & 9.3 & 0 & 0 & 2.38 \\
\hline $26 X-3,0-5$ & 211.5 & 312 & 3,089 & 9.9 & 0 & 0 & 2.06 \\
\hline $26 X-6,0-5$ & 216.0 & 388 & 3,185 & 8.2 & 0 & 0 & 2.13 \\
\hline $27 X-2,139-141$ & 221.3 & 434 & 4,643 & 10.7 & 0 & 0 & 3.09 \\
\hline $27 X-3,0-2$ & 221.3 & 261 & 2,269 & 8.7 & 0 & 0 & 1.51 \\
\hline $27 X-3,8-10$ & 221.4 & 294 & 3,377 & 11.5 & 0 & 0 & 2.25 \\
\hline $27 X-3,20-22$ & 221.5 & 377 & 6,295 & 16.7 & 0 & 0 & 4.19 \\
\hline $27 X-5,0-5$ & 224.1 & 179 & 969 & 5.4 & 0 & 0 & 0.64 \\
\hline $28 X-2,0-5$ & 229.6 & 321 & 5,488 & 17.1 & 0 & 0 & 3.64 \\
\hline $28 X-4,0-5$ & 232.2 & 298 & 3,065 & 10.3 & 0 & 0 & 2.03 \\
\hline $29 X-3,0-5$ & 240.7 & 384 & 4,499 & 11.7 & 0 & 0 & 2.75 \\
\hline $30 \times-3,0-5$ & 250.1 & 427 & 3,290 & 7.7 & 0 & 0 & 2.00 \\
\hline $30 \times-4,0-5$ & 251.1 & 539 & 4,260 & 7.9 & 0 & 0 & 2.59 \\
\hline
\end{tabular}


Table T5 (continued).

\begin{tabular}{|c|c|c|c|c|c|c|c|}
\hline $\begin{array}{l}\text { Core, section, } \\
\text { interval }(\mathrm{cm})\end{array}$ & $\begin{array}{l}\text { Depth } \\
\text { (mbsf) }\end{array}$ & $\mathrm{C}_{1} / \mathrm{C}_{2}$ & $\begin{array}{c}C_{1} \\
(p p m v)\end{array}$ & $\begin{array}{c}C_{2} \\
(p p m v)\end{array}$ & $\begin{array}{c}C_{2=} \\
(p p m v)\end{array}$ & $\begin{array}{c}\mathrm{C}_{3} \\
(\mathrm{ppmv})\end{array}$ & $\begin{array}{c}\mathrm{C}_{1} \\
(\mathrm{mM})^{*}\end{array}$ \\
\hline $31 X-3,0-5$ & 260.1 & 921 & 3,592 & 3.9 & 0 & 0 & 2.23 \\
\hline $31 X-5,0-5$ & 263.1 & 824 & 4,118 & 5.0 & 0 & 0 & 2.57 \\
\hline $32 X-3,0-5$ & 269.7 & 510 & 2,960 & 5.8 & 0 & 0 & 1.87 \\
\hline $32 X-5,0-5$ & 272.7 & 483 & 2,703 & 5.6 & 0 & 0 & 1.72 \\
\hline $33 X-3,0-5$ & 279.3 & 548 & 4,052 & 7.4 & 0 & 0 & 2.62 \\
\hline $33 X-5,0-5$ & 282.3 & 463 & 2,917 & 6.3 & 0 & 0 & 1.89 \\
\hline $34 X-3,0-5$ & 288.9 & 496 & 3,970 & 8.0 & 0 & 0 & 2.62 \\
\hline $34 X-5,0-5$ & 291.9 & 829 & 9,116 & 11.0 & 0 & 0 & 6.05 \\
\hline $35 X-3,0-5$ & 298.5 & 386 & 1,659 & 4.3 & 0 & 0 & 1.12 \\
\hline \multicolumn{8}{|l|}{ 311-U1327D- } \\
\hline $1 \mathrm{H}-1,40-45$ & 0.4 & & 2 & 0 & 0 & 0 & 0.00 \\
\hline $1 \mathrm{H}-1,70-75$ & 0.7 & & 2 & 0 & 0 & 0 & 0.00 \\
\hline $1 \mathrm{H}-1,95-100$ & 1.0 & & 2 & 0 & 0 & 0 & 0.00 \\
\hline $1 \mathrm{H}-2,0-5$ & 1.5 & & 2 & 0 & 0 & 0 & 0.00 \\
\hline $1 \mathrm{H}-2,70-75$ & 2.2 & & 2 & 0 & 0 & 0 & 0.00 \\
\hline $1 \mathrm{H}-2,95-100$ & 2.5 & & 2 & 0 & 0 & 0 & 0.00 \\
\hline $1 \mathrm{H}-3,0-5$ & 3.0 & & 3 & 0 & 0 & 0 & 0.00 \\
\hline $1 \mathrm{H}-3,25-30$ & 3.3 & & 2 & 0 & 0 & 0 & 0.00 \\
\hline $1 \mathrm{H}-3,55-60$ & 3.6 & & 3 & 0 & 0 & 0 & 0.00 \\
\hline $1 \mathrm{H}-4,0-5$ & 4.5 & & 3 & 0 & 0 & 0 & 0.00 \\
\hline $1 \mathrm{H}-4,40-45$ & 4.9 & & 3 & 0 & 0 & 0 & 0.00 \\
\hline $1 \mathrm{H}-4,70-75$ & 5.2 & & 3 & 0 & 0 & 0 & 0.00 \\
\hline $1 \mathrm{H}-4,95-100$ & 5.5 & & 3 & 0 & 0 & 0 & 0.00 \\
\hline $1 \mathrm{H}-5,0-5$ & 6.0 & & 3 & 0 & 0 & 0 & 0.00 \\
\hline $2 \mathrm{H}-1,40-45$ & 7.3 & & 756 & 0 & 0 & 0 & 0.34 \\
\hline $2 \mathrm{H}-1,70-75$ & 7.6 & & 1,607 & 0 & 0 & 0 & 0.72 \\
\hline $2 \mathrm{H}-1,95-100$ & 7.9 & & 2,255 & 0 & 0 & 0 & 1.02 \\
\hline $2 \mathrm{H}-2,0-5$ & 8.4 & & 3,263 & 0 & 0 & 0 & 1.47 \\
\hline $2 \mathrm{H}-2,40-45$ & 8.8 & 7,199 & 4,319 & 0.6 & 0 & 0 & 1.96 \\
\hline $2 \mathrm{H}-2,70-75$ & 9.1 & & 5,020 & 0 & 0 & 0 & 2.28 \\
\hline $2 \mathrm{H}-2,95-100$ & 9.4 & & 5,428 & 0 & 0 & 0 & 2.47 \\
\hline $2 \mathrm{H}-3,0-5$ & 9.9 & & 8,035 & 0 & 0 & 0 & 3.66 \\
\hline $2 \mathrm{H}-3,40-45$ & 10.3 & & 8,827 & 0 & 0 & 0 & 4.03 \\
\hline $2 \mathrm{H}-3,70-75$ & 10.6 & & 7,671 & 0 & 0 & 0 & 3.51 \\
\hline $2 \mathrm{H}-3,95-100$ & 10.9 & & 8,368 & 0 & 0 & 0 & 3.83 \\
\hline $2 \mathrm{H}-4,0-5$ & 11.4 & 8,930 & 10,716 & 1.2 & 0 & 0 & 4.92 \\
\hline $2 \mathrm{H}-4,70-75$ & 12.1 & 10,675 & 9,608 & 0.9 & 0 & 0 & 4.42 \\
\hline $2 \mathrm{H}-4,95-100$ & 12.4 & 9,648 & 13,507 & 1.4 & 0 & 0 & 6.23 \\
\hline $2 \mathrm{H}-5,0-5$ & 12.9 & 9,463 & 14,195 & 1.5 & 0 & 0 & 6.56 \\
\hline $2 \mathrm{H}-5,40-45$ & 13.3 & 9,418 & 14,127 & 1.5 & 0 & 0 & 6.55 \\
\hline $2 \mathrm{H}-5,70-75$ & 13.6 & 8,140 & 14,652 & 1.8 & 0 & 0 & 6.80 \\
\hline $2 \mathrm{H}-5,95-100$ & 13.9 & 8,629 & 14,670 & 1.7 & 0 & 0 & 6.82 \\
\hline $2 \mathrm{H}-6,0-5$ & 14.4 & 10,163 & 14,228 & 1.4 & 0 & 0 & 6.63 \\
\hline $2 \mathrm{H}-6,40-45$ & 14.8 & 12,451 & 7,471 & 0.6 & 0 & 0 & 3.49 \\
\hline $2 \mathrm{H}-6,70-75$ & 15.1 & & 9,445 & 0 & 0 & 0 & 4.42 \\
\hline $2 \mathrm{H}-6,95-100$ & 15.4 & 7,454 & 7,454 & 1.0 & 0 & 0 & 3.49 \\
\hline $2 \mathrm{H}-7,0-5$ & 15.9 & & 4,209 & 0 & 0 & 0 & 1.98 \\
\hline $5 X-3,0-5$ & 128.7 & 1,284 & 3,723 & 2.9 & 0 & 0 & 2.48 \\
\hline $7 X-2,0-5$ & 134.5 & 1,163 & 3,489 & 3.0 & 0 & 0 & 2.33 \\
\hline $7 X-4,0-5$ & 135.9 & 853 & 3,071 & 3.6 & 0 & 0 & 2.05 \\
\hline $8 X-3,0-5$ & 145.3 & 923 & 4,431 & 4.8 & 0 & 0 & 2.99 \\
\hline $11 X-1,19-24$ & 157.3 & 934 & 5,041 & 5.4 & 0 & 0 & 3.43 \\
\hline $15 X-3,0-5$ & 221.5 & 449 & 4,537 & 10.1 & 0 & 0 & 3.02 \\
\hline \multicolumn{8}{|l|}{ 311-U1327E- } \\
\hline $1 \mathrm{H}-1,40-45$ & 3.4 & & 3.2 & 0 & 0 & 0 & 0.00 \\
\hline $1 \mathrm{H}-1,70-75$ & 3.7 & & 13 & 0 & 0 & 0 & 0.01 \\
\hline $1 \mathrm{H}-1,95-100$ & 3.95 & & 4 & 0 & 0 & 0 & 0.00 \\
\hline $1 \mathrm{H}-2,0-5$ & 4.5 & & 12 & 0 & 0 & 0 & 0.00 \\
\hline $1 \mathrm{H}-2,40-45$ & 4.9 & & 3 & 0 & 0 & 0 & 0.00 \\
\hline $1 \mathrm{H}-2,70-75$ & 5.2 & & 5 & 0 & 0 & 0 & 0.00 \\
\hline $1 \mathrm{H}-2,95-100$ & 5.45 & & 3 & 0 & 0 & 0 & 0.00 \\
\hline $1 \mathrm{H}-3,0-5$ & 6.0 & & 3 & 0 & 0 & 0 & 0.00 \\
\hline $1 \mathrm{H}-3,40-45$ & 6.4 & & 4 & 0 & 0 & 0 & 0.00 \\
\hline $1 \mathrm{H}-3,70-75$ & 6.7 & & 4 & 0 & 0 & 0 & 0.00 \\
\hline $1 \mathrm{H}-3,95-100$ & 6.95 & & 4 & 0 & 0 & 0 & 0.00 \\
\hline $1 \mathrm{H}-4,0-5$ & 7.5 & & 7 & 0 & 0 & 0 & 0.00 \\
\hline $1 \mathrm{H}-4,40-45$ & 7.9 & & 40 & 0 & 0 & 0 & 0.02 \\
\hline $1 \mathrm{H}-4,70-75$ & 8.2 & & 863 & 0 & 0 & 0 & 0.39 \\
\hline
\end{tabular}


Table T5 (continued).

\begin{tabular}{|c|c|c|c|c|c|c|c|}
\hline $\begin{array}{l}\text { Core, section, } \\
\text { interval }(\mathrm{cm})\end{array}$ & $\begin{array}{l}\text { Depth } \\
\text { (mbsf) }\end{array}$ & $C_{1} / C_{2}$ & $\begin{array}{c}\mathrm{C}_{1} \\
\text { (ppmv) }\end{array}$ & $\begin{array}{c}\mathrm{C}_{2} \\
\text { (ppmv) }\end{array}$ & $\begin{array}{c}\mathrm{C}_{2=} \\
\text { (ppmv) }\end{array}$ & $\begin{array}{c}\mathrm{C}_{3} \\
\text { (ppmv) }\end{array}$ & $\begin{array}{c}\mathrm{C}_{1} \\
(\mathrm{mM})^{*}\end{array}$ \\
\hline $1 \mathrm{H}-4,95-100$ & 8.45 & & 1,446 & 0 & 0 & 0 & 0.65 \\
\hline $1 \mathrm{H}-5,0-5$ & 9.0 & & 2,721 & 0 & 0 & 0 & 1.23 \\
\hline $1 \mathrm{H}-5,40-45$ & 9.4 & & 3,486 & 0 & 0 & 0 & 1.58 \\
\hline $1 \mathrm{H}-5,70-75$ & 9.7 & & 4,393 & 0 & 0 & 0 & 2.00 \\
\hline $1 \mathrm{H}-5,95-100$ & 9.95 & & 5,910 & 0 & 0 & 0 & 2.69 \\
\hline $1 \mathrm{H}-6,0-5$ & 10.5 & & 6,555 & 0 & 0 & 0 & 2.99 \\
\hline $1 \mathrm{H}-6,40-45$ & 10.9 & & 7,293 & 0 & 0 & 0 & 3.34 \\
\hline $1 \mathrm{H}-6,70-75$ & 11.2 & & 7,129 & 0 & 0 & 0 & 3.27 \\
\hline $1 \mathrm{H}-6,95-100$ & 11.45 & 8,608 & 8,608 & 1.0 & 0 & 0 & 3.95 \\
\hline $1 \mathrm{H}-7,0-5$ & 12.0 & 8,476 & 9,324 & 1.1 & 0 & 0 & 4.29 \\
\hline
\end{tabular}

Note: * ${ }^{*}$ dissolved residual methane obtained by the headspace equilibration method.

Table T6. Concentrations of light hydrocarbon and nonhydrocarbon gases in void gas samples, Hole U1327C.

\begin{tabular}{|c|c|c|c|c|c|c|c|c|c|c|c|c|c|c|}
\hline \multirow{2}{*}{$\begin{array}{l}\text { Core, section, } \\
\text { interval (cm) }\end{array}$} & \multirow{2}{*}{$\begin{array}{l}\text { Depth } \\
\text { (mbsf) }\end{array}$} & \multirow[b]{2}{*}{$\mathrm{C}_{1} / \mathrm{C}_{2}$} & \multirow{2}{*}{$\begin{array}{l}i-\mathrm{C}_{4} / \\
n-\mathrm{C}_{4}\end{array}$} & \multicolumn{7}{|c|}{ Hydrocarbons (ppmv) } & \multicolumn{4}{|c|}{ Volatiles (ppmv) } \\
\hline & & & & $\mathrm{C}_{1}$ & $\mathrm{C}_{2}$ & $\mathrm{C}_{3}$ & $i-\mathrm{C}_{4}$ & $n-C_{4}$ & $i-\mathrm{C}_{5}$ & $n-C_{5}$ & $\mathrm{H}_{2} \mathrm{~S}$ & $\mathrm{CO}_{2}$ & $\mathrm{O}_{2}$ & $\mathrm{~N}_{2}$ \\
\hline \multicolumn{15}{|l|}{ 311-U1327C- } \\
\hline $4 \mathrm{H}-1,36-37$ & 25.46 & 15,166 & & 636,972 & 42.0 & 0 & 0 & 0 & 0 & 0 & 0 & 3,216 & 60,758 & 264,576 \\
\hline $4 \mathrm{H}-7,60-61$ & 34.70 & 12,994 & & 816,018 & 62.8 & 0 & 0 & 0 & 0 & 0 & 0 & 5,158 & 22,477 & 101,880 \\
\hline $5 \mathrm{H}-1,130-131$ & 35.90 & 12,647 & & 900,487 & 71.2 & 0 & 0 & 0 & 0 & 0 & 0 & 4,516 & 1,667 & 27,277 \\
\hline $5 \mathrm{H}-4,75-76$ & 39.85 & 12,475 & & 881,971 & 70.7 & 0 & 0 & 0 & 0 & 0 & 0 & 2,212 & 56,537 & 230,819 \\
\hline 7H-1, 142-143 & 47.52 & 11,811 & & 908,240 & 76.9 & 0 & 0 & 0 & 0 & 0 & 0 & 3,179 & 1,585 & 25,211 \\
\hline $7 \mathrm{H}-5,6-7$ & 52.16 & 11,669 & & 916,043 & 78.5 & 0 & 0.3 & 0 & 0 & 0 & 0 & 1,974 & 107,313 & 455,483 \\
\hline $8 \mathrm{H}-2,14-15$ & 57.24 & 10,556 & & 906,751 & 85.9 & 0 & 0 & 0 & 0 & 0 & 0 & 4,024 & 2,001 & 15,859 \\
\hline $8 \mathrm{H}-5,144-145$ & 63.04 & 10,749 & & 921,149 & 85.7 & 0 & 0.3 & 0 & 0 & 0 & 0 & 3,427 & 970 & 10,119 \\
\hline $9 \mathrm{H}-2,84-85$ & 67.44 & 10,496 & & 921,587 & 87.8 & 0 & 0 & 0 & 0 & 0 & 0 & 3,125 & 1,163 & 10,067 \\
\hline $9 \mathrm{H}-5,114-115$ & 72.24 & 10,755 & & 908,827 & 84.5 & 0 & 0 & 0 & 0 & 0 & 0 & 1,874 & 22,307 & 4,853 \\
\hline $10 \mathrm{H}-2,38-39$ & 76.48 & 10,928 & 0.00 & 970,371 & 88.8 & 0 & 0 & 0.2 & 0 & 0 & 0 & 2,271 & 1,247 & 9,527 \\
\hline $10 \mathrm{H}-6,50-51$ & 81.25 & 10,101 & & 924,273 & 91.5 & 0 & 0 & 0 & 0 & 0 & 0 & 1,320 & 1,240 & 8,698 \\
\hline $11 \mathrm{H}-3,60-61$ & 87.70 & 9,005 & 0.00 & 824,878 & 91.6 & 0 & 0 & 0.3 & 0 & 0 & 0 & 2,649 & 24,489 & 94,881 \\
\hline $11 \mathrm{H}-6,38-39$ & 91.98 & 9,110 & 0.00 & 921,891 & 101.2 & 0 & 0 & 0.4 & 0 & 0 & 0 & 2,788 & 1,119 & 6,768 \\
\hline $12 X-3,7-8$ & 94.83 & 9,415 & 0.00 & 972,591 & 103.3 & 0 & 0 & 0.4 & 0 & 0 & 0 & 2,538 & 816 & 6,128 \\
\hline $12 X-5,67-68$ & 98.29 & 8,583 & 0.00 & 977,551 & 113.9 & 0 & 0 & 0.4 & 0 & 0 & 0 & 3,159 & 1,195 & 7,945 \\
\hline $13 X-2,52-53$ & 104.52 & 7,279 & 0.00 & 920,090 & 126.4 & 0 & 0 & 1.4 & 0 & 0 & 0 & 5,502 & 974 & 6,800 \\
\hline $13 X-4,109-110$ & 108.09 & 7,107 & 0.75 & 945,879 & 133.1 & 0 & 0.6 & 0.8 & 1.9 & 0.6 & 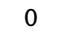 & 3,059 & 22,433 & 76,958 \\
\hline $14 X-1,144-145$ & 113.54 & 5,647 & 0.88 & 890,606 & 157.7 & 0 & 0.7 & 0. & 0.3 & 0.6 & 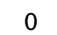 & 3,148 & 36,874 & 137,664 \\
\hline $16 X-4,34-35$ & 128.54 & 3,208 & 1.92 & 923,798 & 288.0 & 0 & 2.5 & 1.3 & 1.5 & 16.8 & 0 & 3,482 & 23,751 & 82,624 \\
\hline $19 X-4,67-68$ & 155.27 & 2,060 & 3.00 & 928,842 & 450.8 & 8.5 & 5.7 & 1.9 & 2 & 0.8 & 0 & 3,389 & 22,404 & 80,418 \\
\hline $19 X-5,85-86$ & 156.95 & 1,885 & 3.41 & 930,685 & 493.7 & 13.7 & 9.2 & 2.7 & 4.2 & 11.6 & 0 & 2,642 & 18,789 & 67,042 \\
\hline $20 X-2,77-78$ & 163.07 & 1,508 & 2.11 & 929,239 & 616.3 & 6.3 & 3.8 & 1.8 & 1.7 & 1 & 0 & 746 & 41,677 & 161,687 \\
\hline $21 X-2,80-81$ & 172.70 & 1,363 & 3.48 & 932,811 & 684.6 & 15.9 & 8 & 2.3 & 1.9 & 0 & 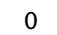 & 1,501 & 589 & 3,439 \\
\hline $21 X-5,4-5$ & 176.06 & 1,058 & 3.30 & 936,687 & 885.0 & 7.8 & 7.6 & 2.3 & 2.3 & 0 & 0 & 2,283 & 603 & 3,551 \\
\hline $22 X-2,64-65$ & 181.91 & 1,447 & 3.80 & 929,095 & 642.2 & 17.5 & 11.4 & 3 & 2.7 & 0 & 0 & 1,419 & 563 & 8,697 \\
\hline $22 X-4,49-50$ & 184.50 & 984 & 3.41 & 930,897 & 946.5 & 12.7 & 7.5 & 2.2 & 2.5 & 0 & 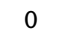 & 1,330 & 533 & 6,130 \\
\hline $23 X-2,1-2$ & 191.32 & 1,189 & 3.74 & 925,101 & 778.3 & 14.6 & 10.1 & 2. & 3 & 0 & 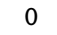 & 1,715 & 1,038 & 7,090 \\
\hline $23 X-4,42-43$ & 194.12 & 1,119 & 3.72 & 926,699 & 827.8 & 13 & 9.3 & 2.5 & 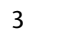 & 0 & 0 & 1,491 & 914 & 5,909 \\
\hline $25 X-2,45-50$ & 200.56 & 792 & 3.60 & 914,021 & $1,153.5$ & 0 & 1.8 & 0.5 & 1 & 0 & 0 & 1,801 & 3,054 & 11,347 \\
\hline $26 \mathrm{X}-1,113-118$ & 210.03 & 1,122 & 7.82 & 920,562 & 820.4 & 13.7 & 13.3 & 1.7 & 5.3 & 0 & 0 & 1,786 & 1,675 & 8,323 \\
\hline $26 X-4,104-105$ & 214.08 & 1,362 & 9.94 & 930,568 & 683.0 & 9.2 & 16.9 & 1.7 & 6.4 & 0 & 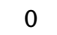 & 1,743 & 1,390 & 7,029 \\
\hline $27 X-2,9-10$ & 219.97 & 906 & 3.43 & 720,671 & 795.7 & 0 & 4.8 & 1.4 & 3.2 & 0.8 & 0 & 1,132 & 65,776 & 257,359 \\
\hline $27 X-5,49-50$ & 224.62 & 1,134 & 4.12 & 702,970 & 620.1 & 6.3 & 10.7 & 2.6 & 5.2 & 1 & 0 & 3,075 & 71,573 & 281,998 \\
\hline $28 X-2,18-19$ & 229.78 & 936 & 1.63 & 925,879 & 988.8 & 0 & 2.6 & 1.6 & 3.8 & 0.7 & 0 & 1,857 & 22,505 & 81,837 \\
\hline $28 \mathrm{X}-3,124-125$ & 232.19 & 1,404 & 1.21 & 930,690 & 662.9 & 11.6 & 2.9 & 2.4 & 3.6 & 0.9 & 0 & 850 & 23,705 & 86,800 \\
\hline $29 X-1,128-129$ & 238.98 & 1,658 & 0.94 & 929,921 & 561.0 & 11.5 & 1.5 & 1.6 & 7.9 & 1 & 0 & 3,829 & 19,615 & 74,945 \\
\hline $29 X-4,60-61$ & 242.80 & 2,055 & 1.00 & 931,879 & 453.5 & 17.3 & 1.7 & 1.7 & 3.4 & 0.8 & 0 & 1,257 & 20,350 & 76,584 \\
\hline $30 X-1,80-81$ & 248.20 & 1,860 & 0.85 & 929,851 & 499.9 & 14.7 & 1.7 & 2 & 6.6 & 0.5 & 0 & 3,151 & 17,423 & 64,580 \\
\hline $30 \times-3,41-42$ & 250.49 & 2,318 & 0.75 & 934,275 & 403.1 & 12 & 1.5 & 2 & 3 & 0.7 & 0 & 1,791 & 21,994 & 80,898 \\
\hline $31 X-2,127-128$ & 259.87 & 4,030 & 0.22 & 936,281 & 232.3 & 15.4 & 0.2 & 0.9 & 0 & 0 & 0 & 2,583 & 383 & 3,384 \\
\hline $31 X-4,29-30$ & 261.85 & 3,671 & 0.69 & 928,080 & 252.8 & 14.6 & 0.9 & 1. & 2 & 0.8 & 0 & 3,450 & 21,988 & 80,283 \\
\hline $32 X-5,94-95$ & 273.64 & 2,698 & 1.40 & 936,925 & 347.3 & 6.5 & 0.7 & 0.5 & 0.5 & 0 & 0 & 489 & 192 & 1,684 \\
\hline $33 X-2,11-12$ & 277.91 & 1,809 & 0.94 & 923,510 & 510.5 & 11.7 & 1.5 & 1.6 & 8.4 & 1.1 & 0 & 6,959 & 22,699 & 83,386 \\
\hline $34 X-5,100-101$ & 292.90 & 2,394 & 0.93 & 932,613 & 389.5 & 8.7 & 1.3 & 1.4 & 2 & 0.9 & 0 & 5,053 & 20,598 & 77,062 \\
\hline $35 X-3,81-82$ & 299.31 & 2,634 & 1.67 & 826,810 & 313.9 & 12.8 & 0.5 & 0.3 & 0.4 & 0 & 0 & 8,599 & 23,157 & 89,309 \\
\hline
\end{tabular}


Table T7. Composition of gas samples from PCS degassing experiments.

\begin{tabular}{|c|c|c|c|c|c|c|c|c|c|c|c|c|c|c|}
\hline \multirow{2}{*}{$\begin{array}{l}\text { Core, } \\
\text { section }\end{array}$} & \multirow{2}{*}{$\begin{array}{l}\text { Depth } \\
\text { (mbsf) }\end{array}$} & \multirow[b]{2}{*}{$\mathrm{C}_{1} / \mathrm{C}_{2}$} & \multirow{2}{*}{$\begin{array}{l}i-C_{4} / \\
n-C_{4}\end{array}$} & \multicolumn{7}{|c|}{ Hydrocarbons (ppmv) } & \multicolumn{4}{|c|}{ Volatiles (ppmv) } \\
\hline & & & & $C_{1}$ & $C_{2}$ & $\mathrm{C}_{3}$ & $i-\mathrm{C}_{4}$ & $n-C_{4}$ & $i-\mathrm{C}_{5}$ & $n-C_{5}$ & $\mathrm{H}_{2} \mathrm{~S}$ & $\mathrm{O}_{2}$ & $\mathrm{~N}_{2}$ & $\mathrm{CO}_{2}$ \\
\hline $311-$ & & & & & & & & & & & & & & \\
\hline U1329C-15P & 121.80 & & & & & & & & & & & & & \\
\hline PCSG 4 & & 6,778 & 0.7 & 762,493 & 112.5 & 6.6 & 1.9 & 2.7 & 1.3 & 0.6 & 0 & 20,614 & 184,404 & 332 \\
\hline U1329C-24P & 197.30 & & & & & & & & & & & & & \\
\hline PCSG 5 & & 1,299 & 5.1 & 947,332 & 729.3 & 0 & 10.0 & 2.0 & 2.1 & 0 & 0 & 5,459 & 21,666 & 0 \\
\hline U1327D-10P & 155.10 & & & & & & & & & & & & & \\
\hline PCSG 10 & & 1,615 & 0.6 & 951,927 & 589.4 & 0 & 0.3 & 0.5 & 0 & 0 & 0 & 2,799 & 13,983 & 0 \\
\hline U1329D-17P & 246.00 & & & & & & & & & & & & & \\
\hline PCSG 3 & & 2,108 & 2.7 & 952,348 & 451.8 & 13.0 & 3.9 & 1.4 & 2.3 & 0 & & 3,788 & 15,050 & 0 \\
\hline PCSG 6 & & 2,068 & 2.6 & 906,411 & 438.3 & 12.6 & 4.0 & 1.5 & 2.4 & 0 & 0 & 13,734 & 52,879 & 0 \\
\hline U1329E-3P & 80.00 & & & & & & & & & & & & & \\
\hline PCSG 5 & & 7,651 & - & 887,866 & 116.1 & 0 & 0.2 & 0.0 & 0 & 0 & 0 & 10,171 & 50,181 & 0 \\
\hline
\end{tabular}

Note: $-=$ not available 
Table T8. Contents of inorganic carbon, $\mathrm{CaCO}_{3}$, organic carbon, total organic carbon, and total nitrogen in sediment, Holes U1327C, U1327D, and U1327E. (See table note. Continued on next page.)

\begin{tabular}{|c|c|c|c|c|c|c|c|}
\hline \multirow[b]{2}{*}{$\begin{array}{l}\text { Core, section, } \\
\text { interval }(\mathrm{cm})\end{array}$} & \multirow[b]{2}{*}{$\begin{array}{l}\text { Depth } \\
\text { (mbsf) }\end{array}$} & \multicolumn{4}{|c|}{ Carbon (wt\%) } & \multirow{2}{*}{$\begin{array}{c}\text { Total } \\
\text { nitrogen } \\
\text { (wt\%) }\end{array}$} & \multirow[b]{2}{*}{$\mathrm{C} / \mathrm{N}$} \\
\hline & & Inorganic & $\mathrm{CaCO}_{3}$ & Total & $\begin{array}{c}\text { Total } \\
\text { organic }\end{array}$ & & \\
\hline \multicolumn{8}{|l|}{ 311-U1327C- } \\
\hline $1 \mathrm{H}-1,140-150$ & 1.4 & 0.25 & 2.08 & 1.14 & 0.89 & 0.07 & 13.1 \\
\hline $1 \mathrm{H}-3,140-150$ & 4.4 & 0.58 & 4.85 & 1.02 & 0.44 & 0.05 & 9.0 \\
\hline $2 \mathrm{H}-1,140-150$ & 7.5 & 0.40 & 3.34 & 0.70 & 0.30 & 0.10 & 3.0 \\
\hline $2 \mathrm{H}-3,140-150$ & 10.5 & 0.47 & 3.94 & 0.69 & 0.22 & 0.04 & 6.1 \\
\hline $2 \mathrm{H}-5,140-150$ & 13.5 & 0.51 & 4.29 & 0.75 & 0.24 & 0.04 & 5.6 \\
\hline $2 \mathrm{H}-7,54-64$ & 15.6 & 0.84 & 7.01 & 1.54 & 0.70 & 0.09 & 7.6 \\
\hline $3 \mathrm{H}-2,140-150$ & 18.5 & 1.11 & 9.23 & 1.98 & 0.87 & 0.08 & 10.5 \\
\hline $3 \mathrm{H}-4,140-150$ & 21.5 & 0.11 & 0.88 & 0.56 & 0.45 & 0.05 & 8.5 \\
\hline $3 \mathrm{H}-6,140-150$ & 24.5 & 0.29 & 2.40 & 0.84 & 0.55 & 0.05 & 10.4 \\
\hline $4 \mathrm{H}-2,135-150$ & 28.0 & 0.57 & 4.76 & 0.98 & 0.41 & 0.05 & 7.7 \\
\hline $4 \mathrm{H}-5,135-150$ & 32.5 & 0.44 & 3.69 & 0.99 & 0.55 & 0.06 & 9.6 \\
\hline $5 \mathrm{H}-5,135-150$ & 42.0 & 0.15 & 1.25 & 0.53 & 0.38 & 0.04 & 10.9 \\
\hline 7H-5, 135-150 & 53.5 & 0.14 & 1.13 & 0.64 & 0.50 & 0.05 & 10.4 \\
\hline $8 \mathrm{H}-5,125-150$ & 62.9 & 0.09 & 0.72 & 0.76 & 0.67 & 0.07 & 9.3 \\
\hline $9 \mathrm{H}-5,125-150$ & 72.4 & 0.23 & 1.95 & 1.19 & 0.96 & 0.12 & 8.2 \\
\hline $10 \mathrm{H}-5,125-150$ & 80.5 & 0.44 & 3.66 & 1.17 & 0.73 & 0.09 & 8.2 \\
\hline $11 \mathrm{H}-5,125-150$ & 91.4 & 0.60 & 4.98 & 1.31 & 0.70 & 0.08 & 8.8 \\
\hline $13 X-2,115-150$ & 105.2 & 0.22 & 1.86 & 1.22 & 1.00 & 0.14 & 7.4 \\
\hline $13 X-5,71-101$ & 108.8 & 0.24 & 2.00 & 0.75 & 0.51 & 0.07 & 7.2 \\
\hline $13 X-6,110-150$ & 110.6 & 0.32 & 2.64 & 1.07 & 0.75 & 0.08 & 8.9 \\
\hline $14 \mathrm{X}-4,102-112$ & 117.6 & 0.14 & 1.14 & 0.86 & 0.72 & 0.09 & 7.8 \\
\hline $15 \mathrm{P}-1,0-25$ & 121.8 & 0.32 & 2.70 & 0.80 & 0.48 & 0.08 & 6.2 \\
\hline $15 \mathrm{P}-1,25-50$ & 122.1 & 0.14 & 1.20 & 0.59 & 0.45 & 0.07 & 6.5 \\
\hline $16 X-2,120-150$ & 126.4 & 0.23 & 1.93 & 0.76 & 0.53 & 0.07 & 7.7 \\
\hline $17 X-2,0-10$ & 132.3 & 0.38 & 3.15 & 1.34 & 0.96 & 0.12 & 7.9 \\
\hline $17 X-2,10-20$ & 132.4 & 0.41 & 3.40 & 1.35 & 0.94 & 0.16 & 5.7 \\
\hline $17 X-3,64-70$ & 133.8 & 0.30 & 2.53 & 1.36 & 1.06 & 0.18 & 6.0 \\
\hline $18 X-2,0-10$ & 142.4 & 0.11 & 0.89 & 1.41 & 1.30 & 0.18 & 7.1 \\
\hline $18 \mathrm{X}-2,120-150$ & 143.6 & 0.10 & 0.83 & 1.23 & 1.13 & 0.14 & 8.3 \\
\hline $18 X-5,120-150$ & 148.1 & 0.11 & 0.89 & 1.18 & 1.07 & 0.15 & 6.9 \\
\hline 19X-2, 69-79 & 153.0 & 0.75 & 6.24 & 1.84 & 1.09 & 0.15 & 7.1 \\
\hline $19 X-4,120-150$ & 155.8 & 0.21 & 1.72 & 0.80 & 0.59 & 0.10 & 6.1 \\
\hline $20 X-4,120-150$ & 165.8 & 0.28 & 2.35 & 0.95 & 0.67 & 0.13 & 5.0 \\
\hline $21 X-4,81-150$ & 175.3 & 0.38 & 3.19 & 0.93 & 0.55 & 0.09 & 6.1 \\
\hline $22 \mathrm{X}-1,0-17$ & 180.1 & 0.48 & 4.03 & 0.91 & 0.43 & 0.08 & 5.4 \\
\hline $22 X-1,17-26$ & 180.3 & 0.48 & 3.99 & 0.98 & 0.50 & 0.09 & 5.7 \\
\hline $22 X-1,26-37$ & 180.4 & 0.42 & 3.49 & 0.96 & 0.54 & 0.09 & 5.9 \\
\hline $23 X-1,131-161$ & 191.0 & 0.30 & 2.51 & 1.17 & 0.87 & 0.19 & 4.6 \\
\hline $25 X-1,51-61$ & 199.8 & 0.08 & 0.69 & 0.28 & 0.20 & 0.05 & 3.7 \\
\hline $25 X-3,0-25$ & 201.3 & 0.23 & 1.94 & 0.55 & 0.32 & 0.05 & 6.4 \\
\hline $26 X-5,120-150$ & 215.7 & 0.74 & 6.15 & 1.80 & 1.06 & 0.14 & 7.7 \\
\hline $27 X-3,0-10$ & 221.3 & 0.20 & 1.65 & 0.85 & 0.65 & 0.07 & 9.0 \\
\hline $27 X-4,114-144$ & 223.8 & 0.34 & 2.86 & 1.23 & 0.89 & 0.10 & 8.9 \\
\hline $28 \mathrm{X}-1,120-150$ & 229.3 & 0.23 & 1.89 & 0.87 & 0.64 & 0.08 & 7.8 \\
\hline $29 X-2,120-150$ & 240.4 & 0.11 & 0.95 & 0.93 & 0.82 & 0.11 & 7.3 \\
\hline $30 X-2,88-118$ & 249.8 & 0.26 & 2.16 & 1.67 & 1.41 & 0.16 & 8.7 \\
\hline $31 X-4,120-150$ & 262.8 & 0.25 & 2.10 & 1.61 & 1.36 & 0.15 & 9.0 \\
\hline $32 X-4,120-150$ & 272.4 & 0.20 & 1.65 & 0.83 & 0.63 & 0.09 & 6.8 \\
\hline $33 X-4,120-150$ & 282.0 & 0.17 & 1.44 & 1.30 & 1.13 & 0.14 & 8.0 \\
\hline $35 X-2,120-150$ & 298.2 & 0.35 & 2.90 & 1.06 & 0.71 & 0.09 & 7.9 \\
\hline \multicolumn{8}{|l|}{ 311-U1327D- } \\
\hline $1 \mathrm{H}-1,25-40$ & 0.3 & 0.34 & 2.84 & 1.76 & 1.42 & 0.17 & 8.6 \\
\hline $1 \mathrm{H}-1,55-70$ & 0.6 & 0.38 & 3.20 & 1.10 & 0.71 & 0.09 & 7.8 \\
\hline $1 \mathrm{H}-1,80-95$ & 0.8 & 0.41 & 3.42 & 1.05 & 0.63 & 0.07 & 9.0 \\
\hline $1 \mathrm{H}-1,135-150$ & 1.4 & 0.35 & 2.91 & 1.21 & 0.86 & 0.10 & 8.4 \\
\hline $1 \mathrm{H}-2,25-50$ & 1.8 & 0.29 & 2.44 & 1.01 & 0.72 & 0.07 & 9.7 \\
\hline $1 \mathrm{H}-2,55-70$ & 2.1 & 0.11 & 0.95 & 0.66 & 0.55 & 0.05 & 11.7 \\
\hline $1 \mathrm{H}-2,80-95$ & 2.3 & 0.34 & 2.84 & 1.16 & 0.82 & 0.09 & 8.9 \\
\hline $1 \mathrm{H}-2,135-150$ & 2.9 & 0.38 & 3.14 & 0.79 & 0.41 & 0.04 & 10.0 \\
\hline $1 \mathrm{H}-3,10-25$ & 3.1 & 0.35 & 2.90 & 0.74 & 0.39 & 0.05 & 8.7 \\
\hline \multicolumn{8}{|l|}{ 311-U1327E- } \\
\hline $1 \mathrm{H}-1,25-40$ & 3.3 & 0.18 & 1.50 & NA & NA & NA & NA \\
\hline $1 \mathrm{H}-1,55-70$ & 3.6 & 0.28 & 2.30 & 0.75 & 0.47 & 0.05 & 9.0 \\
\hline $1 \mathrm{H}-1,80-95$ & 3.8 & 0.23 & 1.94 & 0.74 & 0.51 & 0.04 & 11.9 \\
\hline
\end{tabular}


Table T8 (continued).

\begin{tabular}{lrrrrrrr}
\hline & & \multicolumn{5}{c}{ Carbon (wt\%) } & \multicolumn{3}{c}{\begin{tabular}{c} 
Total \\
nitrogen \\
Core, section, \\
\cline { 3 - 6 } interval (cm)
\end{tabular}} & $\begin{array}{c}\text { Depth } \\
\text { (mbsf) }\end{array}$ & Inorganic & CaCO $_{3}$ & Total & $\begin{array}{c}\text { Total } \\
\text { organic }\end{array}$ & C/N \\
\hline 1H-1, 135-150 & 4.4 & 0.10 & 0.81 & 0.12 & 0.02 & 0.00 & 20.0 \\
$1 \mathrm{H}-2,25-40$ & 4.8 & 0.25 & 2.11 & 0.41 & 0.16 & 0.02 & 8.9 \\
$1 \mathrm{H}-2,55-70$ & 5.1 & 0.58 & 4.83 & 0.99 & 0.41 & 0.03 & 12.1 \\
$1 \mathrm{H}-2,80-95$ & 5.3 & 0.47 & 3.90 & 0.84 & 0.37 & 0.03 & 11.6 \\
$1 \mathrm{H}-2,135-150$ & 5.9 & 0.59 & 4.88 & 0.89 & 0.30 & 0.03 & 10.0 \\
$1 \mathrm{H}-3,25-40$ & 6.3 & 0.42 & 3.48 & 0.66 & 0.24 & 0.03 & 7.7 \\
$1 \mathrm{H}-3,55-70$ & 6.6 & 0.47 & 3.89 & 0.75 & 0.28 & 0.05 & 6.2 \\
$1 \mathrm{H}-3,80-95$ & 6.8 & 0.19 & 1.58 & 0.62 & 0.43 & 0.04 & 12.3 \\
$1 \mathrm{H}-3,135-150$ & 7.4 & 0.24 & 2.01 & 0.64 & 0.40 & 0.03 & 13.3 \\
$1 \mathrm{H}-4,25-40$ & 7.8 & 0.52 & 4.31 & 0.89 & 0.37 & 0.03 & 11.2 \\
$1 \mathrm{H}-4,55-70$ & 8.1 & 0.43 & 3.57 & 0.83 & 0.40 & 0.03 & 11.8 \\
$1 \mathrm{H}-4,80-95$ & 8.3 & 0.39 & 3.29 & 0.84 & 0.45 & 0.04 & 10.2 \\
$1 \mathrm{H}-4,135-150$ & 8.9 & 0.27 & 2.22 & 0.67 & 0.40 & 0.03 & 11.8 \\
$1 \mathrm{H}-5,25-40$ & 9.3 & 0.26 & 2.13 & 0.66 & 0.40 & 0.03 & 11.8 \\
$1 \mathrm{H}-5,55-70$ & 9.6 & 0.50 & 4.19 & $\mathrm{NA}$ & $\mathrm{NA}$ & $\mathrm{NA}$ & $\mathrm{NA}$ \\
$1 \mathrm{H}-5,135-150$ & 10.4 & 0.44 & 3.70 & 0.69 & 0.25 & 0.03 & 7.4 \\
$1 \mathrm{H}-6,25-40$ & 10.8 & 0.42 & 3.54 & 0.94 & 0.52 & 0.03 & 16.8 \\
$1 \mathrm{H}-6,55-70$ & 11.1 & 0.40 & 3.37 & 0.79 & 0.39 & 0.04 & 10.3 \\
$1 \mathrm{H}-6,80-95$ & 11.3 & 0.41 & 3.39 & 0.68 & 0.27 & 0.03 & 9.3 \\
$1 \mathrm{H}-6,135-150$ & 11.9 & 0.24 & 2.04 & 0.68 & 0.44 & 0.04 & 11.6 \\
$1 \mathrm{H}-7,50-65$ & 12.5 & 0.25 & 2.08 & 0.64 & 0.39 & 0.04 & 9.5 \\
\hline & & & & & & & \\
\hline
\end{tabular}

Note: NA = not analyzed.

Table T9. Perfluorocarbon tracer and fluorescent microsphere concentrations, Site U1327.

\begin{tabular}{|c|c|c|c|c|c|}
\hline \multirow{2}{*}{$\begin{array}{l}\text { Core, section, } \\
\text { interval }(\mathrm{cm})\end{array}$} & \multirow{2}{*}{$\begin{array}{l}\text { Depth } \\
\text { (mbsf) }\end{array}$} & \multicolumn{2}{|c|}{$\begin{array}{c}\text { Detected PFT } \\
\text { (ng/g sediment) }\end{array}$} & \multicolumn{2}{|c|}{$\begin{array}{l}\text { Detected particles } \\
\text { (number/g sediment) }\end{array}$} \\
\hline & & Inner & Outer & Inner & Outer \\
\hline \multicolumn{6}{|l|}{ 311-U1327C- } \\
\hline $3 \mathrm{H}-4,35-40$ & 20.45 & 0.12 & 0.1 & BDL & $>1.0 \times 10^{4}$ \\
\hline $10 \mathrm{H}-5,0-5$ & 79.25 & 0.04 & 0.05 & $\mathrm{BDL}$ & $\mathrm{BDL}$ \\
\hline $12 X-5,0-5$ & 97.62 & $\mathrm{BDL}$ & $\mathrm{BDL}$ & $\mathrm{BDL}$ & $\mathrm{BDL}$ \\
\hline $29 X-5,0-5$ & 243.55 & 0.09 & 0.07 & BDL & $>1.0 \times 10^{4}$ \\
\hline
\end{tabular}

Note: PFT = perfluorocarbon tracers, $\mathrm{BDL}=$ below detection limit. 
Table T10. Moisture and density, Holes U1327B, U1327C, and U1327D. (Continued on next two pages.)

\begin{tabular}{|c|c|c|c|c|}
\hline \multirow{2}{*}{$\begin{array}{l}\text { Core, section } \\
\text { interval }(\mathrm{cm})\end{array}$} & \multirow{2}{*}{$\begin{array}{l}\text { Depth } \\
\text { (mbsf) }\end{array}$} & \multicolumn{2}{|c|}{ Density $\left(\mathrm{g} / \mathrm{cm}^{3}\right)$} & \multirow{2}{*}{$\begin{array}{c}\text { Porosity } \\
\text { (\%) }\end{array}$} \\
\hline & & Bulk & Grain & \\
\hline \multicolumn{5}{|l|}{ 311-U1327B- } \\
\hline $1 \mathrm{H}-2,112-114$ & 2.62 & 1.662 & 2.790 & 63.9 \\
\hline $1 \mathrm{H}-4,34-36$ & 4.84 & 1.695 & 2.735 & 60.8 \\
\hline $1 \mathrm{H}-6,109-111$ & 8.59 & 1.703 & 2.756 & 60.8 \\
\hline \multicolumn{5}{|l|}{ 311-U1327C- } \\
\hline $1 \mathrm{H}-1,43-45$ & 0.43 & 1.459 & 2.787 & 75.3 \\
\hline $1 \mathrm{H}-2,54-56$ & 2.04 & 1.545 & 2.996 & 73.6 \\
\hline $1 \mathrm{H}-3,28-30$ & 3.28 & 1.624 & 2.758 & 65.4 \\
\hline $1 \mathrm{H}-4,89-91$ & 5.39 & 1.663 & 2.817 & 64.3 \\
\hline $2 \mathrm{H}-1,6-8$ & 6.16 & 1.646 & 2.814 & 65.3 \\
\hline $2 \mathrm{H}-1,46-48$ & 6.56 & 2.079 & 2.790 & 40.3 \\
\hline $2 \mathrm{H}-2,47-49$ & 8.07 & 1.693 & 2.756 & 61.4 \\
\hline $2 \mathrm{H}-2,126-128$ & 8.86 & 1.684 & 2.798 & 62.8 \\
\hline $2 \mathrm{H}-3,43-45$ & 9.53 & 1.756 & 2.810 & 59.0 \\
\hline $2 \mathrm{H}-4,35-37$ & 10.95 & 1.817 & 2.755 & 54.2 \\
\hline $2 \mathrm{H}-4,94-96$ & 11.54 & 1.711 & 2.776 & 60.8 \\
\hline $2 \mathrm{H}-5,10-12$ & 12.20 & 1.672 & 2.821 & 64.0 \\
\hline $2 \mathrm{H}-5,70-72$ & 12.80 & 1.718 & 2.765 & 60.1 \\
\hline $2 \mathrm{H}-6,24-26$ & 13.84 & 1.729 & 2.773 & 59.7 \\
\hline $2 \mathrm{H}-6,75-77$ & 14.35 & 1.844 & 2.806 & 54.0 \\
\hline $2 \mathrm{H}-6,130-132$ & 14.90 & 1.785 & 2.790 & 56.9 \\
\hline $2 \mathrm{H}-7,22-24$ & 15.32 & 1.713 & 2.748 & 60.0 \\
\hline $3 \mathrm{H}-1,123-125$ & 16.83 & 1.712 & 2.805 & 61.3 \\
\hline $3 \mathrm{H}-2,42-44$ & 17.52 & 1.731 & 2.797 & 60.1 \\
\hline $3 \mathrm{H}-2,117-119$ & 18.27 & 1.691 & 2.758 & 61.5 \\
\hline $3 \mathrm{H}-4,26-30$ & 20.36 & 1.693 & 2.756 & 61.4 \\
\hline $3 \mathrm{H}-4,71-72$ & 20.81 & 1.936 & 2.749 & 47.1 \\
\hline $3 \mathrm{H}-4,133-135$ & 21.43 & 1.715 & 2.778 & 60.6 \\
\hline $3 \mathrm{H}-5,32-34$ & 21.92 & 1.694 & 2.688 & 59.7 \\
\hline $3 \mathrm{H}-5,132-134$ & 22.92 & 1.661 & 2.683 & 61.6 \\
\hline $3 \mathrm{H}-6,31-33$ & 23.41 & 1.711 & 2.726 & 59.6 \\
\hline $3 \mathrm{H}-6,95-97$ & 24.05 & 1.712 & 2.739 & 59.9 \\
\hline $3 \mathrm{H}-7,21-23$ & 24.81 & 1.790 & 2.756 & 55.8 \\
\hline $3 \mathrm{H}-7,71-73$ & 25.31 & 1.706 & 2.721 & 59.8 \\
\hline $4 \mathrm{H}-1,38-40$ & 25.48 & 1.730 & 2.733 & 58.7 \\
\hline $4 \mathrm{H}-2,28-30$ & 26.88 & 1.743 & 2.727 & 57.8 \\
\hline $4 \mathrm{H}-2,107-109$ & 27.67 & 1.765 & 2.721 & 56.4 \\
\hline $4 \mathrm{H}-3,48-50$ & 28.58 & 1.709 & 2.731 & 59.9 \\
\hline $4 \mathrm{H}-3,134-136$ & 29.44 & 1.710 & 2.754 & 60.3 \\
\hline $4 \mathrm{H}-4,48-50$ & 30.08 & 1.682 & 2.767 & 62.3 \\
\hline $4 \mathrm{H}-4,119-121$ & 30.79 & 1.932 & 2.765 & 47.8 \\
\hline $4 \mathrm{H}-5,7-9$ & 31.17 & 1.782 & 2.761 & 56.4 \\
\hline $4 \mathrm{H}-6,25-27$ & 32.85 & 1.865 & 2.754 & 51.4 \\
\hline $4 \mathrm{H}-6,107-109$ & 33.67 & 1.771 & 2.773 & 57.3 \\
\hline $4 \mathrm{H}-7,3-5$ & 34.13 & 1.861 & 2.758 & 51.7 \\
\hline $4 \mathrm{H}-7,78-80$ & 34.88 & 2.076 & 2.769 & 39.7 \\
\hline $5 \mathrm{H}-1,32-34$ & 34.92 & 1.703 & 2.781 & 61.3 \\
\hline $5 \mathrm{H}-1,106-108$ & 35.66 & 1.787 & 2.797 & 56.9 \\
\hline $5 \mathrm{H}-2,34-36$ & 36.44 & 1.708 & 2.773 & 60.9 \\
\hline $5 \mathrm{H}-2,92-94$ & 37.02 & 1.744 & 2.737 & 58.0 \\
\hline $5 \mathrm{H}-3,33-35$ & 37.93 & 1.700 & 2.707 & 59.9 \\
\hline $5 \mathrm{H}-3,121-123$ & 38.81 & 1.808 & 2.830 & 56.6 \\
\hline $5 \mathrm{H}-4,32-34$ & 39.42 & 2.020 & 2.854 & 45.6 \\
\hline $5 \mathrm{H}-4,88-90$ & 39.98 & 1.990 & 2.754 & 44.2 \\
\hline $5 \mathrm{H}-6,51-53$ & 42.61 & 1.866 & 2.743 & 51.0 \\
\hline $5 \mathrm{H}-6,110-112$ & 43.20 & 1.831 & 2.810 & 54.8 \\
\hline $7 \mathrm{H}-1,18-20$ & 46.28 & 1.772 & 2.765 & 57.0 \\
\hline $7 \mathrm{H}-1,102-104$ & 47.12 & 1.797 & 2.871 & 58.1 \\
\hline $7 \mathrm{H}-2,45-47$ & 48.05 & 1.770 & 2.870 & 59.6 \\
\hline $7 \mathrm{H}-2,94-96$ & 48.54 & 1.979 & 2.773 & 45.4 \\
\hline $7 \mathrm{H}-3,42-44$ & 49.52 & 1.888 & 2.861 & 53.0 \\
\hline $7 \mathrm{H}-3,96-98$ & 50.06 & 1.872 & 2.829 & 53.0 \\
\hline $7 \mathrm{H}-4,47-49$ & 51.07 & 1.901 & 2.778 & 50.0 \\
\hline 7H-4, 141-143 & 52.01 & 1.800 & 2.777 & 55.7 \\
\hline $7 \mathrm{H}-6,19-21$ & 53.79 & 1.834 & 2.865 & 56.0 \\
\hline 7H-6, 99-101 & 54.59 & 1.927 & 2.884 & 51.5 \\
\hline 7H-7, 20-22 & 55.30 & 1.878 & 2.739 & 50.2 \\
\hline $8 \mathrm{H}-1,40-42$ & 56.00 & 1.834 & 2.684 & 51.2 \\
\hline
\end{tabular}

\begin{tabular}{|c|c|c|c|c|}
\hline \multirow{2}{*}{$\begin{array}{l}\text { Core, section } \\
\text { interval }(\mathrm{cm})\end{array}$} & \multirow{2}{*}{$\begin{array}{l}\text { Depth } \\
\text { (mbsf) }\end{array}$} & \multicolumn{2}{|c|}{ Density $\left(\mathrm{g} / \mathrm{cm}^{3}\right)$} & \multirow{2}{*}{$\begin{array}{c}\text { Porosity } \\
(\%)\end{array}$} \\
\hline & & Bulk & Grain & \\
\hline $8 \mathrm{H}-1,122-124$ & 56.82 & 1.906 & 2.767 & 49.4 \\
\hline $8 \mathrm{H}-2,38-40$ & 57.48 & 1.860 & 2.786 & 52.6 \\
\hline $8 \mathrm{H}-2,101-103$ & 58.11 & 1.857 & 2.828 & 53.8 \\
\hline $8 \mathrm{H}-3,101-103$ & 59.61 & 1.780 & 2.743 & 56.0 \\
\hline $8 \mathrm{H}-5,39-41$ & 61.99 & 1.788 & 2.807 & 57.2 \\
\hline $8 \mathrm{H}-5,105-107$ & 62.65 & 1.828 & 2.758 & 53.7 \\
\hline $8 \mathrm{H}-6,13-15$ & 63.23 & 1.756 & 2.795 & 58.7 \\
\hline $8 \mathrm{H}-6,132-134$ & 64.42 & 1.786 & 2.866 & 58.6 \\
\hline $8 \mathrm{H}-7,43-45$ & 65.03 & 1.748 & 2.729 & 57.6 \\
\hline $9 \mathrm{H}-1,21-23$ & 65.31 & 1.757 & 2.840 & 59.6 \\
\hline $9 \mathrm{H}-1,115-117$ & 66.25 & 1.789 & 2.799 & 56.9 \\
\hline $9 \mathrm{H}-2,27-29$ & 66.87 & 1.763 & 2.921 & 61.0 \\
\hline $9 \mathrm{H}-2,93-95$ & 67.53 & 1.748 & 2.721 & 57.4 \\
\hline $9 \mathrm{H}-3,44-46$ & 68.54 & 1.746 & 2.852 & 60.5 \\
\hline $9 \mathrm{H}-3,82-84$ & 68.92 & 1.780 & 2.718 & 55.4 \\
\hline $9 \mathrm{H}-4,27-29$ & 69.87 & 1.843 & 2.760 & 52.9 \\
\hline $9 \mathrm{H}-4,128-130$ & 70.88 & 1.850 & 2.749 & 52.1 \\
\hline $9 \mathrm{H}-6,20-22$ & 72.80 & 1.651 & 2.654 & 61.5 \\
\hline $9 \mathrm{H}-6,136-138$ & 73.96 & 1.784 & 2.728 & 55.4 \\
\hline $9 \mathrm{H}-7,57-59$ & 74.67 & 1.866 & 2.765 & 51.6 \\
\hline $10 \mathrm{H}-1,39-41$ & 74.99 & 1.904 & 2.703 & 47.6 \\
\hline $10 \mathrm{H}-1,116-118$ & 75.76 & 1.812 & 2.744 & 54.2 \\
\hline $10 \mathrm{H}-2,29-31$ & 76.39 & 1.806 & 2.736 & 54.3 \\
\hline $10 \mathrm{H}-2,78-80$ & 76.88 & 1.785 & 2.715 & 55.0 \\
\hline $10 \mathrm{H}-3,32-34$ & 77.92 & 1.819 & 2.770 & 54.5 \\
\hline $10 \mathrm{H}-3,115-117$ & 78.75 & 1.768 & 2.723 & 56.2 \\
\hline $10 \mathrm{H}-6,5-7$ & 80.80 & 1.814 & 2.748 & 54.2 \\
\hline $10 \mathrm{H}-6,67-69$ & 81.42 & 1.797 & 2.724 & 54.5 \\
\hline $10 \mathrm{H}-7,5-7$ & 81.80 & 1.890 & 2.769 & 50.4 \\
\hline $10 \mathrm{H}-7,47-49$ & 82.22 & 1.768 & 2.744 & 56.7 \\
\hline $11 \mathrm{H}-1,27-29$ & 84.37 & 1.900 & 2.733 & 48.8 \\
\hline $11 \mathrm{H}-1,109-111$ & 85.19 & 1.883 & 2.693 & 48.5 \\
\hline $11 \mathrm{H}-2,26-28$ & 85.86 & 1.852 & 2.725 & 51.3 \\
\hline $11 \mathrm{H}-2,105-107$ & 86.65 & 1.794 & 2.732 & 54.9 \\
\hline $11 \mathrm{H}-3,5-7$ & 87.15 & 1.848 & 2.720 & 51.4 \\
\hline $11 \mathrm{H}-3,49-51$ & 87.59 & 1.941 & 2.694 & 45.1 \\
\hline $11 \mathrm{H}-3,92-94$ & 88.02 & 2.074 & 2.720 & 38.1 \\
\hline $11 \mathrm{H}-3,125-127$ & 88.35 & 1.852 & 2.696 & 50.5 \\
\hline $11 \mathrm{H}-5,4-6$ & 90.14 & 1.900 & 2.719 & 48.3 \\
\hline $11 \mathrm{H}-6,20-22$ & 91.80 & 1.852 & 2.753 & 52.1 \\
\hline $11 \mathrm{H}-6,81-82$ & 92.41 & 1.875 & 2.721 & 49.8 \\
\hline $12 X-1,14-16$ & 93.04 & 1.769 & 2.779 & 57.5 \\
\hline $12 X-2,13-15$ & 93.39 & 1.814 & 3.026 & 60.6 \\
\hline $12 X-2,115-117$ & 94.41 & 1.716 & 2.508 & 53.4 \\
\hline $12 X-3,6-8$ & 94.82 & 1.793 & 2.796 & 56.6 \\
\hline $12 X-3,54-56$ & 95.30 & 1.775 & 2.790 & 57.5 \\
\hline $12 X-4,47-49$ & 96.73 & 1.706 & 2.817 & 62.0 \\
\hline $12 X-4,88-90$ & 97.14 & 1.833 & 2.810 & 54.7 \\
\hline $12 X-6,12-14$ & 99.24 & 1.862 & 2.816 & 53.2 \\
\hline $12 X-6,78-80$ & 99.90 & 1.834 & 2.838 & 55.4 \\
\hline $13 X-1,18-20$ & 102.68 & 1.636 & 2.704 & 63.6 \\
\hline $13 X-1,101-103$ & 103.51 & 1.657 & 2.748 & 63.3 \\
\hline $13 X-2,31-33$ & 104.31 & 1.732 & 2.702 & 57.8 \\
\hline $13 X-2,91-93$ & 104.91 & 1.701 & 2.773 & 61.3 \\
\hline $13 X-3,24-26$ & 105.74 & 1.841 & 2.763 & 53.0 \\
\hline $13 X-3,62-64$ & 106.12 & 1.917 & 2.730 & 47.7 \\
\hline $13 X-3,135-137$ & 106.85 & 1.760 & 2.748 & 57.3 \\
\hline $13 X-4,21-23$ & 107.21 & 1.877 & 2.768 & 51.1 \\
\hline $13 X-4,97-99$ & 107.97 & 2.003 & 2.801 & 44.9 \\
\hline $13 X-5,10-12$ & 108.20 & 1.843 & 2.692 & 50.9 \\
\hline $13 X-5,55-57$ & 108.65 & 2.062 & 2.703 & 38.2 \\
\hline $13 X-7,17-19$ & 111.13 & 1.717 & 2.713 & 59.0 \\
\hline $14 \mathrm{X}-1,30-32$ & 112.40 & 1.858 & 2.816 & 53.5 \\
\hline $14 \mathrm{X}-1,108-110$ & 113.18 & 1.911 & 2.755 & 48.8 \\
\hline $14 X-2,18-20$ & 113.78 & 1.892 & 2.754 & 49.8 \\
\hline $14 X-2,95-97$ & 114.55 & 1.975 & 2.772 & 45.6 \\
\hline $14 X-3,16-18$ & 115.26 & 1.910 & 2.779 & 49.5 \\
\hline $14 X-3,67-69$ & 115.77 & 1.905 & 2.747 & 48.8 \\
\hline
\end{tabular}


Table T10 (continued).

\begin{tabular}{|c|c|c|c|c|}
\hline \multirow{2}{*}{$\begin{array}{l}\text { Core, section } \\
\text { interval }(\mathrm{cm})\end{array}$} & \multirow{2}{*}{$\begin{array}{l}\text { Depth } \\
\text { (mbsf) }\end{array}$} & \multicolumn{2}{|c|}{ Density $\left(\mathrm{g} / \mathrm{cm}^{3}\right)$} & \multirow{2}{*}{$\begin{array}{c}\text { Porosity } \\
\text { (\%) }\end{array}$} \\
\hline & & Bulk & Grain & \\
\hline $14 X-4,31-33$ & 116.91 & 2.066 & 2.737 & 39.2 \\
\hline $14 X-4,79-81$ & 117.39 & 1.874 & 2.741 & 50.5 \\
\hline $15 P-1,50-51$ & 122.30 & 1.931 & 2.768 & 48.0 \\
\hline $16 X-1,46-48$ & 124.26 & 1.750 & 2.668 & 55.8 \\
\hline $16 X-1,128-130$ & 125.08 & 1.887 & 2.709 & 48.8 \\
\hline $16 X-2,25-27$ & 125.45 & 1.889 & 2.744 & 49.7 \\
\hline $16 X-2,94-96$ & 126.14 & 1.833 & 2.730 & 52.6 \\
\hline $16 X-3,9-11$ & 126.79 & 1.963 & 2.746 & 45.5 \\
\hline $16 X-3,124-126$ & 127.94 & 1.858 & 2.711 & 50.6 \\
\hline $16 X-5,19-21$ & 129.89 & 1.846 & 2.755 & 52.5 \\
\hline $16 X-5,91-93$ & 130.61 & 1.805 & 2.723 & 54.0 \\
\hline $17 X-2,50-52$ & 132.81 & 1.793 & 2.650 & 52.7 \\
\hline $17 X-3,19-21$ & 133.37 & 1.793 & 2.625 & 52.0 \\
\hline $17 X-4,34-36$ & 134.26 & 1.919 & 2.713 & 47.0 \\
\hline $17 X-5,7-9$ & 134.75 & 1.910 & 2.713 & 47.5 \\
\hline $18 X-1,46-48$ & 141.96 & 1.783 & 2.663 & 53.7 \\
\hline $18 X-3,21-23$ & 144.06 & 1.876 & 2.679 & 48.5 \\
\hline $18 X-4,95-97$ & 146.30 & 1.893 & 2.756 & 49.8 \\
\hline $18 X-6,15-17$ & 148.50 & 1.853 & 2.666 & 49.5 \\
\hline $19 X-2,46-48$ & 152.77 & 1.644 & 2.668 & 62.3 \\
\hline $19 X-3,48-50$ & 153.58 & 1.704 & 2.609 & 57.1 \\
\hline $19 X-5,75-77$ & 156.85 & 1.854 & 2.707 & 50.7 \\
\hline $19 X-6,93-95$ & 158.53 & 1.868 & 2.710 & 49.9 \\
\hline $19 X-7,49-51$ & 159.09 & 2.075 & 2.722 & 38.1 \\
\hline $20 X-1,55-57$ & 161.35 & 2.062 & 2.955 & 46.3 \\
\hline $20 x-2,35-37$ & 162.65 & 2.013 & 2.768 & 43.3 \\
\hline $20 X-3,51-53$ & 163.59 & 2.032 & 2.834 & 44.3 \\
\hline $20 X-5,60-62$ & 166.68 & 1.902 & 2.763 & 49.5 \\
\hline $21 X-1,36-38$ & 170.76 & 1.971 & 2.773 & 45.8 \\
\hline $21 X-1,126-128$ & 171.66 & 1.996 & 2.766 & 44.2 \\
\hline $21 X-2,7-9$ & 171.97 & 1.981 & 2.769 & 45.2 \\
\hline $21 X-2,95-97$ & 172.85 & 1.953 & 2.752 & 46.2 \\
\hline $21 X-3,39-41$ & 173.72 & 1.922 & 2.774 & 48.7 \\
\hline $21 X-3,88-90$ & 174.21 & 1.924 & 2.743 & 47.6 \\
\hline $21 X-4,12-14$ & 174.64 & 1.980 & 2.761 & 45.0 \\
\hline $21 X-4,64-67$ & 175.16 & 1.911 & 2.739 & 48.3 \\
\hline $21 X-5,16-18$ & 176.18 & 1.879 & 2.686 & 48.5 \\
\hline $21 X-5,84-86$ & 176.86 & 1.890 & 2.709 & 48.6 \\
\hline $22 X-1,8-10$ & 180.18 & 1.866 & 2.764 & 51.6 \\
\hline $22 X-1,67-69$ & 180.77 & 1.825 & 2.749 & 53.5 \\
\hline $22 X-2,11-13$ & 181.38 & 1.867 & 2.759 & 51.4 \\
\hline $22 X-2,56-58$ & 181.83 & 1.903 & 2.725 & 48.3 \\
\hline $22 X-3,21-23$ & 182.66 & 1.927 & 2.767 & 48.2 \\
\hline $22 X-5,37-39$ & 185.24 & 1.905 & 2.774 & 49.6 \\
\hline $22 X-5,95-97$ & 185.82 & 1.928 & 2.814 & 49.5 \\
\hline $23 X-1,27-29$ & 189.97 & 1.840 & 2.733 & 52.3 \\
\hline $23 X-1,117-119$ & 190.87 & 1.925 & 2.948 & 53.1 \\
\hline $23 X-2,4-6$ & 191.35 & 1.881 & 2.749 & 50.3 \\
\hline $23 X-2,110-112$ & 192.41 & 2.001 & 2.879 & 47.3 \\
\hline $23 X-3,28-30$ & 193.09 & 1.860 & 2.758 & 51.8 \\
\hline $23 X-4,1-3$ & 193.71 & 1.810 & 2.806 & 55.9 \\
\hline $23 X-4,54-56$ & 194.24 & 1.821 & 2.776 & 54.5 \\
\hline $25 X-1,23-25$ & 199.53 & 1.934 & 2.811 & 49.1 \\
\hline $25 X-2,1-3$ & 200.12 & 1.971 & 2.759 & 45.4 \\
\hline $25 X-2,94-96$ & 201.05 & 1.986 & 2.782 & 45.3 \\
\hline $26 X-1,13-15$ & 209.03 & 1.884 & 2.762 & 50.5 \\
\hline $26 X-1,116-118$ & 210.06 & 1.944 & 2.788 & 47.8 \\
\hline $26 X-2,42-44$ & 210.82 & 1.811 & 2.772 & 55.0 \\
\hline $26 X-3,7-9$ & 211.61 & 1.937 & 2.746 & 47.0 \\
\hline $26 X-3,88-90$ & 212.42 & 1.951 & 2.750 & 46.3 \\
\hline $26 X-4,12-14$ & 213.16 & 1.881 & 2.737 & 50.0 \\
\hline $26 X-4,65-67$ & 213.69 & 1.899 & 2.695 & 47.6 \\
\hline $26 X-4,141-143$ & 214.45 & 1.866 & 2.727 & 50.6 \\
\hline $26 X-6,11-13$ & 216.15 & 1.859 & 2.774 & 52.3 \\
\hline $26 X-6,77-79$ & 216.81 & 1.849 & 2.684 & 50.3 \\
\hline $26 X-6,133-135$ & 217.37 & 1.845 & 2.675 & 50.3 \\
\hline $27 X-1,5-7$ & 218.55 & 1.877 & 2.731 & 50.0 \\
\hline $27 X-1,94-96$ & 219.44 & 1.931 & 2.789 & 48.6 \\
\hline
\end{tabular}

\begin{tabular}{|c|c|c|c|c|}
\hline \multirow{2}{*}{$\begin{array}{l}\text { Core, section } \\
\text { interval }(\mathrm{cm})\end{array}$} & \multirow{2}{*}{$\begin{array}{l}\text { Depth } \\
\text { (mbsf) }\end{array}$} & \multicolumn{2}{|c|}{ Density $\left(\mathrm{g} / \mathrm{cm}^{3}\right)$} & \multirow{2}{*}{$\begin{array}{c}\text { Porosity } \\
\text { (\%) }\end{array}$} \\
\hline & & Bulk & Grain & \\
\hline $27 X-2,28-30$ & 220.16 & 1.906 & 2.682 & 46.8 \\
\hline $27 X-2,119-121$ & 221.07 & 1.981 & 2.689 & 42.5 \\
\hline $27 X-3,12-14$ & 221.41 & 2.025 & 2.739 & 41.7 \\
\hline $27 X-3,77-79$ & 222.06 & 2.022 & 2.733 & 41.6 \\
\hline $27 X-5,14-16$ & 224.27 & 1.860 & 2.683 & 49.6 \\
\hline $27 X-5,77-79$ & 224.90 & 1.877 & 2.761 & 50.9 \\
\hline $27 X-6,13-15$ & 225.26 & 1.959 & 2.711 & 44.6 \\
\hline $28 X-1,11-13$ & 228.21 & 2.025 & 2.777 & 42.9 \\
\hline $28 X-1,81-83$ & 228.91 & 1.989 & 2.778 & 45.0 \\
\hline $28 X-2,22-24$ & 229.82 & 1.941 & 2.756 & 47.1 \\
\hline $28 X-2,92-94$ & 230.52 & 1.918 & 2.717 & 47.2 \\
\hline $28 X-4,20-22$ & 232.40 & 1.902 & 2.756 & 49.3 \\
\hline $28 X-4,98-100$ & 233.18 & 1.899 & 2.779 & 50.1 \\
\hline $28 X-5,48-50$ & 234.18 & 1.908 & 2.756 & 49.0 \\
\hline $29 X-1,19-21$ & 237.89 & 1.833 & 2.696 & 51.6 \\
\hline 29X-1, 117-119 & 238.87 & 1.765 & 2.679 & 55.2 \\
\hline $29 X-3,19-21$ & 240.89 & 1.842 & 2.693 & 51.0 \\
\hline $29 X-3,122-124$ & 241.92 & 1.907 & 2.692 & 47.1 \\
\hline $29 X-4,24-26$ & 242.44 & 1.853 & 2.661 & 49.3 \\
\hline $29 X-4,105-107$ & 243.25 & 1.836 & 2.706 & 51.7 \\
\hline $29 X-5,8-10$ & 243.63 & 1.852 & 2.639 & 48.7 \\
\hline $29 X-5,132-134$ & 244.87 & 1.749 & 2.592 & 53.8 \\
\hline $29 X-6,41-43$ & 245.46 & 1.653 & 2.602 & 60.1 \\
\hline $30 x-1,31-33$ & 247.71 & 1.674 & 2.632 & 59.6 \\
\hline $30 X-3,51-53$ & 250.59 & 1.707 & 2.582 & 56.2 \\
\hline $30 \times-4,136-138$ & 252.47 & 1.975 & 2.763 & 45.3 \\
\hline $30 \times-5,37-39$ & 252.98 & 1.948 & 2.769 & 47.1 \\
\hline $31 X-1,96-98$ & 258.06 & 1.604 & 2.218 & 51.4 \\
\hline $31 X-2,75-77$ & 259.35 & 1.708 & 2.631 & 57.5 \\
\hline $31 X-3,82-84$ & 260.92 & 1.741 & 2.608 & 54.7 \\
\hline $32 X-1,42-44$ & 267.12 & 1.857 & 2.416 & 40.1 \\
\hline $32 X-1,105-107$ & 267.75 & 1.987 & 2.768 & 44.8 \\
\hline $32 X-2,40-42$ & 268.60 & 2.009 & 2.720 & 41.9 \\
\hline $32 X-2,93-95$ & 269.13 & 2.038 & 2.767 & 41.8 \\
\hline $32 X-3,56-58$ & 270.26 & 1.836 & 2.491 & 44.7 \\
\hline $32 X-3,123-125$ & 270.93 & 1.962 & 2.739 & 45.3 \\
\hline $32 X-5,34-36$ & 273.04 & 1.965 & 2.756 & 45.6 \\
\hline $32 X-5,88-90$ & 273.58 & 1.986 & 2.762 & 44.7 \\
\hline $32 X-6,18-20$ & 274.38 & 1.801 & 2.344 & 41.1 \\
\hline $32 X-7,82-84$ & 275.93 & 1.886 & 2.787 & 51.1 \\
\hline $33 X-1,70-72$ & 277.00 & 1.854 & 2.824 & 53.9 \\
\hline $33 X-1,117-119$ & 277.47 & 1.817 & 2.774 & 54.7 \\
\hline $33 X-2,53-55$ & 278.33 & 1.933 & 2.875 & 50.9 \\
\hline $33 X-3,109-111$ & 280.39 & 1.630 & 2.187 & 47.9 \\
\hline $33 X-5,11-13$ & 282.41 & 2.071 & 3.637 & 59.9 \\
\hline $33 X-5,97-99$ & 283.27 & 2.035 & 3.287 & 55.3 \\
\hline $33 X-6,10-12$ & 283.90 & 1.597 & 2.028 & 42.9 \\
\hline $34 X-1,34-36$ & 286.24 & 1.909 & 2.817 & 50.6 \\
\hline $34 X-1,112-114$ & 287.02 & 1.941 & 2.730 & 46.2 \\
\hline $34 X-2,11-13$ & 287.51 & 1.908 & 2.702 & 47.3 \\
\hline $34 X-2,118-120$ & 288.58 & 1.895 & 2.697 & 48.0 \\
\hline $34 X-3,46-48$ & 289.36 & 1.910 & 2.814 & 50.5 \\
\hline $34 X-3,122-124$ & 290.12 & 1.924 & 2.746 & 47.7 \\
\hline $34 X-5,52-54$ & 292.42 & 1.897 & 2.733 & 48.9 \\
\hline $34 X-5,115-117$ & 293.05 & 1.914 & 2.711 & 47.3 \\
\hline $34 X-6,57-59$ & 293.93 & 1.894 & 2.799 & 51.0 \\
\hline $34 X-7,36-38$ & 294.72 & 1.790 & 2.745 & 55.5 \\
\hline $35 X-1,20-22$ & 295.70 & 1.806 & 2.657 & 52.1 \\
\hline $35 X-1,85-87$ & 296.35 & 1.823 & 2.682 & 51.8 \\
\hline $35 X-3,82-84$ & 299.32 & 2.005 & 2.772 & 43.9 \\
\hline $35 X-3,107-109$ & 299.57 & 1.937 & 2.771 & 47.7 \\
\hline \multicolumn{5}{|l|}{ 311-U1327D- } \\
\hline $4 \mathrm{E}-1,50-52$ & 125.80 & 1.849 & 2.764 & 52.6 \\
\hline $5 X-1,68-69$ & 126.98 & 2.291 & 2.862 & 31.0 \\
\hline $5 X-1,78-80$ & 127.08 & 1.865 & 2.778 & 52.0 \\
\hline $5 X-1,119-121$ & 127.49 & 1.839 & 2.785 & 53.7 \\
\hline $5 X-2,37-39$ & 128.17 & 1.960 & 2.734 & 45.3 \\
\hline
\end{tabular}


Table T10 (continued).

\begin{tabular}{|c|c|c|c|c|}
\hline \multirow{2}{*}{$\begin{array}{l}\text { Core, section } \\
\text { interval }(\mathrm{cm})\end{array}$} & \multirow{2}{*}{$\begin{array}{l}\text { Depth } \\
\text { (mbsf) }\end{array}$} & \multicolumn{2}{|c|}{ Density $\left(\mathrm{g} / \mathrm{cm}^{3}\right)$} & \multirow{2}{*}{$\begin{array}{c}\text { Porosity } \\
\text { (\%) }\end{array}$} \\
\hline & & Bulk & Grain & \\
\hline $5 X-3,23-25$ & 128.97 & 1.816 & 2.714 & 53.1 \\
\hline $5 X-3,73-75$ & 129.47 & 1.804 & 2.676 & 52.8 \\
\hline $5 X-4,9-11$ & 129.83 & 1.927 & 2.765 & 48.2 \\
\hline $6 Y-1,30-32$ & 132.30 & 1.901 & 2.824 & 51.3 \\
\hline $7 X-1,53-55$ & 133.53 & 1.840 & 2.735 & 52.3 \\
\hline $7 X-1,92-94$ & 133.92 & 1.819 & 2.822 & 55.8 \\
\hline $7 X-2,17-19$ & 134.67 & 1.830 & 2.697 & 51.8 \\
\hline $7 X-4,100-102$ & 136.86 & 1.723 & 2.661 & 57.3 \\
\hline $8 X-1,71-73$ & 143.01 & 1.710 & 2.603 & 56.6 \\
\hline $8 X-1,121-123$ & 143.51 & 1.852 & 2.690 & 50.3 \\
\hline $8 X-2,45-47$ & 144.25 & 1.803 & 2.708 & 53.8 \\
\hline $8 X-2,103-105$ & 144.83 & 1.793 & 2.626 & 52.0 \\
\hline $8 X-3,64-66$ & 145.94 & 1.891 & 2.733 & 49.3 \\
\hline $8 X-4,68-70$ & 147.24 & 1.855 & 2.742 & 51.6 \\
\hline $8 X-5,32-34$ & 147.88 & 1.888 & 2.739 & 49.6 \\
\hline $9 X-1,136-138$ & 153.26 & 1.805 & 2.725 & 54.1 \\
\hline $9 X-2,37-39$ & 153.77 & 1.826 & 2.653 & 50.7 \\
\hline $9 X-3,41-43$ & 155.31 & 1.963 & 2.752 & 45.7 \\
\hline $10 P-1,34-36$ & 155.44 & 2.065 & 2.737 & 39.2 \\
\hline $10 P-1,57-59$ & 155.67 & 2.060 & 2.779 & 41.0 \\
\hline $11 X-3,78-80$ & 160.10 & 2.007 & 2.738 & 42.6 \\
\hline $11 X-3,119-121$ & 160.51 & 2.057 & 2.795 & 41.7 \\
\hline $11 X-4,42-44$ & 161.24 & 1.944 & 2.727 & 46.0 \\
\hline $13 Y-1,12-14$ & 203.72 & 1.878 & 2.762 & 50.8 \\
\hline $13 Y-1,28-30$ & 203.88 & 1.946 & 2.800 & 48.1 \\
\hline $13 Y-1,37-39$ & 203.97 & 1.939 & 2.783 & 48.0 \\
\hline $15 X-1,90-92$ & 219.60 & 1.903 & 2.734 & 48.6 \\
\hline $15 X-2,22-24$ & 220.26 & 1.946 & 2.724 & 45.8 \\
\hline $15 X-2,88-90$ & 220.92 & 1.854 & 2.730 & 51.4 \\
\hline $15 X-3,12-14$ & 221.59 & 1.840 & 2.732 & 52.2 \\
\hline $15 X-4,28-30$ & 222.45 & 2.002 & 2.742 & 43.1 \\
\hline $15 X-4,78-80$ & 222.95 & 1.982 & 2.735 & 44.0 \\
\hline $15 X-6,20-22$ & 224.56 & 1.992 & 2.755 & 44.1 \\
\hline $17 P-1,35-37$ & 246.35 & 1.830 & 2.784 & 54.2 \\
\hline 17P-1, 67-69 & 246.67 & 1.828 & 2.740 & 53.1 \\
\hline
\end{tabular}

Table T11. Comparison of density gradients at Sites U1327 and U1329.

\begin{tabular}{ccccc}
\hline $\begin{array}{c}\text { Depth interval } \\
\text { (mbsf) }\end{array}$ & $\begin{array}{c}\text { Density } \\
\text { gradient } \\
\left(\mathrm{g} / \mathrm{cm}^{3} / \mathrm{m}\right)\end{array}$ & Uncertainty & $\begin{array}{c}\text { Intercept at } \\
0 \mathrm{mbsf} \\
\left(\mathrm{g} / \mathrm{cm}^{3}\right)\end{array}$ & $\begin{array}{c}\text { Uncertainty } \\
\left(\mathrm{g} / \mathrm{cm}^{3} / \mathrm{m}\right)\end{array}$ \\
\hline Site U1327 & & & & \\
$0-11$ & 0.024 & 0.009 & 1.56 & 0.06 \\
$11-60$ & 0.004 & 0.0008 & 1.67 & 0.03 \\
$60-300$ & 0.0003 & 0.0009 & 1.81 & 0.02 \\
Site U1329 & & & & \\
$0-11$ & 0.001 & 0.004 & 1.68 & 0.03 \\
$11-60$ & -0.0007 & 0.0007 & 1.76 & 0.03 \\
$60-185$ & 0.001 & 0.0003 & 1.64 & 0.04 \\
\hline
\end{tabular}

Note: Gradient determined from moisture and density data $\left(\mathrm{g} / \mathrm{cm}^{3}\right)$. 
Table T12. Compressional wave velocity, Hole U1327C.

\begin{tabular}{|c|c|c|c|c|}
\hline \multirow{2}{*}{$\begin{array}{l}\text { Core, section, } \\
\text { interval }(\mathrm{cm})\end{array}$} & \multirow{2}{*}{$\begin{array}{l}\text { Depth } \\
\text { (mbsf) }\end{array}$} & \multicolumn{3}{|c|}{ Velocity $(\mathrm{m} / \mathrm{s})$} \\
\hline & & PWS1 & PWS2 & PWS3 \\
\hline \multicolumn{5}{|l|}{ 311-U1327C- } \\
\hline $1 \mathrm{H}-2,92$ & 2.42 & & 1511.6 & \\
\hline $1 \mathrm{H}-2,92$ & 2.42 & & & 1534.4 \\
\hline $1 \mathrm{H}-3,52$ & 3.52 & 1489.5 & & \\
\hline $1 \mathrm{H}-3,52$ & 3.52 & & 1516.1 & \\
\hline $1 \mathrm{H}-3,52$ & 3.52 & & & 1513.0 \\
\hline $1 \mathrm{H}-4,72$ & 5.22 & 1510.5 & & \\
\hline $1 \mathrm{H}-4,72$ & 5.22 & & & 1519.3 \\
\hline $2 \mathrm{H}-1,7.5$ & 6.18 & 1516.2 & & \\
\hline $2 \mathrm{H}-1,17.1$ & 6.27 & & 1515.6 & \\
\hline $2 \mathrm{H}-1,32$ & 6.42 & & & 1479.8 \\
\hline $2 \mathrm{H}-1,47$ & 6.57 & 1694.6 & & \\
\hline $2 \mathrm{H}-2,16$ & 7.76 & & & 1529.8 \\
\hline $2 \mathrm{H}-2,22$ & 7.82 & & 1542.4 & \\
\hline $2 \mathrm{H}-2,22$ & 7.82 & & & 1550.4 \\
\hline $2 \mathrm{H}-2,24$ & 7.84 & 1536.6 & & \\
\hline $2 \mathrm{H}-2,47$ & 8.07 & & 1502.2 & \\
\hline $2 \mathrm{H}-2,47$ & 8.07 & & & 1525.2 \\
\hline $2 \mathrm{H}-2,50$ & 8.10 & 1510.4 & & \\
\hline $2 \mathrm{H}-2,74$ & 8.34 & & & 1533.0 \\
\hline $2 \mathrm{H}-2,75$ & 8.35 & & 1526.0 & \\
\hline $2 \mathrm{H}-2,78$ & 8.38 & 1530.4 & & \\
\hline $2 \mathrm{H}-2,105$ & 8.65 & & 1511.2 & \\
\hline $2 \mathrm{H}-2,107$ & 8.67 & 1533.8 & & \\
\hline $2 \mathrm{H}-2,129$ & 8.89 & & 1517.3 & \\
\hline $2 \mathrm{H}-2,130$ & 8.90 & 1502.3 & & \\
\hline $2 \mathrm{H}-2,133$ & 8.93 & & & 1512.1 \\
\hline $2 \mathrm{H}-3,16$ & 9.26 & & & 1529.8 \\
\hline $2 \mathrm{H}-3,45$ & 9.55 & & & 1521.9 \\
\hline $2 \mathrm{H}-3,98$ & 10.08 & & 1528.7 & \\
\hline $2 \mathrm{H}-4,12$ & 10.72 & & & 1529.0 \\
\hline $2 \mathrm{H}-4,91$ & 11.51 & & & 1510.4 \\
\hline $2 \mathrm{H}-4,95$ & 11.55 & & 1505.5 & \\
\hline $2 \mathrm{H}-4,122$ & 11.82 & & 1505.5 & \\
\hline $2 \mathrm{H}-4,122$ & 11.82 & & & 1521.5 \\
\hline $2 \mathrm{H}-5,12$ & 12.22 & & & 1495.9 \\
\hline $2 \mathrm{H}-5,48$ & 12.58 & & & 1541.6 \\
\hline $2 \mathrm{H}-5,70$ & 12.80 & & & 1536.1 \\
\hline $2 \mathrm{H}-5,111$ & 13.21 & & & 1513.6 \\
\hline $2 \mathrm{H}-6,16$ & 13.76 & & & 1545.3 \\
\hline $2 \mathrm{H}-6,25$ & 13.85 & & & 1512.4 \\
\hline $2 \mathrm{H}-6,62$ & 14.22 & & & 1527.9 \\
\hline $2 \mathrm{H}-6,75$ & 14.35 & & & 1561.7 \\
\hline $2 \mathrm{H}-7,16$ & 15.26 & & & 1545.3 \\
\hline $3 \mathrm{H}-1,36$ & 15.96 & & & 1515.7 \\
\hline $3 \mathrm{H}-1,73$ & 16.33 & & & 1531.2 \\
\hline $3 \mathrm{H}-1,104$ & 16.64 & & & 1523.3 \\
\hline $3 \mathrm{H}-1,139$ & 16.99 & & & 1521.9 \\
\hline $3 \mathrm{H}-2,9$ & 17.19 & & & 1537.3 \\
\hline $3 \mathrm{H}-2,42$ & 17.52 & & & 1532.9 \\
\hline $3 \mathrm{H}-2,80$ & 17.90 & & & 1535.7 \\
\hline $3 \mathrm{H}-2,118$ & 18.28 & & & 1535.3 \\
\hline $3 \mathrm{H}-4,29$ & 20.39 & & & 1553.1 \\
\hline
\end{tabular}

Note: $P W S=P$-wave sensor. 
Table T13. Torvane shear strength, Hole U1327C.

\begin{tabular}{lrcc}
\hline \multicolumn{1}{c}{$\begin{array}{c}\text { Core, section, } \\
\text { interval }(\mathrm{cm})\end{array}$} & $\begin{array}{r}\text { Depth } \\
\text { (mbsf) }\end{array}$ & $\begin{array}{c}\text { Torvane shear } \\
\text { strength (kPa) }\end{array}$ & $\begin{array}{c}\text { Torvane } \\
\text { size }\end{array}$ \\
\hline $311-\mathrm{U} 1327 \mathrm{C}-$ & & & \\
$1 \mathrm{H}-1,43-45$ & 0.43 & 4 & $\mathrm{M}$ \\
$2 \mathrm{H}-1,13-15$ & 6.23 & 12 & $\mathrm{M}$ \\
$2 \mathrm{H}-1,44-46$ & 6.54 & 11 & $\mathrm{M}$ \\
$2 \mathrm{H}-2,53-55$ & 8.13 & 16 & $\mathrm{M}$ \\
$2 \mathrm{H}-2,133-135$ & 8.93 & 22 & $\mathrm{M}$ \\
$2 \mathrm{H}-3,33-35$ & 9.43 & 20 & $\mathrm{M}$ \\
$2 \mathrm{H}-4,30.5-32.5$ & 10.90 & 20 & $\mathrm{M}$ \\
$2 \mathrm{H}-4,98-100$ & 11.58 & 23 & $\mathrm{M}$ \\
$2 \mathrm{H}-5,15-17$ & 12.25 & 20 & $\mathrm{M}$ \\
$2 \mathrm{H}-5,74-76$ & 12.84 & 21 & $\mathrm{M}$ \\
$2 \mathrm{H}-6,28-30$ & 13.88 & 17 & $\mathrm{M}$ \\
$2 \mathrm{H}-6,79-81$ & 14.39 & 30 & $\mathrm{M}$ \\
$2 \mathrm{H}-6,133-135$ & 14.93 & 27 & $\mathrm{M}$ \\
$2 \mathrm{H}-7,29-31$ & 15.39 & 28 & $\mathrm{M}$ \\
$3 \mathrm{H}-1,42-44$ & 16.02 & 17 & $\mathrm{M}$ \\
$3 \mathrm{H}-1,117-119$ & 16.77 & 28 & $\mathrm{M}$ \\
$3 \mathrm{H}-2,37-39$ & 17.47 & 20 & $\mathrm{M}$ \\
$3 \mathrm{H}-2,113-115$ & 18.23 & 29 & $\mathrm{M}$ \\
$3 \mathrm{H}-4,32-34$ & 20.42 & 32 & $\mathrm{M}$ \\
$3 \mathrm{H}-4,128-130$ & 21.38 & 27 & $\mathrm{M}$ \\
$3 \mathrm{H}-5,36.5-38.5$ & 21.97 & 30 & $\mathrm{M}$ \\
$3 \mathrm{H}-5,129-131$ & 22.89 & 36 & $\mathrm{M}$ \\
$3 \mathrm{H}-6,91-93$ & 24.01 & 30 & $\mathrm{M}$ \\
$3 \mathrm{H}-6,91-93$ & 24.01 & 34 & $\mathrm{M}$ \\
$3 \mathrm{H}-7,26-28$ & 24.86 & 25 & $\mathrm{M}$ \\
$3 \mathrm{H}-7,71.5-73.5$ & 25.32 & 37 & $\mathrm{M}$ \\
$4 \mathrm{H}-1,42-44$ & 25.52 & 31 & $\mathrm{M}$ \\
$4 \mathrm{H}-1,132-134$ & 26.42 & 34 & $\mathrm{M}$ \\
$4 \mathrm{H}-2,32-34$ & 26.92 & 49 & $\mathrm{M}$ \\
$4 \mathrm{H}-2,112-114$ & 27.72 & 35 & $\mathrm{M}$ \\
$4 \mathrm{H}-3,43-45$ & 28.53 & 33 & $\mathrm{M}$ \\
$4 \mathrm{H}-3,131-133$ & 29.41 & 33 & $\mathrm{M}$ \\
$4 \mathrm{H}-4,51-53$ & 30.11 & 38 & $\mathrm{M}$ \\
$4 \mathrm{H}-4,123-125$ & 30.83 & 30 & $\mathrm{M}$ \\
$4 \mathrm{H}-6,21-23$ & 32.81 & 40 & $\mathrm{M}$ \\
$4 \mathrm{H}-6,103-105$ & 33.63 & 34 & $\mathrm{M}$ \\
$4 \mathrm{H}-7,7.9-9.9$ & 34.18 & 30 & $\mathrm{M}$ \\
$4 \mathrm{H}-7,74-76$ & 34.84 & 20 & $\mathrm{M}$ \\
$4 \mathrm{H}-5,11-13$ & 31.21 & 37 & $\mathrm{M}$ \\
$5 \mathrm{H}-1,56-58$ & 35.16 & 17 & $\mathrm{M}$ \\
$5 \mathrm{H}-2,105-107$ & 37.15 & 18 & $\mathrm{M}$ \\
$5 \mathrm{H}-3,116-118$ & 38.76 & 25 & $\mathrm{M}$ \\
$5 \mathrm{H}-4,124-126$ & 40.34 & 31 & $\mathrm{M}$ \\
& & & \\
& & &
\end{tabular}

\begin{tabular}{lccc}
\hline $\begin{array}{c}\text { Core, section, } \\
\text { interval (cm) }\end{array}$ & $\begin{array}{c}\text { Depth } \\
\text { (mbsf) }\end{array}$ & $\begin{array}{c}\text { Torvane shear } \\
\text { strength (kPa) }\end{array}$ & $\begin{array}{c}\text { Torvane } \\
\text { size }\end{array}$ \\
\hline $5 \mathrm{H}-6,18-20$ & 42.28 & 30 & $\mathrm{M}$ \\
$5 \mathrm{H}-7,82-84$ & 44.42 & 28 & $\mathrm{M}$ \\
$7 \mathrm{H}-1,81-83$ & 46.91 & 46 & $\mathrm{M}$ \\
$7 \mathrm{H}-2,87-89$ & 48.47 & 43 & $\mathrm{M}$ \\
$7 \mathrm{H}-3,101-103$ & 50.11 & 43 & $\mathrm{M}$ \\
$7 \mathrm{H}-4,69-71$ & 51.29 & 28 & $\mathrm{M}$ \\
$7 \mathrm{H}-5,7-9$ & 52.17 & 40 & $\mathrm{M}$ \\
$7 \mathrm{H}-6,42-44$ & 54.02 & 59 & $\mathrm{M}$ \\
$7 \mathrm{H}-7,26-28$ & 55.36 & 57 & $\mathrm{M}$ \\
$8 \mathrm{H}-2,96-98$ & 58.06 & 44 & $\mathrm{M}$ \\
$8 \mathrm{H}-1,101-103$ & 56.61 & 46 & $\mathrm{M}$ \\
$8 \mathrm{H}-3,96-98$ & 59.56 & 32 & $\mathrm{M}$ \\
$8 \mathrm{H}-5,64-66$ & 62.24 & 35 & $\mathrm{M}$ \\
$8 \mathrm{H}-7,69-71$ & 65.29 & 53 & $\mathrm{M}$ \\
$9 \mathrm{H}-1,40-42$ & 65.50 & 65 & $\mathrm{M}$ \\
$9 \mathrm{H}-2,40-42$ & 67.00 & 65 & $\mathrm{M}$ \\
$10 \mathrm{H}-1,45-47$ & 75.05 & 162.5 & $\mathrm{~S}$ \\
$10 \mathrm{H}-1,110-112$ & 75.70 & 142.5 & $\mathrm{~S}$ \\
$10 \mathrm{H}-2,34-36$ & 76.44 & 112.5 & $\mathrm{~S}$ \\
$10 \mathrm{H}-2,83-85$ & 76.93 & 115 & $\mathrm{~S}$ \\
$10 \mathrm{H}-3,37-39$ & 77.97 & 117.5 & $\mathrm{~S}$ \\
$10 \mathrm{H}-3,119-121$ & 78.79 & 102.5 & $\mathrm{~S}$ \\
$10 \mathrm{H}-6,11-13$ & 80.86 & 170 & $\mathrm{~S}$ \\
$10 \mathrm{H}-6,71-73$ & 81.46 & 65 & $\mathrm{~S}$ \\
$10 \mathrm{H}-7,42-44$ & 82.17 & 152.5 & $\mathrm{~S}$ \\
$11 \mathrm{H}-1,22.5-24.5$ & 84.32 & 105 & $\mathrm{~S}$ \\
$11 \mathrm{H}-2,30.5-32.5$ & 85.90 & 152.5 & $\mathrm{~S}$ \\
$11 \mathrm{H}-2,111-113$ & 86.71 & 135 & $\mathrm{~S}$ \\
$11 \mathrm{H}-3,44-46$ & 87.54 & 132.5 & $\mathrm{~S}$ \\
$11 \mathrm{H}-3,112-114$ & 88.22 & 122.5 & $\mathrm{~S}$ \\
$11 \mathrm{H}-4,26-28$ & 88.86 & 152.5 & $\mathrm{~S}$ \\
$11 \mathrm{H}-4,125-127$ & 89.85 & 177.5 & $\mathrm{~S}$ \\
$11 \mathrm{H}-5,18-20$ & 90.28 & 132.5 & $\mathrm{~S}$ \\
$11 \mathrm{H}-5,90-92$ & 91.00 & 157.5 & $\mathrm{~S}$ \\
$12 \mathrm{X}-3,3-5$ & 94.79 & 12.5 & $\mathrm{~S}$ \\
$12 \mathrm{X}-6,82-84$ & 99.94 & 70 & $\mathrm{~S}$ \\
$13 \mathrm{X}-1,13-15$ & 102.63 & 11 & $\mathrm{M}$ \\
$13 \mathrm{X}-3,87-89$ & 106.37 & 40 & $\mathrm{M}$ \\
$13 \mathrm{X}-5,58-60$ & 108.68 & 37 & $\mathrm{M}$ \\
$14 \mathrm{X}-2,60-62$ & 114.20 & 35 & $\mathrm{M}$ \\
$17 \mathrm{X}-4,40-42$ & 134.32 & 90 & $\mathrm{M}$ \\
$17 \mathrm{X}-5,13-15$ & 134.81 & 87.5 & $\mathrm{~S}$ \\
\hline & & & \\
\hline & & & \\
\hline
\end{tabular}

Note: $\mathrm{M}=$ medium $(2.5 \mathrm{~cm}$ diameter $), \mathrm{S}=$ small $(1.9 \mathrm{~cm}$ diameter $)$.

Table T14. AVS shear strength, Hole U1327C.

\begin{tabular}{|c|c|c|c|c|}
\hline \multirow{2}{*}{$\begin{array}{l}\text { Core, section, } \\
\text { interval }(\mathrm{cm})\end{array}$} & \multirow{2}{*}{$\begin{array}{l}\text { Depth } \\
\text { (mbsf) }\end{array}$} & \multirow{2}{*}{$\begin{array}{l}\text { Vane } \\
\text { size }\end{array}$} & \multicolumn{2}{|c|}{ Shear strength $(\mathrm{kPa})$} \\
\hline & & & Peak & Residual \\
\hline \multicolumn{5}{|l|}{ 311-U1327C- } \\
\hline $11 \mathrm{H}-3,34$ & 87.44 & A & 149.4 & 22.6 \\
\hline $11 \mathrm{H}-3,112$ & 88.22 & A & 82.0 & 27.7 \\
\hline $11 \mathrm{H}-3,135$ & 88.45 & A & 117.7 & 50.3 \\
\hline $11 \mathrm{H}-4,33$ & 88.93 & A & 122.4 & 83.0 \\
\hline $11 \mathrm{H}-4,87$ & 89.47 & A & 159.0 & 53.4 \\
\hline $11 \mathrm{H}-4,121$ & 89.81 & A & 168.5 & 68.1 \\
\hline
\end{tabular}

Notes: A = small vane size. AVS values calibrated for spring constant used to calculate shear strength. 
Table T15. Contact resistivity, Hole U1327C. (Continued on next page.)

\begin{tabular}{|c|c|c|}
\hline $\begin{array}{l}\text { Core, section, } \\
\text { interval }(\mathrm{cm})\end{array}$ & $\begin{array}{l}\text { Depth } \\
\text { (mbsf) }\end{array}$ & $\begin{array}{c}\text { Resistivity } \\
(\Omega \mathrm{m})\end{array}$ \\
\hline \multicolumn{3}{|l|}{ Parallel } \\
\hline \multicolumn{3}{|l|}{ 311-U1327C- } \\
\hline $1 \mathrm{H}-1,2$ & 0.02 & 0.333 \\
\hline $1 \mathrm{H}-1,2$ & 0.02 & 0.329 \\
\hline $1 \mathrm{H}-1,27$ & 0.27 & 0.326 \\
\hline $1 \mathrm{H}-1,52$ & 0.52 & 0.304 \\
\hline $1 \mathrm{H}-2,5$ & 1.55 & 0.349 \\
\hline $1 \mathrm{H}-2,30$ & 1.80 & 0.266 \\
\hline $1 \mathrm{H}-2,55$ & 2.05 & 0.345 \\
\hline $1 \mathrm{H}-2,72$ & 2.22 & 0.486 \\
\hline $1 \mathrm{H}-2,72$ & 2.22 & 0.537 \\
\hline $1 \mathrm{H}-2,97$ & 2.47 & 0.357 \\
\hline $1 \mathrm{H}-2,122$ & 2.72 & 0.431 \\
\hline $1 \mathrm{H}-3,10$ & 3.10 & 0.288 \\
\hline $1 \mathrm{H}-3,35$ & 3.35 & 0.304 \\
\hline $1 \mathrm{H}-3,55$ & 3.55 & 0.313 \\
\hline $1 \mathrm{H}-4,5$ & 4.55 & 0.284 \\
\hline $1 \mathrm{H}-4,30$ & 4.80 & 0.620 \\
\hline $1 \mathrm{H}-4,55$ & 5.05 & 0.531 \\
\hline $1 \mathrm{H}-4,80$ & 5.30 & 0.392 \\
\hline $1 \mathrm{H}-4,105$ & 5.55 & 0.373 \\
\hline $1 \mathrm{H}-4,130$ & 5.80 & 0.373 \\
\hline $1 \mathrm{H}-4,130$ & 5.80 & 0.387 \\
\hline $2 \mathrm{H}-1,4$ & 6.14 & 0.379 \\
\hline $2 \mathrm{H}-1,18$ & 6.28 & 0.329 \\
\hline $2 \mathrm{H}-1,29$ & 6.39 & 0.440 \\
\hline $2 \mathrm{H}-1,40$ & 6.50 & 0.403 \\
\hline $2 \mathrm{H}-1,47$ & 6.57 & 0.500 \\
\hline $2 \mathrm{H}-1,53$ & 6.63 & 0.371 \\
\hline $2 \mathrm{H}-2,11$ & 7.71 & 0.419 \\
\hline $2 \mathrm{H}-2,26$ & 7.86 & 0.353 \\
\hline $2 \mathrm{H}-2,48$ & 8.08 & 0.330 \\
\hline $2 \mathrm{H}-2,71$ & 8.31 & 0.341 \\
\hline $2 \mathrm{H}-2,88$ & 8.48 & 0.313 \\
\hline $2 \mathrm{H}-2,111$ & 8.71 & 0.343 \\
\hline $2 \mathrm{H}-2,132$ & 8.92 & 0.376 \\
\hline $2 \mathrm{H}-3,4$ & 9.14 & 0.334 \\
\hline $2 \mathrm{H}-3,18$ & 9.28 & 0.378 \\
\hline $2 \mathrm{H}-3,34$ & 9.44 & 0.403 \\
\hline $2 \mathrm{H}-3,49$ & 9.59 & 0.435 \\
\hline $2 \mathrm{H}-3,12$ & 9.22 & 0.383 \\
\hline $2 \mathrm{H}-4,27$ & 10.87 & 0.383 \\
\hline $2 \mathrm{H}-4,22$ & 10.82 & 0.356 \\
\hline $2 \mathrm{H}-4,33$ & 10.93 & 0.348 \\
\hline $2 \mathrm{H}-4,54$ & 11.14 & 0.453 \\
\hline $2 \mathrm{H}-4,76$ & 11.36 & 0.299 \\
\hline $2 \mathrm{H}-4,91$ & 11.51 & 0.376 \\
\hline $2 \mathrm{H}-4,110$ & 11.70 & 0.440 \\
\hline $2 \mathrm{H}-4,117$ & 11.77 & 0.346 \\
\hline $2 \mathrm{H}-5,5$ & 12.15 & 0.379 \\
\hline $2 \mathrm{H}-5,20$ & 12.30 & 0.442 \\
\hline $2 \mathrm{H}-5,35$ & 12.45 & 0.427 \\
\hline $2 \mathrm{H}-5,69$ & 12.79 & 0.381 \\
\hline $2 \mathrm{H}-5,84$ & 12.94 & 0.390 \\
\hline $2 \mathrm{H}-5,108$ & 13.18 & 0.409 \\
\hline $2 \mathrm{H}-6,6$ & 13.66 & 0.390 \\
\hline $2 \mathrm{H}-6,25$ & 13.85 & 0.453 \\
\hline $2 \mathrm{H}-6,52$ & 14.12 & 0.375 \\
\hline $2 \mathrm{H}-6,77$ & 14.37 & 0.502 \\
\hline $2 \mathrm{H}-6,97$ & 14.57 & 0.385 \\
\hline $2 \mathrm{H}-6,115$ & 14.75 & 0.542 \\
\hline $2 \mathrm{H}-6,135$ & 14.95 & 0.403 \\
\hline $2 \mathrm{H}-7,4$ & 15.14 & 0.377 \\
\hline $2 \mathrm{H}-7,17$ & 15.27 & 0.567 \\
\hline $2 \mathrm{H}-7,30$ & 15.40 & 0.436 \\
\hline $3 \mathrm{H}-1,22$ & 15.82 & 0.607 \\
\hline $3 \mathrm{H}-1,38$ & 15.98 & 0.718 \\
\hline $3 \mathrm{H}-1,58$ & 16.18 & 0.734 \\
\hline $3 \mathrm{H}-1,74$ & 16.34 & 0.700 \\
\hline
\end{tabular}

Core, section, Depth Resistivity

interval $(\mathrm{cm}) \quad(\mathrm{mbsf}) \quad(\Omega \mathrm{m})$

\begin{tabular}{lll}
\hline $3 \mathrm{H}-1,95$ & 16.55 & 0.691 \\
& & \\
$3 \mathrm{H}-1,112$ & 16.72 & 0.611
\end{tabular}

$\begin{array}{lll}3 \mathrm{H}-1,147 & 17.07 & 0.727\end{array}$

$\begin{array}{lll}3 \mathrm{H}-2,4 & 17.14 & 0.701\end{array}$

$3 \mathrm{H}-2,24 \quad 17.34 \quad 0.732$

$3 \mathrm{H}-2,42 \quad 17.52 \quad 0.654$

$3 \mathrm{H}-2,60 \quad 17.70 \quad 0.747$

$3 \mathrm{H}-2,80 \quad 17.90 \quad 0.634$

$3 \mathrm{H}-2,108 \quad 18.18 \quad 0.601$

$3 \mathrm{H}-2,128 \quad 18.38 \quad 0.621$

$3 \mathrm{H}-3,2 \quad 18.62 \quad 0.601$

$3 \mathrm{H}-4,8 \quad 20.18 \quad 0.623$

$3 \mathrm{H}-4,28 \quad 20.38 \quad 0.693$

$3 \mathrm{H}-4,47 \quad 20.57 \quad 0.680$

$3 \mathrm{H}-4,64 \quad 20.74 \quad 0.661$

$3 \mathrm{H}-4,84 \quad 20.94 \quad 0.571$

$3 \mathrm{H}-4,110 \quad 21.20 \quad 0.594$

$3 \mathrm{H}-4,133 \quad 21.43 \quad 0.705$

$\begin{array}{lll}3 \mathrm{H}-5,5 & 21.65 & 0.647\end{array}$

$3 \mathrm{H}-5,25 \quad 21.85 \quad 0.632$

$3 \mathrm{H}-5,45 \quad 22.05 \quad 0.597$

$3 \mathrm{H}-5,66 \quad 22.26 \quad 0.994$

$\begin{array}{lll}3 \mathrm{H}-5,88 & 22.48 & 0.500\end{array}$

$3 \mathrm{H}-5,132 \quad 22.92 \quad 0.728$

$3 \mathrm{H}-5,144 \quad 23.04 \quad 0.990$

$3 \mathrm{H}-6,5 \quad 23.15 \quad 0.757$

$3 \mathrm{H}-6,30 \quad 23.40 \quad 0.636$

$3 \mathrm{H}-6,50 \quad 23.60 \quad 0.782$

$3 \mathrm{H}-6,77 \quad 23.87 \quad 0.820$

$\begin{array}{lll}3 \mathrm{H}-6,93 & 24.03 & 0.721\end{array}$

$3 \mathrm{H}-6,115 \quad 24.25 \quad 0.725$

$3 \mathrm{H}-7,11 \quad 24.71 \quad 0.636$

$3 \mathrm{H}-7,31 \quad 24.91 \quad 0.642$

$3 \mathrm{H}-7,53 \quad 25.13 \quad 0.601$

$3 \mathrm{H}-7,76 \quad 25.36 \quad 0.606$

$4 \mathrm{H}-1,14 \quad 25.24 \quad 0.629$

$4 \mathrm{H}-1,33 \quad 25.43 \quad 1.411$

$4 \mathrm{H}-1,40 \quad 25.50 \quad 0.664$

$\begin{array}{lll}4 \mathrm{H}-1,58 & 25.68 & 0.748\end{array}$

$4 \mathrm{H}-1,80 \quad 25.90 \quad 0.726$

$4 \mathrm{H}-1,100 \quad 26.10 \quad 0.785$

$4 \mathrm{H}-1,118 \quad 26.28 \quad 0.735$

$4 \mathrm{H}-1,139 \quad 26.49 \quad 0.777$

$4 \mathrm{H}-2,10 \quad 26.70 \quad 0.681$

$4 \mathrm{H}-2,30 \quad 26.90 \quad 0.765$

$4 \mathrm{H}-2,50 \quad 27.10 \quad 0.673$

$\begin{array}{lll}4 \mathrm{H}-2,70 & 27.30 & 2.297\end{array}$

$4 \mathrm{H}-2,90 \quad 27.50 \quad 0.887$

$4 \mathrm{H}-2,110 \quad 27.70 \quad 0.695$

$4 \mathrm{H}-3,10 \quad 28.20 \quad 0.692$

$4 \mathrm{H}-3,30 \quad 28.40 \quad 0.703$

$4 \mathrm{H}-3,50 \quad 28.60 \quad 0.862$

$4 \mathrm{H}-3,70 \quad 28.80 \quad 0.784$

$\begin{array}{lll}4 \mathrm{H}-3,89 & 28.99 & 0.883\end{array}$

$4 \mathrm{H}-3,109 \quad 29.19 \quad 0.996$

$4 \mathrm{H}-3,129 \quad 29.39 \quad 0.971$

$\begin{array}{lll}4 \mathrm{H}-3,8 & 28.18 & 0.702\end{array}$

$4 \mathrm{H}-4,28 \quad 29.88 \quad 0.697$

$\begin{array}{lll}4 \mathrm{H}-4,27 & 29.87 & 0.857\end{array}$

$4 \mathrm{H}-4,50 \quad 30.10 \quad 1.032$

$\begin{array}{lll}4 \mathrm{H}-4,71 & 30.31 & 0.789\end{array}$

$4 \mathrm{H}-4,100 \quad 30.60 \quad 1.018$

$4 \mathrm{H}-4,121 \quad 30.81 \quad 1.300$

$4 \mathrm{H}-4,137 \quad 30.97 \quad 0.689$

$\begin{array}{lll}4 \mathrm{H}-5,5 & 31.15 & 0.694\end{array}$

$4 \mathrm{H}-6,27 \quad 32.87 \quad 0.942$

$\begin{array}{lll}4 \mathrm{H}-6,48 & 33.08 & 1.041\end{array}$

$\begin{array}{lll}4 \mathrm{H}-6,67 & 33.27 & 0.906 \\ 4 \mathrm{H}-6,80 & 33.40 & 1.063\end{array}$

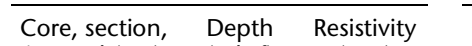

\begin{tabular}{ccc} 
interval $(\mathrm{cm})$ & $(\mathrm{mbsf})$ & $(\Omega \mathrm{m})$ \\
\hline $4 \mathrm{H}-6,100$ & 33.60 & 0.986
\end{tabular}

$\begin{array}{lll}4 \mathrm{H}-6,100 & 33.60 & 0.986 \\ 4 \mathrm{H}-6,142 & 34.02 & 1.072\end{array}$

$\begin{array}{lll}4 \mathrm{H}-6,142 & 34.02 & 1.072 \\ 4 \mathrm{H}-7,5 & 34.15 & 1.101\end{array}$

$4 \mathrm{H}-7,31 \quad 34.41 \quad 1.060$

$4 \mathrm{H}-7,56 \quad 34.66 \quad 0.797$

$4 \mathrm{H}-7,76 \quad 34.86 \quad 0.804$

$5 \mathrm{H}-1,18 \quad 34.78 \quad 0.898$

$5 \mathrm{H}-1,38 \quad 34.98 \quad 0.874$

$5 \mathrm{H}-1,58 \quad 35.18 \quad 0.844$

$5 \mathrm{H}-1,92 \quad 35.52 \quad 1.246$

$5 \mathrm{H}-1,112 \quad 35.72 \quad 1.360$

$5 \mathrm{H}-1,129 \quad 35.89 \quad 1.887$

$\begin{array}{lll}5 \mathrm{H}-2,6 & 36.16 & 1.079\end{array}$

$\begin{array}{lll}5 \mathrm{H}-2,47 & 36.57 & 0.776\end{array}$

$5 \mathrm{H}-2,108 \quad 37.18 \quad 1.073$

$5 \mathrm{H}-3,50 \quad 38.10 \quad 1.010$

$5 \mathrm{H}-3,101 \quad 38.61 \quad 0.868$

$5 \mathrm{H}-3,101 \quad 38.61 \quad 1.045$

$\begin{array}{lll}5 \mathrm{H}-4,39 & 39.49 & 1.482\end{array}$

$5 \mathrm{H}-4,68 \quad 39.78 \quad 1.190$

$5 \mathrm{H}-4,78 \quad 39.88 \quad 0.897$

$\begin{array}{lll}5 \mathrm{H}-4,101 & 40.11 & 1.287\end{array}$

$5 \mathrm{H}-4,126 \quad 40.36 \quad 0.936$

$5 \mathrm{H}-6,10 \quad 42.20 \quad 0.925$

$5 \mathrm{H}-6,50 \quad 42.60 \quad 1.004$

$5 \mathrm{H}-6,121 \quad 43.31 \quad 1.011$

$5 \mathrm{H}-7,40 \quad 44.00 \quad 1.067$

$5 \mathrm{H}-7,83 \quad 44.43 \quad 0.960$

$\begin{array}{lll}7 \mathrm{H}-1,8 & 46.18 & 0.893\end{array}$

$\begin{array}{lll}7 \mathrm{H}-1,48 & 46.58 & 0.861\end{array}$

$\begin{array}{lll}7 \mathrm{H}-1,82 & 46.92 & 1.038\end{array}$

$\begin{array}{lll}7 \mathrm{H}-1,127 & 47.37 & 1.029\end{array}$

$7 \mathrm{H}-1,127 \quad 47.37 \quad 0.871$

$\begin{array}{lll}7 \mathrm{H}-2,19 & 47.79 & 0.716\end{array}$

$\begin{array}{lll}7 \mathrm{H}-2,53 & 48.13 & 0.840\end{array}$

$\begin{array}{lll}7 \mathrm{H}-2,119 & 48.79 & 0.731\end{array}$

$\begin{array}{lll}7 \mathrm{H}-3,10 & 49.20 & 0.830\end{array}$

$\begin{array}{lll}7 \mathrm{H}-3,51 & 49.61 & 0.819\end{array}$

$\begin{array}{lll}7 \mathrm{H}-3,75 & 49.85 & 0.853\end{array}$

$\begin{array}{lll}7 \mathrm{H}-4,5 & 50.65 & 0.761\end{array}$

$\begin{array}{lll}7 \mathrm{H}-4,61 & 51.21 & 0.798\end{array}$

7H-4, $111 \quad 51.71 \quad 1.026$

$\begin{array}{lll}7 \mathrm{H}-6,14 & 53.74 & 0.879\end{array}$

$\begin{array}{lll}7 \mathrm{H}-6,61 & 54.21 & 0.862\end{array}$

$\begin{array}{lll}7 \mathrm{H}-6,98 & 54.58 & 0.987\end{array}$

$\begin{array}{lll}7 \mathrm{H}-6,98 & 54.58 & 1.051\end{array}$

$8 \mathrm{H}-1,22 \quad 55.82 \quad 0.796$

$8 \mathrm{H}-1,62 \quad 56.22 \quad 0.867$

$8 \mathrm{H}-1,102 \quad 56.62 \quad 0.843$

$8 \mathrm{H}-1,6 \quad 55.66 \quad 0.752$

$8 \mathrm{H}-2,6 \quad 57.16 \quad 0.769$

$\begin{array}{lll}8 \mathrm{H}-2,6 & 57.16 & 0.918\end{array}$

$8 \mathrm{H}-2,76 \quad 57.86 \quad 0.852$

$8 \mathrm{H}-3,29 \quad 58.89 \quad 0.866$

$8 \mathrm{H}-3,70 \quad 59.30 \quad 0.861$

$8 \mathrm{H}-3,87 \quad 59.47 \quad 3.809$

$8 \mathrm{H}-3,87 \quad 59.47 \quad 0.749$

$8 \mathrm{H}-4,20 \quad 60.30 \quad 1.088$

$8 \mathrm{H}-5,35 \quad 61.95 \quad 0.739$

$8 \mathrm{H}-5,35 \quad 61.95 \quad 0.741$

$8 \mathrm{H}-5,64 \quad 62.24 \quad 0.857$

$\begin{array}{lll}8 \mathrm{H}-5,64 & 62.24 & 0.849\end{array}$

$\begin{array}{lll}8 \mathrm{H}-5,97 & 62.57 & 0.769\end{array}$

$\begin{array}{lll}8 \mathrm{H}-6,7 & 63.17 & 0.758\end{array}$

$8 \mathrm{H}-6,124 \quad 64.34 \quad 0.756$

$8 \mathrm{H}-7,2 \quad 64.62 \quad 0.824$

$8 \mathrm{H}-7,68 \quad 65.28 \quad 0.851$

$\begin{array}{lll}8 \mathrm{H}-7,68 & 65.28 & 0.817\end{array}$

$9 \mathrm{H}-1,10 \quad 65.20 \quad 0.744$

\begin{tabular}{|c|c|c|}
\hline $\begin{array}{l}\text { Core, section, } \\
\text { interval }(\mathrm{cm})\end{array}$ & $\begin{array}{l}\text { Depth } \\
\text { (mbsf) }\end{array}$ & $\begin{array}{c}\text { Resistivity } \\
(\Omega \mathrm{m})\end{array}$ \\
\hline $9 \mathrm{H}-1,36$ & 65.46 & 0.790 \\
\hline $9 \mathrm{H}-1,61$ & 65.71 & 0.714 \\
\hline $9 \mathrm{H}-1,111$ & 66.21 & 0.788 \\
\hline $9 \mathrm{H}-2,25$ & 66.85 & 0.786 \\
\hline $9 \mathrm{H}-2,50$ & 67.10 & 0.722 \\
\hline $9 \mathrm{H}-2,80$ & 67.40 & 0.833 \\
\hline $9 \mathrm{H}-2,108$ & 67.68 & 0.774 \\
\hline $9 \mathrm{H}-3,25$ & 68.35 & 0.754 \\
\hline $9 \mathrm{H}-3,50$ & 68.60 & 0.724 \\
\hline $9 \mathrm{H}-3,75$ & 68.85 & 0.695 \\
\hline $9 \mathrm{H}-3,100$ & 69.10 & 0.722 \\
\hline $9 \mathrm{H}-4,15$ & 69.75 & 0.717 \\
\hline $9 \mathrm{H}-4,30$ & 69.90 & 0.765 \\
\hline $9 \mathrm{H}-4,70$ & 70.30 & 0.771 \\
\hline $9 \mathrm{H}-6,13$ & 72.73 & 0.695 \\
\hline $9 \mathrm{H}-6,36$ & 72.96 & 0.842 \\
\hline $9 \mathrm{H}-6,80$ & 73.40 & 0.839 \\
\hline $9 \mathrm{H}-6,125$ & 73.85 & 0.906 \\
\hline $9 \mathrm{H}-7,6$ & 74.16 & 0.952 \\
\hline $9 \mathrm{H}-7,83$ & 74.93 & 0.874 \\
\hline $10 \mathrm{H}-1,7$ & 74.67 & 0.936 \\
\hline $10 \mathrm{H}-1,20$ & 74.80 & 1.032 \\
\hline $10 \mathrm{H}-1,40$ & 75.00 & 1.196 \\
\hline $10 \mathrm{H}-1,65$ & 75.25 & 1.250 \\
\hline $10 \mathrm{H}-1,90$ & 75.50 & 1.277 \\
\hline $10 \mathrm{H}-1,115$ & 75.75 & 1.158 \\
\hline $10 \mathrm{H}-1,144$ & 76.04 & 1.061 \\
\hline $10 \mathrm{H}-2,3$ & 76.13 & 1.074 \\
\hline $10 \mathrm{H}-2,30$ & 76.40 & 1.148 \\
\hline $10 \mathrm{H}-2,55$ & 76.65 & 1.166 \\
\hline $10 \mathrm{H}-2,79$ & 76.89 & 1.092 \\
\hline $10 \mathrm{H}-2,102$ & 77.12 & 1.038 \\
\hline $10 \mathrm{H}-3,8$ & 77.68 & 1.071 \\
\hline $10 \mathrm{H}-3,32$ & 77.92 & 1.109 \\
\hline $10 \mathrm{H}-3,57$ & 78.17 & 1.240 \\
\hline $10 \mathrm{H}-3,85$ & 78.45 & 1.148 \\
\hline $10 \mathrm{H}-3,110$ & 78.70 & 1.257 \\
\hline $10 \mathrm{H}-3,139$ & 78.99 & 1.172 \\
\hline $10 \mathrm{H}-6,7$ & 80.82 & 1.138 \\
\hline $10 \mathrm{H}-6,35$ & 81.10 & 1.233 \\
\hline $10 \mathrm{H}-6,69$ & 81.44 & 1.234 \\
\hline $10 \mathrm{H}-6,96$ & 81.71 & 1.368 \\
\hline $10 \mathrm{H}-7,6$ & 81.81 & 1.298 \\
\hline $10 \mathrm{H}-7,28$ & 82.03 & 1.396 \\
\hline $10 \mathrm{H}-7,49$ & 82.24 & 1.060 \\
\hline $11 \mathrm{H}-1,6$ & 84.16 & 1.248 \\
\hline $11 \mathrm{H}-1,26$ & 84.36 & 1.215 \\
\hline $11 \mathrm{H}-1,50$ & 84.60 & 1.363 \\
\hline $11 \mathrm{H}-1,71$ & 84.81 & 1.087 \\
\hline $11 \mathrm{H}-1,109$ & 85.19 & 1.157 \\
\hline $11 \mathrm{H}-1,129$ & 85.39 & 1.230 \\
\hline $11 \mathrm{H}-2,3$ & 85.63 & 1.170 \\
\hline $11 \mathrm{H}-2,25$ & 85.85 & 1.283 \\
\hline $11 \mathrm{H}-2,52$ & 86.12 & 1.331 \\
\hline $11 \mathrm{H}-2,78$ & 86.38 & 1.078 \\
\hline $11 \mathrm{H}-2,105$ & 86.65 & 1.127 \\
\hline $11 \mathrm{H}-3,5$ & 87.15 & 1.165 \\
\hline $11 \mathrm{H}-3,27$ & 87.37 & 1.294 \\
\hline $11 \mathrm{H}-3,49$ & 87.59 & 1.416 \\
\hline $11 \mathrm{H}-3,74$ & 87.84 & 1.202 \\
\hline $11 \mathrm{H}-3,102$ & 88.12 & 1.349 \\
\hline $11 \mathrm{H}-3,127$ & 88.37 & 1.314 \\
\hline $11 \mathrm{H}-4,4$ & 88.64 & 1.202 \\
\hline $11 \mathrm{H}-4,29$ & 88.89 & 1.149 \\
\hline $11 \mathrm{H}-4,37$ & 88.97 & 1.279 \\
\hline $11 \mathrm{H}-4,61$ & 89.21 & 1.193 \\
\hline $11 \mathrm{H}-4,86$ & 89.46 & 1.404 \\
\hline $11 \mathrm{H}-4,112$ & 89.72 & 1.345 \\
\hline $11 \mathrm{H}-4,130$ & 89.90 & 1.309 \\
\hline
\end{tabular}


Table T15 (continued).

\begin{tabular}{|c|c|c|c|c|c|}
\hline $\begin{array}{l}\text { Core, section, } \\
\text { interval }(\mathrm{cm})\end{array}$ & $\begin{array}{l}\text { Depth } \\
\text { (mbsf) }\end{array}$ & $\begin{array}{l}\text { Resistivity } \\
(\Omega \mathrm{m})\end{array}$ & $\begin{array}{l}\text { Core, section, } \\
\text { interval }(\mathrm{cm})\end{array}$ & $\begin{array}{l}\text { Depth } \\
\text { (mbsf) }\end{array}$ & $\begin{array}{l}\text { Resistivity } \\
\text { ( }(\mathrm{m})\end{array}$ \\
\hline $11 \mathrm{H}-5,5$ & 90.15 & 1.227 & $13 X-4,99$ & 107.99 & 1.823 \\
\hline $11 \mathrm{H}-6,6$ & 91.66 & 1.365 & $13 X-5,11$ & 108.21 & 1.403 \\
\hline $11 \mathrm{H}-6,23$ & 91.83 & 1.529 & $13 X-5,55$ & 108.65 & 2.544 \\
\hline $11 \mathrm{H}-6,40$ & 92.00 & 1.240 & $13 X-7,19$ & 111.15 & 1.542 \\
\hline $11 \mathrm{H}-6,57$ & 92.17 & 1.325 & $14 X-1,18$ & 112.28 & 0.790 \\
\hline $11 \mathrm{H}-6,83$ & 92.43 & 1.630 & $14 X-1,52$ & 112.62 & 1.105 \\
\hline $11 \mathrm{H}-6,107$ & 92.67 & 1.326 & $14 X-1,96$ & 113.06 & 1.134 \\
\hline $12 X-1,3$ & 92.93 & 1.014 & $14 X-1,115$ & 113.25 & 0.928 \\
\hline $12 X-1,20$ & 93.10 & 1.022 & $14 X-1,135$ & 113.45 & 1.127 \\
\hline $12 X-1,32$ & 93.22 & 1.044 & $14 X-2,10$ & 113.70 & 1.236 \\
\hline $12 X-2,14$ & 93.40 & 0.884 & $14 X-2,38$ & 113.98 & 1.167 \\
\hline $12 X-2,35$ & 93.61 & 0.895 & $14 X-2,62$ & 114.22 & 1.279 \\
\hline $12 X-2,69$ & 93.95 & 0.799 & $14 X-2,94$ & 114.54 & 1.802 \\
\hline $12 X-2,95$ & 94.21 & 0.945 & $14 X-3,11$ & 115.21 & 1.348 \\
\hline $12 X-2,114$ & 94.40 & 0.840 & $14 X-3,39$ & 115.49 & 1.293 \\
\hline $12 X-2,130$ & 94.56 & 0.833 & $14 X-3,68$ & 115.78 & 1.372 \\
\hline $12 X-2,142$ & 94.68 & 0.900 & $14 X-3,98$ & 116.08 & 1.158 \\
\hline $12 X-3,4$ & 94.80 & 0.915 & $14 X-3,135$ & 116.45 & 1.573 \\
\hline $12 X-3,23$ & 94.99 & 0.777 & $14 X-3,11$ & 115.21 & 1.239 \\
\hline $12 X-3,46$ & 95.22 & 0.875 & $14 X-4,36$ & 116.96 & 1.245 \\
\hline $12 X-3,72$ & 95.48 & 0.913 & $14 X-4,33$ & 116.93 & 1.484 \\
\hline $12 X-3,98$ & 95.74 & 0.966 & $14 X-4,48$ & 117.08 & 1.202 \\
\hline $12 X-4,7$ & 96.33 & 0.917 & $14 X-4,81$ & 117.41 & 1.566 \\
\hline $12 X-4,23$ & 96.49 & 0.983 & $16 X-1,34$ & 124.14 & 1.270 \\
\hline $12 X-4,46$ & 96.72 & 0.607 & $16 X-1,66$ & 124.46 & 1.823 \\
\hline $12 X-4,65$ & 96.91 & 0.852 & $16 X-1,90$ & 124.70 & 1.658 \\
\hline $12 X-4,93$ & 97.19 & 0.911 & $16 X-1,110$ & 124.90 & 1.544 \\
\hline $12 X-4,121$ & 97.47 & 0.959 & $16 X-1,136$ & 125.16 & 1.462 \\
\hline $12 X-6,3$ & 99.15 & 0.780 & $16 X-2,11$ & 125.31 & 1.645 \\
\hline $12 X-6,24$ & 99.36 & 0.882 & $16 X-2,26$ & 125.46 & 2.034 \\
\hline $12 X-6,47$ & 99.59 & 0.919 & $16 X-2,59$ & 125.79 & 1.664 \\
\hline $12 X-6,72$ & 99.84 & 0.914 & $16 X-2,90$ & 126.10 & 1.701 \\
\hline $12 X-6,92$ & 100.04 & 0.923 & $16 X-2,113$ & 126.33 & 1.250 \\
\hline $12 X-7,4$ & 100.16 & 0.965 & $16 X-3,21$ & 126.91 & 1.837 \\
\hline $12 X-7,26$ & 100.38 & 1.073 & $16 X-3,55$ & 127.25 & 1.622 \\
\hline $12 X-7,49$ & 100.61 & 1.012 & $16 X-3,86$ & 127.56 & 1.518 \\
\hline $13 X-1,6$ & 102.56 & 1.360 & $16 X-3,133$ & 128.03 & 2.210 \\
\hline $13 X-1,33$ & 102.83 & 1.340 & $16 X-5,13$ & 129.83 & 2.000 \\
\hline $13 X-1,48$ & 102.98 & 1.117 & $16 X-5,37$ & 130.07 & 1.808 \\
\hline $13 X-1,73$ & 103.23 & 1.291 & $16 X-5,65$ & 130.35 & 3.999 \\
\hline $13 X-1,98$ & 103.48 & 1.472 & $16 X-5,95$ & 130.65 & 1.951 \\
\hline $13 X-1,127$ & 103.77 & 1.701 & $16 X-5,113$ & 130.83 & 1.724 \\
\hline $13 X-2,12$ & 104.12 & 1.049 & $17 X-4,40$ & 134.32 & 1.373 \\
\hline $13 X-2,64$ & 104.64 & 1.604 & $17 X-5,5$ & 134.73 & 1.433 \\
\hline $13 X-2,90$ & 104.90 & 1.490 & $17 X-5,15$ & 134.83 & 1.520 \\
\hline $13 X-3,0$ & 105.50 & 1.557 & $17 X-5,40$ & 135.08 & 4.037 \\
\hline $13 X-3,44$ & 105.94 & 1.437 & $18 X-1,50$ & 142.00 & 1.565 \\
\hline $13 X-3,88$ & 106.38 & 1.518 & $18 X-1,75$ & 142.25 & 1.045 \\
\hline $13 X-3,121$ & 106.71 & 1.371 & $18 X-4,50$ & 145.85 & 1.258 \\
\hline $13 x-4,6$ & 107.06 & 1.357 & $18 X-4,107$ & 146.42 & 1.202 \\
\hline $13 X-4,24$ & 107.24 & 1.451 & $18 X-6,14$ & 148.49 & 1.244 \\
\hline $13 X-4,60$ & 107.60 & 1.528 & $19 X-2,15$ & 152.46 & 4.839 \\
\hline
\end{tabular}


Table T16. Thermal conductivity, Holes U1327B and U1327C.

\begin{tabular}{|c|c|c|c|c|c|}
\hline \multirow{2}{*}{$\begin{array}{l}\text { Core, section, } \\
\text { interval }(\mathrm{cm})\end{array}$} & \multirow{2}{*}{$\begin{array}{l}\text { Depth } \\
\text { (mbsf) }\end{array}$} & \multicolumn{4}{|c|}{ Thermal conductivity $(\mathrm{W} /[\mathrm{m} \cdot \mathrm{K}])$} \\
\hline & & Average & 1 & 2 & 3 \\
\hline \multicolumn{6}{|l|}{ 311-U1327B- } \\
\hline $1 \mathrm{H}-2,91$ & 2.41 & 1.065 & 1.060 & 1.074 & 1.060 \\
\hline $1 \mathrm{H}-4,73$ & 5.23 & 1.128 & 1.127 & 1.131 & 1.126 \\
\hline $1 \mathrm{H}-6,72$ & 8.22 & 1.143 & 1.142 & 1.142 & 1.145 \\
\hline \multicolumn{6}{|l|}{ 311-U1327C- } \\
\hline $1 \mathrm{H}-4,71$ & 5.21 & 1.078 & 1.084 & 1.078 & 1.072 \\
\hline $2 \mathrm{H}-2,80$ & 8.40 & 1.135 & 1.133 & 1.130 & 1.142 \\
\hline $2 \mathrm{H}-4,95$ & 11.55 & 1.147 & 1.161 & 1.142 & 1.139 \\
\hline $2 \mathrm{H}-6,54$ & 14.14 & 1.056 & 1.033 & 1.032 & 1.102 \\
\hline $3 \mathrm{H}-2,15$ & 17.25 & 1.122 & 1.133 & 1.119 & 1.115 \\
\hline $3 \mathrm{H}-4,66$ & 20.76 & 1.245 & 1.241 & 1.251 & 1.243 \\
\hline $4 \mathrm{H}-1,25$ & 25.35 & 1.102 & 1.100 & 1.101 & 1.106 \\
\hline $4 \mathrm{H}-1,30$ & 25.40 & 1.112 & 1.119 & 1.108 & 1.108 \\
\hline $4 \mathrm{H}-3,10$ & 28.20 & 0.989 & 0.990 & 0.987 & 0.991 \\
\hline $4 \mathrm{H}-7,30$ & 34.40 & 0.686 & 0.708 & 0.701 & 0.650 \\
\hline $5 \mathrm{H}-1,25$ & 34.85 & 0.816 & 0.810 & 0.819 & 0.820 \\
\hline $5 \mathrm{H}-3,30$ & 37.90 & 0.814 & 0.819 & 0.818 & 0.806 \\
\hline $5 \mathrm{H}-7,78$ & 44.38 & 0.626 & 0.666 & 0.604 & 0.609 \\
\hline $7 \mathrm{H}-1,25$ & 46.35 & 1.017 & 1.018 & 1.017 & 1.015 \\
\hline $7 \mathrm{H}-3,25$ & 49.35 & 0.764 & 0.773 & 0.761 & 0.757 \\
\hline $7 \mathrm{H}-6,45$ & 54.05 & 0.911 & 0.913 & 0.907 & 0.912 \\
\hline $8 \mathrm{H}-1,61$ & 56.21 & 1.016 & 1.018 & 1.017 & 1.014 \\
\hline $8 \mathrm{H}-3,118$ & 59.78 & 0.931 & 0.935 & 0.931 & 0.926 \\
\hline $8 \mathrm{H}-5,42$ & 62.02 & 0.958 & 0.960 & 0.959 & 0.956 \\
\hline $9 \mathrm{H}-2,44$ & 67.04 & 0.985 & 0.981 & 0.986 & 0.987 \\
\hline $9 \mathrm{H}-4,28$ & 69.88 & 0.911 & 0.918 & 0.908 & 0.906 \\
\hline $9 \mathrm{H}-6,36$ & 72.96 & 0.999 & 0.992 & 1.002 & 1.003 \\
\hline $10 \mathrm{H}-2,60$ & 76.70 & 1.003 & 1.007 & 1.001 & 1.001 \\
\hline $10 \mathrm{H}-6,44$ & 81.19 & 1.180 & 1.172 & 1.176 & 1.192 \\
\hline $11 \mathrm{H}-2,44$ & 86.04 & 1.199 & 1.205 & 1.195 & 1.197 \\
\hline $11 \mathrm{H}-4,74$ & 89.34 & 1.177 & 1.180 & 1.176 & 1.174 \\
\hline $11 \mathrm{H}-6,38$ & 91.98 & 1.155 & 1.154 & 1.164 & 1.146 \\
\hline $12 X-2,45$ & 93.71 & 1.208 & 1.207 & 1.207 & 1.209 \\
\hline $12 X-4,121$ & 97.47 & 1.024 & 1.026 & 1.023 & 1.023 \\
\hline $12 X-6,41$ & 99.53 & 1.171 & 1.171 & 1.169 & 1.172 \\
\hline $13 X-2,72$ & 104.72 & 0.975 & 0.976 & 0.975 & 0.974 \\
\hline $13 X-4,30$ & 107.30 & 0.936 & 0.935 & 0.935 & 0.939 \\
\hline $14 \mathrm{X}-2,49$ & 114.09 & 1.252 & 1.258 & 1.247 & 1.250 \\
\hline $14 X-4,40$ & 117.00 & 0.875 & 0.881 & 0.880 & 0.865 \\
\hline $16 \mathrm{X}-3,75$ & 127.45 & 1.260 & 1.260 & 1.256 & 1.263 \\
\hline $17 X-3,34$ & 133.52 & 1.043 & 1.053 & 1.044 & 1.032 \\
\hline $18 X-3,80$ & 144.65 & 0.822 & 0.816 & 0.824 & 0.826 \\
\hline $19 X-3,61$ & 153.71 & 0.762 & 0.764 & 0.761 & 0.762 \\
\hline $20 X-5,35$ & 166.43 & 1.020 & 1.020 & 1.019 & 1.021 \\
\hline $21 X-3,100$ & 174.33 & 1.132 & 1.138 & 1.132 & 1.126 \\
\hline $22 X-3,21$ & 182.66 & 1.008 & 0.990 & 1.016 & 1.017 \\
\hline $23 X-1,62$ & 190.32 & 1.058 & 1.059 & 1.057 & 1.057 \\
\hline $25 X-2,33$ & 200.44 & 1.004 & 1.009 & 0.996 & 1.007 \\
\hline $26 X-3,43$ & 211.97 & 1.053 & 1.056 & 1.052 & 1.051 \\
\hline $27 X-6,30$ & 225.43 & 1.215 & 1.220 & 1.213 & 1.212 \\
\hline $28 X-5,35$ & 234.05 & 0.903 & 0.911 & 0.893 & 0.904 \\
\hline $29 X-6,26$ & 245.31 & 0.965 & 0.963 & 0.963 & 0.969 \\
\hline $30 \times-5,39$ & 253.00 & 0.985 & 0.981 & 0.985 & 0.988 \\
\hline $31 X-3,81$ & 260.91 & 0.993 & 0.992 & 0.993 & 0.993 \\
\hline $32 X-6,45$ & 274.65 & 1.126 & 1.126 & 1.126 & 1.127 \\
\hline $33 X-6,45$ & 284.25 & 0.841 & 0.838 & 0.841 & 0.844 \\
\hline $34 X-5,74$ & 292.64 & 0.981 & 0.983 & 0.973 & 0.987 \\
\hline $34 X-6,51$ & 293.87 & 1.040 & 1.043 & 1.040 & 1.038 \\
\hline $35 X-1,43$ & 295.93 & 0.943 & 0.939 & 0.950 & 0.941 \\
\hline $35 X-3,52$ & 299.02 & 1.002 & 1.000 & 1.003 & 1.002 \\
\hline
\end{tabular}


Table T17. In situ temperature, Hole U1327C.

\begin{tabular}{lccccccl}
\hline Core & $\begin{array}{c}\text { Depth } \\
(\mathrm{mbsf})\end{array}$ & \multicolumn{2}{c}{ Temperature $\left({ }^{\circ} \mathrm{C}\right)$} & $\begin{array}{c}\text { Thermal } \\
\text { conductivity } \\
(\mathrm{W} /[\mathrm{m} \cdot \mathrm{K}])\end{array}$ & $\begin{array}{c}\text { Calibration } \\
\text { correction }\left({ }^{\circ}\right)\end{array}$ & $\begin{array}{c}\text { Temperature } \\
\text { tool }\end{array}$ & $\begin{array}{c}\text { Solution } \\
\text { reliability }\end{array}$ \\
\hline $311-\mathrm{U} 1327 \mathrm{C}-$ & & & & & & & \\
$3 \mathrm{H}$ & 25.1 & NA & NA & NA & -0.97 & APCT16 & Poor \\
$5 \mathrm{H}$ & 44.1 & 4.95 & 5.92 & 1.1 & -0.97 & APCT16 & Good \\
$7 \mathrm{H}$ & 55.6 & 5.73 & 6.7 & 1.1 & -0.97 & APCT16 & Good \\
$7 \mathrm{H}$ & 74.6 & 7.15 & 8.12 & 1.1 & -0.97 & APCT16 & Excellent \\
$19 \mathrm{X}-20 \mathrm{X}$ & 161 & NA & NA & NA & NA & DVTP & Instrument failed \\
$25 \mathrm{X}-26 \mathrm{X}$ & 209 & 15.1 & 15.1 & 1.1 & 0 & DVTPP3 & Excellent \\
$34 \mathrm{X}-35 \mathrm{X}$ & 295 & NA & NA & NA & NA & DVTPP3 & Poor \\
\hline
\end{tabular}

Notes: NA = not available. APCT = Advanced Piston Corer Temperature tool, DVTP $=$ Davis-Villinger Temperature Probe, DVTPP $=$ Davis-Villinger Temperature-Pressure Probe.

Table T18. Summary of pressure coring operations, Site U1327.

\begin{tabular}{|c|c|c|c|c|c|c|c|}
\hline \multirow[b]{2}{*}{ Core } & \multirow{2}{*}{$\begin{array}{l}\text { Core-top } \\
\text { depth } \\
\text { (mbsf) }\end{array}$} & \multirow{2}{*}{$\begin{array}{l}\text { Length } \\
\text { recovered* } \\
(\mathrm{cm})\end{array}$} & \multirow{2}{*}{$\begin{array}{l}\text { Length } \\
\text { curated } \\
(\mathrm{cm})\end{array}$} & \multirow{2}{*}{$\begin{array}{l}\text { Pressure at } \\
\text { core depth } \\
\quad(\mathrm{MPa})\end{array}$} & \multicolumn{2}{|c|}{$\begin{array}{c}\text { Pressure recovered } \\
(\mathrm{MPa})\end{array}$} & \multirow[b]{2}{*}{ Comments } \\
\hline & & & & & Logged $^{\dagger}$ & Gauge $e^{\ddagger}$ & \\
\hline \multicolumn{8}{|c|}{ 311-U1327C- } \\
\hline $6 \mathrm{P}$ & 44.1 & 47 & 47 & 13.5 & 0 & - & Burst disk failed \\
\hline 15P & 121.8 & 98 & 96 & 14.3 & 7.3 & - & Normal operation \\
\hline $24 \mathrm{P}$ & 197.3 & 98 & 100 & 15.1 & 6.8 & 2.0 & Normal operation \\
\hline \multicolumn{8}{|c|}{ 311-U1327D- } \\
\hline $3 \mathrm{P}$ & 83.0 & 0 & 0 & 13.9 & 0 & - & No pressure \\
\hline $4 \mathrm{E}$ & 125.3 & 110 & 110 & 14.3 & 12.1 & 12.0 & Broken catcher ring prevented transfer of core \\
\hline $6 Y$ & 132.0 & 84 & 84 & 14.4 & 0 & - & Liner imploded; corer over-retracted \\
\hline $10 \mathrm{P}$ & 155.1 & 98 & 92 & 14.7 & 7.3 & 4.1 & Normal operation \\
\hline $12 \mathrm{E}$ & 170.5 & 114 & 114 & 14.8 & 11.7 & 12.0 & Normal operation; logged in MSCL-P and stored in SC \\
\hline $13 Y$ & 203.6 & 48 & 48 & 15.1 & - & 2.0 & Data logger failed; no pressure/temperature data \\
\hline $14 \mathrm{E}$ & 217.7 & 115 & 115 & 15.3 & 12.4 & 12.5 & Normal operation; logged in MSCL-P and stored in SC \\
\hline $17 P$ & 246.0 & 98 & 98 & 15.6 & 6.4 & 2.0 & Normal operation \\
\hline \multicolumn{8}{|c|}{ 311-U1327E- } \\
\hline $2 \mathrm{P}$ & 40.0 & 90 & 90 & 13.5 & 0 & - & No core, no pressure \\
\hline $3 P$ & 80.0 & 98 & 95 & 13.9 & 5.5 & 0.7 & Normal operation \\
\hline $4 \mathrm{E}$ & 128.0 & 48 & 48 & 14.4 & 0 & - & Side pressure seal broken \\
\hline
\end{tabular}

Notes: Water depth at Site U1327 is 1303 mbsl. P = Pressure Core Sampler (PCS), Y = Fugro Percussion Corer (FPC), E = HYACE Rotary Corer (HRC). ${ }^{*}=$ based on X-ray imaging and gamma ray density profiling prior to degassing. $\dagger=$ last pressure recorded before data logger disconnected from corer autoclave. Temperature $2^{\circ}-4^{\circ} \mathrm{C}$ unless otherwise noted. $\ddagger=$ pressure measured when autoclave pressure transducer connected to computer (PCS cores) or external gauge (PCS, FPC, HRC cores). Pressure measured at $7^{\circ} \mathrm{C}$ unless otherwise noted. SC $=\mathrm{HYACINTH}$ storage chamber, MSCL-P $=$ Geotek pressure multisensor core logger. $-=$ no data. 
Table T19. In situ conditions of PCS cores recovered from Site U1327.

\begin{tabular}{|c|c|c|c|c|c|c|}
\hline \multirow[b]{2}{*}{ Core } & \multicolumn{2}{|c|}{ Depth (mbsf) } & \multirow{2}{*}{$\begin{array}{c}\text { Temperature } \\
\left({ }^{\circ} \mathrm{C}\right)\end{array}$} & \multirow{2}{*}{$\begin{array}{l}\text { Pressure } \\
(\mathrm{MPa})\end{array}$} & \multirow[b]{2}{*}{ Salinity } & \multirow{2}{*}{$\begin{array}{l}\text { Methane } \\
\text { saturation } \\
(\mathrm{mM})\end{array}$} \\
\hline & Top & Bottom & & & & \\
\hline \multicolumn{7}{|c|}{ 311-U1327C- } \\
\hline $15 \mathrm{P}$ & 121.8 & 122.8 & 10.4 & 14.3 & 23 & 78.9 \\
\hline $24 \mathrm{P}$ & 197.3 & 198.3 & 15.0 & 15.1 & 21 & 120.2 \\
\hline \multicolumn{7}{|c|}{ 311-U1327D- } \\
\hline $10 \mathrm{P}$ & 155.1 & 156.1 & 12.4 & 14.7 & 21 & 93.8 \\
\hline $17 \mathrm{P}$ & 246.0 & 247.0 & 18.0 & 15.6 & 21 & 147.7 \\
\hline \multicolumn{7}{|c|}{ 311-U1327E- } \\
\hline $3 \mathrm{P}$ & 80.0 & 81.0 & 7.9 & 13.9 & 24 & 65.1 \\
\hline
\end{tabular}

Notes: Salinity was analyzed in interstitial water samples from Cores 311-U1327C-15P, 24P, and 311-U1327E-3P (Table T3). For all other cores we used the background salinity for in situ calculations, since interstitial water analysis revealed significant freshening of the pore water caused by hydrate dissociation. Temperature was calculated from sediment depth assuming a seafloor temperature of $2.95^{\circ} \mathrm{C}$ and a thermal gradient of $61^{\circ} \mathrm{C} / \mathrm{km}$. Pressure was calculated from sediment and water depth. Methane saturation was calculated based on sediment and water depth, seafloor temperature, thermal gradient, and salinity according to Xu $(2002,2004)$.

Table T20. Results from degassing experiments, Site U1327.

\begin{tabular}{|c|c|c|c|c|c|c|c|c|c|c|c|}
\hline \multirow[b]{2}{*}{ Core } & \multirow{2}{*}{$\begin{array}{l}\text { Total volume } \\
\text { of gas released } \\
(\mathrm{mL})\end{array}$} & \multirow{2}{*}{$\begin{array}{l}\text { Total volume } \\
\text { of methane } \\
\text { released }(\mathrm{mL})\end{array}$} & \multicolumn{5}{|c|}{$\begin{array}{l}\text { Average concentration } \\
\text { of released gas components }(\%)^{*}\end{array}$} & \multirow{2}{*}{$\begin{array}{l}\text { Total volume of } \\
\text { - water released } \\
(\mathrm{mL})\end{array}$} & \multirow{2}{*}{$\begin{array}{l}\text { Salinity } \\
\text { of released } \\
\text { water }\end{array}$} & \multirow{2}{*}{$\begin{array}{c}\text { Temperature } \\
\text { during } \\
\text { degassing }\left({ }^{\circ} \mathrm{C}\right)\end{array}$} & \multirow{2}{*}{$\begin{array}{c}\text { Air pressure } \\
\text { during } \\
\text { degassing } \\
(\mathrm{MPa})\end{array}$} \\
\hline & & & $\mathrm{C}_{1}$ & $\mathrm{C}_{2}$ & $\mathrm{CO}_{2}^{\dagger}$ & $\mathrm{N}_{2}$ & $C_{1} / C_{2}^{\dagger}$ & & & & \\
\hline \multicolumn{12}{|c|}{ 311-U1327C- } \\
\hline $15 \mathrm{P}$ & 1,545 & 1,065 & 85.1 & 0.0113 & $\mathrm{BD}$ & 11.8 & 6778 & 262 & - & $6.8 \pm 0.3$ & 0.1009 \\
\hline $24 \mathrm{P}$ & 4,483 & 4,148 & 98.0 & 0.0729 & BD & $\mathrm{BD}$ & 1299 & 84 & 32.0 & $7.0 \pm 0.4$ & 0.1020 \\
\hline \multicolumn{12}{|c|}{ 311-U1327D- } \\
\hline $10 \mathrm{P}$ & 10,305 & 9,443 & 98.1 & 0.0589 & $\mathrm{BD}$ & BD & 1615 & 286 & 32.2 & $7.0 \pm 0.4$ & 0.1011 \\
\hline $17 \mathrm{P}$ & 4,592 & 3,636 & 96.6 & 0.0445 & $\mathrm{BD}$ & 1.1 & 2088 & 120 & 32.2 & $6.9 \pm 0.4$ & 0.1011 \\
\hline \multicolumn{12}{|c|}{ 311-U1327E- } \\
\hline $3 P$ & 1,174 & 907 & 95.4 & 0.0116 & BD & 1.7 & 7651 & 172 & 32.0 & $7.0 \pm 0.5$ & 0.1016 \\
\hline
\end{tabular}

Notes: * excludes initially released gas increments that are diluted by dead volume of manifold system. $\dagger=$ obtained for selected samples using methods described in "Organic geochemistry" in the "Methods" chapter (see Table T7). BD = below detection limit. $-=$ no data.

Table T21. Characteristics of PCS cores used for mass balance calculations, Site U1327.

\begin{tabular}{|c|c|c|c|c|c|c|c|c|}
\hline Core & $\begin{array}{l}\text { Core } \\
\text { length } \\
\text { recovered } \\
(\mathrm{m})\end{array}$ & $\begin{array}{l}\text { Sediment volume } \\
\text { in inner core } \\
\text { barrel }(\mathrm{mL})\end{array}$ & $\begin{array}{l}\text { Porosity } \\
\text { (\%) }\end{array}$ & $\begin{array}{c}\text { Pore water } \\
\text { volume in inner } \\
\text { core barrel }(\mathrm{mL})\end{array}$ & $\begin{array}{l}\text { Volume of water } \\
\text { in outer core } \\
\text { barrel }(\mathrm{mL})\end{array}$ & $\begin{array}{l}\text { Sediment extruded } \\
\text { with outer core } \\
\text { barrel water, dry } \\
\text { weight (g) }\end{array}$ & $\begin{array}{c}\text { Headspace } \\
\text { volume in outer } \\
\text { core barrel }(\mathrm{mL})\end{array}$ & $\begin{array}{l}\text { Salinity of water } \\
\text { in outer core } \\
\text { barrel }\end{array}$ \\
\hline \multicolumn{9}{|c|}{ 311-U1327C- } \\
\hline $15 \mathrm{P}$ & 0.98 & 1,436 & 50 & 712 & - & - & - & - \\
\hline $24 \mathrm{P}$ & 0.98 & 1,436 & 51 & 725 & 2,610 & 58 & 354 & 35.8 \\
\hline \multicolumn{9}{|c|}{ 311-U1327D- } \\
\hline 10P & 0.98 & 1,436 & 47 & 672 & 2,210 & 139 & 750 & 32.0 \\
\hline $17 P$ & 0.98 & 1,436 & 54 & 771 & 1,740 & 207 & 1,220 & 32.0 \\
\hline \multicolumn{9}{|c|}{ 311-U1327E- } \\
\hline $3 P$ & 0.98 & 1,436 & 50 & 715 & 2,680 & 110 & 284 & 31.5 \\
\hline
\end{tabular}

Note: $-=$ no data . 
Table T22. Mass balance calculations based on degassing experiments, Site U1327.

\begin{tabular}{|c|c|c|c|c|c|c|c|c|c|c|c|c|}
\hline \multirow{2}{*}{ Core } & \multirow{2}{*}{\multicolumn{2}{|c|}{ Depth (mbsf) }} & \multirow{2}{*}{$\begin{array}{l}\text { Total } \mathrm{C}_{1} \\
\text { released } \\
\left(10^{-3} \mathrm{~mole}\right)\end{array}$} & \multicolumn{5}{|c|}{$C_{1}$ concentration $(\mathrm{mM})$} & \multirow{2}{*}{\multicolumn{2}{|c|}{$\begin{array}{l}\text { In situ nondissolved } C_{1} \\
\text { as percentage of pore } \\
\text { volume if present as }\end{array}$}} & \multicolumn{2}{|c|}{$\begin{array}{l}\text { Potential pore water } \\
\text { freshening caused } \\
\text { by gas hydrate } \\
\text { decomposition }\end{array}$} \\
\hline & & & & Total & \multicolumn{2}{|c|}{ At laboratory conditions } & \multicolumn{2}{|c|}{ In situ } & & & $\begin{array}{c}\text { Water } \\
\text { release }(\mathrm{mL})\end{array}$ & $\begin{array}{l}\text { Freshening } \\
\text { (\%) }\end{array}$ \\
\hline \multicolumn{13}{|c|}{ 311-U1327C- } \\
\hline $15 \mathrm{P}$ & 121.8 & 122.8 & 67 & 96 & 2.4 & 94 & 78.9 & 17 & 0.3 & 0.2 & 1.3 & 0.2 \\
\hline $10 \mathrm{P}$ & 155.1 & 156.1 & 453 & 674 & 1.4 & 673 & 93.8 & 580 & 9.4 & 7.9 & 42 & 6.3 \\
\hline $17 P$ & 246.0 & 247.0 & 160 & 209 & 1.1 & 208 & 147.7 & 61 & 1.0 & 0.8 & 5.1 & 0.7 \\
\hline \multicolumn{13}{|c|}{ 311-U1327E- } \\
\hline $3 P$ & 80.0 & 81.0 & 58 & 83 & 1.7 & 81 & 65.1 & 18 & 0.3 & 0.2 & 1.4 & 0.2 \\
\hline
\end{tabular}

Notes: ${ }^{*}=$ obtained by HS analysis of extruded sediment except for Core 311-U1327C-15P, where data was extrapolated from adjacent XCB cores (Table T6). $\dagger=$ calculated based on the total amount of $C_{1}$ released during the degassing experiment and the pore water volume recovered by the PCS. $\ddagger=$ methane saturation (Table T20).

Table T23. Parr vessel samples from Core 311-U1327D-14E.

\begin{tabular}{|c|c|c|c|}
\hline $\begin{array}{l}\text { Core depth } \\
(\mathrm{cm})\end{array}$ & $\begin{array}{c}\text { Parr } \\
\text { vessel ID }\end{array}$ & $\begin{array}{c}\text { Orientation } \\
\text { in vessel }\end{array}$ & $\begin{array}{l}\text { Initial gauge } \\
\text { pressure (psi) }\end{array}$ \\
\hline $25-45$ & BHPAR22 & Top of core down & 720 \\
\hline $45-65$ & BAPAR15 & Top of core up & 730 \\
\hline $65-85$ & AYPAR13 & Top of core down & 680 \\
\hline $85-105$ & AWPAR11 & Top of core up & 710 \\
\hline
\end{tabular}

Table T24. Receiver depths, measured first break times, and first break times corrected for horizontal source offset and gun depth in the vertical seismic profile, Hole U1327D.

\begin{tabular}{ccccc}
\hline \multicolumn{2}{c}{ Receiver depth } & & \multicolumn{2}{c}{ First break time (s) } \\
\cline { 1 - 2 } \cline { 5 - 5 } (mbrf) & (mbsf) & & Uncorrected & Corrected \\
\hline 1495.0 & 181.0 & & 0.992042 & 0.992815 \\
1500.0 & 186.0 & & 0.995957 & 0.996732 \\
1504.0 & 190.0 & & 0.997160 & 0.997936 \\
1516.0 & 202.0 & & 1.003630 & 1.004410 \\
1525.0 & 211.0 & & 1.009010 & 1.009793 \\
1530.0 & 216.0 & & 1.011270 & 1.012054 \\
1535.0 & 221.0 & & 1.013590 & 1.014375 \\
1540.0 & 226.0 & & 1.016280 & 1.017067 \\
1545.0 & 231.0 & & 1.019900 & 1.020688 \\
1548.0 & 234.0 & & 1.021530 & 1.022319 \\
1565.0 & 251.0 & & 1.029410 & 1.030204 \\
1570.0 & 256.0 & & 1.032520 & 1.033315 \\
1580.0 & 266.0 & & 1.042190 & 1.042990 \\
1584.9 & 270.9 & & 1.044790 & 1.045591 \\
1590.0 & 276.0 & & 1.048040 & 1.048843 \\
\hline
\end{tabular}

